\title{
Nuclear Disarmament and Non-Proliferation
}

Towards a nuclear-weapon-free world?

\section{Sverre Lodgaard}

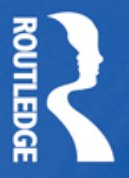

Routledge Global Security Studies 


\section{Nuclear Disarmament and Non-Proliferation}

This book examines the current debate on nuclear non-proliferation and disarmament, notably the international non-proliferation regime and how to implement its disarmament provisions.

Discussing the requirements of a new international consensus on nuclear disarmament and non-proliferation, this book builds on the three pillars of the nuclear non-proliferation treaty (NPT): non-proliferation, disarmament and peaceful uses of nuclear energy. It reviews the impact of Cold War and postCold War policies on current disarmament initiatives and analyses contemporary proliferation problems: how to deal with the states that never joined the NPT (India, Pakistan and Israel); how states that have been moving towards nuclear weapons have been brought back to non-nuclear-weapon status; and, in particular, how to deal with Iran and North Korea. The analysis centres on the relationship between disarmament and non-proliferation in an increasingly multi-centric world involving China and India as well as the US, the European powers and Russia. It concludes with a description and discussion of three different worlds without nuclear weapons and their implications for nuclear-disarmament policies.

This book will be of great interest to all students of arms control, strategic studies, war and conflict studies, and IR/security studies in general.

Sverre Lodgaard is a Senior Research Fellow at the Norwegian Institute of International Affairs, Oslo. 


\section{Routledge Global Security Studies}

Series editors: Aaron Karp, Regina Karp and Terry Teriff

1 Nuclear Proliferation and International Security

Sverre Lodgaard and Morten Bremer Maerli

2 Global Insurgency and the Future of Armed Conflict

Debating fourth-generation warfare

Terry Terriff, Aaron Karp and Regina Karp

\section{Terrorism and Weapons of Mass Destruction}

Responding to the challenge

Edited by Ian Bellany

4 Globalization and WMD Proliferation

Edited by James A. Russell and Jim J. Wirtz

5 Power Shifts, Strategy and War

Declining states and international conflict

Dong Sun Lee

6 Energy Security and Global Politics

The militarization of resource management

Edited by Daniel Moran and James A. Russell

7 US Nuclear Weapons Policy After the Cold War Russians, "rogues" and domestic division

Nick Ritchie

8 Security and Post-Conflict Reconstruction

Dealing with fighters in the aftermath of war

Edited by Robert Muggah

9 Network Centric Warfare and Coalition Operations

The new military operating systems

Paul T. Mitchell 
10 American Foreign Policy and the Politics of Fear

Threat inflation since 9/11

Edited by A. Trevor Thrall and Jane K. Cramer

11 Risk, Global Governance and Security

The other war on terror

Yee-Kuang Heng and Kenneth McDonagh

12 Nuclear Weapons and Cooperative Security in the 21st Century

The new disorder

Stephen J. Cimbala

13 Political Economy and Grand Strategy

A neoclassical realist view

Mark R. Brawley

14 Iran and Nuclear Weapons

Protracted conflict and proliferation

Saira Khan

15 US Strategy in Africa

AFRICOM, terrorism and security challenges

Edited by David J. Francis

16 Great Powers and Strategic Stability in the 21st Century

Competing visions of world order

Edited by Graeme P. Herd

17 The Globalisation of NATO

Intervention, security and identity

Veronica M. Kitchen

18 International Conflict in the Asia-Pacific

Patterns, consequences and management

Jacob Bercovitch and Mikio Oishi

19 Nuclear Proliferation and International Order

Challenges to the Non-Proliferation Treaty

Edited by Olav Njølstad

20 Nuclear Disarmament and Non-Proliferation

Towards a nuclear-weapon-free world?

Sverre Lodgaard 



\section{Nuclear Disarmament and Non-Proliferation}

Towards a nuclear-weapon-free world?

\section{Sverre Lodgaard}


First published 2011

by Routledge

2 Park Square, Milton Park, Abingdon, Oxon OX14 4RN

Simultaneously published in the USA and Canada

by Routledge

270 Madison Avenue, New York, NY 10016

Routledge is an imprint of the Taylor \& Francis Group, an informa business

This edition published in the Taylor \& Francis e-Library, 2010.

To purchase your own copy of this or any of Taylor \& Francis or Routledge's collection of thousands of eBooks please go to www.eBookstore.tandf.co.uk.

(C) 2011 Sverre Lodgaard

All rights reserved. No part of this book may be reprinted or reproduced or utilised in any form or by any electronic, mechanical, or other means, now known or hereafter invented, including photocopying and recording, or in any information storage or retrieval system, without permission in writing from the publishers.

British Library Cataloguing in Publication Data

A catalogue record for this book is available from the British Library

Library of Congress Cataloging-in-Publication Data

A catalog record has been requested for this book

ISBN 0-203-84259-6 Master e-book ISBN

ISBN13: 978-0-415-58634-4 (hbk)

ISBN13: 978-0-203-84259-1 (ebk) 


\section{Contents}

PART I

Power shifts and nuclear weapons

\section{PART II}

The legacies of nuclear history and the requirements of a new consensus on non-proliferation and disarmament

2 The first nuclear era

3 Post-Cold War doctrines

4 A global consensus on non-proliferation and disarmament

\section{PART III}

Proliferation problems and the role of nuclear disarmament

6 Rollback experiences

7 Challenge from within: the case of Iran 
viii Contents

8 How to understand North Korea 151

9 The relationship between disarmament and non-proliferation $\quad 168$

\section{PART IV}

Towards a nuclear-weapon-free world

10 Towards a nuclear-weapon-free world

Notes

References

239

Index 


\section{Abbreviations}

ABACC Agency for Accounting and Control of Nuclear Materials

ABM anti-ballistic missile

ALCM air-launched cruise missile

ANWFZ African Nuclear-Weapon-Free Zone

ASEAN Association of South East Asian Nations

BMD ballistic missile defence

BRIC Brazil, Russia, India, China

BWC Biological Weapons Convention

CBM confidence-building measures

CD Conference on Disarmament

CIA Central Intelligence Agency

CPI Counter-Proliferation Initiative

CTBT Comprehensive Test-Ban Treaty

CWC Chemical Weapons Convention

DPRK Democratic People's Republic of Korea

E3 Britain, France and Germany

ECO Economic Cooperation Organisation

EU European Union

Euratom European Atomic Energy Community

FMCT Fissile Material Cut-Off Treaty

G8

Group of eight leading industrial countries

GCC Gulf Cooperation Council

HEU highly enriched uranium

HWR heavy-water reactor

IAEA International Atomic Energy Agency

IBSA India, Brazil, South Africa Dialogue Forum

ICBM intercontinental ballistic missile

ICJ International Court of Justice

INF Intermediate-Range Nuclear Forces

INFCIRC Information Circular (IAEA)

IRGC Iran Revolutionary Guards Corps

KEDO Korean Peninsula Energy Development Organisation

LEU low-enriched uranium 


\begin{tabular}{|c|c|}
\hline LWR & light-water reactor \\
\hline MAD & mutually assured destruction \\
\hline MTCR & missile technology control regime \\
\hline NAM & non-aligned movement \\
\hline NATO & North Atlantic Treaty Organisation \\
\hline NFU & no-first-use \\
\hline NGO & non-governmental organisation \\
\hline NIE & National Intelligence Estimate \\
\hline NNWS & non-nuclear-weapon state(s) \\
\hline NPR & Nuclear Posture Review \\
\hline NPT & Nuclear Non-Proliferation Treaty \\
\hline NSG & Nuclear Suppliers Group \\
\hline NWFW & nuclear-weapon-free world \\
\hline NWFZ & nuclear-weapon-free zone \\
\hline NWS & nuclear-weapon state(s) \\
\hline P5 & five permanent members of UN Security Council \\
\hline PASDARAN & Iran Revolutionary Guards Corps \\
\hline PLA & People's Liberation Army (China) \\
\hline PSI & Proliferation Security Initiative \\
\hline RevCon & Review Conference (NPT) \\
\hline $\mathrm{ROK}$ & Republic of [South] Korea \\
\hline SAARC & South Asian Association for Regional Cooperation \\
\hline SALT & Strategic Arms Limitation Talks \\
\hline SDI & Strategic Defense Initiative \\
\hline SLBM & submarine-launched ballistic missile \\
\hline SLCM & sea-launched cruise missile \\
\hline SLOC & Sea Line of Communication \\
\hline SORT & Strategic Offensive Reductions Treaty \\
\hline START & Strategic Arms Reduction Talks \\
\hline SWF & Sovereign Wealth Fund \\
\hline TLAM/N & Tomahawk Land Attack Cruise Missile/Nuclear \\
\hline TRR & Teheran research reactor \\
\hline UNGA & United Nations General Assembly \\
\hline UNIDIR & United Nations Institute for Disarmament Research \\
\hline UNMOVIC & UN Monitoring, Verification and Inspection Commission \\
\hline UNSC & United Nations Security Council \\
\hline UNSCOM & United Nations Special Commission (Iraq) \\
\hline VCLT & Vienna Convention on the Law of Treaties \\
\hline WMD & weapons of mass destruction \\
\hline WMDFZ & weapons-of-mass-destruction-free zone \\
\hline WTO & World Trade Organisation \\
\hline
\end{tabular}




\section{Introduction}

When the Cold War drew to an end, the superpower leaders offered a vision of a world without nuclear weapons, in all earnest. They were heavily criticised both by their own establishments and by others, and the world was taken by surprise. Secretary of State George Shultz met the critics and proponents of status quo asking, "What's so good about a world where you can be wiped out in thirty minutes?"

On the twentieth anniversary of the 1986 Reagan-Gorbachev summit in Reykjavik, a group of former American statesmen revived the vision of a nuclearweapon-free world (NWFW). The call was followed up by Barack Obama and leaders of other countries. In many parts of the world, states are waiting to see what comes of it. Elimination of nuclear weapons has been proposed before - the Baruch plan of 1946, the McCloy-Zorin proposal of 1961, the ReaganGorbachev attempt in Reykjavik in 1986, Rajiv Gandhi's plan and plea before the UN General Assembly in 1988 - and those initiatives were short-lived. Will it fizzle out this time, too? Will the interests tied to nuclear weapon complexes hit back and reaffirm the relevance of nuclear arms? Mostly, other countries have not been negative, but they are cautiously waiting to assess the realism of it.

Some take a grimmer view. They see the call as part of a double agenda, the real purpose of which is to sustain and enhance Western unilateral advantage. The synergies of disarmament and non-proliferation may stop smaller and weaker states from acquiring the "great equaliser" - a nuclear capability of their own - and new US conventional weapons that can instantly destroy targets all around the globe are more likely to be used than nuclear systems. In a world without nuclear arms, the United States may therefore be even more superior, for nobody can match its conventional strength. At low levels of offensive nuclear forces, improved US ballistic missile defences may, furthermore, create fears of first-strike capabilities. If the shield becomes increasingly effective, others may be threatened from a position of near impunity. Seen in one or more of these ways, nuclear disarmament is not a hallmark of progressive politics, but a change to maintain the dominance of the United States and the West. Change in order to preserve.

The US unipolar moment was precisely that - a moment - yielding to a multicentric world. Emerging powers wedded to state sovereignty, territorial integrity 


\section{Introduction}

and non-interference in internal affairs are changing the parameters of global geopolitics, and states in Asia, Africa and Latin-America cooperate more with each other to reduce their dependence on Western powers. Hence the debate about "the West and the World Without the West". The systemic changes redefine fundamentally important questions of cooperation and conflict in international affairs.

The role of nuclear weapons is embedded in international politics. Nuclear disarmament presupposes a cooperative approach to international security. Big power cooperation is of the essence; regional cooperation likewise. Disarmament initiatives must attend to the interests of the emerging powers and to the hopes, doubts and scepticisms of states on all continents: to be effective, the initiatives must be aligned with ongoing power shifts in the international system. Part I of this book tries to situate the functions of nuclear weapons in the context of systemic change, reviewing contemporary power shifts and geopolitical orientations and discussing their implications for nuclear disarmament (Chapter 1).

The Cold War left important legacies that continue to influence nuclear weapon policies. Particularly noteworthy are the continuation of threat-based policies and nuclear deterrence doctrines, extended deterrence and policies of first-use included. President Clinton focused on the benefits of globalisation as much as on how to avert threats, but when the period of opportunity of the early 1990s was over, the politics of fear picked up again. To the extent that specific threats no longer sufficed to justify the maintenance of strong nuclear postures, they were arguably needed to defend against the unknown. In the mindset of the Cold War, uncertainties about the future had to be met by the strongest of weapons. Later, 9/11 put the terrorist threat up front; Saddam was turned into a threat beyond proportion; and Iran became a strong driver of threat-based policies. The doctrines of nuclear deterrence therefore outlived the global rivalry and confrontation between the United States and the Soviet Union: they were adapted, but in essence maintained. Part II of the book starts with a review of these legacies (Chapter 2), followed by an examination of nuclear-weapon state (NWS) doctrines (Chapter 3).

The obligation to disarm is inscribed in Art. VI of the NPT. Legally speaking, failure to take "effective measures relating to cessation of the nuclear arms race at an early date and to nuclear disarmament" does not necessarily amount to non-compliance by any particular state. Progress depends on the seriousness of all negotiating parties and is arguably beyond the powers of any single participant. However, the political process that led to the NPT clarifies that Art. VI was conceived as part of a dynamic bargain to be implemented over time, erasing in due course - the distinction between NWS and NNWS. Converging expectations were created and a review mechanism was set up to facilitate abolition. Although no timeline was given, "cessation of the arms race at an early date" left a sense of urgency. Art. VI therefore calls for negotiations in good faith. Attempts have been made to clarify the meaning of it and to make the commitments more explicit, binding and tangible. However, in the view of a great many parties to the Treaty, the results have been disappointing. 
Another part of the grand bargain - the one in the title of the NPT: nonproliferation - has held up better than expected. In addition to the five NWS recognised by the NPT, only four states have acquired nuclear weapons. Throughout the nuclear age, more than 20 states did "something" in the direction of a nuclear weapon capability at some point or other, but dropped the ambition or were stopped in their tracks.

The first half of the 1990s was the golden age of non-proliferation: Russia became the sole heir of Soviet nuclear weapons; South Africa abandoned its weapons and joined the NPT; NPT membership increased considerably; the Conference of Disarmament agreed on a mandate for negotiation of a fissile material cut-off treaty (FMCT); and by the time the 1995 NPT Review and Extension Conference was convened, a comprehensive test-ban treaty (CTBT) was in sight. The US and Russian nuclear arsenals were significantly reduced. The Review Conference therefore came at the end of a period of good news, facilitating the decision to extend the Treaty indefinitely. At this point in time, non-proliferation seemed to be a winning proposition.

That turned out to be flawed analysis. India, Pakistan and North Korea went on to test, and Iran became a state of growing proliferation concern. Proliferation concerns grew, disarmament negotiations came to a halt, big power relations deteriorated, and more functions were assigned to nuclear weapons in national military doctrines. The grand bargain from 1968 that led to the NPT came apart - until a new US government with high disarmament ambitions opened a new window of opportunity to revive it. Part II ends with an overview of the basic requirements of such a consensus (Chapter 4).

Part III is devoted to the problems at the outskirts of the regime. It starts with an analysis of the three-state problem (India, Pakistan, Israel), and of the nuclear cooperation agreement between the United States and India in particular (Chapter 5). It continues with a review and summary of lessons learnt from 27 cases of nuclear rollback, i.e. of states that have moved towards nuclear weapons at some time or other, but that dropped the ambition or were stopped in their tracks and rolled back to non-nuclear status (Chapter 6). The chapter reviews the explanatory power of realist assumptions and idealist perspectives, and concludes with a list of 16 propositions shedding light on what it may take to turn would-be proliferators back to non-nuclear status. These lessons are, in turn, used in analyses of the Iranian and North Korean problems (Chapters 7 and 8). Part III winds up with a discussion of the relationship between disarmament and non-proliferation (Chapter 9).

In legal terms, the link between disarmament and non-proliferation is well established. More than anything else, the NPT review process has centred on the relationship between them, and the academic literature has excellent analyses of the subject. Therefore, the discussion in Chapter 9 is not conducted in the legal framework, but focuses on the political and military dimensions of the disarmament-non-proliferation relationship. Is disarmament important to align the three outliers to the non-proliferation regime? Is it important for purposes of rollback? Does it matter for North Korea and Iran? The other way around, how 
important is non-proliferation for disarmament? How can the non-nuclearweapon states (NNWS) contribute to nuclear disarmament by making their nonnuclear status more convincing? Special attention is paid to the distinction between disarmament as a process and disarmament as a state of affairs, and to the concept of rank disequilibrium, which appears to have strong explanatory power in cases like Iran and India.

Looking ahead, the NPT is a regulatory mechanism for non-proliferation, disarmament and peaceful uses all the way to zero. However, it says nothing about the precise meaning of zero and it is no more than a skeleton agreement, so new rules guiding the final approaches to a NWFW will be needed. This is the topic of the final Part of the book (Chapter 10), which starts with a discussion of the pros and cons of different versions of the vision.

To what extent can a vision be a guide to action? All the way, due respect must be paid to the path dependency of nuclear disarmament. It would be presumptuous to claim to know much about a world approaching zero: at that stage, the issues will be seen through lenses that are different from the contemporary ones. However, some force constellations are more dangerous than others, and much is known about the conditions of military stability. The chapter takes a closer look at their relevance for the structuring of nuclear disarmament, concluding with a concrete proposition regarding the final steps to a NWFW.

The book is comprehensive in its coverage of disarmament and nonproliferation issues, but stays within the confines of the state paradigm. There is nothing about international terrorism. Peaceful uses of nuclear energy - the third pillar of the NPT - are referred to intermittently in some of the chapters, but not discussed at any length. The focus is on the other pillars: disarmament and nonproliferation. The notes and cross references are made in order to enable the readers to use single chapters without having to read the entire book.

A preliminary version of Chapter 4 was presented at the Twentieth Anniversary Conference of Rajiv Gandhi's disarmament speech at the United Nations in 1988 (Delhi, June 2008). Chapter 7 was first presented at the Nobel Symposium on "Peace, stability and nuclear order: Theoretical assumptions, historical experiences, future challenges", Oscarsborg, Oslo, June 2009. Chapter 10 is a much expanded version of an article with the same title in Daedalus, Fall 2009.

While working on the book I have been a visiting fellow at the Centre for Strategic and International Studies (CSIS, Washington, DC), at the Tsinghua University (Beijing) and at the Monterey Institute of International Studies (Centre for Nuclear Studies (CNS), Monterey, California). I have benefited greatly from colleagues at all these places. My thanks go first of all to John Hamre, Li Bin and William Potter who hosted me and shared of their rich insights with me. I received financial support from the Norwegian Ministry of Foreign Affairs: I am grateful to Ambassador Kaare Aas, in particular, for his cooperation and encouragement in the early phases of the work. First of all, however, my gratitude goes to the Norwegian Institute of International Affairs (NUPI), which I had the privilege to direct for ten years and which gave me optimal working conditions when I stepped down from the directorship. 
I have benefited from comments by colleagues in many parts of the world - at conference tables and informally, in reference to conference papers and in freewheeling discussions. I would like to thank Steven Miller, Oystein Noreng, Benoit Pelopidas, Leon Sigal, Nikolai Sokov and Aruni Wijewardane in particular, for their inputs in the final stages of the work. The responsibility for the end result is mine alone.

Like so many times before, Jan Risvik (NUPI) assisted me, competently and efficiently, language-wise and otherwise. Lala Kylycheva (CNS) assisted in the preparation of notes and references and in meeting other editorial requirements. Her professionalism and devotion has been impressive.

Sverre Lodgaard

Monterey and Oslo, March/April 2010 

Part I

Power shifts and nuclear weapons 



\section{Power shifts and nuclear weapons}

\section{Disarmament, non-proliferation and the security environment}

Globalisation fosters interdependence and invites rule-based international institutions. It raises the opportunity costs of hostilities and wars, and offers hope for a better-organised world where arms regulation is deemed to be in the common interest. However, state sovereignty remains a defining characteristic of the international system, and international organisations are usually asked to facilitate cooperation between sovereign states. The security sector, in particular, is not bound by growing volumes of international interaction, but follows its own logic. At the beginning of the twentieth century, trade between European states was booming, but this did not prevent the First World War. Today, China is Japan's largest market and Japan is China's third largest, but they remain wary of each other as far as national security is concerned. Much the same applies to India and China. Growing interdependence has not led to political integration and the formation of security communities. The European Union, where economic cooperation did develop into political integration and cooperation on security and defence issues, is an exception in this respect.

The framework conditions for nuclear disarmament and non-proliferation are further complicated by the ongoing shifts of power in the international system from the west to the east and south. The US hegemony is challenged. Historically, such transitions have been fraught with tension. For the hegemon, the "second country" - the state that is next to it in the international power hierarchy - has been the main problem. If the "second country" is rising, it must be stopped in its tracks. Others watch such rivalries carefully, satisfied states rallying around the hegemon and dissatisfied ones tending to side with the challenger. For the US, the "second country" is primarily China.

Even if the challenger aims at no more than equal status, what the hegemon sees is a trajectory that threatens to cross and overtake its own. In the 1970s, the Soviet Union said it aimed for no more than nuclear parity with the US, but the US had its eyes on capabilities that were rising faster than its own, leading to another round of intensified arms racing. China proceeds cautiously, stressing the peaceful nature of its development, while Americans debate their hedging 
strategies, some arguing that cooperation is possible and others that confrontation is unavoidable.

With Barack Obama, US unilateralism is slowing down. The state of the American economy discourages new, expensive foreign policy adventures, and American public opinion wants the administration to extricate itself from the wars in the Middle East. The confrontational foreign policy agenda of the Bush administration turned out to be too demanding even for the US. Obama emphasises international cooperation on the basis of international law. Still, the US military budget continues to increase. Cuts are seen as signs of weak leadership.

To set nuclear disarmament in motion, Obama has to come to terms with Russia. If not, the grand ambition of a nuclear-weapon-free world (NWFW) will fail before it gets started. The successor agreement to START I is no big deal, but without cancellation of the missile defence plans for Poland and the Czech Republic, it may not have been possible. Agreement on deeper cuts requires more comprehensive accommodation of national interests. Obama recognises that disarmament depends on cooperative big power relations, so his vision of an NWFW - the number-one priority in his maiden speech at the United Nations is a driver for a cooperative security environment.

For the time being, the rationale for nuclear disarmament and the economic and political incentives for improved international cooperation therefore reinforce each other in the conduct of US foreign affairs. However, US emphasis on military superiority and the reactions and priorities of other powerful actors in an increasingly multi-centric world make the continuation open to question. The security environment may become more cooperative and so facilitate disarmament, or it may deteriorate into the traditional security dilemma that fuelled the arms race of the Cold War, where an increase in the power of one state weakens the position of others and drive them to increase their own military capabilities. ${ }^{1}$ The opposite prescription is that of "common security" which says that in the nuclear age, security is something that adversaries have to build together (ICDSI 1982). Unilateral steps at the expense of others will not do: the means to enhance one's own security must also make the others feel more secure.

The negation of the Bush administration's priorities does not mean that unilateralism is out for ever. Unilateralism is a structural phenomenon that derives from the superior position of the US in world affairs, and it would be no surprise if the pendulum were to swing back in an effort to reconfirm US superiority and keep the challengers at bay. The Bush administration left Russia, China and others with a deep distrust of the United States, so it would be premature for them to assume that Obama's policies are the beginning of a new, benign longterm trend. Elimination of nuclear weapons may take decades, and those who prefer a more assertive foreign policy backed by sophisticated nuclear forces may get the upper hand again before disarmament has gone very far.

The Nuclear Non-Proliferation Treaty (NPT) is predicated on international cooperation across a broad range of issues concerning peaceful as well as military utilisations of nuclear energy. To function effectively, it requires more concord between the big powers than is common in the international system. 
Only in two very brief intervals has the UN Security Council functioned the way the Charter prescribes and a smooth functioning of the NPT requires: in the periods of opportunity immediately after the Second World War and after the end of the Cold War. The Treaty also labours under conflicts of interest between states in the northwest and states in the south. The latter object to supplier-state restrictions on international nuclear commerce and sharply criticise the NWS for their failure to disarm. Under mounting pressure from both sets of conflicts, the Treaty was in jeopardy when UNSC Resolution 1887 from the Security Council summit of September 2009 reconfirmed the validity of its main elements. Many NNWS were critical of the Resolution, non-aligned countries in particular: still, the new commitment to international cooperation and nuclear disarmament did much to facilitate the 2010 NPT Review Conference.

\section{The West}

\section{The unipolar moment}

The unipolar moment in world politics - the unrivalled hegemonial position of the United States, the first truly global military power in the history of humankind - was short-lived. It came into being in the 1990s; reached its apex in the spring of 2003 following the invasion of Iraq; and dissipated quicker than anybody expected. In part, the moment was squandered by the destructive policies of the US itself; in part, it yielded to economic and political developments that had been in the making for several years.

The foreign policy of the Bush administration has been amply described by analysts in and out of the United States. Unilateralism was part and parcel of it, but not among its defining characteristics. Unilateralism grew in the 1990s, after the Cold War, and was inherited by the neoconservatives who took it to new heights. The neocons added exceptionalism to it - the idea that exceptional rules should apply to the exceptionally strong, sometimes in reference to the Roman empire and Roman law. The statutes of the International Criminal Court became an early example: the rest of the world might well adopt it, but no US citizen should ever be put before the Court. In the history of the United States, exceptionalism is not new either, but after 9/11 the Bush administration leaped ahead to take it in new directions. Notable among them were the policies of preventive action and regime change, by force if need be. Another distinguishing feature was the administration's unwillingness to talk with its most ardent opponents.

In practice, unilateralism meant that the US withdrew from some international agreements and refrained from joining others. International rules, norms and standards were treated selectively in order to not restrict US freedom of action. However, once it decided to leave an agreement, it did so the way the treaty prescribed. If the treaty said that a party might leave on 6 months' notice, the US did so. Unilateralism limited the scope of applicable international law, but did not challenge its foundations. This is what exceptionalism does: by advocating particular rules for the particularly strong, this philosophy takes exception to the 
principle of the sovereign equality of states, which lies at the root of international law.

The US National Security Strategy of 2002 announced it. It emphasised that "the struggles of the twentieth century [left the world with] a single sustainable model for national success: freedom, democracy and free enterprise" (White House 2002). Insofar as US policies promoted these values, there would be no need to legitimise them in reference to the UN Charter, international law and multilateral organisations. The policies would legitimise themselves by their contribution to basic values. Unilateralism and exceptionalism became parts of the same continuum: at the low end of it, the US would extricate itself from international rules, norms and standards by withdrawing in orderly fashion; at the high end, it would feel free to disregard and contravene them.

On the international scene, the rule of law was therefore discarded in favour of unilateralism and exceptionalism. The National Defense Strategy of 2005 emphasised that "Our strength as a nation state will continue to be challenged by those who employ a strategy of the weak using international fora, judicial processes, and terrorism" (DoD 2005). While the rule of law is based on a single standard for all parties, hegemonial rule is based on two standards, one for the hegemon and one for the subjects. The US was the global rule-maker, but did not always have to play by the rules. The National Security Strategy of 2006, which was an update along the lines of the 2002 document, provided yet another confirmation (White House 2006).

When Bush declared victory in Iraq, exceptionalism was in high standing in Washington. Iraq was supposed to be the first showcase. However, while unilateralism is almost certain to stay in some form or other, exceptionalism has been on the retreat. Retreating but not disappearing: where the US remains an undisputed number one, there will still be a propensity to act on the basis of selfdefined rules. Exceptionalism's longest shelf life will therefore be in military affairs, where the US is likely to reign supreme in high-tech capabilities for a long time to come. Preventive military action remains an option; regime change too. Since the beginning of the Cold War, the US has toppled many governments of other countries, but the prominence given to it by the Bush administration has gone. The Bush administration stands out as being both more extreme and more straightforward in its declaratory policies than other administrations - some say more honest than many others.

\section{US military superiority: ambition undiminished}

At the core of US dominance is the use or threat of use of force. US foreign policy is heavily militarised. Under the heading Global Strike, the Bush administration planned for quick destruction of all targets of significance wherever and whenever it was deemed necessary. The plans were offensive and pre-emptive in nature and based on advanced conventional, space and information warfare capabilities. Nuclear weapons also figured prominently (Kristensen 2006). Another element was missile defence, based on the logic that Richard Nixon used in 1972 
when justifying the ABM Treaty: if you have a shield, it is easier to use the sword. Parts of Global Strike were cancelled because conventional strikes could be mistaken for nuclear attacks. Other parts just went under the radar.

The network of foreign military bases tells a lot about the world's first global military power. Towards the end of George W. Bush's presidency, the United States had 190,000 soldiers and 115,000 civilians at 909 military facilities in 46 countries and territories. Additional to these numbers were the forces in Iraq and Afghanistan and non-declared facilities in Kuwait, the Philippines, Israel and other places. US forces trained soldiers from a majority of the world's 200 countries. $^{2}$

President Obama therefore inherited a military posture driven by the highest of ambitions. The role of military force was confined neither to preventive attack nor to national defence: the idea was to make US military superiority so overwhelming that it would dissuade others from taking up arms. The sword had become impressively potent, but the shield remained imperfect. Chinese weapons rendered US assets in outer space vulnerable, and other Asian states were exploiting US and Western military vulnerabilities by going for ballistic missiles that might do great harm to US bases. "The great equaliser" - nuclear weapons - had obvious appeal.

More than anything else, however, the experiences in Iraq and Afghanistan shed doubt on the realism of the ambition. While the military instruments were sharper than ever before, their political utility left much to be desired. In Clausewitzian terms, the US military machine failed to provide an effective continuation of politics by other means. That lesson came on top of a long-term undercurrent - globalisation - that reduces the applicability of military force by raising the stakes in peaceful futures and the opportunity costs of war.

Nevertheless, the US military budget shows no sign of abating, big budget and current-account deficits notwithstanding. The US remains determined not to allow any other state or combination of states to challenge its military superiority. ${ }^{3}$ During the 2008 presidential campaign, cutting the Bush administration's defence budget for FY 2009 was anathema. Had the President asked for more, he would have had more. President Obama's FY 2010 budget represents a further 2.1 per cent increase in real terms (SIPRI 2010), in spite of the financial crisis. Clearly, the political centre has moved to the right in this respect. Military superiority is written in stone, and political leaders know that proposals for budget cuts may be devastating for their careers.

Behind the high-tech conventional weapons there has often been a nuclear shadow. Throughout the nuclear age, the US has threatened to use nuclear weapons more than 20 times (see Chapter 3). The Bush administration widened the option of nuclear weapons use to include contingencies where the adversary has no WMDs, only conventional forces. The restrictions that previous administrations professed to abide by - always sharply criticised by NNWS for being too weak - were eliminated. As is customary for a new president, Obama set out to rewrite the doctrine: he limited the functions of nuclear weapons to a narrower spectrum of situations. At the same time, he gave new impetus to Global Strike, 


\section{Power shifts and nuclear weapons}

now referred to as Prompt Global Strike (PGS) or Conventional Prompt Global Strike (CPGS) (see Chapter 3).

\section{US political clout: diminished}

The harder it is to convert high-tech military force to lasting political gains, the more important it becomes to gain the allegiance of others by serving the interests of all. This was the way the US established its hegemonial position after the Second World War, spearheading the UN and the Bretton Woods institutions and launching the Marshall Plan. If the hegemon ignores the priorities of others, authority erodes. This century, the US has acted in blatant disregard of these ground rules and has paid a heavy price for it. In most regions of the world, US reputation has fallen dramatically. A notable exception is India, where the US-India nuclear agreement made headway.

President Obama inherited a long tradition of threat-based foreign and security policies. Except for a period in the 1990s, when the Clinton administration had its eyes on the opportunities of globalisation, the Cold War fixation on threats remains vibrant, much invigorated by $9 / 11$. It is as if foreign policy has to be based on threats - in recent years radical Islam, terrorism, Iran and to some extent North Korea - even when statistics show that the world has become less violent. Deaths caused by organised violence are at the lowest level since the 1950s, and the number of major armed conflicts has gone down since the end of the Cold War (SIPRI Yearbook 2009). For a couple of decades, the expansion of the global economy has been the dominant theme of international affairs, only interrupted by the Asia crisis at the end of the 1990s and the global financial crisis a decade later. Nevertheless, contrary to much of the rest of the world, the US has focused not only on what it sees as violent threats, but has also become sceptical of immigration and of globalisation practices that suppress wages. In the state that spearheaded globalisation, there are now protectionist tendencies at work.

President Obama tries to reconstruct the image of the US by reaching out to others across major dividing lines in international affairs; using multilateral diplomacy; substituting cooperation for confrontation; and calling for nuclear disarmament. This way, he may be able to convince others to pursue agendas similar to his own. The shift is reminiscent of Hegelian dialectics, which says that in all socio-political processes there are contradictory elements, and it is the tensions between them that create the dynamics of development. Hence, a phenomenon may turn into its own negation. President Bush took his policies to the extremes: with Obama, the pendulum hit back. The question is to what extent he will be able to follow up on his ambitions.

\section{US economic strength: on the decline}

The United States, Europe and Canada account for a diminishing share of the global domestic product - down to about 55 per cent in 2008 - and the financial 
crisis enhanced the downward trend. Foremost among the emerging states are the big powers of Asia.

Limitations on immigration, which restrain the innovative capabilities that have come with foreign scientific talents working and settling in the US, have a distinctly negative impact on the US economy. Foreign students and immigrants account for about 50 per cent of all science researchers in the US. In 2006, they received 40 per cent of all PhDs: in 2010, close to 75 per cent of all science PhDs will be awarded to foreign students. ${ }^{4}$ When these graduates settle in the US, they create economic opportunities. When they go home, as is now increasingly the case, the creative capabilities will shrink. Poorer economic prospects in the US combine with better working conditions in many countries of origin to bring more highly educated people back home. ${ }^{5}$ Strict and cumbersome procedures for entry into the US after 9/11 add to the problem.

The US has benefited greatly from owning the international means of payment, much the way Britain benefited from the pound in the days of the British Empire. Current-account deficits can be managed because dollars spent abroad find their way back to the US. If need be, huge deficits can be temporarily managed by printing more money, which the US did during the financial crisis of 2008/2009. This privileged position is not going to last, however. History shows that the international currency comes and goes with power shifts in international affairs. When the British Empire went down, the pound was replaced - with a certain delay - by the dollar. Today, as the US is ceding power to others in an increasingly multi-centric world, a handful of power centres will have a say in the development of a system that would be beneficial for many and not just advantageous for one. To own the international currency is to own a very important means of economic and political influence, so the struggle over this issue is going to be intense.

The US unipolar moment was exactly that - just a moment in modern history. It is followed by a rapid transition to a world where the US remains unrivalled in military terms, but where other powers are on a steep rise economically and politically. In the evolving multi-centric system, the United States will be one of many centres and in that sense more of a "normal" country, although still a particularly important one.

\section{The "second country" is the problem}

The "second country" is the problem, the challenge or, eventually, the enemy. In the days of the British Empire, London had its eyes fixed on the "second country", that is, on the one(s) that was next to it in the power hierarchy and that might be able to undermine its hegemonial status. For the United States today, the "second country" is primarily China. Therefore, it has strengthened its military cooperation with Japan; Japan and Australia have signed a Joint Declaration on Security Cooperation: trilateral cooperation between the US, Japan and Australia has been enhanced; the US and Japan are courting India in a bid for geopolitical cooperation against China; in 2007 the US, Japan and India held a joint 
military exercise for the first time in history; and the nuclear deal between the US and India is a door-opener for comprehensive cooperation between them. However, while being involved in a subdued arms competition with China, India is intent on maintaining an independent foreign policy in all directions and keeps its options in relation to China open. In Japan, the Hatoyama government launched a comprehensive review of the US alliance for the first time in decades, setting out to reduce the US footprint in Japan and to improve relations with China.

In some respects, the "second country" is also the European Union (EU). The European challenge is economic and monetary: the EU is the world's biggest economy in macro terms, and the growing demand for euros means reduced demand for dollars. Also, the EU can deny the US legitimacy for its actions. The Union is based on international rules, norms and standards, and in that sense programmatically obliged to sustain international rules of the road in its external affairs. It is therefore a challenge to the US in soft power terms. The Bush administration's attempts to circumvent international law demonstrated that the costs of doing so can be very high.

The Bush administration tried to split EU members into "new" and "old" Europe. The new members in Eastern and Central Europe were easy prey: in view of their history of subordination to the Soviet Union and Soviet use of force, they believe the US is needed to defend them. The EU is too weak. To enhance the likelihood that the Americans will come to their defence, they welcomed US military bases right up to Russia's borders, bringing relations with Russia to their lowest after the end of the Cold War. Russia suspended its participation in the CFE agreement and threatened to withdraw from the INF Treaty. Alarmed by NATO's war over Kosovo, it upgraded the role of nuclear weapons in its military doctrine. When NATO could go to war against Serbia without a mandate from the UN Security Council, it might do so again closer to Russia's borders.

The US partnerships with East European states drove a wedge into the Union's efforts to develop a common security and defence policy. The "second country" was hampered in its integration endeavours and constrained in its ability to act in international affairs. This is no more than a temporary hurdle, however, for in due course "the new Europe" is likely to fold into "the old Europe". The shift may be slow and arduous, but this is the political law of gravity. The EU integration process is all-encompassing, and the new members in the east are small compared with the founding states and other member countries further west. President Obama's conciliatory policy towards Russia facilitates it. There may be US bases in Poland, Romania, Bulgaria and other East European countries for a long time to come, but the most contentious plans are gone. The more cooperative relations between the USA and Russia become, the easier it will be to unite new and old members behind common approaches to security and defence. The moves are incremental and modest, but they point in the direction of enhanced integration. Still, for a long time to come the EU will be unable to muster its economic strength for global geopolitical ends. 
When the Cold War ended, European political leaders stressed that Russia had to be drawn into European cooperation and security, but US/NATO policies and Russian nationalism came in the way. East European anxieties and the domestic situation in Russia - authoritarian rule, restrictions on civil and human rights, corruption and uncertainties about economic policies - continue to pose problems. Still, there is more that binds than separates these heavyweights. In the long term, geographic proximity, mutual economic interests, absence of military threats and security challenges in their common neighbourhoods will knit them closer together. However, what could have changed quickly in the beginning of the 1990s, during the latest period of opportunity for systemic change, is now likely to be a slow movement towards Russian integration into the European economic space and an all-European security architecture.

\section{Diverging interests across the Atlantic}

The Western world is a network of democracies. Economically, it is closely integrated. Cross-Atlantic investment flows are massive and despite the recession, the United States and Europe remain each other's most important foreign commercial markets (Hamilton and Quinlan 2010). Culturally, the commonalities are well-known. The historical roots are weakening, yet significant. The US entertainment industry dominates in Europe as well. English is the first foreign language in most European countries. On the Internet, English has no real competition. Politically, the transatlantic community is tied together by tradition and common institutions. After eight years of relative US neglect, the Obama administration is paying more attention to transatlantic cooperation in NATO.

Still, the cohesion is not what it used to be. In the United States, the political regions of gravity have shifted from the northeast to the south and west. John F. Kennedy was the last president from the northeast. Many Americans distance themselves from what they perceive as European "socialism", a bad word in the US. Most important, the US no longer relates to international law the way Europeans do. While most Europeans remain true to international agreements and multilateral cooperation, US unilateralism persists. There will be more or less of it - with the Obama administration, less - but the shifts are likely to be variations of the same theme. Different attitudes towards international rules, norms and standards are at the core of transatlantic controversies and are also likely to be a source of much contention across the Atlantic in the years to come. Differences do not necessarily translate into incompatibilities, however: occasionally, they may be complementary. For instance, in some respects, European nonproliferation policies and American counter-proliferation strategies may reinforce each other to restrain the spread of nuclear weapons (Lodgaard 2007).

Another related source of contention concerns the use of force. Most Europeans do not condone US use of force in violation of international law. The occupation of Iraq marked a watershed in that respect. For many years, use of force against Iran has been a recurrent issue in US politics, and Obama's diplomatic overture did not rule this option out. The Europeans, on the other hand, have 
warned against it all the time. East European governments may be inclined to follow where the US leads, but there is no certainty about it. On Iraq and other issues of war and peace, European public opinion has been more reserved about cooperation with the US than European governments, and that goes for Eastern Europe as well.

NATO has adapted to the transatlantic cleavages by changing from being a coherent alliance under US leadership to becoming a two-pillar structure where both sides of the Atlantic may use NATO infrastructure for their own purposes, and sometimes for a common purpose like stabilisation of Afghanistan. NATO is no longer the decision-making body it used to be - decisions are made in Washington and in Europe - but a platform for transatlantic consultations.

The West has therefore become a diverse political entity. The US, which urged the Europeans to unite after the Second World War to become a better partner, now has to treat the Union and its largest members both as a partners and challengers.

\section{Implications for armaments and disarmament}

The Europeans are norm-bound and supportive of the international nonproliferation regime. The EU attaches non-proliferation provisions to its trade agreements, which are negotiated and entered into at the Union level. In the NPT review process, common EU positions are comprehensive, and the Union can be counted on to strongly support the Treaty and the regime that it harbours in the future.

The US is less predictable over the long haul because of the likely fluctuations of unilateralism. Under President Obama there appears to be a comprehensive overlap between US and European non-proliferation polices, but that was not the case under President Bush and it may not be the case under the next president. Differences can amount to complementarities, but will more often cause tensions.

The US is committed to superior military strength and increases its military expenditures in spite of its economic problems. This translates into a propensity to solve foreign-policy problems by military means, whereas the Europeans have cut their military investments to the bone after the Cold War and therefore emphasise non-military solutions to problems out of necessity as well as conviction. Confronted with acute challenges at the outskirts of the non-proliferation regime, this may lead to different responses on the two sides of the Atlantic.

As for the NPT commitment to cessation of the nuclear arms race at an early date and disarmament and the US call for abolition, the Europeans are split. In simplified terms, non-nuclear Germany is pitted against pro-nuclear France with the UK being outspoken in favour of multilateral nuclear disarmament while considering modernisation of its sea-based deterrent. Obama's call for nuclear disarmament is strongly supported by most Europeans. Sarkozy reiterates the importance of nuclear weapons for France - continuity prevails in French nuclear policy - but he is not unaffected by the reinvigorated debate about an NWFW (Tertrais 2008). 
Progress in disarmament affairs depends very much on accommodation with Russia. To reduce its reliance on nuclear weapons, threat perceptions must be alleviated. The US accounts for 45 per cent of world military expenditures; Russia for 3 per cent; so to wait for stronger conventional forces to reduce the role of nuclear weapons makes little sense. For the West, that means policies that can ease tensions along Russia's borders in Europe, the Caucasus and Central Asia. When Obama pushed the "reset button" to improve relations with Russia, US policy got closer to that of the big West European countries, but caused anxiety in Eastern Europe. Three different political cultures were at work: a Western European culture where Germany is the heavyweight, disposed to closer cooperation with Russia depending on political and economic developments there: an East European culture still marked by its recent history of subordination to the Soviets, but gradually moving closer to the rest of the EU; and an American culture, which currently translates into policies that are sensitive to Russian concerns, but which has controversial elements. The first one seems rather stable and predictable. The second one is likely to swing back and forth on the way to closer EU integration. US culture bodes for political shifts of much greater consequence.

\section{The World Without the West}

\section{Defining characteristics}

The West is economically, culturally and scientifically attractive, and politically and militarily powerful. Many countries are therefore drawn into its orbit. Given its dominant position in world affairs, anything else would have been a surprise. The pull is supplemented by political and military power, which instils respect and projects influence. The gravitational field around the Western star is strong. Quite often, bandwagoning pays off.

Globalisation, which makes everything flow more easily across borders, emanated from the West. Western technologies facilitated it and the West is capitalising on it. The extension of norms, institutions and habits is essentially an outward flow from the West. The Western world has formidable soft power, and those who defy co-option and assimilation may be exposed to its equally formidable hard power. Small and medium-sized states either play with the West or they risk being discredited and isolated. Even a big state like China steps carefully not to antagonise the US. In the US, the debate about China typically revolves around two wellestablished camps: one of them wants to engage China and make it a responsible stakeholder in the international system while hedging against hostile behaviour. The other holds a starker view, envisioning an inevitable conflict between the two countries. It is either systemic conflict or assimilation. Discussions often boil down to the question of how much hedging is enough and how much is too much, i.e. risking becoming a self-fulfilling prophecy.

This rudimentary description fits the past better than the present, however, and ignores other options that are opening up to the non-Western world. During 
the US unipolar moment it would have been a fair description; today, it fails to capture the power shift that is going on in the international system. The financial crisis has accelerated it: for Brazil, China, India and many smaller countries of Asia it meant no more than a blip in their formidable growth rates - in China and India, down to 8 and 6 per cent in 2009 - while the economies of Western countries had zero or negative growth. The same countries were also among the first to get out of it. Naturally, they are coming out with enhanced selfconfidence.

For the emerging powers of Asia, Africa and Latin America, the power shift also presents new international options. They are no longer confined to integrating into the existing liberal order or challenging the West for international leadership. By building relations with each other, they are making the West less relevant. More and more, they take what they need from the West while routing around the US-led order. Empowered by the same technologies that the West has been using in its globalisation drive, they are giving preferential treatment to each other, gradually establishing their own frames of reference in international affairs. To enact their own preferences they no longer have to confront the West, but can more often afford to ignore it.

Under the headline "A World Without the West", Barma, et al. (2007) started an important debate on this subject. Their reading of globalisation was as follows:

While connectivity for the globe as a whole has increased in the last twenty years, it is increasing at a much faster rate among countries outside the Western bloc. The World Without the West is becoming preferentially and densely interconnected. This creates the foundation for the development of a new parallel international system, with its own set of rules, institutions and ways of doing things - and currencies of power.

(Barma et al. 2007)

For instance, trade between the 20 largest and wealthiest countries in the world is growing significantly faster than world trade, and faster than standard economic models would predict. Economic growth in big countries like China, India and Brazil does not account for all of it. These countries are trading preferentially with each other. They are not cutting their ties to the West, but the relative importance of those ties is diminishing. The same goes for foreign direct investments and telecommunications. Indigenous media networks make it increasingly difficult for the Western media to penetrate other political cultures. The World Without the West is shaping its own narratives of world affairs, reducing that source of power in Western hands. Preferential connectivity SouthSouth is underwritten by intergovernmental institutions that coordinate and stimulate cooperation between its members. Well-known examples are IBSA (the India, Brazil, South Africa Dialogue Forum), ASEAN, ASEAN+1 (China) and ASEAN +3 (China, South Korea and Japan), and the Shanghai Cooperation Organisation (China, Russia, Kazakhstan, Uzbekistan, Tajikistan; Mongolia, 
Iran, Pakistan and India being observers). During the Bush presidency, the nonaligned movement also became more active again.

The rules governing relations "Without the West" are neo-Westphalian: state sovereignty, territorial integrity and non-interference in internal affairs. In Asia in particular, states tend to behave the way the authors of the UN Charter said they should back in 1945 - less so in India, South Korea and Japan; more so in China, Russia and Iran. Inviolable sovereignty - the right to determine one's own social, economic and political order - rejects key tenets of liberal internationalism like global civil society, development aid tied to good governance, and international responsibility to protect people who are ill-treated or left in misery by their governments. Sovereign states determine their own domestic order while dealing with each other on a market basis. Communal, rather than individual, traditions are strong. State stewardship of the economy is the dominant ideology. The material foundations are natural resource endowments, manufacturing capacities and incremental innovation, i.e. learning by doing. International institutions have no legitimate business other than to serve and facilitate these ends. Interdependence is growing, gradually shifting from the West to the World Without the West, but without fostering political integration. The financial crisis pushed it further: to compensate for the slack in Western markets, the World Without the West is dealing more with each other.

The strategy of the West is to turn the emerging powers into responsible stakeholders in the institutions of the existing liberal order. To make it work, the rules are adapted to the new distribution of power. The G8 is being replaced by the G20, but the leaders of the former will continue to meet a couple of times per year, apparently as an inner core. The new heavyweights have got greater roles and expanded voting rights in the Bretton Woods system, the WTO and other international organisations, but all the time on the assumption that the global political economy shall be structured around rules sponsored by the West and that the organisations shall be led by Westerners. The head of the World Bank is American and the head of the IMF is European, by a tradition to be upheld. It follows that there is a tendency for the emerging powers to be left with less than their importance would suggest, especially since greater voting weights have to come at the cost of somebody else: if the US is not willing to give way, the Europeans have to, but the enlarged EU has the biggest GDP in the world. For some time, China and the other emerging powers have been working within this system, accommodating to it and not trying to overturn it. Will it continue this way, or will the current system have to yield to more radical changes in the global political order?

Some years ago, Flynt Leverett pointed out that "the sustained rise in energy prices since 2002 is redistributing wealth - and prospectively, economic power across the world" (Leverett 2008). The major beneficiaries were major oil exporters in the Middle East and the former Soviet Union and major industrial exporters such as China, Japan and Germany. The principal loser was the United States. In 2008 and 2009, the prices came down again, but at the level of $\$ 70$ per barrel, the petroleum business remained lucrative. The winners are deepening 
and multiplying their economic linkages: "If a world without the West is ... indeed taking shape - these linkages are its foundation" (Leverett 2008). Twothirds of current oil exports from the Persian Gulf are going to Asian customers, and for the Gulf States and Russia the most important growth markets lie in the East. The other way, India, China, Japan and other Asian energy importers have compelling strategic interests in deepening their ties to major oil and gas exporters. Investment flows between them are building up both ways. Before the financial crisis struck, the combined current account surpluses of Russia and the six members of the Gulf Cooperation Council exceeded that of China, leading to increasing volumes of eastbound investment. To secure its energy and rawmaterial supplies, China is investing wherever supplies can be obtained. The interests are strong and mutual, adding economic substance to the World Without the West.

Leverett notes that sovereign wealth funds (SWF) and similar kinds of stateowned investment channels provide a potential for coalitions of creditor nations to restrain the US from acting contrary to their interests. So far, the central banks of major creditor countries have had their eyes on macroeconomic stabilisation, and most SWFs have focused on maximising the value of their assets. Looking ahead, state-controlled entities may turn to strategic as well as economic considerations. Such actions can restrict the flow of financing for the US currentaccount deficit, further diversify away from the dollar as a reserve asset, and broaden the currency regime for international oil trading to include other currencies than the dollar.

Iran is at the interface between the West and the rising powers of Asia. Russia, China and Iran support each other on issues of vital national interest: Russia and Iran back China on the Taiwan issue; China and Iran support Russia in Chechnya; and for Russia and China it is important that Iran does not fall back into the US sphere of influence. India weighs in to strengthen Iran's eastward orientation, tempered by its new relationship with the United States. Iran may support the Nabucco pipeline to Europe, which does not pass Russian territory and which may not be fully fed without Iranian supplies, or it may send more gas eastwards and leave westward deliveries to Russia through South Stream and other pipelines. Traditionally, Iran has been as much oriented towards the East and Northeast as it has been oriented towards the West, and more comprehensive Western sanctions in response to its nuclear programme are likely to enhance its eastward orientation. The Western part of its external affairs is where its problems and conflicts lie; the Eastern part meets growing opportunities. Under the circumstances, Asia is about to become a comfort zone for Iran.

Taking a second look at the Goldman Sachs prediction that with sound political leadership and a bit of luck the BRIC (Brazil, Russia, India and China) could outpace the original G6 nations in dollar terms by 2040, Ian Bremmer argues that the political factors that drive the economic policies of these countries "differ in crucial ways, undermining any notion that they carry collective weight as a coherent economic bloc" (Bremmer 2009). As for China, there are numerous question marks about its ability to manage the effects of globalisation. 
Another vulnerability is access to energy to fuel its blistering economic growth. The energy market is tense; the competition is tough; state intervention is all over the place; and the leadership has little experience in handling political risks in the Middle East, Africa and Latin America. India faces risks of fragmentation and is hampered by poorly developed infrastructure. India and China have an agreement about joint exploration of foreign energy sources to temper competition, but more often than not they compete for commercial opportunities.

Russia, with its comprehensive definition of "strategic sectors", has proven less interested in opening its economy to market forces than in leveraging its energy wealth to consolidate domestic politics and restore Moscow's international influence. This has limited its growth potential, as does its singular concentration on the energy sector. This sector accounts for about 1 per cent of Russia's jobs, yet energy exports account for 20 per cent of its economic growth. Small- and medium-sized businesses account for only 13 per cent of its GDP. However, the financial crisis, which struck Russia very hard, may persuade it to diversify its economy and leave some strategic sectors for privatisation.

\section{Interdependence, but not integration}

Gradually, states outside the Western world are left with more choices than assimilating with the West or confronting it. China, India, Brazil and other economic powerhouses make the West less dominant and relevant, and they can enhance that trend by enhancing the connectivity with each other.

Continuation along these lines cannot be taken for granted, however. Globalisation, and the power that unfolds in this rapidly expanding space, is based on factors that often change. Assets are shifting hands all the time, and the uncertainties are exacerbated by domestic dislocations and political instabilities. Usually, authoritarian political systems like China, Russia and Iran are assumed to be more vulnerable to domestic ruptures than democratic ones such as India, South Korea and Japan.

Growing interdependence between emerging powers does not translate into political integration between them. China, India and Russia have opened their economies to the outside world - China from 1978, India from 1991, Russia in fits and starts from its reconstitution in the early 1990s - but they all stress the importance of state sovereignty. China and Russia are converging in their management of civil society. Coming to it from different backgrounds - Russia from the liberal and chaotic years under Yeltsin and China from the totalitarianism of traditional communist rule - they are trying hard to control their own domestic order. China and Japan are trading partners of sorts, but this does not convert into a high degree of political trust. If trade and investments between China and India develop into a common market - hyperbole, maybe, but not excluded they may still be wary of each other when it comes to geopolitics and military dispositions. Relations between the US and the EU underscore the same point: cross-Atlantic investments are peaking and the North Atlantic alliance remains, but the political cultures are different. 


\section{Power shifts and nuclear weapons}

Liberal internationalists are right in saying that interdependence raises the stakes in peaceful relations. They rightly emphasise that globalisation is the essential driving force that limits the ability of any nation to control its own development and makes adaptation the key to success. But realists are also right in claiming that the politico-military sphere is different from the economic realm. There is no comparison with the European Union, where the Coal and Steel Union was established with a view to political unification and became the starting point of remarkable progress in that direction. The EU became the prime example of international political integration, while in East Asia a number of cooperative frameworks have been established, yet none of them with integrationist aspirations comparable with the EU.

The principles of state sovereignty, territorial integrity and non-interference mesh with nation-building and nationalism. Following "the century of shame", the civil war, the turbulence of the great leap forward and the cultural revolution, China has had only 30 years of steady nation-building. Nationalist sentiments are strong. The Russians, about to regain their pride and part of the power position that was lost with the demise of the USSR, are in a nationalist mood as well. Provoked by the establishment of US and NATO positions along its borders, the government thrives and legitimises its policies in reference to Russian history and big power traditions. India is more conscious of its size and weight than ever before. Nationalism is a strong force there, too: it was the nationalist government of Prime Minister Vajpayee that went ahead and tested nuclear weapons in 1998. In dozens of countries, one can see the same set of forces at work: a growing economy, a resurgent society, a vibrant culture, growing military self-confidence, and a rising sense of national pride. In some of them, nationalism also arises out of frustration over American and other Western narratives of history and interpretations of contemporary affairs. Divergent narratives are nothing new, but now the information revolution exposes and disseminates them. Nationalism adds to state sovereignty in restraining the impact of globalisation and whatever interests there might be in going from interdependence to integration.

\section{Implications for armaments and disarmament}

What are the implications for world armaments and disarmament? In particular, what does it mean for nuclear weapon policies?

First, strong economic growth facilitates strong growth of military budgets. In East Asia, two-digit economic growth has fostered military build-up of the same order (Ball 1993-1994). In the decade 1999-2008, China's increase has roughly paralleled its economic growth; India's likewise (SIPRI 2009). In the case of China, significant hidden expenditures come on top of this. So far, however, national build-ups have stopped short of arms racing. There has been no distinct tendency for national military acquisitions to interact and feed on each other, except for the Indian-Pakistani relationship where Pakistan tries hard to keep pace with India. China, India and Pakistan are all modernising and expanding their nuclear forces: China by introducing different versions of the DF-31 ICBM 
and building four or five new SSBNs; India by aiming at a minimum deterrence triad; and Pakistan by building more nuclear warheads for delivery by landbased ballistic missiles. While the US and Russia reduce their nuclear arsenals, the Asian NWS are doing the opposite.

Second, interdependence without integration underpins this trend. Interdependence raises the costs of war, but for lack of political integration the security sector is a sphere of its own depicting a dangerous world. Far from constituting a security community, ${ }^{6}$ Asian powers attend to the risks of war all the time. They are rearming but, conscious of how much is at stake, they try to avoid the dangers posed by arms racing.

Third, a nuclear-disarmament strategy that tries to generate support from likeminded states in order, subsequently, to build mounting pressure on recalcitrant ones in the east and south (Daalder and Lodal 2008) would be short-sighted. The power shift away from the West, and growing cooperation within the World Without the West, translate into diminishing Western leverage and greater staying power for the emerging powers. China, India and other states are less and less susceptible to pressure and increasingly able to pursue their national interests. The call for an NWFW started as a US and Western initiative, and without US leadership such a call would have gotten nowhere, but the sooner the Asian NWS are included in dialogues on how to proceed, the better. If their priorities are not taken properly into account, leaving them with no feeling of ownership to the process, progress will be hard to sustain.

Fourth, does the World Without the West make it easier for Asian powers, Brazil, South Africa and others, to coordinate their positions on nuclear disarmament and non-proliferation issues? There are institutional vehicles at hand: the non-aligned movement (NAM), the G77 and China, regional fora like the ASEAN Regional Security Forum and smaller groups like IBSA may all be used for that purpose. For instance, IBSA played a role in forging support for the USIndia nuclear cooperation agreement. Similar to the growth in South-South economic cooperation, South-South political consultations are also likely to expand in the time ahead.

However, India is not a fully legitimate partner in nuclear-weapon discussions. Pakistan is far from being there. Even if India is recognised as an NWS, China and India are generally too far apart to discuss nuclear-weapon issues with a view to common positions. A strategic dialogue between them is desirable, but not near at hand. The others are non-nuclear-weapon parties to the NPT and in the great majority of cases also members of nuclear-weapon-free zones, urging all NWS to disarm. Thus, coordination efforts can hardly go far. Rather, the "have nots" - protesting against nuclear weapons and supplierinstituted technology restraints - can be expected to maintain a common front against the "haves". India remains a member of NAM, and NAM can reinforce important tenets of Indian foreign policy by facilitating the transition from a uni-centric to a multi-centric world. However, after 1998, India has grown out of its traditional NAM leadership role, aspiring instead to be accepted as a bona fide NWS. 
Fifth, the front against the NWS is not a front against a homogeneous group of nuclear powers. The World Without the West knows to distinguish between the main Cold War antagonists and the emerging powers of Asia. For one thing, the growing body of economic cooperation between China and other states in Asia, Africa and Latin America makes the latter less eager to criticise China. For another, there is less of a reason, too, as long as China's nuclear profile is a low one focused on core deterrence and prevention of nuclear coercion. China and India abstain from nuclear posturing, keeping their weapons in a low state of preparedness. Their power play is unfolding on arenas other than the nuclear one, first of all in the economic sphere where trade relations, the attractions of their huge domestic markets and their savings and investment capital are powerful assets that can be used for political ends. China's centralised political system makes it particularly well equipped to do so. In short, the salience of nuclear weapons in China's foreign affairs is modest while in India, it looms larger as long as the fight for big power status on a par with other centres of the emerging multi-centric system is going on.

\section{The shift to Asia}

\section{The historical narrative}

In a lecture in Copenhagen in 1831, the German philosopher Georg Wilhelm Friedrich Hegel said that history is moving from the East to the West. It started in the East and is ending in the West, where the highest level of civilisation is taking shape. When the Cold War ended, Francis Fukuyama said much the same, i.a. in reference to Hegel. He declared "the end of history", claiming that the economic and political organisation of the West - i.e. market economy, multiparty democracy, human rights and rule of law - represents the end station of a long historical development. The West has come to the end of history while the rest is still in it, having longer or shorter distances to go.

These are chauvinistic misconceptions. One flaw has to do with the West's own shortcomings - a big subject that the financial crisis helped us to recognise - another that it fails to make proper account of history. Nearly 100 years before Columbus, the Chinese admiral Zheng He took a flotilla of 317 ships, much bigger and better than those of Columbus, through the waters of the Indian Ocean and around Southeast Asia. As late as 1820, when the Qing dynasty had been on the decline for a while, China and India still accounted for some 45 per cent of the world's economic output. They were centres of a comprehensive regional trading network.

Today, when the Chinese speak of rejuvenation, they mean restoring China's power position to that which it used to enjoy in previous centuries. This can only be realised if China grows significantly faster than the others, and Chinese elites consider that to be fair. There is something natural about it that can only be understood against the background of long historical periods of superior performance and strength. Rejuvenation is nothing new. It is destiny. 
India's history is also one of big power, and Indian elites of the twentieth century who rediscovered their country's rich heritage were convinced of India's "exceptionalism". The first prime minister upon independence, Jawaharlal Nehru, noted that fate had marked India out for big things, and that it was entirely natural for New Delhi to take a leadership role in world affairs. Similar to China's notion of rejuvenation, Nehru's notion of greatness is part of the nation's mental make-up. Indian exceptionalism is not of American proportions - Americans keep emphasising that the US is "a great force for good", "the greatest force for good" or even "the greatest force for good in the history of mankind" (John McCain during the presidential campaign) - but it seems stronger than that of the Chinese. In one important respect it is distinctly different. Nehru's call for greatness had strong moral underpinnings. It was not a topdown ambition backed by military force.

Rejuvenation or restoration by whatever name: it is both destiny and strategy. The strategy is openness - China from the end of the 1970s, India from the beginning of the 1990s. China's historical experience is unambiguous in this respect: during periods of openness, China did well; in periods of isolation, it declined. The story of Zheng He is as striking as any illustration can be. From the 1430s onwards, the voyages were cut back and soon discontinued altogether. They were considered too costly as Mongols and other raiders threatened the frontiers. Seafaring was judged to be an expensive distraction from more important tasks. China turned its back on trade and exploration and oriented itself inwards. While the Western powers were energised by the new discoveries and substituted observations, experiments and critical thought for the dogmas, beliefs and rituals of the Middle Ages, China stagnated. The fact that by 1820 it still accounted for as much as 30 per cent of world output has to be explained in demographic terms.

China can therefore be trusted to stay open to the outside world to the best if its ability, and so can India. Like China, development is India's overriding priority, informing a foreign policy that prioritises accordingly, stressing the importance of peace and stability. It therefore reserves itself in relation to US balancing strategies against China. The Indian economy is not as open as China's, and in terms of ease of doing business it has been ranked as number 120 on a list of 178 states. $^{7}$ However, subsidies and protectionism are clearly giving way. When Russians emphasise that they can manage this and that on their own without attending to others, the Chinese disapprove of it and so do many Indians.

In a stark illustration of the difference between the security sector and other sectors, China is highly secretive on nuclear matters. Secrecy is an important part of its nuclear posture, and in this respect there is no sign of change.

\section{Contemporary China}

For good reasons, analyses of ongoing power shifts revolve around the US and China. Other important actors are the EU, Russia, India and Japan. 
When China's foreign minister asked Secretary of State Madeleine Albright to characterise US foreign policy in one word, she said "leadership". Despite mounting problems and declining influence in recent years, the US still sees itself in a global leadership role. In the view of many Americans, the US remains the essential nation and a force for good, destined to lead the world. No politician aspiring for high office would suggest that the US should abdicate from the leadership role. The means by which it is exercised vary from one administration to the next. Compared with his predecessor, President Obama is upgrading the importance of alliances and multilateral cooperation in conformity with international law.

Returning the question, her Chinese counterpart said "partnership". China treasures partnerships in all directions, conscious of the importance of harmonious external relations to sustain its formidable domestic modernisation project. At the same time, it is keenly interested in its own power position in the world. Measuring comprehensive national power is a favourite sport among think tanks and university institutes specialising in foreign affairs. It begs the question of what that power is going to be used for. One thing is clear: comprehensive national power is a relative concept, not an absolute one. What is measured is China's strength relative to other big powers, to the US in particular.

In 2003, Chinese leaders introduced the term "peaceful rise". The word "rise" was commonly assumed to imply superpower status. "Rejuvenation" does the same: that expression was introduced by Sun Yat-sen and reiterated by Mao Zedong, Deng Xiaoping, Jiang Zemin and $\mathrm{Hu}$ Jintao. Both expressions mean restoring China's power position to that enjoyed during the prime of the Han, Tang and early Qing dynasties (Yan 2006). The objective of China's rise is therefore to regain its lost international status, and what should be regained is top rank in the international system conditioned by superior achievements and overall strength. However, realising that "rise" has offensive connotations that may worry China's neighbours and opposite numbers in world affairs, "peaceful development" substituted for "peaceful rise" in $2004 .^{8}$

The thrust is nevertheless the same in both expressions. China wants to alleviate concerns that a rapidly growing China will upset the global status quo, conscious that the rise of new powers tends to cause turbulence, especially as ascending powers have been about to overtake established leaders. In particular, peaceful development is intended to reassure neighbours that China is seeking win-win outcomes in its foreign affairs. In a well-documented analysis, David Kang shows that, so far, China has been successful in this respect. The smaller countries of Southeast Asia cooperate more and more with China without cutting their ties with the US, not because they are afraid of China but because it is deemed to be in their best interest. They are neither balancing nor bandwagoning. Realism, liberal internationalism and constructivism all help to explain the evolving regional system: the only theory that Kang emphatically rejects is that of balance of power (Kang 2007). However, relations with Japan, Vietnam and India remain difficult.

Chinese commentators link the strategy of peaceful development to China's domestic situation. The magnitude of its growth is matched by the magnitude of 
its internal problems. If the past is a guide to the future, domestic upheavals are very much what the leadership should watch out for. The "Great Leap Forward" caused a major set-back in 1959-1963; the "Cultural Revolution" meant another period of decline in 1966-1976; and in 1989-1993, starting with the Tiananmen Square massacre, the reform economy hit a blow and China's political standing suffered. Since 1993, it has emerged from the international isolation that started in 1989 and achieved around 10 per cent annual economic growth. The East Asian financial crisis of 1997 hit hard at other countries in the region but not at China, which greatly enhanced its overall position in the area. Based on the firm conviction that isolation was the major factor behind China's periods of decline and that openness to the outside world is a sine qua non, the strategy therefore acknowledges the need for a peaceful international environment in order to not jeopardise domestic developments.

These strategic assumptions found their way into declaratory policy in the late 1990s and early 2000s. ${ }^{9}$ First, China seeks to maintain a stable international environment, especially around its periphery, so that it can focus on economic, social and political problems at home. "A developing China needs a peaceful international environment and a favourable climate in its periphery" (Information Office of the State Council of China 2002). Second, China aims to augment its wealth and influence, but in a way that reassures its neighbours about its peaceful and mutually beneficial intent. In effect, China tries to manage the security dilemma in a common security spirit (ICDSI 1982). In similar fashion, China is saying to its neighbours that in the age of globalisation, economic, social and political progress is something that nations must pursue together, for mutual benefit.

Third, China seeks to alleviate and circumvent what it sees as excessive US influence around its periphery while avoiding confrontation with the US. Mindful of US power and of its own relative weakness, it does not want the US to see it as a foe (Wang 2005). Rejuvenation is a long-term process, and there is no better choice for China than to step carefully in relation to the one and only existing superpower.

Compared with other big powers, China has a relatively balanced power profile: economically, politically and militarily, it can be rated as strong, while France, the UK, Russia, Japan and Germany are strong in some respects and weak in others. China has, moreover, a strategic purpose and a will to pursue its national strategy. If comprehensive power is understood to be the product rather than the sum of hard and soft power the way Cline's function assume $-P p=$ $(C+E+M) \times(S+W)$, where $P p$ is perceived power, $C$ critical mass, $E$ economic capability, $M$ military capability, $S$ strategic purpose and $W$ the will to pursue national strategy - China is therefore relatively well positioned. ${ }^{10}$

If power is seen not only as something states possess, but also as something that is embedded in the structure of international affairs, China is progressing from a low starting point. It opened up to the outside world only 30 years ago. A natural preference is East Asian regionalisation - but Japan is reluctant to accept the rise of China and is a brake on regional cooperation. If regionalisation nevertheless proceeds - multilateral cooperation is usually advantageous for smaller 
countries and therefore draws much support from them - it has been indicated that Japan might follow the example of the UK. The UK is a member of the EU, yet in part on the sidelines, maintaining a special relationship with the US (Yan 2006).

\section{Implications for armaments and disarmament}

In China and India, the nuclear-weapon programmes are rooted in great national ambitions. For China, rejuvenation in reference to the power position it used to enjoy in previous centuries suggests that the aim is a dominant position in international affairs. In India, there is a strand of exceptionalism in its pursuit of a leadership role in world affairs, and nuclear weapons are deemed necessary in order to attain that role. If the United States is seen to reduce its reliance on nuclear weapons as part of a strategy to maintain US military superiority nobody can match its conventional forces - while achievement of an NWFW is in the blue, none of them are likely to be cooperative. Then, disarmament would run contrary to their historical claims for greatness. In order for China and India to contribute to a disarmament process in good faith, there has to be a distinct element of equity built into it.

This is underscored by their growing national self-confidence. High economic growth and vibrant nationalism fosters it, and it was enhanced by successful management of the latest financial crisis. The emerging powers - China, India and Brazil foremost among them - were reassured of the appropriateness of their development strategies and foreign policies. In some fundamental respects, China is ready for nuclear disarmament. The main missing element is a strategic dialogue with the US based on mutual deterrence. Influenced by the US disarmament initiatives, India has revived its radical disarmament rhetoric, but will hardly be prepared for much disarmament action until a minimum deterrent force has been established and a seat at the negotiating table has been secured. Both are sensitive to the contents and sequencing of the specific steps to be taken India in particular, since it is playing for time. The Asian giants are powers in their own right, increasingly averse to external attempts to interfere with their national interests.

Secrecy is an impediment to disarmament. For China it is an important element of its strategic posture, and a sign of weakness. The Chinese nuclear arsenal is small and vulnerable. Confronted with improved US ballistic missile defence systems and long-range conventional precision-guided munitions, it may therefore want to maintain a high level of secrecy while modernising its arsenal and going for less vulnerable deployment modes. In the face of such policies, it will not be an easy partner in disarmament deliberations in the years ahead. 


\section{The structure of geopolitics}

\section{The US, China and the EU}

It is commonly assumed that global geopolitics will revolve more and more around the United States and China, and they see it that way themselves. For the US, China and the EU are "second countries"; for China, the US is number one in all main respects, being the only superpower, while the EU is unlikely to emerge superior to China in comprehensive power because of the slow pace of its political integration.

In terms of economic growth, China is outdoing the US and the EU by a wide margin. Politically, China's ascent depends on the political mobilisation capabilities of the US and on European integration. The US capability to rally international support behind its policies has declined considerably, but may take a U-turn with Obama's commitment to multilateralism, alliance politics and international law. In East Asia, China has usurped the traditional US role of exporting hope, optimism and reassurance. ${ }^{11}$ In Europe, EU enlargement put a brake on integration and the financial crisis hit the Union hard, but integration remains an overriding political objective. In short, the US and China are the likely drivers of geopolitics in the time ahead, while the EU attracts the keen attention of both of them.

In one important respect, the EU and China are coming closer to each other: the sea route through the polar basin is opening up for an expanding part of the year, reducing the transport time between Shanghai and Rotterdam by more than 50 per cent. Geopolitics is about the impact of geography on politics, and the geography of the Arctic is changing rapidly as a function of global warming.

The EU is China's largest market, and in ten years' time China may eclipse the US as the EU's largest trading partner. The EU has no hard power aspirations in East Asia and does not share US perceptions of the need to curb China's military capabilities. Growing Chinese military investments do not present a threat to Europe; Taiwan is a peripheral issue for the Europeans; and Chinese activities in the South China Sea and the Malacca Strait are not of prime concern either. Protection of SLOCs all the way to the energy sources in the Middle East, from which they both draw, establishes an interface between them, but far from being any new departure in international politics, China's emerging blue water navy brings it in line with other big powers. Energy is a strategic commodity of sorts, and big powers have long been in the habit of protecting their maritime lifelines - the United States for some 200 years.

China's shortcomings with regard to democratic practices and human rights are sources of irritation. The plight of ethnic minorities in Tibet, Sinkiang and other places are discouraging and censorship practices comprehensive. Official statistics tell that there are some 100,000 public protests of various kinds per year. However, if China's economic and political performance continues to improve, and Europe adopts broader and more instrumental approaches to democracy and human rights as China becomes better known, tensions will be alleviated. 
Richard Carney and Richard Bitzinger have argued that China and the EU can be seen as a binary star system in which both stars revolve around each other, but effectively constitute a single sun. They have no security concerns in relation to each other, and substantial economic and political interests in common. They share a common interest in a multi-centric world order, and they both wish to enhance their role in global governance institutions. They see the US as the single star of a neighbouring solar system (Carney and Bitzinger 2007). This is a minority view, however. Most observers believe that for a long time to come, the commonalities of interest between the EU and the US outweigh the cooperative potential of European-Chinese relations as far as security issues are concerned.

\section{The other Asian powers}

\section{India}

How does India tie into such a geopolitical constellation? India is another huge country on a steeply rising curve, although not as steep as China's.

India has a rugged and resilient democracy, and historical and linguistic ties to the West. Up to the 1990s, it practised economic policies of import substitution and protectionism and security policies in close cooperation with Russia, both of which kept it at a distance from China and Japan as well as the US. With the end of the Cold War and Russia's opening to the US and China, its common geostrategic interests with Russia dissipated and threatened to leave it isolated. This spurred it into a search for improved relations with China. During Wen Jiabao's successful visit to India in 2005, a strategic partnership was declared. China formally recognised Indian sovereignty over the Himalayan territory of Sikkim, and India reaffirmed its position that Tibet is a part of China. The two sides also agreed on a road map for settlement of the border dispute, which had brought them to war in 1962.

Along the border, a number of confidence-building measures have been instituted, including a ceiling on troop deployments, agreement to clarify the line of control, advance notification of military movements and manoeuvres, periodic meetings of force commanders, and measures to avoid violations of each other's airspace. The parties have also agreed to refrain from use of force to change existing borders: this is a precondition for confidence-building measures to work as intended. Following the visit, India got China's support for a permanent seat on the UN Security Council, and China was accorded observer status to the South Asia Association for Regional Cooperation (SAARC).

Given the historical complexities; China's traditional support for Pakistan; and the potential rivalry between them; this turn of events was remarkable. Still, the border conflict is far from settled, and economic cooperation is hampered by material shortcomings such as weak Indian infrastructure and lack of knowledge about each other's social and economic systems and ways of doing business. China sees Russia, Japan and the US as neighbours, but India is far away. Oscillating between indifference and rivalry, the relations between India and China 
are vulnerable to tactics of divide and rule. The nuclear cooperation agreement between the US and India has such a geopolitical aspect. It opens a broad range of economic, political and military cooperation between them. Clearly, the agreement has an edge against China, which therefore had misgivings about it, yet did not see fit to block consensus about it in the Nuclear Suppliers Group (NSG).

The nuclear-weapon dimension looms in the background. Within the framework of the US-India agreement, India can produce in the order of 50 nuclear weapons per year if it makes maximum use of its capacity. This is not going to happen, however: neither India nor China wants to be trapped in a nuclear arms race. By the end of 2008, India was estimated to have in the order of 60 to 70 weapons, aiming at a minimum deterrent in the low hundreds. Since India's forces are meant to deter both China and Pakistan, and the function of China's weapons is to deter the US, Russia and India, they are facing multiple incentives to upgrade and expand their arsenals: China from the US and India in the form of US missile defences and an expanding Indian arsenal, and India from Pakistani and Chinese expansion and modernisation. China is modernising and diversifying its forces, but it is unclear to what extent it intends to expand its capabilities beyond substituting new, more survivable missiles for old ones. By January 2009, China was estimated to have 186 operational weapons and a total stockpile of 240 warheads (SIPRI 2009).

In the India-Pakistan relationship, threats and use of nuclear weapons cannot be excluded. There is a major unresolved territorial conflict between them (Kashmir). In the relationship between China and India, the prospects are better: here, the role of nuclear weapons may be contained within an expanding totality of cooperative ventures. However, it takes politically astute leaderships in Beijing and Delhi and skilful diplomacy to clarify the functions of their nuclear weapons and avoid being entangled in competitive arms acquisitions.

Standing in an unbroken tradition of non-alignment, India shuns alliances. It is mindful of its independence and widely assumed to be the fulcrum of balance in Asia. As characterised by Matthew Rudolph, its stance will be neither balancing nor bandwagoning, but aimed at ensuring a dynamic equilibrium both domestically and internationally - domestically between cultural and political forces such as nationalism/cosmopolitanism, anti-Americanism/ pro-Americanism, self-sufficiency/trade optimism; internationally between American technological and commercial affinity versus American hegemonial ambitions, and Chinese commercial appeal versus concerns about Chinese pressure (Rudolph 2006).

\section{Russia}

The Soviets did not use the term "geopolitics", but the Russians do. Geopolitical analyses tend to see the world through zero-sum lenses - what one party gains another loses - and the Russians have always been inclined to read international politics this way. Fresh experiences remind them of the validity of it: when the 
Soviet Union and the Warsaw Pact fell apart and Russia was left weak and impoverished, the West used the opportunity to move east, right up to Russia's borders, filling the vacuum. Today, geopolitics is prominent in Russian analyses of international affairs.

NATO's bombing of Yugoslavia in 1999, without a UN mandate and therefore in violation of international law, triggered a sea change in Russia's attitude towards the West. Since NATO could do this, it might do more of the same closer to Russia's borders. Its conventional forces were weak and clearly inferior to NATO's, so Russia upgraded the role of nuclear weapons in response.

While the Bush administration suffered severe set-backs in the Middle East, it was successful in extending its sphere of influence to Russia's borders in Eastern Europe and the Caucasus. It tried to do the same in Central Asia, but inconclusively so. New physical facts were established on the ground in the form of US military bases in Eastern Europe and assistance to Georgia, while efforts to enlarge NATO even further to include the Ukraine and Georgia were thwarted. These developments could only come at the expense of relations with Russia and the arms control architecture. In contrast with China, which tries to avoid open confrontation with the US, rising Russia tried to hit back as soon as it overcame the economic difficulties and humiliations of the 1990s.

US-Russian relations were therefore at a low point when George Bush left the White House. Under Barack Obama they quickly improved, much as a function of his ambitious nuclear disarmament plans. Without another agreement with Russia for further cuts, his high-profile call for an NWFW would have come to nought. When the plans for a missile shield in Poland and the Czech Republic were shelved, the stage was set for another agreement to replace START I, which expired on 5 December 2009.

Russia's relations with China have been much improved. The border dispute has been settled. The Shanghai Cooperation Organisation (SCO) promotes common interests in fighting terrorism and keeping the US out of Central Asia. The SCO may also be used to regulate their access to Central Asia's energy resources, but so far there is more competition than cooperation in that respect. Russia and China support each other on Taiwan and Chechnya, and they have a common geopolitical interest in keeping Iran out of US hands. To the extent that they feel encircled and contained by the US, they are likely to strengthen their ties in opposition. However, China does not want geopolitics to tilt in this direction and Russia, which has been a major arms supplier to China in recent years, is ambivalent with regard to arms and oil supplies, vacillating between economic interests and political concerns not to boost China's position. Relations between these powers are pacific, but restrained.

Russia's relations with the EU suffer from its own economic policies as well as from its authoritarian political system. Its economic openness is limited by a comprehensive governmental hold of strategic sectors, and human rights and rule of law deficiencies obviate against closer cooperation. In the long run, however, history, geographic proximity, a growing Russian market and economic complementarity speak in favour of closer cooperation between them. 
The EU is Russia's biggest market. Similar to China and the EU, Russia acts out of respect for the UN Charter and international law. For Russia, its veto power in the Security Council is particularly important given its weakness on many other dimensions of power.

Russia's relations with Japan are constrained by the territorial dispute over the Kurile Islands, for which there are no signs of early resolution. This is more of a non-relationship than a strained relationship. The coupling of Japanese technology and economic strength to Russian raw materials in Siberia, a matter of much speculation and intermittent hopes since the end of the Cold War, has not materialised.

What is left for Russia? First of all, the answer is energy, which is a formidable economic and geopolitical card. The answer is also the European option. Most of Russia's economy is in the European part of the country and oriented towards the West. The exercise of this option - to become an integral part of the European economic space - is up to Russia itself, for it is primarily a matter of economic and political reforms. Other options are cooperation with China, India, Iran and others in Asia: there are a variety of common interests between them. If China and the EU form a binary star system some day, Russia is somewhere in its gravitational field.

Putin took Russia from chaos and decay in the 1990s to stability and economic growth in this century. The correlates of that transformation were authoritarian presidential rule, a firm governmental grip on a comprehensive set of strategic sectors, and virulent nationalism. The next phase may see democratic reforms and economic liberalisation stimulating more diversified and robust economic growth and opening the doors both to Europe and the economic powerhouses of Asia.

The military doctrine of 2000 stated that the upgraded role of nuclear weapons was temporary, awaiting the reconstitution of sufficient conventional forces. In addition to being a counterweight against NATO, nuclear weapons are deemed important also in defending the vast and thinly populated expanses of Siberia bordering China. There is considerable uncertainty about Russia's inventory of sub-strategic or tactical nuclear weapons, but on the basis of available delivery platforms, SIPRI estimates that Russia has approximately 2,000 operational warheads and about 5,400 altogether, reserves and weapons awaiting dismantlement included. In 2008, the Russian chief of staff affirmed Russia's commitment to non-strategic weapons in reference to the situation in Europe. ${ }^{12}$ The 2010 military doctrine signals continuity, but constrains the role of nuclear weapons somewhat (see Chapter 3).

If a reduced role for nuclear weapons must await conventional force upgrades that are substantial enough to assure the Russian leadership that its borders can be defended by conventional means, one will have to wait a long time. However, in view of Obama's rapprochement with Russia, the threat perceptions may be downgraded and the importance accorded to nuclear weapons likewise. Certainly, in order to reach another disarmament agreement beyond the START I replacement, the sub-strategic weapons have to be included in the negotiations. 
The Russian inventory of sub-strategic weapons is significantly larger than the US one, so for the US to agree to, say, no more than 1,000 deployed strategic weapons while leaving Russian sub-strategic weapons aside is virtually unthinkable.

\section{Japan}

Few relationships display such a stark contrast between economic interdependence on the one hand, and political and military animosity on the other, as that between Japan and China. Trade is flourishing while historical grievances, territorial disputes in the South China Sea, political rivalry in Southeast Asia, strategic competition for vitally important natural resources and mutual security concerns - Japanese perceptions of Chinese assertiveness and Chinese worries about the evolution of the US-Japan alliance - put heavy strains on relations between them. The Taiwan issue exacerbates the tensions, and so does Japan's involvement in the US missile defence programme.

Following the incursion of a Chinese submarine into the waters off Okinawa in November 2004, Japan unveiled new defence policy guidelines which for the first time named China as a possible military threat. In response, China expressed deep concerns over the adjustments of Japan's military strategy and over a joint US-Japan statement in February 2005 declaring Taiwan to be a common security issue for the two of them. At that time, Chinese officials deemed the relationship to be at its lowest since the establishment of diplomatic relations in 1972. A number of popular nationalistic protests were levelled at Japan: such manifestations can be spontaneous, but the government in Beijing may also have it in its power to trigger them.

When Bush left, the US-Japan alliance was stronger than ever before, and Obama wants to enhance US alliances both in Asia and in Europe. The guidelines for Japan-US defence cooperation includes consideration of situations in areas surrounding Japan, which the Chinese take to be a reference to Taiwan. Rather than using the alliance to constrain Japan, China is concerned that the US empowers it. US defence commitments to Taiwan rely on logistical support based in Japan and if it comes to another Taiwan Strait contingency, Japan might be involved. In one important respect, however, the alliance does restrain Japan: while conservative nationalist politicians openly advocate Japanese acquisition of nuclear weapons, the alliance keeps those circles at bay. The new Japanese government seems, moreover, to take a different view of US extended deterrence, possibly favouring a doctrine of no-first-use. No-first-use means that nuclear weapons would be used only to retaliate in kind.

In the face of stronger US political and military commitments in East Asia, China is doing in relation to Japan what it did in relation to India when the USIndia agreement was in the making: doing its best to warm relations and alleviate the pressures from its geopolitical opponents. In this respect, Hu Jintao's visit to Japan in May 2008 may be compared with his visit to India in November 2006. He went out of his way to highlight the cooperative dimensions of the relationship and downplay the conflicts of interest. 
North Korea complicates the geopolitics in East Asia by deepening Japan's cooperation with the US on missile defence and bringing Japanese nuclearweapon considerations into the open, and by making China wary of Japanese rearmament and further strengthening of its alliance with the US. The US missile defence deployments in Alaska and California, ostensibly to defend against missiles from North Korea, may as well detract from the Chinese deterrent. This amounts to a strong common interest in bringing North Korea back to nonnuclear status, but not always to agreement on the best strategy to make it happen.

\section{The US call for disarmament and the reactions of other powers}

In response to President Obama's call for an NWFW, what can we expect of the emerging powers of Asia?

China and India are rearming: China to maintain a credible deterrent; India to establish a minimum deterrent. For both of them, disarmament would mean a turn of trends. In some respects, China nevertheless seems ready for it. It does not depend on nuclear weapons to compensate for conventional weakness, and its international status is less dependent on nuclear weapons than that of any other NWS save the US. Having a huge population, a vast territory, impressive economic growth, a prestigious historical record and rapidly growing selfconfidence, China cannot be ignored. It has no need for nuclear weapons to be heard. For China, the most pertinent questions concern its strategic relationship with the US.

The US never resolved to base the relationship with China on mutual vulnerability and deterrence. Opponents of mutual deterrence argue that it would be irresponsible to leave the US, Japan and Taiwan vulnerable to Chinese nuclear weapons as long as these weapons can be negated by a combination of offensive and defensive capabilities. In the face of emerging US missile defence systems, China is therefore bound to take precautionary measures in the form of more weapons in less vulnerable deployment modes. Also, it reserves its position on the fissile material cut-off issue because it is not sure that it has enough weapongrade materials in stock to meet future requirements. To remove these rearmament incentives and build confidence in future cooperation, a US decision to accept mutual deterrence along with a strategic dialogue on how to manage it is therefore of the essence.

US PGS capabilities pose another challenge. The United States wants to reduce its reliance on nuclear weapons by assigning more functions to new conventional systems - systems that others do not have. If it launches a conventional attack on Chinese strategic assets, what would China do? To avoid the first-use dilemma in the face of a declaratory policy never to be the first to use nuclear weapons, new investments to enhance their survivability is a logical answer. This is what China is doing, i.a. by investing more in nuclear-equipped submarines. The challenge is not unique for China, but presents similar dilemmas for 
Russia and others. In other words: the United States may be about to reduce its reliance on nuclear weapons in ways that make it more, not less, difficult for others to embark on disarmament. In the view of ardent US critiques, it confirms one of the most sinister interpretations of US disarmament policy, which sees it as a variation of the conservative theme of change in order to preserve, i.e. preserving US military superiority.

China acquired nuclear weapons to deter others and avoid being coerced, and adopted a policy of no-first-use from the beginning. In this respect, it is usually credited with a progressive disarmament policy. A couple of reservations may be in order, however. First, with the century of shame in mind, there are lingering concerns that others may be trying to get at China, and a feeling that nuclear weapons help to keep challengers at a distance. Second, even if nuclear weapons are marginal to China's overall status in international affairs, there is an element of pride in the nuclear achievements also in this country.

India will continue its nuclear-weapon programme until a minimum deterrent force of some sort has been established. Only then will it be ready to join multilateral disarmament talks. In the meantime, it may feel compelled to accede to the CTBT if the US, China and others ratify the Treaty and urge it to do the same, but this is far from certain. It is not ready for a fissile material cut-off, but willing to participate in negotiations. It had a high profile on disarmament matters before it started to align itself with the international arms control order after the 1998 tests. Other states may encourage India to build on the tradition from Jawaharlal Nehru and Rajiv Gandhi and get ready for disarmament talks as soon as possible.

Sequencing is important both for China and India. Art. VI starts with a call for "cessation of the nuclear arms race at an early date ...": this was always understood to refer to a test ban and a ban on production of fissile materials for weapons. In the bipolar world of the Cold War, it was logical to start with measures that would bring the qualitative and quantitative dimensions of the arms race to a halt and then proceed to disarmament. But it did not have to be done in that order: the original bargain did not tie the members to any particular sequence. A CTBT and an FMCT are important both for substantial and symbolic reasons, and have been uppermost on the priority list of states from the beginning of nuclear-arms-control endeavours 50 years ago, but so have reductions in operative arsenals. The latter was never made conditional on achievement of the former. Today, the interests of India and China suggest that further deep cuts in US and Russian arsenals should come first. Increasingly, the Asian giants are able to put political weight behind their preferences.

For instance, Russia and the United States have conducted about 1,000 nuclear weapon tests each, while India have conducted five. The advanced NWS are increasingly sophisticated in simulating nuclear explosions: the latecomers do not have the same capabilities. Will the CTBT be accepted under such circumstances? Will it have to be supplemented by NWS commitments not to introduce new types of weapons? Or should the sequencing be different, going for further substantial cuts first and trying to clinch a CTBT later? Similar questions 
can be asked of the FMCT. China is hedging and hesitates to proceed to an early cut-off agreement. India is in the process of building up its arsenal and is therefore all the more unprepared. To Western voices arguing nuclear disarmament, Asians say, "Go ahead, we'll support you." But if the response is an arms-control agenda that constrains them while leaving the usual suspects largely off the hook, initiatives will quickly go sour.

Russia has two important foreign-policy assets: petroleum and other raw materials, and nuclear weapons. Unable to equilibrate upwards, it does its utmost to preserve and capitalise on the top-dog positions it holds, using its oil and gas exports both politically and economically, and assigning important roles to nuclear weapons in its national military doctrine. Russia's economic growth is slower, more uneven and more vulnerable than China's and India's, so at best, it will take a long time to beef the conventional forces up to the point where nuclear weapons would no longer be needed for other purposes than core nuclear deterrence. Alternatively, it takes a much more benign security environment to get there. This is the option to be pursued: reduction of threats and accommodation of vital interests are necessary for deep cuts and multilateral talks to be agreed. Gorbachev was unable to realise his vision of a European house. Medvedev has called for a new European security architecture (Bobo 2009). The scars from the Cold War have not been healed, but to prepare Russia for deep and comprehensive cuts, they must be overcome.

The United States and its allies in Europe and Asia are conducting policies of extended deterrence. These policies are up for review. The states to be deterred are primarily China, Russia and North Korea. The alliances are not at stake and neither is nuclear deterrence, but the question concerns what nuclear weapons are supposed to deter. So far, the claim has been that, for extended deterrence to be credible, the first-use option must be kept, but for how long will the Japanese and the Europeans stay by this policy? What will the US do? What will it take to drop it and be ready to deter and defend against a conventional attack by conventional means, limiting the nuclear dimension of extended deterrence to deterrence of nuclear attack? The Hatoyama government that came to power in Japan in 2009 started a comprehensive review of the alliance with the US inter alia with a view to redefine the role of nuclear arms. Most Europeans want to send the remaining US nuclear weapons in Europe back to the United States, and few consider the first-use option to be important for the cohesion of the Alliance.

What is the dynamics of alliance relations in this regard? During the Cold War, US and European hardliners fed on each other to build support for new arms acquisitions. Hardliners on one side of the Atlantic colluded with likeminded people on the other to raise security concerns that arguably needed a military response, to which they could conveniently refer when arguing for new weapon programmes at home. The same kind of interplay has been at work in US-Japanese affairs to thwart Obama's disarmament ambition. At this juncture, however, it may be that the governments of European countries, Japan and the United States, all of which are poised to take a fresh look at the role of nuclear weapons, will develop common interests in reducing the role that these weapons 


\section{Power shifts and nuclear weapons}

play in their bilateral relationship and internationally, and that this cooperation will outweigh the collusion of nuclear-weapon interests.

During the Cold War, nuclear weapons were spread over large parts of the globe, at sea and on land. Starting with the Presidential Initiatives of 1991/1992, all of them have been removed from foreign territory and sent back to their possessors, except some 200 aerial bombs in Europe. By the winter of 2010, they were also up for consideration. 


\section{Part II}

The legacies of nuclear history and the requirements of a new consensus on non-proliferation and disarmament 



\section{The first nuclear era}

\section{The bomb in the mind}

In his eminent book The Seventh Decade: the New Shape of Nuclear Danger, Jonathan Schell emphasises that "Before there was a physical bomb, there was a virtual bomb, a bomb in the mind" (2007: 26). The first bomb sprang to life not in 1945, but in the brain of Leo Szilard a decade earlier. It is the bomb in the mind that stands at the heart of the nuclear proliferation problems, for the mental one is available to all.

The physical one, in the possession of states, came about for fear of others. Szilard was appalled by the physical destruction of the bomb, but feared Hitler even more. Roosevelt did the same. Hitler's Germany became the driver of the Manhattan Project. Later, all members and aspirants to the nuclear club have said that they wanted the bomb for fear of others.

In a prelude to the concerns of the twenty-first century, the British MAUD report of 1942 made an ominous elaboration: even if Hitler failed to get it first, England would need it, for no nation "would care to risk being caught without a weapon of such decisive capabilities" (Rhodes 1986: 369). In other words, if the threat is not manifest it will always be latent, for the bomb in the mind does not know geographical borders and the future is unpredictable. Current rationales for retention and modernisation of nuclear arms are reminiscent of the MAUD report. For instance, the stated rationale for the British proposition to build a replacement for the Trident submarine system emphasises the need to defend against the unpredictable. The same rationale can be used by many other states, and it fits some states much better than it fits Britain.

During the Cold War, the fundamental flaw of this rationale was coined "the fallacy of the last step" - the mistaken belief that the latest military acquisition would provide a lasting advantage. The Cold War became replete with examples. No solution to the fallacy was found then, and there is none now. Further proliferation, horizontal and vertical, remains a matter of great concern, horizontal proliferation more so than during the Cold War. 


\section{The legacies of the Cold War}

The first nuclear era - that of the Cold War - left four important legacies influencing the policies of the second. First, the recurrent attempts at threat inflation and the corresponding politics of fear. Often, policies were made on the basis of worst-case analysis. Sometimes, it was worse than that: they were made in reference to images deliberately construed to justify enhanced arms build-up. Advocacy substituted for analysis. When the period of opportunity of the early 1990s was over, this practice was resumed in reference to new threats, from non-state as well as state actors. Second, the doctrine of nuclear deterrence outlived the global rivalry and confrontation between the United States and the Soviet Union. It was adapted, but in essence maintained. Threats of using nuclear weapons, a recurrent practice during the Cold War, have also been issued later. Third, the arms race left enormous stocks of weapons and fissile materials behind, many of them in excess of military needs and without adequate protection. Risks connected with lax controls fed into strong elements of push and pull for nuclear proliferation both in the state and non-state paradigm, and still do. Finally, as the Cold War drew to an end, the superpower leaders offered a vision of a world without nuclear weapons, in all earnest $-\mathrm{a}$ vision that was revived 20 years later.

\section{Threat inflation and the politics of fear}

The first period of the nuclear age - the first nuclear era - was part and parcel of the Cold War. The distinct characteristics of this world order translated into an equally distinct nuclear arms race driven by threat inflation and politics of fear.

For a couple of centuries, the lifetime of international orders had been limited to a few decades. From the end of the Napoleonic war to the end of the Cold War - 175 years - Europe saw five orders corresponding to five distinctly different distributions of power, for an average of 35 years each. The Cold War lasted for 40. This historical observation passed unnoticed, however: the Cold War was sometimes referred to as a duel without end, and the nuclear arms race as a race to oblivion (York 1970). Innovators know that to get on to something new, it is important to go back to basics and start from scratch. The rigidities of the Cold War discouraged any such attempt. Like bad chess players, decision-makers considered each move to be a necessity, without trend-breaking alternatives. Scholars and observers met to discuss security and arms-control issues, but the agenda was usually confined to small-scale, reformist variations of existing policies, and even modest refinements seemed unrealistic.

Threat inflation and politics of fear were essential features of security politics on both sides of the East-West divide. Its origin and form differed, but it was so deeply ingrained both in Moscow and Washington that it survived the Cold War and got a new lease on life in this century. In the United States, the practice reemerged towards the end of the 1990s and got a formidable boost when terrorism struck the United States on 11 September 2001. 


\section{The way it worked in the United States}

All through the Cold War, threat inflation was used by American politicians and experts to promote arms programmes. Under the pretence of analysis, a series of reports were in effect advocacies of enhanced arms build-up. Among the most prominent ones were the following:

1 In the spring of 1950, Paul Nitze and his staff prepared "NSC-68: United States Objectives and Programs for National Security". The report (NSC68 .. 1950) claimed that, should a major war occur that year, the Soviet Union could immediately overrun Western Europe, drive towards the oilrich areas of the Near and Middle East, consolidate communist gains in the Far East, launch air attacks against Britain and air and sea attacks against the shipping lanes of both the Atlantic and the Pacific, and attack selected targets in Alaska, Canada and the United States with nuclear weapons. While Truman was sceptical at first, the Korean War helped persuade him to endorse the report, leading to a fourfold increase in the defence budget. Thus began a new budget practice prioritising defence over all else. Most administrations after Truman have determined defence requirements first, and then allocated the rest to domestic needs. Or the budget was run with a deficit. Steady, significant economic growth allowed it. In rare cases, taxes were raised. The weapons laboratories did not wait for the military to define the needs, but found out themselves what the art of the possible would be. They made it up as they went along (Rhodes 2007: 83).

2 In 1957, the Gaither panel conducted a similar exercise, widening the mandate given to it by President Eisenhower to correspond to that of NSC68. The NSC-68 had identified 1954 as the year of maximum danger: the Gaither report moved it forward to 1959, predicting that a catastrophic missile gap was in the making. Presidential candidate John Kennedy took it on board, appealing to fear for political advantage. When incoming Secretary of Defense McNamara found that there was a missile gap, but in the US's favour, the President told him that the politics of the matter had come to a point that necessitated as many as 1,000 Minuteman missiles (in addition to the Titans already deployed, for a total of 1,054).

3 In 1976, George H.W. Bush, the director of the Central Intelligence Agency (CIA), appointed three "B-teams" to review the data and conclusions of the CIA's own "A-teams" that prepared the 1976 National Intelligence Estimate (NIE). The real initiators of the review were John Foster and Edward Teller, both of the Lawrence Livermore Laboratory, taking the view that intelligence officers should deliberately try to influence policy by emphasising the worst that the Soviet Union could do. The conclusions lived up to it:

While hoping to crash the "capitalist" realm by other than military means, the Soviet Union is nevertheless preparing for a Third World War as if it were unavoidable.... Within the ten year period of the National 
Estimate the Soviets may well expect to achieve a degree of military superiority which would permit a dramatically more aggressive pursuit of their hegemonial objectives.

(Rhodes 2007: 125)

With the benefit of hindsight, the B-team's allegations about Soviet weapon systems were all wrong - but that, in a sense, is beside the point.

4 At first, the B-teams had little impact. However, their conclusions were followed up by the Committee on the Present Danger, which declared war on Jimmy Carter and his notions of nuclear sufficiency. The Strategic Arms Limitation Talks (SALT II) agreement was not ratified and Jimmy Carter was not re-elected. The politics of fear played into the hands of Ronald Reagan. During his presidency, the hegemon-challenger dilemma - the challenger claiming parity; the hegemon fearing it would go for more ushered into another major wave of Cold War. At times, East-West affairs were about little more than nuclear arms racing and bean counting. For a while, Soviet spokesmen characterised the early 1980s as a pre-war period.

\section{The Soviet side}

To hide Soviet weakness after the Second World War, Stalin put the loss of human lives at 15 million. Real losses were much higher, and they came on top of millions of victims of the "Great Terror" of the 1930s. When the nuclear age began, the Soviet Union was, therefore, on its knees, much inferior to the United States. The feeling of inferiority haunted Soviet leaders all through the Cold War. Soviet politics of fear emanated from this inferiority complex, and from the self-interests of a military sector that grew to almost one half of its gross national product (GNP), eventually breaking the back of Soviet economy.

Nevertheless, up to the Cuban crisis of 1962, Soviet policies were to some extent budget-driven, conservative and cautious - although the grip on Eastern Europe was maintained without hesitation by threat or use of military force in East Germany (1953), Poland (1956) and Hungary (invaded in 1956). In another reading of the same period, the resource limitations left the leadership without any real possibility of matching the United States. However, the political restraints of those years become clear when juxtaposed to what followed after the Cuban crisis. Cuba became a turning point.

At the time of the Cuban crisis, modest numbers of Soviet Bear and Bison bombers were based deep inside the Soviet Union and would have to be forward deployed before flying inter-continentally. That could reveal their intention and make them vulnerable to pre-emptive attack. The Soviets had a few R-7 and R-16 intercontinental ballistic missiles (ICBMs) carrying 2.8 megaton thermonuclear warheads, and Soviet submarines in the Caribbean could use their missiles against targets in the United States in retaliation. ${ }^{1}$ American forces consisted of several thousand bombs on 1,576 Strategic Air Command (SAC) bombers, 183 Atlas and Titan ICBMs, 144 Polaris missiles on nine nuclear sub- 
marines, and the first squadron of ten Minuteman I missiles, brought to full alert for the first time at the height of the crisis on 26 October 1962. That day, Castro asked Khrushchev for a pre-emptive nuclear strike on the United States. Khrushchev declined (Reed 2005:18).

The parties drew similar conclusions from the showdown. Swallowing their humiliating retreat, the Soviet leaders were determined to deny the United States another dictate. Vasily Kuznetsov, the diplomat who negotiated the crisis settlement for the Soviet Union, told his American counterpart that much: "I want to tell you something. You'll never do this to us again" (Rhodes 2007: 94). Parity with the United States became economic priority number one - a formidable ambition for a much smaller economy - but the dictatorship had it in its powers to pursue it. For the US leaders, the outcome confirmed the importance of strategic superiority. They could better afford it: US military expenditures peaked in the 1960s at 11 per cent of the GNP. By the end of the 1970s, the two powers were in for the classical dilemma referred to above: while the (Soviet) challenger said it aimed at parity, the (US) hegemon saw a rising curve threatening to overtake its own. The result was an annual 10 per cent increase in US military expenditures from 1980 to 1986 - and renewed fear in Moscow about US superiority and nuclear war.

Old habits die hard. In 1998, the Commission to Assess the Ballistic Missile Threat to the United States, better known as the Rumsfeld Commission, focused on the dangers posed by rogue states developing ballistic missiles capable of reaching the United States, arguing that the US intelligence community had underestimated these threats. Proponents of missile defence used the findings to push their case. The Commission grouped Iran, Iraq and North Korea together because they all pursued missile programmes based on Soviet Scuds: some observers have seen a line from its report to the "axis of evil". In due course, missile-defence deployments in Alaska and California were justified in reference to North Korea and the planned deployments in Poland and the Czech Republic in reference to Iran. In Russia, President Putin was riding high on a nationalistic trend, upgrading external threats and capitalising on his own strongman image.

\section{Nuclear deterrence}

During the first nuclear era, nuclear weapons were tailored to all sorts of delivery systems - to land-, air- and sea-based missiles of various ranges, to land- and carrier-based aircraft, and to artillery systems. The Soviet Union had nuclear land-mines as well. Nuclear weapons substituted for conventional munitions to such an extent that by the 1960s and 1970s, important US and Soviet force categories had little capacity for conventional warfare.

In numerical terms, the reliance on nuclear arms grew astronomically. In the United States, Eisenhower sought unilateral advantage through quantitative superiority. During his presidency, the US stockpile leaped from 1,400 to 20,000 warheads, while the Soviet arsenal grew from 120 to 1,000 warheads. The Cuban crisis triggered a veritable Soviet catch-up effort, demonstrating - in the course 
of 15 years - the fallacy of the last step also in quantitative respects. When the Cold War ended, the world's arsenals contained about 60,000 warheads, 98 per cent of them Soviet and American ones.

These numbers, and the incessant pursuit of nuclear superiority and parity that produced them, speak to the formidable importance that the United States and the Soviet Union assigned to nuclear weapons during the Cold War. The weapons were explained and justified in terms of deterrence: mutually assured destruction (MAD) was the best guarantee against nuclear war. To explain the ever-expanding size of the arsenals, nuclear war-fighting doctrines were added. To be able to destroy each other's weapons in series of attacks and counterattacks, large diversified and well-protected arsenals were arguably needed.

The doctrines of deterrence and war-fighting are related. For deterrence to work there has to be a will to use the weapons if attacked; the best way to convince the adversary about that is to prepare for it; and the only way to be seen to be ready is actually to be ready. Especially if you think you can win a nuclear war - and this is what the war-fighting doctrines were about - the inhibitions against use goes down; hence the argument that war-fighting doctrines are helpful in making deterrence credible.

Did strategic scenarios envisaging attacks and counter-attacks and use of nuclear weapons in the thousands make it to the "real world of real political leaders"? McGeorge Bundy, Kennedy's and Johnson's national security advisor, said "no". In the real world of real political leaders "ten H-bombs on ten cities would be a disaster beyond history; and a hundred bombs on a hundred cities unthinkable" (Bundy 1969). He argued that the mere existence of nuclear weapons had a restraining effect irrespective of the sophistry of nuclear-war planning. Having the Cuban missile crisis fresh in mind, Bundy introduced the term "existential deterrence". In the "real world", deterrence theory may have boiled down to existential deterrence all through the Cold War - yet the nuclear build-up continued and the nuclear doctrines became ever-more sophisticated.

What disappeared with the Cold War and what was left behind? The nuclear arsenals have been cut by more than 60 per cent. Still, there are altogether some 23,000 nuclear weapons in the arsenals of nine nuclear-weapon states (NWS). Nuclear doctrines are no longer in the foreground of international affairs, but nearly one decade into the twenty-first century they stayed much the same. Deterrence, war-fighting and possible first-use of nuclear arms remained key organising concepts. Only the rising Asia giant - China - was committed to a policy of no-first-use (NFU). After the tests in 1998, India also adopted such a policy, but later extended the role of nuclear weapons to include deterrence of chemical and biological weapons. As was the case during the Cold War, nuclear policies were driven by fear of the other(s); by vested domestic interests in research, development and production of arms; and by a belief in the political significance of military superiority, notably in the United States, where it was written in stone. Others may think the same way without admitting to it, because they are unable to challenge it.

China's outlook appears different, however. During the second wave of US-Soviet arms racing in the 1980s, China showed remarkable restraint, and 
by 2009 it still had only 24 ICBMs capable of reaching the West Coast of the United States. The Chinese evidently consider that if a few (megaton) bombs can be detonated over US cities, that is enough to deter a US nuclear attack, and they are most probably right. For any US administration, a few H-bombs on US population centres mean unacceptable destruction. India has not defined what its objective of minimum deterrence would mean and it is too early to judge where it is heading, but it seems bent on avoiding an arms race with China.

\section{Remnants of the Cold War}

When the duel was over and the Berlin Wall came down, 40 years of arms racing had produced 70,000 nuclear weapons and huge amounts of highly enriched uranium (HEU) and plutonium. The collapse of the Soviet Union, which had based its nuclear management on physical control without any rigorous material accountancy, caused grave concerns about proliferation to state and non-state entities. Later, the discovery of the Abdul Qadeer Khan network widened it into a concern tous azimuth: firms and individuals from more than 30 countries on four continents had contributed to the network, but nothing seemed to have come from the former Soviet Union. Effective implementation of Article I of the Treaty on the Non-Proliferation of Nuclear Weapons (NPT), obliging suppliers not to assist others in the acquisition of nuclear weapons, became an issue of the highest order. ${ }^{2}$

The first nuclear bomb to be dropped - over Hiroshima - had not been tested. Testing was not considered necessary, for by shooting two significant amounts of HEU at each other, the weapon developers were virtually certain that a nuclear explosion would follow. The Hiroshima bomb had a yield of 12.5 kilotons, i.e. equivalent of 12,500 tons of TNT.

Ever since Hiroshima, latecomers and newcomers to the nuclear club, therefore, knew that they had a choice: if they went for HEU, they could declare their capabilities by testing or they could leave others "in the dark" and still be virtually certain that they had a weapon that would work. They had that choice using plutonium as well, but with some additional problems to overcome: implosion technologies had to be mastered and unstable isotopes $(240,241$, etc.) had to be controlled. The plutonium bomb that was used over Nagasaki had been tested at Alamogordo. Most of the newcomers chose to test, while Israel and South Africa adopted policies of opacity and ambiguity.

When the risk of nuclear proliferation began to transcend the state paradigm, the lesson from Hiroshima became particularly relevant. For terrorists, there is little doubt that the material of choice is HEU. Equally obvious, the first and most effective line of defence is at the source, meaning reduction of weapons and weapons-grade materials, and effective control of the remaining inventories. There is an extensive literature assessing this problem, describing the multitude of programmes that try to come to grips with it and discussing shortcomings and remedies (Ferguson and Potter 2005). 
Risk is probability times outcome. The probability of catastrophic terrorism is a function of time. The outcome may be a question of what a nuclear explosion will do to an urban area, i.e. another Hiroshima. Even more dramatic, it may be a question of how the United States would react to a nuclear explosion in one of its cities. 9/11 hit a raw nerve in its government machinery and changed the world: the reactions to an act of nuclear terrorism would be even more dramatic. Somehow, the superpower would probably strike in revenge, e.g. against states that are believed to host or support the group behind the terror. The political system of the United States may change very much for the worse, and so may that of others. The world economy would take a severe blow. The consequences are actually hard to imagine.

\section{Reykjavik}

As the Cold War began to wind down, a spectacular attempt was made to rid the world of nuclear weapons. Mikhail Gorbachev and Ronald Reagan shared the objective of a nuclear-weapon-free world (NWFW), and had a go at it in Reykjavik in October 1986.

The prelude was the summit meeting in Geneva in November 1985, best known for a joint statement emphasising that a nuclear war cannot be won and must never be fought. The following year, Gorbachev sought direct dialogue with the United States at the highest level, aiming, first of all, at agreements in the field of arms control and disarmament. Reagan, too, preferred to do business that way. He shied away from bottom-up summits issuing communiqués that had been negotiated in advance. Geneva had been conducted in a top-down way, and Reykjavik was cast in the same mode. Without it, there was no chance of getting around old habits blocking new departures towards cooperative security.

In his memoirs, Gorbachev says that "our generals and even some people in the Foreign Ministry and in our negotiating team in Geneva ... were firmly stuck in the logic of antagonism, and the military sought to protect their corporate interests" (1996: 415-416). Much the same applied on the American side. Elaborating on "what really happened at Reykjavik", Secretary Shultz writes that "the outcome of Reykjavik portended such a departure from the past that it split my colleagues in the State Department" (1993). Some argued that comprehensive disarmament would undermine the Western alliance and make the Europeans accommodate to the Soviets. Nuclear weapons knit the alliance together. Reykjavik had been a trap. The argument was anchored in the past, in the textbooks of the Cold War, void of readiness and ability to imagine what a world without East-West confrontation and nuclear weapons might be like.

At Reykjavik, Reagan and Gorbachev confirmed to each other their objective of eliminating all nuclear weapons, observing parity and equality at each step along the way. Gorbachev seized on the Palme Commission's notion of common security (Rhodes 2007: 220-221). The Commission had emphasised that, in the nuclear age, security was something the parties had to seek together, to mutual advantage. It was not something one party could achieve at the expense of the 
other. Disarmament had to proceed through a series of win-win stages. Gorbachev proposed a timeline for elimination of all nuclear weapons by the year 2000.

The stumbling block was the US Strategic Defense Initiative (SDI). In his correspondence to Gorbachev of 25 July 1986, Reagan had proposed that the side that wished to deploy strategic defences should be obligated to present a plan for sharing the benefits of them and for eliminating offensive ballistic missiles. If the missiles were eliminated before deployment of defences against them, then no capability for a first strike would exist. Deployment of defences would be justified anyway, as an insurance policy against cheating or against some other power that might acquire offensive strategic missiles (Shultz 1993: 754). Reagan's rationale was much different from that of later administrations, which can best be described the way President Nixon justified the Anti-Ballistic Missile (ABM) Treaty of 1972 (which prohibited national missile defences): "If you have a shield, it is easier to use the sword."

Gorbachev tried as best as he could to curtail the SDI, partly because of commitments he had made at home, partly because the programme was of genuine concern to him. The mix was unclear, however. Soviet scientists had told him that the SDI could be neutralised for 10 per cent of what the missile shield would cost. In February 1986, he had asked some of his assistants, "Maybe it is time to stop being afraid of the SDI?" (Dobrynin 1995: 620). At Reykjavik, Gorbachev insisted that the SDI should be confined to laboratory research and testing for a period of ten years - and that blocked the big deal. The leap towards an NWFW failed. In effect, the Reykjavik summit nevertheless prepared the ground for the Intermediate-Range Nuclear Forces (INF) agreement, which eliminated all US and Soviet missiles in this category, and for the Strategic Arms Reduction Treaty (START I), which reduced operational strategic nuclear weapons by 50 per cent.

Reflecting on the issues that thwarted the high ambitions of the leaders, Anatoly Dobrynin wrote:

As an eyewitness to Reykjavik, I feel Gorbachev was no less responsible than Reagan for its failure because he held SDI hostage for the success of the meeting. He held good cards with impressive disarmament proposals, and he could have played them far better if he had not been as stubborn on SDI as Reagan. It could have been postponed for further consideration if they had reached agreement on a deep reduction of nuclear weapons, and as a matter of fact Gorbachev followed that bargaining strategy in later negotiations toward the end of the Reagan administration.

This assessment seemed appropriate at the time it was written, and even more so today, knowing the technological difficulties that ballistic missile defence (BMD) still encounter.

Two issues were glaringly absent from the Reykjavik negotiations. First, when talking about an NWFW, the superpowers seem to have taken the consent 
of the other NWS for granted. Neither are there any references to the question in the US and Soviet memoranda of conversation, nor is there any mention of it in Reagan's, Shultz's, Gorbachev's and Dobrynin's accounts of the discussions. This speaks to a fundamentally important feature of the first nuclear era: without a shred of doubt, the superpowers were dominant, certainly in their own eyes and most probably also in those of others. The other NWS were mere appendices to the bilateral dimension of this world order.

Second, there was no mention of the NPT, despite the fact that Article VI of the NPT made elimination of nuclear weapons an international legal obligation. This confers credence to the view that, for the major powers, the NPT was somewhat marginal to their core security concerns. Or they had never paid much attention to Article VI and, therefore, failed to recognise it even as they tried to implement it.

In his account of the meeting, George Shultz writes:

The achievements at the Reykjavik summit were greater than those in any U.S.-Soviet meeting before, but the popular perception of the outcome in Iceland at the time was one of near disaster or near farce. Over the years, that perception hardened into accepted truth.

Gorbachev notes that Margaret Thatcher "rushed her fences": "We must not allow a second Reykjavik to happen" (1996: 420). There was something unreal about it all, partly because it had not dawned on those who received the news that the Cold War might soon be over. In part, it was also due to the way it happened. Between Geneva and Reykjavik, there had been some 25 communications back and forth in preparation of the summit, but they were high-level secret ones setting the stage for a leader-driven negotiation. Therefore, the news took governments and public opinion by surprise. Also, they were met with incredulity because the leaders had been thinking big in unconventional ways. Could this be part of the real world?

While much progress was made in the field of disarmament, an NWFW was not to be. However, Reykjavik revived the vision, shaking governmental bureaucracies entrenched in the nuclear paradigms of the Cold War and giving hope to the people who had been at their mercy.

George Shultz met the critics of Reykjavik and proponents of status quo asking, "What's so good about a world where you can be wiped out in thirty minutes?" (1993: 780). When commemorating Reykjavik 20 years later, he was joined by other former US leaders. Together, they published an article in the Wall Street Journal highlighting the goal of an NWFW (Shultz et al. 2007). 


\section{Post-Cold War doctrines}

\section{The functions of nuclear weapons}

The first nuclear era conferred many functions on nuclear weapons. They were deployed in the name of national security and they enhanced the status and prestige of their possessors. By moving them forward, including them in military manoeuvres and keeping them in high states of readiness, nuclear weapons were used to maintain superpower spheres of interest and mark political ambitions. Produced in enormous numbers, widely distributed and well-integrated in the military machines of their owners, there was a nuclear shadow to many deployments, operations and conflicts.

After the Cold War, some of these functions have continued unabated; others have been weakened and discarded; and yet others have been given a new lease of life by adapting the nuclear postures to new political and military circumstances. To better understand what it takes to change the role of nuclear weapons, a closer look at their current functions is in order.

\section{The structural impact}

Karl Marx wrote that the most effective power is the structural one which functions without being used. Nuclear weapons function this way. Military strength is an important determinant of the international hierarchy of states, and nuclear weapons are the ultimate expression of strength. States are sensitive to the international hierarchy: consciously or subconsciously, they shape their policies and actions with a view to the power that others can wield, accommodating to those who are high in the hierarchy. Nuclear weapons are unique in their destructive capacity, instilling a sense of awe in the minds of opponents and fostering caution and respect in the minds of others. Their structural impact comes down to what McGeorge Bundy (1969) called "existential deterrence": stripped of sophisticated doctrines and war plans, nuclear weapons influence others by their sheer existence. They function without being used, just by being there. ${ }^{1}$

The status value of nuclear weapons played a role in the British and French decisions to go nuclear. They got what they wanted in the way of "a place at the table" (Bundy 1988). France also got the muscle to chart an independent foreign 


\section{The legacies of nuclear history}

policy. In 1966, it withdrew from NATO's military organisation. In 1968, when the Nuclear Non-Proliferation Treaty (NPT) was opened for signature, the structural significance of nuclear weapons was enshrined in treaty form. The NPT is based on the distinction between "haves" and "have-nots", between five big powers and all others - a distinction that persists in a somewhat diluted form another four de facto nuclear-weapon states (NWS) have been added - despite the fact that it was supposed to be temporary. Precisely because the weapons are in the hands of a privileged few, their status value becomes all the more conspicuous.

Some 30 years later, domestic as well as international prestige played a role in India's declaration of nuclear-weapon status. Elements of the Indian scientific community pushed for it to show that they mastered the technology. In the beginning, the international reactions to the 1998 tests were harsh and condemning, but today, India is well on its way to become a recognised NWS, adding self-confidence to strong sentiments of national sovereignty and independence.

\section{Deterrence and war-fighting}

The end of the Cold War eliminated the political and ideological confrontation between East and West, but the nuclear doctrines remained much the same. The United States and Soviet/Russian forces were much reduced, but the Clinton administration's Nuclear Posture Review (NPR) became an exercise in continuity, the first-use policy included. Russia changed its doctrine to make it more similar to that of the United States. Nuclear planning resisted political change.

The stated rationale for acquisition of nuclear weapons has always been phrased in terms of national security. It comes in several forms. One of them is deterrence by mutually assured destruction (MAD). During the Cold War, all NWS adopted this logic, although operationally, they gave very different meanings to it. The United States and the Soviet Union built enormous forces to guarantee unacceptable destruction; China, France and the United Kingdom introduced notions of sufficiency and minimal deterrence.

Deterrence of strong conventional forces is another function. For the United States, this goes back to the Soviet blockade of West Berlin in 1948 and what it might take to defend the city. In the face of superior Soviet conventional forces, use or threats of use of nuclear weapons were deemed necessary to maintain access to the city and to defend it. First-use became a crucial part of NATO strategy from the inception of the alliance, and led to the deployment of thousands of tactical nuclear weapons in Europe.

This function also outlived the Cold War, but now the tables were turned: it was Russia's turn to be conventionally inferior and to raise the role of nuclear weapons to compensate for weakness. Russia discarded the Soviet declaration of no-first-use of 1982 and adopted the Western first-use policy. ${ }^{2}$ For Israel, deterrence of Arab conventional forces has always been the essence of its nuclear policy, along with a determination to maintain nuclear monopoly in the Middle East. Later, the role of Pakistan's nuclear weapons also came to centre on firstuse, deterring India from making deep intrusions into its territory. 
A third function was that of nuclear war-fighting, contemplating nuclear exchanges between the USA and the USSR involving thousands of nuclear weapons back and forth, as if nuclear war could be similar to conventional war and be lost or won. Even without actual war, the theoretical possibility of victory was thought to translate into political advantage: this was one of the perceived lessons of the Cuban missile crisis. Even in the absence of any expectation of waging large-scale nuclear war, both powers therefore went for demonstrated capabilities to win or at least deny victory to the other party. These plans, which could justify whatever number of weapons - about 10,000 deployed strategic nuclear weapons on each side during the height of the Cold War - were among the worst excesses of the Cold War.

When the Cold War ended, the arsenals were significantly scaled back. The Intermediate-Range Nuclear Forces (INF) Treaty eliminated land-based intermediate range missiles; the Strategic Arms Reduction Treaty (START I) reduced the strategic forces by one-third; the Presidential initiatives of 1991/1992 ordered comprehensive withdrawal of tactical nuclear weapons; the Strategic Offensive Reductions Treaty (SORT) limited the number of deployed strategic weapons to 1,700-2,200 by 31 December 2012; and a new agreement replacing START I further reduced the strategic arsenals. Today, the role of nuclear weapons in war is geared less to strategic big-power settings and more to regional contingencies.

A fourth function was that of extended deterrence. The United States maintains extended deterrence postures in cooperation with its allies in Europe and East Asia. The end of the Cold War changed the weapons configurations in these regions, ${ }^{3}$ but not the essence of the doctrines. The United States keeps the option of being first to use nuclear weapons in response to an attack on its allies, be it an attack by conventional or by unconventional means.

The credibility of this doctrine has always been in doubt. At one point, Henry Kissinger warned the European allies not to repeat requests for assurances that the United States could not possibly mean. ${ }^{4}$ President Obama's disarmament initiatives triggered renewed debate about extended deterrence at official levels both in Japan and Europe, leading politicians holding that the role of nuclear weapons should be limited to deterring their use by others. The alliances were not at stake, nor nuclear deterrence: the issue was the first-use doctrine.

\section{The impact of nuclear threats}

Over the years, the United States has issued specific nuclear threats more than 20 times. Before Barack Obama, nine out of ten presidents of the nuclear age have done so during crises and limited wars in Berlin, Cuba, East Asia, Indochina and the Middle East. The one exception - Ronald Reagan - did not experience a crisis of the kind that made the other presidents invoke such threats. All ten have maintained continuous commitments, along with up-to-date planning and readiness, to implement nuclear plans should a major challenge arise in the NATO area, the Middle East or other countries under the US nuclear umbrella, such as Japan and South Korea (Ellsberg 2009). 
None of them is known to have considered adopting a no-first-use posture. To many Europeans, this seemed a logical thing to do when the conventional imbalance that justified NATO's first-use policy disappeared and big-power cooperation got off to a new start. That, however, was naive, because it ignored the importance that the United States attaches to possible first-use elsewhere in the world. Also, the United States was increasingly bent on exploiting its superiority, seeing no need for compromise and accommodation of Russian interests or those of others. European governments went along with it, more or less.

Threats of first-use have been made to maintain US spheres of interest. Sometimes, they were invoked to protect US forces far away from home from larger ground forces in their neighbourhoods. Sometimes, friends and allies who might not be able to stand their ground on their own needed support. When they were in danger of being surrounded or overrun, resort to nuclear weapons often came up for consideration: in support of US marines at the Chosin Reservoir and Khe San, the French at Dienbienphu, Chiang Kai-shek's troops deployed on Quemoy. The nuclear card was played to defend US positions: it was not played to extend them (Ellsberg 2009). Some of the threats were bluffs, some were defied and some may have worked more or less as intended.

Shortly after the Iron Curtain came down, nuclear threats were levelled at Iraq in connection with the first Gulf War. Delivering a warning letter to Iraqi Foreign Minister Tariq Aziz, Secretary of State James Baker says in his memoirs that, "I purposely left the impression that the use of chemical or biological agents against Israel could invite tactical nuclear retaliation" (Baker 1995). President Bush says in his memoirs that he had "privately decided" not to do so: in his own mind, the threat was therefore a bluff (Bush 1999). However, William Arkin's interviews with Iraqi officials left him in no doubt that Saddam Hussein and his government believed the United States was prepared to use nuclear weapons had Iraq used chemical weapons against coalition forces or against Israel (Arkin 1996).

Another reading points in a different direction. Baker's letter also warned Aziz that if Iraq used chemical or biological weapons, supported terrorist attacks and burnt Kuwaiti oil fields, the US objective "won't just be the liberation of Kuwait, but elimination of the current Iraqi regime" (Baker 1995). Two of these three actions were actually taken by the Iraqis during the last days of the war, which perhaps implies that they were not deterred from using chemical weapons either. So why did Iraqi leaders say that the nuclear threat deterred them from using chemical and biological weapons? Joseph Fitchett cites an unnamed Arab diplomat:

The regime had to explain to its military commanders why it was pulling back from the brink, so it looked a lot better to say that it was sparing the Iraqi people from nuclear holocaust than to admit that the leaders were worried about their own skins. 
However, Baker believes the calculated ambiguity about the US response was part of the reason why Iraq did not use its chemical and biological weapons. To him and others, the utility of nuclear threats therefore appeared to be confirmed. Whether that interpretation was correct or not, whatever chance there might have been for the United States to adopt a policy of no-first-use after the dissolution of the Warsaw Pact and the Soviet Union, it effectively disappeared with this experience.

Later, the Clinton administration issued threats of nuclear-use against North Korea (1995, shortly after a near-launch of a US conventional attack in 1994) and publicly warned of the nuclear option against Libya (1996, in reference to the Tarhuna underground chemical weapons facility). The Bush administration issued threats against Iraq (2003) to deter Saddam from using chemical and biological weapons against US and allied troops and against Israel. ${ }^{5}$ In 2009, the bipartisan US Congressional Strategic Posture Commission under the leadership of William Perry and James Schlesinger (Perry et al. 2009) rejected a no-firstuse policy because it would "undermine the potential contributions of nuclear weapons to the deterrence of attack by biological weapons" (and be "unsettling to some US allies").

The Bush administration also made contingency plans for the use of conventional as well as nuclear weapons against Iran, and the administration repeatedly emphasised that "all options are on the table". To make contingency plans is quite customary, however, and to say that all options are on the table falls well short of specific threats for specific purposes, but governmental statements made the nuclear option a live issue for public attention and debate. Among the leading candidates for the 2009 presidential election, only Obama took partial exception to the use of nuclear weapons - against Afghanistan and Pakistan, "involving civilians" - but not against Iran. The military brass seemed more sceptical of threats and use of nuclear weapons than their political leaders.

The threats against Iraq and Iran were not made in defence of US spheres of interest, but in an effort to expand American influence in the Middle East. ${ }^{6}$ They were part of Bush's policy of regime change, which targeted the regimes in Iran, Iraq, Lebanon, Libya, Somalia, Sudan and Syria. ${ }^{7}$ The general mood was assertive: many others therefore went along with it, to not weaken their own credibility. Such was the bandwagoning effect. However, during the second term of Bush's presidency, the policy of regime change lost much of its appeal and credibility because of the traumatic experiences in Iraq and Afghanistan.

\section{Discrete political use of force}

In a study of US politico-military behaviour from January 1946 to December 1975, Barry Blechman and Stephen Kaplan examined 215 instances in which armed forces were used in a discrete way for specific political objectives (Blechman and Kaplan 1978). To qualify for inclusion on the list, a physical change in the disposition of armed forces had to occur for the specific purpose of influencing the behaviour of another actor in a particular situation, short of any intent 
to go to war. The foremost instrument was the navy. Ships are easier to move around than army units or land-based aircraft. They can be nearby yet out of sight, and therefore be used more discreetly than land-based forces. In part, using the navy was also a matter of tradition: for most of US history, there were no or few forces stationed abroad, so the navy was the only available instrument. Aircraft carriers took part in half of the instances.

During the Cold War, nuclear weapons were deployed at sea and in other countries for strategic and tactical warfare. Warships had nuclear weapons on board for surface-to-air missiles (SAMs) and anti-submarine warfare, and aircraft carriers had nuclear air-to-ground ordnance as well. Any deployment of such forces to the vicinity of hot spots, or involvement in incidents in other regions of the world, could therefore be used to extend a nuclear signal of some sort. At the very least, the projection of nuclear weapons on to foreign shores, their use in military exercises and shifting levels of readiness were recurrent reminders of their comprehensive existence and integration into the force postures. Without extending specific threats of nuclear-weapon use, they left the impression that nuclear weapons were weapons of war, and that was indeed the intention.

Naval nuclear weapons were mixed with conventional firepower. Other weapon systems had a designated role in the strategic war plans against the Soviet Union. In the period under study, such systems played a role in 19 of the 215 instances.

Of course, the relative size and sophistication of military forces influence the propensity to use them. Stronger postures widen their applicability and enhance the confidence of their owners that they can be brought to bear on others with positive results. In particular, the US monopoly on nuclear weapons was an important asset in its foreign affairs - for as long as it lasted. The bombing of Hiroshima and Nagasaki contributed to it: had nuclear weapons never been used in war, they might have been classed with chemical and biological weapons and considered so abhorrent that they would be discounted in the calculations of policy-makers. Similarly, the Soviet acquisition of a nuclear capability strengthened the diplomacy of Soviet leaders, primarily vis-à-vis the United States and NATO. Still, for many years they were clearly inferior, learning it the hard way during the Cuban missile crisis in October 1962. They drew the lesson that neither quick fixes nor basic deterrence would work: not to be humiliated again, they invested enormously in an assured second-strike capability aiming at parity with the United States It seems to have had the expected effect: Blechman and Kaplan found that, as the Soviet Union gained in nuclear and conventional strength relative to the United States, especially after the mid-1960s, the United States employed its armed forces less frequently for political objectives. ${ }^{8}$

\section{A norm of non-use}

In the final analysis, the functions noted above depend on the political will to employ the weapons more or less the way the doctrines prescribe. If the will is seen to be weak and wavering, their credibility will be undermined. This is what 
more than 60 years of non-use in combat tends to do. Ever since 1945, decisionmakers have shied away from using these weapons in war. There is a certain truth to the observation that the more time that passes without a nuclear weapon being used, the stronger the norm of non-use.

T.V. Paul (2009) speaks of an "informal tradition" of non-use arising from two interrelated factors: the unique destructiveness of nuclear weapons and the reputational costs of using them. In a globalising world, both governments and non-governmental organisations have to care about their reputation. The United States abstained from nuclear-weapon use in Vietnam, and the Soviet Union shied away from using nuclear arms in Afghanistan. The non-use tradition is a function both of reputational costs, which tend to grow with growing interrelatedness and media coverage, and the length of time without nuclear-weapon use (Tannenwald 2007).

During the Cold War, the leading powers had a relatively easy job upholding the credibility of nuclear-weapon use. Well-established threat-based policies were always helpful in this respect. The threats were highlighted and exaggerated, and stronger nuclear forces were recommended in response. In this environment, the focus was all the time on the risks of nuclear war, not on the view that the threat might be receding because of a creeping norm of non-use.

Shows of force in the vicinity of hot spots around the world also helped to maintain the credibility of nuclear policies. They raised the visibility of the nuclear assets and alerted the conflicting parties to the stakes involved. Usually, these manifestations were many steps away from nuclear use, but they reminded others of the global reach of nuclear weapons and had the potential to instil awe and respect in their minds. They testified to the relevance of nuclear weapons in the conduct of international politics.

Nevertheless, the nuclear-weapon establishments could not but be concerned about the utility of what they were producing. The United States had a big military-industrial complex closely linked to the political system. ${ }^{9}$ The Soviet Union came close to being such a complex. To keep and, if possible, expand their share of government budgets, the nuclear weapon establishments went for new nuclear weapons that would be more usable. A range of weapons suitable for a variety of tasks were built, including low-yield weapons approaching the yield of the largest conventional bombs. Manipulation of effects - blast, heat, radiation and fallout - to tailor them to specific purposes was also tried. The best-known example is enhanced radiation weapons (neutron weapons): by releasing more of their energy in the form of radiation and less in the form of blast and heat, killing people while inflicting less damage to material structures, they were held to be particularly suitable for use. The logic was bizarre. President Carter turned them down, against the recommendation of his closest advisors.

After a lull in the early and mid-1990s, when President Clinton focused on the opportunities of globalisation and Russia had more than enough to do in coping with its own internal problems, threat-based policies picked up again towards the end of the decade. This time, the focus was on regional contingencies rather than global ones between the major powers. The idea that one could 
gain a significant advantage in relation to other nuclear powers by investing heavily in nuclear forces had lost much of its currency.

Shows of force of the kind discussed above have nearly disappeared. The presidential initiatives of 1991/1992, which eliminated tactical nuclear weapons from surface ships and removed all nuclear deployments from foreign soil except airborne weapons in the low hundreds in Europe, did away with almost all those options. The introduction of new types of nuclear weapons has also been severely restricted by the moratoria on nuclear-weapon tests and the signatures on the Comprehensive Nuclear Test Ban Treaty (CTBT), although to some extent more sophisticated simulation techniques enable the most advanced NWS to circumvent the limits imposed by a test ban and defy its original purpose. All NWS have issued unilateral moratoria on nuclear testing.

By the turn of the century, the means to counter the creeping norm of non-use had therefore shrunk. That predicament was soon to be addressed, however, in new and provocative ways.

\section{The neoconservative ambition}

The US National Security Strategy of 2002 emphasised that "the struggles of the twentieth century" left the world with "a single sustainable model for national success: freedom, democracy and free enterprise" ${ }^{10}$ This is the American model. In so far as US policies promote these values, there would be no need to legitimise them in reference to international law, the United Nations (UN) Charter and multilateral organisations.

On the international scene, the rule of law was downplayed in favour of unilateralism and exceptionalism. The US National Defense Strategy of 2005 reconfirmed it: "Our strength as a nation state will continue to be challenged by those who employ a strategy of the weak using international fora, judicial processes, and terrorism." While the rule of law is based on a single standard for all parties, hegemonial rule is based on two standards, one for the hegemon and one for the subjects. To maximise its freedom of action, the United States withdrew from some international agreements and abstained from others.

At the core of US hegemonial rule was economic, cultural, technological and political strength and, increasingly, the use or threat of use of force to dissuade, deter or - if deterrence failed - defeat those who sought to challenge it. US foreign policy had become heavily militarised. Under the heading "Global Strike" - headquarters in Offutt, Nebraska - the aim was to be able to destroy, on short notice, all targets of significance wherever and whenever it was deemed necessary (Kristensen 2006). Ever since the deployment of solid-fuelled intercontinental ballistic missiles (ICBMs) in the 1960s, the United States had had such a capability in the form of ICBMs and submarine-launched ballistic missiles (SLBMs) on alert. Global Strike was different, however, because it focused on regional scenarios; incorporated conventional capabilities along with nuclear ones; and emphasised pre-emptive and preventive attacks rather than retaliatory strikes. Missile defence was another, interrelated part of military planning, based 
on the logic that Richard Nixon used in 1972 when justifying the ABM Treaty, which prohibited national missile defence systems: "If you have a shield, it is easier to use the sword." ${ }^{11}$ Like so many other technologies, missile defence can be used for attack as well as defence. This time, however, missile defence was conceptualised differently. By forcing total vulnerability upon any potential adversary and creating near-invulnerability for the United States, it was primarily intended to stop countries from challenging the American hegemony.

The military ambition was therefore highest. The role of military force was confined neither to preventive attack nor to national defence: the idea was to make US military superiority so overwhelming that it would dissuade others from taking up arms. The sword had become impressively potent, but the shield was marred by technological problems and remains incomplete to this day.

\section{The evolution of nuclear doctrines}

\section{US doctrine}

The National Security Strategies of 2002 and 2006 said that the United States must deter and defend against the threat of weapons of mass destruction (WMDs) before they are unleashed. It will not do to wait until the targeted regimes have built their weapons and can retaliate with them. President Bush called it a strategy of pre-emption, in accordance with the way this expression had been used in the past, but that use of the term blurs the important distinction between pre-emption and prevention. The difference is one of timing and legality. In international law, pre-emption - at the moment an attack is about to be set in motion - is permitted. ${ }^{12}$ Preventive attack, against an opponent who may or may not become a real threat in the future, is not. The Bush administration embraced preventive action, but did not elaborate on the means that might be used. ${ }^{13}$

The NPR of 31 December 2001 introduced a new triad of forces. Substituting for the old triad of the Cold War - ICBM, SLBM and heavy bombers - the new one had an offensive leg combining these delivery systems with conventional strike capabilities; a defensive leg including ballistic missile defences; and a revitalised defence infrastructure including the nuclear weapon production complex. The first leg obscured the qualitative differences between nuclear and conventional weapons (radiation effects, legal and moral inhibitions): they were all parts of increasingly flexible war-fighting capabilities that could more easily be adapted to evolving circumstances. Putting all kinds of offensive weapons into a continuum also invited new weapons to fill eventual gaps. Three new types of nuclear weapons were pursued: weapons of lower yield to reduce collateral damage, weapons to destroy chemical and biological agents, and better weapons for use against hardened or deeply buried targets, referred to as robust nuclear earth penetration (RNEP) warheads or "bunker busters" (Kristensen 2007). However, Congress blocked acquisition of them. Further advances in these directions were limited to adaptation of existing warheads. ${ }^{14}$ 
The integration of nuclear and conventional weapons into one and the same offensive leg, without distinction, left the impression that nuclear weapons were treated on a par with other offensive weapons. This way, nuclear weapons also appeared more acceptable and credible in roles other than the retaliatory one visà-vis other NWS. Another aspect of the organisational change pointed in a different direction: greater roles for conventional weapons could be taken to reduce the relevance of nuclear arms. The effect on the nuclear threshold therefore seemed different depending on which aspect one chose to emphasise. However, when considered in conjunction with simultaneous doctrinal changes that allowed for the use of nuclear weapons not only to deter chemical and biological weapons, but also in situations where the adversary has conventional arms only, the picture becomes clearer. By integrating all means of offensive warfare nuclear and conventional - into one and the same continuum with no special doctrinal restrictions on any of its elements, use of nuclear weapons became easier to contemplate and in that sense more likely to happen. ${ }^{15}$

The NPR shifted "planning for America's strategic forces from the threatbased approach of the Cold War to a capabilities-based approach". ${ }^{16}$ In the face of growing uncertainty about the new international environment, all sorts of military assets could be justified, "just in case". Still, the NPR listed six countries as potential targets (in addition to Russia): China, Iran, Iraq, Libya, North Korea and Syria. More enemies and greater target complexity called for a wider array of military options against regional adversaries. Therefore, strategic weapons would be available for tactical purposes as well, and there would be greater flexibility in the numbers of nuclear weapons that might be used. In part, this could be seen as compensation for the withdrawal of sub-strategic weapons that the presidential initiatives of 1991/1992 set in motion; in part, it strengthened the utility of nuclear weapons in regional conflicts. Nuclear planning was reoriented in order to enhance US force-projection capabilities.

More than anything else, the NPR departed from past nuclear policy by downplaying and repudiating international arms-control instruments. The Bush administration renounced the Anti-Ballistic Missile (ABM) Treaty and did not seek ratification of the CTBT. ${ }^{17}$ It adopted an à la carte approach to the NPT, stressing the non-proliferation provisions and belittling the obligation to disarm. These moves were made in the name of flexibility: the Cold War had given way to a unipolar world in which the United States was in a class of its own, especially in military terms. Therefore, the removal of restraints on the US exercise of power should have come as no surprise. The Bush team criticised the Clintonites for not having done more to exploit US superiority after the Cold War.

In 1978, the Carter administration stated that the United States would not use nuclear weapons against non-nuclear-weapon state (NNWS) parties to the NPT unless they were allied or associated with an NWS in an attack against the United States or its allies. In 1995, UN Security Council (UNSC) Resolution 984, which summarised the security assurances given by the five permanent members of the Council, reaffirmed it. ${ }^{18}$ The Clinton administration added another reservation. Believing that deterrence would be strengthened by ambigu- 
ity, it took the position that "no options are ruled out" in response to an attack by any WMD, i.e. in response to chemical and biological weapons, as well as nuclear weapons, irrespective of whether the state in question was taking part in an attack together with an NWS. In connection with the US signature of the protocol to the African Nuclear-Weapon-Free Zone (ANWFZ) Treaty in 1996, it announced that US adherence "will not limit options available to the United States in response to an attack by a NWFZ party using weapons of mass destruction" (Mendelsohn 1999). ${ }^{19}$

The Bush administration took it further, allowing for the use of nuclear weapons in settings where the adversary possesses conventional weapons only. Clearly, US policy evolved to become substantially at odds with UNSC Resolution 984. It may be argued that a UNSC Resolution has the force of international law and therefore trumps national strategy documents. However, there is little doubt that, in reality, it was the other way around, especially as the Bush administration showed little respect for the UN and disregard for much of what the Clinton administration did. Moreover, since Resolution 984 does not authorise any action, but merely collects the unilateral assurances declared by the five, its legal force is disputed.

For a while, the moratorium on nuclear tests and the end to discrete political use of nuclear force enhanced the norm of non-use. However, doctrinal changes - starting in the 1990s and taken to the extremes in this century - stemmed that development. The United States widened the spectrum of possible nuclear use, thereby correcting the diminishing utility of nuclear arms. The Russian and French doctrines also assigned new roles to nuclear weapons, and the British and Indian doctrines did the same, only to a smaller extent.

The Obama administration's Nuclear Posture Review (NPR) turned the trend (Nuclear Posture Review Report 2010). This administration will not use or threaten to use nuclear weapons against NPT members in good standing. Chemical and biological weapons will be deterred by conventional means, with reservations made for new scientific developments in the biological sector. In practice, this negative security assurance covers about 180 states. Exempt are the NWS and NPT members that in the US's view do not comply with their NPT obligations, such as Iran and possibly Syria.

"The fundamental role of US nuclear weapons, which will continue as long as nuclear weapons exist, is to deter nuclear attack on the United States, its allies and partners" (Department of Defense 2010). The NPR does not go as far as nofirst-use, but commits the administration to "work to establish conditions under which such a policy [of no-first-use] could be safely adopted" (Nuclear Posture Review Report: viii). In the case of Russia, this is a tall order, for the European political architecture would have to change in a way that substantially reduces Russian threat perceptions. ${ }^{20}$ However, progress in this direction is also necessary so that deeper cuts in US and Russian arsenals can be agreed. The US wants follow-on negotiations with Russia when New START has been ratified. Other obstacles are Pakistan, which sticks to a policy of first-use because of its conventional inferiority vis-à-vis India, and Israel and North Korea. 
Adoption of no-first-use doctrines is a promising way to de-legitimise nuclear weapons and enhance the norm of non-use. Obama's NPR articulated the objective: "It is in the US interest and that of all other nations that the nearly 65-year record of nuclear non-use be extended forever" (Nuclear Posture Review Report: ix). The Geneva Protocol of 1925 prohibiting the use of chemical and biological weapons - in practice, a no-first-use protocol - made these weapons illegitimate, whereupon possession of the weapons were prohibited by international treaties. Also, such doctrines have an intriguing in-built disarmament corollary. They limit the functions of nuclear weapons to one and one only - deterring others from using theirs. It follows that nobody would need them if nobody had them.

\section{Russian doctrine}

In 1993, Russia formally dropped the Soviet no-first-use policy. Promulgated in the early 1980s, some Westerners saw it as admission that nuclear weapons were no longer essential. To them, the NFU doctrine confirmed Soviet conventional superiority. In the view of others, this policy had little credibility as long as large numbers of tactical nuclear weapons were deployed along the dividing line in Europe. Had war broken out, there would have been strong pressures to use them early, and possibly first. ${ }^{21}$ The doctrine and the military posture told different stories. Seen this way, the change to first-use made little difference.

There is no evidence, however, that the Soviet nuclear posture was ever optimised for first strike, as was widely believed in the United States under Reagan. Like previous doctrines, the Russian military doctrine of 1993 reserved nuclear weapons for the eventuality of global nuclear war.

The MAD policies outlasted the political rivalry with the United States. Inertia prevailed, the sea change in US-Russian relations notwithstanding. By the turn of the century, renewed tension between the Cold War antagonists removed any the need for artificial life support.

For Russia, the nuclear arsenal underpins its sovereignty and helps it maintain an independent foreign policy. The nuclear sector is the only field where Russia can claim equal status with the United States, so it benefits from the structural impact of nuclear weapons on international affairs. By 2009, it deployed a fifthgeneration silo-based as well as road-mobile ICBM (Topol M); introduced a new SLBM (Bulava); built new ballistic-missile submarines (SSBNs; the Borey class); had developed a manoeuvrable warhead for the Topol $\mathrm{M}$ and enhanced defence-penetration capabilities for the Bulava and a new version of the SS-N23 (Sineva); and upgraded existing long- and medium-range bombers. Also, it was introducing a new, conventional air-launched cruise missile (ALCM) and several new, shorter range sea-launched cruise missiles (SLCMs). Except for the Bulava, virtually all of these modernisation programmes were launched during the Soviet era. Sharp budget reductions limited modernisation to already-existing programmes.

Starting in 1999, a new National Security Concept was elaborated, and formally adopted in January 2000 (Sokov 2007b). A new Military Doctrine fol- 
lowed in April 2000, and the role of nuclear weapons was further elaborated in a White Paper that was adopted in autumn 2003. ${ }^{22}$ These documents introduced a new mission: in regional conflicts of a conventional nature, Russia might have to use nuclear weapons first in the form of demonstrative strikes against targets located in unpopulated areas in the enemy's rear, or by detonating a few tactical devices on the battlefield. The background was US and NATO expansion towards Russia's borders and, specifically, the war over Kosovo. Since NATO could bomb Serbia in violation of international law, without any mandate from the UNSC, it might exploit Russia's weakness and do the same closer to its borders, or even inside it. In 1999, Russian leaders were worried about possible Western interference in Chechnya, where a second war broke out that year. ${ }^{23}$ Another postulated threat was foreign attempts to take control of Russian natural resources (Sokov 2007b).

If such an attack were to occur, demonstrative nuclear strikes would force the enemy to stop hostilities or face nuclear escalation. The more inferior the Russian conventional forces turned out to be, the lower the nuclear threshold. Since the stakes would be higher for the defender (Russia) than the attacker (US, NATO), it is assumed that the attacker would not be willing to escalate the war to the strategic level, but prefer retreat. Therefore, limited use of nuclear weapons could be an effective tool for deterring and fighting limited conflicts. The credibility of nuclear use would neutralise threats of force for political ends, and actual use of a few weapons might be an effective means of de-escalation.

Limited use of nuclear weapons was entertained during the Cold War as well. Such options could best be performed by tactical nuclear weapons causing less damage and entailing lower risks of escalation than strikes with strategic systems. By and large, however, it was considered unrealistic. Efforts to contain nuclear war were likely to fail, leading to a strategic nuclear war that nobody wanted. Contemporary Russian doctrine attaches realism to limited use in regional contexts, primarily to stop conventional attacks by Western NWS, but tactical weapons are not necessarily the weapons of choice any longer. Influenced by the US's use of long-range strike assets in Kosovo, Afghanistan and Iraq, as well as the Bush administration's NPR, the White Paper of 2003 emphasises the need for long- and intermediate-range strike systems. The United States had kept important assets at considerable distance from the areas of combat, so the counterstrategy had to target weapon systems and command, control and communications (C3) centres in the enemy's rear. Long-range aircraft equipped with dual-capable cruise missiles and precision-guided gravity bombs might be suitable for such missions.

Tactical or sub-strategic weapons have therefore lost part of their relevance, although they are still considered essential theatre-level assets. Elements of the strategic forces, which have been justified in reference to the increasingly unlikely eventuality of global nuclear war, can be assigned to regional missions as well without undermining strategic deterrence. To obtain the desired deescalation effect, a few weapons may do: in military exercises, no more than ten weapons have been used for this purpose. This may facilitate inclusion of 
sub-strategic weapons in US-Russian disarmament negotiations. So far, however, the Russians have been recalcitrant in the face of Western demands for transparency and reductions of this category of weapons.

The new mission is the product of perceptions of dire threats as well as acute weakness. The main threat is believed to come from the West - from the United States and its allies in Europe - which may use force on a limited scale for limited political goals in a manner similar to the wars in the Balkans. ${ }^{24}$ Targets in Japan, the Pacific Ocean and the Indian Ocean have also figured in Russian military exercises. Clearly, pressures from the West are seen in the wider context of US and allied encirclement of Eurasia. There is a latent concern, moreover, about Russia's territorial integrity in the Far East, where vast and thinly populated areas in Siberia meet a populous and rapidly growing China. ${ }^{25}$ These worries have been somewhat softened as the borders between China, Russia and the neighbouring Central Asian states have been agreed and a stronger partnership with China has been forged. However, the Russian military still considers China as a potential future adversary, and nuclear weapons feature prominently in such scenarios.

The weakness pertains to the conventional forces, which all of a sudden became inferior when the Warsaw Pact and the Soviet Union fell apart, and which labour under stricter financial constraints than potential opponents both in the East and in the West. The nuclear compensation has been phrased in assertive terms: "Due to the existing geopolitical risks we rely on the qualitative improvement of strategic forces, so as to eliminate the aggressor by a retaliatory strike or by launching under attack in any situation" (Ivanov 2006). The new Russian military doctrine of 2010 reconfirms the role of nuclear weapons in regional and large-scale global wars, but whereas the 2000 document foresaw resort to nuclear weapons "in situations critical for the national security" of Russia, the 2010 version allows for their use in situations when "the very existence of [Russia] is under threat". ${ }^{26}$ The change suggests that the criterion for employment of nuclear weapons has been somewhat tightened. Like the earlier document, the new doctrine reserves the right to use nuclear weapons in response to nuclear attack, attack with other WMDs and also in response to conventional attack. To carry out these missions, a deterrence capability at the level of sufficiency, defined as the ability to inflict predetermined or tailored damage to an aggressor under any circumstances, is required.

Russia used to distinguish between nuclear and conventional firepower both in its military doctrine and in its organisational set-up. The 2010 doctrine indicates a change in this respect. The doctrine assigns high-precision conventional weapons to strategic deterrence, apparently following the US lead in equipping some longrange delivery vehicles with conventional warheads. In so far as this happens, the organisational distinction between nuclear and conventional weapons is lost. Like in the US, the mix of conventional and nuclear assets may also provide for greater flexibility in the choice of weapons to meet security challenges.

Russia's de-escalation concept includes possible first-use of nuclear weapons in response to attack by any kind of weaponry. The security assurances incorporated in UNSC Resolution 984 apply unless Russia is attacked by an NWS or by 
an NNWS operating together with an NWS. It is unclear whether the military doctrine is consistent with these assurances. The much-emphasised threat of NATO involvement in regional conflicts near its borders indicates that it is.

The reliance on nuclear weapons is a function of the range of missions assigned to them and the probability of the scenarios where they may play a role (Sokov 2007b). The 2000 doctrine expanded the range of missions to include regional contingencies, and the probability of use in such scenarios has gone from nil to something more. Concerns about the effectiveness of the strategic retaliatory capabilities persist - regarding the debate about missile defence deployments in general and regional defences for Europe in particular - but the probability of global nuclear war is deemed to be close to zero. Retaliatory capabilities are maintained and modernised "just in case", and in order to reinforce the credibility of regional deterrence. The 2000 doctrine emphasised that the increased reliance on nuclear weapons will last only until the conventional forces are sufficiently modernised and strengthened. The 2010 doctrine puts stronger emphasis on conventional weapons relative to nuclear ones, but unless the threat perceptions are much alleviated, it may take a long time to remove the need for nuclear stop-gap measures.

\section{French and British doctrines}

France's nuclear weapons were never intended for use on the battlefield. Nuclear escalation was not a part of it. The French weapons were deployed to deter other nuclear powers tous azimut - omni-directionally; the main target being Russia. If it comes to war, the objective is to give the French armed forces a decisive advantage. Deterrence of other nuclear powers is primarily for the navy, while the air force may be better suited for missions that require flexibility. ${ }^{27}$ For the strategie de dissuasion to be credible, there must be no doubt about the professionalism of the officers and the will of the president to implement it. These fundamentals remain unchanged.

In January 2006, President Chirac indicated a number of other functions. In a speech at France's main nuclear submarine base in Bretagne, he went beyond the doctrine set out in the "Livre blanc sur la défense" of 1994, elaborating and expanding on changes that were set in motion after the $9 / 11$ attacks on the United States (Chirac 2006). ${ }^{28}$

Similar to US doctrine, the main new element is deterrence of regional powers. More employable nuclear options have been developed for this purpose: "All our nuclear forces have been reconfigured accordingly." The choice is not between inaction or annihilation, but the "flexibility and reactivity of our strategic forces would enable us to exercise our response directly against the centres of power and its capacity to act". The message was addressed to states sponsoring terrorism or contemplating the use of WMDs:

The leaders of states who use terrorist methods against us, as well as those who consider using in one way or another weapons of mass destruction, 
must understand that they will expose themselves to a firm and appropriate reaction on our part.

In October 2001, Chirac had warned that France could not rule out the use of nuclear weapons against regimes which "are busy developing their own weapons of mass destruction. This response could be of a conventional kind. It could also be of a different kind." At that time, his statement was primarily intended for Iraq and North Korea. Repeating it in 2006, Iran topped the list.

Strategic supplies - meaning petroleum, first of all - is another vital interest that may be protected by the nuclear deterrent. ${ }^{29} \mathrm{Chirac}$ also reiterated the idea of extending the French nuclear umbrella to cover its European allies: France has had regular discussions of nuclear issues with Britain since 1995. Two years later, President Sarkozy touched on the same proposition - sometimes referred to as "concerted deterrence" - inviting a broader dialogue on the role of nuclear weapons in European security. ${ }^{30}$ Sarkozy stressed the basics of deterrence in a way that some observers took to be a step back from Chirac's expansion of roles, yet without defining the vital interests that might bring nuclear weapons into play.

French nuclear doctrine has traditionally included the possibility of a nuclear warning shot to persuade an aggressor to desist or risk a massive nuclear strike. Chirac reiterated that option. Two forms have been indicated: detonation of a small warhead in an uninhabited area, and detonation of a warhead at high altitude so that the electromagnetic pulse could destroy electronic systems (Merchet 2006).

Chirac hailed the achievements of the nuclear programme as a matter of national pride, emphasising that "nuclear deterrence ... became the very image of what our country is capable of producing when it has set itself a task and holds to it". The prestige that Iran has come to attach to its nuclear programme is similar to the pride that France takes in its nuclear achievements.

The British nuclear force consists of four SSBNs, each carrying 16 Trident D5 missiles. The total number of deployed warheads is less than 200. Only one submarine is on patrol at any time. The time it takes to fire the missiles has been extended from a few minutes to a few days. Having eliminated its air-launched nuclear weapons, the British force is less flexible than the French one.

British doctrine has nevertheless evolved in directions similar to the US and French doctrines. The strategic role is first and foremost to deter aggression against the United Kingdom and its allies. Then there is another role - "an option for a limited strike that would not automatically lead to a full scale nuclear exchange". Like the French doctrine, a small nuclear weapon might be used as a demonstration or "a shot across the bow" to signal to aggressors that they have miscalculated Britain's resolve, without using the full destructive power that Trident offers. A third role is retaliation against biological and chemical weapon attacks on Britain or its allies. Finally, pre-emptive use is envisaged against a state that threatens Britain's vital national interests. The meaning of pre-emption probably extends beyond use on concrete signals that an attack is coming: as in US terminology, it seems to include prevention as well. 
In many respects, the French doctrine is similar to that of the US under George W. Bush. The regional focus, the emphasis on state-sponsored terrorism, putting power centres at risk, deterrence of chemical and biological weapons use and the possibility of nuclear use to deter proliferators are much the same. Not surprisingly, the British doctrine also ties in, but in ways that are somewhat less specific. The accuracy of the Trident missile allows for regional uses in much the same way that the United States envisaged to use its strategic systems in regional roles. With reservations made for the limitations on French and British capabilities, which do not allow for as wide a range of options as US forces do, there was a high degree of coherence in the national doctrines of NATO's NWS.

\section{Chinese and Indian doctrines}

To maintain a credible deterrence posture in the face of improved enemy intelligence and surveillance assets, ballistic missile defence systems and conventional precision-strike capabilities, China deploys road-mobile ICBMs and introduces new long-range missiles on new submarines. Ground- and air-launched cruise missiles add to the survivability and flexibility of the nuclear force. Nuclear artillery and other sub-strategic systems may be on their way in. A comprehensive modernisation programme is going on, probably leading to a net expansion of the force. Still, China's arsenal is small: of a total stockpile of 240 weapons, fewer than 200 are deployed (SIPRI 2009). Much information is missing, however, for secrecy remains an important part of China's military posture.

At the strategic level, the emphasis is on "gaining mastery by striking after the enemy has struck" (Chase et al. 2009). Chinese retaliation will not be immediate, but delayed. ${ }^{31}$ The objective is to deter nuclear attack and preclude nuclear coercion. The goal is also to prevent conventional war from escalating into nuclear war, and to prevent low-intensity nuclear war from escalating. Deterrence therefore imposes stringent requirements on the Chinese nuclear posture, from the strategic level down to the tactical. The leadership of the Second Artillery Corps (SAC) has consistently highlighted the importance of educating highquality officers.

In some respects, China's disarmament policy has high credibility. China did not acquire nuclear weapons to make up for conventional weakness. The fundamental motive was to avoid nuclear coercion and be able to retaliate if attacked. By entering the core group of NWS, it enhanced its status in the international system, but today, a modest nuclear force does not count much compared with the status that economic and political strength provide. For China as well as others, the sequencing of disarmament measures is important to ensure that its national security is not diminished on the way to zero. Generally, however, the military and political utility of its nuclear weapons is limited, so in that fundamental sense it is well-positioned for global disarmament to zero.

No-first-use has been China's doctrine since the first nuclear test in 1964, and remains a much-emphasised part of its posture. It is not elevated above discussion, however. China's arsenal is both small and vulnerable, so is the NFU 
policy credible? In particular, is delayed retaliation realistic? The ongoing modernisation and expansion programme addresses these questions and may put China on a rearmament path for quite some time to come. If Chinese nuclear assets are attacked by highly accurate conventional means, what should the reaction be? In a military conflict over Taiwan, would resort to nuclear weapons always be ruled out? If the People's Liberation Army (PLA) faces defeat and China's territorial integrity is at stake, there would be strong incentives to lower the nuclear threshold. In such a situation, the doctrine seems to allow for an exception to the rule of no-first-use: first-use on China's own territory may be legitimate to avoid defeat.

India issued a draft nuclear doctrine in 1999 and unveiled a final set of political principles and administrative arrangements in January 2003. It sets out to build a credible minimum deterrent in the form of a classical nuclear triad: air-, land- and sea-based systems. The ultimate size and structure of the force - the operationalisation of credible minimum deterrence - remains to be seen. While China has a rudimentary capacity for tactical nuclear warfare, India has none so far.

After the tests in 1998, India committed itself to no-first-use. Nuclear weapons would only be used in retaliation of a nuclear attack on It territory or Indian forces elsewhere. However, in a departure from this announcement, the official doctrine of 2003 extended the mission to include deterrence of chemical and biological weapons as well.

The arms control and disarmament policy includes non-use of nuclear weapons against NNWS; strict export controls; a moratorium on nuclear tests; participation in Fissile Material Cut-Off Treaty (FMCT) negotiations, i.e. in principle: it is not ready for such a cut-off any time soon; and work towards the goal of universal nuclear disarmament.

India treats nuclear weapons as political instruments of deterrence rather than military tools of war-fighting. This is in line with idealist and liberal currents in the Indian political culture. Also, it helps to keep the costs down. Trying to come to terms with a hostile international environment after the tests in 1998, India aligned itself with the international arms-control order. However, elements of its traditional disarmament policy, such as an international convention on security assurances for NNWS and an international convention on nuclear disarmament, were retained.

Under the impact of Western doctrinal developments, India took a step away from its original no-first-use stance, but it may not take much to drop the reference to chemical and biological weapons again. Like China, it routinely maintains its nuclear capabilities at low levels of readiness, keeping warheads and delivery vehicles at different locations. For both, the primary function of nuclear weapons is to avoid coercion and ensure retribution in case deterrence breaks down. There is no strategic dialogue between Beijing and Delhi, but they have common interests in avoiding a competitive arms build-up.

Today, India is not ready for nuclear disarmament. First, it wants to establish its minimum-deterrence force at a level it may have defined, but not declared, 
and to be recognised as an NWS. If it is to be included in multilateral disarmament negotiations, de jure recognition is a sine qua non. However, when that has been achieved, India may be ready to participate in good faith. Status and prestige were important in going nuclear, but once a seat at the table has been obtained, that ambition is fulfilled. Much like China, India's international status would no longer depend on the possession of nuclear weapons. From then on, it might revive its strong disarmament tradition and build on that heritage in pursuit of global disarmament. Inspired by the American gang of four and President Obama, it has already begun to do so. Its disarmament diplomacy unfolds along two tracks: the pragmatic one which positioned it for the nuclear cooperation agreement with the United States (see Chapter 5), and the normative longterm one charting a road to zero.

\section{Impediments to disarmament}

When the bipolar world order that fuelled the nuclear arms race came to an end, a fundamental reconsideration of the role of nuclear weapons would have been appropriate. When so much else was in for radical change, a radical change of nuclear doctrines would have been natural. The underlying premise for the main mission of the weapons - the confrontation between the US and the USSR - disappeared, inviting a fundamental rewrite of nuclear logic. That did not happen, however. On the contrary, the Clinton administration's nuclear posture review carried the stamp of inertia. Russia, too, made only minor adjustments: it admitted that large-scale nuclear war was unlikely, but maintained the traditional logic of nuclear deterrence. The changes boiled down to elimination of surplus weapons from the Cold War and to management of the disintegration of the Eastern bloc and the Soviet Union. In essence, the rationale for high numbers of weapons was maintained.

More significant doctrinal changes came later, and they went in the opposite direction of what the end of the Cold War had invited. Except for China, a gap opened up between the national strategy documents of the five NWS and their negative security assurances as summarised in UNSC Resolution 984. The strategy documents became more permissive of nuclear-weapon use than the assurances codified in the UNSC resolution. India took a step in the same direction.

These doctrinal changes may be understood in the context of ongoing changes in the international system. By the turn of the century, international affairs were in a state of flux. In the state paradigm there were conflicting elements of unipolarity and multipolarity, and in the non-governmental sphere international terrorism became a big concern, especially after $9 / 11$. The emergence of states that could challenge the world order - Iran, in particular - also drove policy developments, especially in the United States. During the Cold War, the threats were clearly defined and security planning threat-based: now, governments worried more about how to defend against the unforeseen. Part of the answer was retention of nuclear weapons as an insurance premium in relation to unforeseen dangers. 


\section{The legacies of nuclear history}

It did not stop there, however. During the Cold War, elaborate plans were made for the use of nuclear weapons, including thousands of weapons for battlefield use, yet it was widely believed that any use would lead to large-scale war. This century, assumptions were entertained that in regional contexts, where the big powers were not at loggerheads with each other, nuclear war could be contained. Russia upgraded the role of nuclear weapons under the influence of Kosovo. Seized by the unipolar moment and under the influence of $9 / 11$, the US did the same.

What followed was a series of strikingly similar doctrinal developments, not so much because the United States leant on other NWS to do the same, but because it set an example that other powers found it convenient to imitate. Thus, the United States came to legitimise a wider role for nuclear weapons in the national planning not only of NATO allies, but also of India, which appears to have followed the US lead when diluting its no-first-use commitment (Subrahmanyam 2009). Only China stayed true to its policy of no-first-use. This served to uphold the utility of nuclear weapons in world affairs, counteracting the restraints that the testing moratoria and the Presidential Initiatives imposed. Whether such considerations were part of the motivation for the new doctrines is not known. It may not have been designed to stem the norm of non-use, but it had that effect.

Generally, the doctrinal changes detracted from the inhibitions of international norms. When the one and only global superpower turned its back on important international agreements, it could not but influence the salience of international law. For instance, to care about the consistency between UNSC Resolution 984 and national strategy documents became a petty matter. Another opportunity to enhance the applicability of nuclear weapons emerged, and the big powers seized it, to the detriment of the norm of non-use.

The new US policy may - once again - lead other NWS to follow the US example. In important respects, NATO's new strategic concept will have to forge a new doctrinal understanding between the Alliance's NWS. To what extent other powers will be influenced by Obama's turn of trends is more uncertain, but it is not far-fetched to assume that the new US negative security assurances will also be imitated by other NWS. Russia hardly considers the non-nuclear members of NATO to be a threat, and may therefore extend assurances to them while retaining the option of using nuclear weapons first if confronted with NATO as a whole. The UK often follows the US, and China is already on board. France may have reservations, but if the other P5 are ready for it, would it resist? Another Security Council resolution on security assurances based on the new US formula, replacing Resolution 984 of 1995, may be within reach.

Since the end of the Cold War, the arsenals of the NATO powers have been reduced and so has Russia's. Weapons are withdrawn from active service and kept in reserve or slated for dismantlement. The dismantlement process is slow, however: one US gravity bomb contains nearly 7,000 parts and, by 2008 , dismantlement of plutonium pits was done at a rate of 350 per year. 
While the Western world and Russia cut their arsenals, Asia is on a different trajectory. China modernises its forces, and in numerical terms the introduction of new systems will probably outweigh the withdrawal of old ones. India and Pakistan are building minimum deterrents of unknown size. Assuming that they will end up in the low hundreds of weapons, none of them is more than halfway towards such levels. India claims, moreover, that one of the 1998 tests was a thermonuclear one, which may lead to an arsenal of fusion as well as fission weapons. However, the success of this test is disputed (see Chapter 5). In Asia, more states are acquiring ballistic missiles of longer range and higher precision that may carry nuclear, chemical and biological weapons. One of them has acquired nuclear weapons (North Korea); another may or may not do so (Iran); and yet others may be taking steps in this direction. The Middle East and East Asia are the main regions of proliferation concern. In South Asia, Pakistan is under scrutiny for fear of proliferation to non-state actors.

In 2000, Paul Bracken published Fire in the East: the Rise of Asian Military Power and the Second Nuclear Age. Bracken argued that, just as Asia began to assert itself economically in the 1960s and 1970s, by the turn of the century it was doing so militarily. Not by taking up a competition with the United States and the Western world on their terms, but by exploiting Western military vulnerabilities. Asian weapons of choice were ballistic missiles and WMDs, and the Achilles heel of the United States was fixed military bases in the region. China, India, Iran, Iraq (interrupted by "ceasefire" Resolution 687 and the United Nations Special Commission, UNSCOM), Israel, North Korea, Pakistan and Syria were all building ballistic missiles. Some of them pursued chemical or biological weapons, and some were building nuclear weapons. Targeted on US vulnerabilities, Asian ballistic missiles and WMDs might trump the West's technological lead, making state-of-the-art technology a somewhat irrelevant measure of actual military capability.

Distinguishing between technologies that sustain advantage and technologies that disrupt it, Bracken made a powerful analogy to the way IBM was outflanked by Microsoft. Concentrating on its undisputed lead in PC hardware and how best to maintain it, IBM was undercut as Microsoft wrapped up the software market. Similarly, the US's focus on further improvement of electronic surveillance systems, aircraft and mechanised land power made it vulnerable to asymmetric, disruptive Asian responses. China emphasises asymmetric warfare capabilities aimed at the enemy's computer and communication networks in particular (US Department of Defense 2007). The stage was set for a major contest between US efforts to sustain its advantage and Asian efforts to undermine it.

The full significance of these developments emerges when seen in conjunction with the deployment of missile defences. In response to the threat that increasingly sophisticated Asian ballistic missiles pose to US and allied bases, the United States has deployed ballistic-missile interceptors in Alaska and California, laying the foundation for more robust systems intended to thwart intercontinental capabilities in East Asia - officially against North Korea, but affecting the Chinese deterrent too. Together with NATO, it is building a 


\section{The legacies of nuclear history}

missile-defence system to neutralise Iranian and other Middle Eastern short- and medium-range missiles. For a long while, it has been deploying theatre defences in the vicinity of US and allied bases and forces. The same technologies can be used for offensive as well as defensive purposes: the Western powers emphasise their defensive nature, while their opponents fear that as the West acquires a shield, it will be more willing to use the sword. A race in asymmetric technologies is going on between Asian efforts to exploit US vulnerabilities and US and other Western efforts to hold Asian states at risk from a position of impunity.

As the role of nuclear weapons is reduced, conventional weapons will take on a greater share of the mission requirements. Additional options are explored to be able to destroy targets around the world on shorter notice. "Today, we can present some conventional options to the president to strike a target anywhere on the globe that range from 96 hours, to several hours maybe, 4, 5, 6 hours." This might not be fast enough, and "the only thing that we have that goes faster is a nuclear response" (General Kevin P. Chilton, as quoted in Sanger and Shanker 2010). The Obama administration therefore proposes a new spin on the Bush administration's Global Strike plan, now named Prompt Global Strike, using the most advanced technology in the military today and some not yet invented, such as warheads on missiles travelling through the atmosphere at several times the speed of sound, which would be much more manoeuvrable than ballistic missiles.

The Bush administration shelved important parts of Global Strike because the Russians feared that if conventional weapons were placed on ballistic missiles, it would be impossible to know whether the missiles carried nuclear warheads or conventional ones. The Russian concern persists and is reflected in New START: conventional warheads on strategic delivery vehicles would be counted within the 1,550 warhead limit. However, the Pentagon emphasises that the bar is high enough to accommodate PGS: "the New START Treaty does not contain any constraints on current or planned conventional prompt global strike capability." 32

PGS should enable the US to destroy threatening targets in timely fashion without crossing the nuclear threshold, such as North Korean missiles on their way to the launch pads, Iranian nuclear sites and terrorists before they move and escape. The Russians and Chinese are worried that they could be targeted at them, and that the US would be more inclined to use them because they are conventional. For instance, anti-satellite (ASAT) capabilities in central China may be destroyed promptly and pre-emptively at the start of a potential conflict.

To meet the objections, the PGS concept envisages that other powers would be invited to regularly inspect the PGS silos to assure themselves that the weapons are conventional and not nuclear, and the silos would be placed in locations far from the strategic nuclear forces. That, however, would hardly be enough to allay the fears. While a benign interpretation would put this concept in the context of nuclear disarmament, facilitating deeper cuts in US arsenals, sceptics see it as part of a broader effort to sustain US military superiority and widen the gap between it and the rest of the world. 
In conclusion, this poses three major challenges to the drive for disarmament. First, the growth of Asian nuclear arsenals represents a challenge, especially the South Asian ones since India, and by implication Pakistan, may go for fullfledged minimum-deterrence postures before being ready to accept arms-control measures and participation in multilateral disarmament talks. Second, the asymmetric offence-defence competition between the United States and other Western powers on the one hand, and Asian states on the other, has to be defused in the name of disarmament and non-proliferation. This question taps into the broader debate about the relationship between disarmament and ballistic-missile defence. The ABM Treaty of 1972 was built on the premise that ballistic-missile defences were destabilising. Today, that Treaty is gone, but in the view of many states the premise remains valid. And third, PGS adds to the fear that the transition from nuclear to conventional weapons is a way to enhance US military superiority, creating new security concerns rather than eliminating existing fears. In the next round of US-Russian disarmament negotiations, the Russians will certainly want to include both PGS and ballistic-missile defence. There is the risk that a programme that can win broader support for nuclear disarmament within the US political system creates additional obstacles for global disarmament and non-proliferation endeavours. 


\section{A global consensus on non- proliferation and disarmament}

\section{The Non-Proliferation Treaty: a winning proposition at the age of 25 ?}

During the first decade of the Nuclear Age, 1945-1955, three nuclear-weapon states (NWS) emerged: the US, the USSR and the UK. The second decade saw another two, France and China, and in the third decade, one more: Israel readied the first couple of weapons in 1967, before the Six-Day War (Cohen 1999). In the fourth decade, South Africa produced half-a-dozen bombs, but dismantled them in the fifth decade (around 1990) (von Baeckmann et al. 1995).

The end of the Cold War brought significant progress both in terms of disarmament and non-proliferation. Nuclear arsenals were significantly reduced; Russia became the sole heir of Soviet nuclear weapons; South Africa abandoned its weapons and joined the NPT; NPT membership increased considerably; the Conference of Disarmament agreed on a mandate for FMCT negotiations; and, by the time the 1995 NPT Review and Extension Conference was convened, a CTBT was in sight. The Review Conference therefore came at the end of a period of good news, facilitating the decision to extend the Treaty indefinitely. Non-proliferation seemed to be a winning proposition.

At that point, the P5 may have thought that the proliferation problems could be managed irrespective of their own investments in nuclear weapons. Governmental and non-governmental experts reiterated that nuclear proliferation was driven by security concerns of a regional nature, more or less unrelated to the nuclear investments of the major powers. The NNWS, for their part, had reasons to believe that the downsizing of nuclear arsenals would continue in the years ahead. The rhetoric of the NWS seemed to confirm it: as late as 1997, at the first PrepCom for the 2000 NPT Review Conference, the five NWS issued a joint statement reaffirming "their determination to continue the pursuit ... of systematic and progressive efforts to reduce nuclear weapons globally, with the ultimate goal of eliminating those weapons ..." (NPT/CONF.2000/ PC.II.8). 


\section{The delusion of 1995}

This proved to be shallow, misleading analyses, however. First, the NNWS were wrong for the simple reason that the end of the Cold War naturally gave way to significant reductions of arsenals. After the breakdown of the Soviet Union and the end of a world order characterised by arms racing, elimination of overkill capabilities had its own unavoidable logic. With one important exception - the Presidential Initiatives by the US and the USSR/Russia of 1991/1992, not to lose control over tactical nuclear weapons (see Chapter 3) - they were not made out of concern for nuclear proliferation or as concessions to NNWS parties to the NPT. In 1995 this was not yet clear, for in so many respects the future of international affairs seemed an open question.

Much was removed from the operative arsenals and much was kept. Ominously, in national military doctrines the reliance on nuclear weapons was maintained (see Chapter 3). After a period of downsizing, the NWS "dug in": the disarmament rhetoric disappeared; at the 2002 PrepCom for the 2005 NPT Review Conference, the NWS issued no commitment for the elimination of nuclear weapons; and the US distanced itself from both the Principles and Objectives document of 1995 and from the 13 steps towards nuclear disarmament of 2000. The NWS seemed firmly intent on keeping major arsenals for the foreseeable future.

Second, the analysis was shallow for lack of consciousness about the special nature of post-war politics. There is a period of opportunity after all major wars and so, too, after the Cold War. Karl Deutsch (1963) described it in information terms: these are periods when the ratio of current to background information is high because much background information from the archives has been rendered irrelevant. In these situations, decision-makers have to rely on current information flows and are therefore freer and more likely to move in new directions. For better or worse, their action space is much enlarged. For instance, in the beginning of the 1990s, for the first time in UN history except for a brief interlude immediately after the Second World War, the UN Security Council functioned the way the founders had envisaged. Such periods are brief, however, usually limited to a few years. Boutros-Ghali drew the line at the Dayton negotiations in the autumn 1995, when the UN representative was relegated to the corridors; others drew it earlier (Boutros-Ghali 1999). In the minds of many, the period of opportunity was misread as a new, encouraging trend in international affairs. With the benefit of hindsight, the sense of progress that inspired the 1995 NPT Review and Extension Conference was unfounded.

A few years later, indefinite extension would no longer have been possible. New problems emerged along with new ways of handling them. Then, the outcome would probably have been a limited extension of the Treaty for one or more periods, ${ }^{1}$ giving the NNWS more leverage in relation to the nuclear powers. In the absence of such checkpoints, the NWS are freer to behave the way they see fit, which they did, to the point of jeopardising the entire Treaty. The bargain that had been struck between the three pillars of the NPT - 
non-proliferation, disarmament and peaceful uses - came apart. Common ground evaporated.

\section{Turn of trends}

The NWS were deluded, too. After 1995, India and Pakistan, which had been nuclear-weapon states in the making for quite a while, tested; North Korea did the same; and Iran became a case of grave concern. More states turned their eyes to the nuclear-weapon option, and some non-state actors did so too (Mowatt-Larssen 2010). This was a turn of trends, and a more dangerous world also for the NWS. Far from being manageable, proliferation might get out of hand.

The NPT was in jeopardy not least because the NWS paid little attention to their disarmament commitments. The US and others treated Article VI much like Article V (as if it did not exist), ${ }^{2}$ and the 1995 Resolution on the Middle East an integral part of the decision to extend the NPT indefinitely - was not followed up upon. ${ }^{3}$ There was a tendency to pick and choose from the treaty provisions, stressing the non-proliferation provisions and ignoring others. Under these circumstances, NNWS found it hard to accept more comprehensive safeguards and more proliferation-resistant peaceful-use practices that would qualify their rights under Article IV, because it would further aggravate the skewed implementation of rights and obligations.

Despite the fact that only North Korea has left the NPT and that the "holdouts" - states that had not joined the NPT - had shrunk to comprise Israel, India and Pakistan only, the Treaty suffered from a growing legitimacy deficit. There seemed to be a loss of voluntary compliance. This did not necessarily mean that the non-proliferation regime was going down the drain (Price 2007). In theory, coercion, economic and diplomatic pressures may substitute for voluntary compliance. The US tried that, largely in the shape of policies of regime change, but without success. It threatened North Korea and Iran; they responded by intensifying their nuclear programs; whereupon the US used it to strengthen its own case against these regimes. Regime change became a proliferation driver. In the case of North Korea, many years were lost until a negotiating approach based on reciprocal concessions, step-by-step, was agreed in early 2007(see Chapter 8). In the case of Iran, there were no negotiations with the US, only sticks - and no progress (see Chapter 7). These policies did not compensate for the legitimacy deficit, but compounded them to the detriment not only of the NPT, but of the non-proliferation regime in general.

\section{Reconfirming the grand bargain}

For many years, nuclear arms-control arrangements revolved around two treaties: the Anti-Ballistic Missile (ABM) Treaty and the Nuclear Non-Proliferation Treaty (NPT). This century, the US withdrew from the ABM Treaty, and the grand NPT bargain from the second half of the 1960s eroded. 
All states except four are members of the NPT. Among the four, there is still hope that North Korea will be willing to trade its nuclear weapons for a peace treaty, reconciliation with the US and the rest of the world, and economic benefits (see Chapter 8). The remaining three - India, Pakistan and Israel - are unlikely to relinquish their nuclear weapons sooner than any of the five recognised NWS. They cannot become members of the NPT - they do not want to, and in practice the Treaty amendment procedure would not make it possible anyhow - but they may be asked to behave "as if" they were members of the Treaty, the formula that France applied until it became a regular party in 1992 (see Chapter 5).

Many NPT members stick to what is known as the Swedish example: regardless of what the NWS do, it would not be in Sweden's interest to acquire nuclear arms. ${ }^{4}$ In Europe, Africa and South America, many NNWS stay committed to this kind of thinking and to the NPT. Also in Northeast Asia and the Middle East, where proliferation may occur and get out of hand, there is broad support for the Treaty. If it unravels, there are no nuclear-weapon-free zones (NWFZ) to fall back upon in these regions. International safeguards may continue on the basis of facility agreements (INFCIRC/66), but this is an incomplete substitute for NPT-type safeguards. In short: redundancies exist, but the fallback options are not attractive. For the great majority of states, breakdown of the NPT would therefore be a significant loss.

The best, and quite possibly the only, realistic chance for a new global consensus on non-proliferation is therefore to reconfirm the validity of the old one, i.e. the grand bargain that was struck in the second half of the 1960s, which led to the NPT and a comprehensive international non-proliferation regime. ${ }^{5}$ S/Res/1887 on Nuclear Non-Proliferation and Nuclear Disarmament, adopted by the Security Council Summit meeting on 24 September 2009, is a step in that direction. $^{6}$

Below, ten requirements for a new global consensus are discussed. They tie into each other, so the order in which they are listed is neither an order of importance nor an order of priority.

\section{The unit of account}

For a global consensus to be re-established, requirement number one is to forge agreement on the unit of account. In the NPT, nuclear weapons are the units of account. It is the weapons that should not proliferate and it is the weapons that should finally be eliminated. The Bush administration shifted its attention to their possessors, of which there were good and bad ones: bona fide states and unreliable rogues. The President frequently asserted that the weapons had to be in the right hands, or that the worst weapons had to be kept out the worst hands. One favoured way to do it was by regime change, if need be by use of force. The US would itself be the arbiter of the new two-tier system.

Regime change is nothing new in US foreign policy. The novelty of the Bush administration was that it took it to the extremes, both in its declarations and in 
its actions. Ardent enemies and suspected proliferators should be overthrown: you don't talk to evil, you eliminate it. Obama took a different approach. $\mathrm{He}$ showed respect for the Islamic Republic of Iran, its leaders and its people, as is ordinary code of conduct in inter-state affairs, and entered negotiations to steer the Iranian nuclear programme away from weapons. Regime change may not have been completely abandoned - for instance, it was unclear whether or to what extent the covert programmes that Bush ran in Iran were cancelled - but it was no priority. With Israel, Obama remained true to the understanding originally reached by Richard Nixon and Golda Meir in September 1969, i.e. to the policy of opacity. The US supports the objective of NPT universality, but for all practical purposes Israel is treated as an exemption. One year into the Obama presidency, the impression was therefore that it harkened back to US policies before Bush, focusing on weapons as the units of account, but not without exceptions. $^{7}$

\section{Negotiations}

Second, negotiations must be reinstated as a bona fide modality of nonproliferation policy.

As long as the US was unwilling to talk with its most ardent adversaries - to representatives of the nexus of terrorism and weapons of mass destruction there could be no agreed strategy for non-proliferation and disarmament. Then, there could only be select areas of cooperation. The main targets were Iran and North Korea. As noted above, the quest for regime change and the refusal to negotiate became proliferation drivers.

It stands to reason that, under such a policy, the other side was not keen to talk either. Knowing that the US objective was to cut their throat, the adversaries had little incentive to negotiate. It was not until January 2007 - when the Americans sat down with the North Koreans in Berlin - that the Korean problem took a turn for the better, however short-lived (see Chapter 8). Unfortunately, it happened on the heels of the North Korean test in October 2006, which seemed to confirm the political utility of nuclear weapons.

The P5+1 (Germany) were ready to negotiate with Iran if Iran brought all fuel-cycle works to a halt and accepted an Additional Protocol to the NPT safeguards agreement. This position turned what should have been the object of negotiations - restrictions on uranium enrichment first of all - into a precondition for them. To Iranian eyes, it was tantamount to saying that, first, you must accept defeat, and then we may sit down and talk.

During the election campaign, Barack Obama said he was willing to talk to other governments without preconditions, however hostile they might be to the US. Negotiations with Iran began in Geneva on 1 October 2009, and ways to resume talks with North Korea were explored. The talks with Iran were shortlived: the Western powers took the view that the confidence-building measure that was tabled in Geneva was a "take it or leave it" proposition, and the Iranian government was split over the issue. By the turn of 2009/2010, Western policy 
was back on the sanctions track (see Chapter 7). Talks with North Korea were slow to materialise. Still, diplomacy and other non-military measures were the favoured instruments of non-proliferation policy, but preventive use of force was not deleted from the agenda.

\section{Preventive military action}

The US National Security Strategy of 2002, updated in 2006 (see White House 2006), stated that the US must deter and defend against the threat of weapons of mass destruction (WMD) before they are unleashed. It will not do to wait until the enemies have built their weapons and can use and retaliate with them. President Bush called it a strategy of pre-emption, in accordance with the way this expression had been used for a decade, but that use of the term blurs the important distinction between pre-emption and prevention. The difference is one of timing and legality. In international law, pre-emption - at the moment an attack is about to be launched - is permitted. ${ }^{8}$ Preventive attack, against an opponent who may or may not become a real threat in the future, is not.

In recent decades, there have been four well-known cases of preventive action against actual or alleged proliferators of weapons of mass destruction (WMD): Osiraq, Iraq (1981), El Shifa, Sudan (1998), the occupation of Iraq (2003) and Al Kibar, Syria (2007). Except for Al Kibar - which may have been a success on Israeli premises, but a mixed blessing for the non-proliferation regime - the results have been discouraging.

The international non-proliferation regime is rooted in international law. Illegal preventive actions undermine it. Had the intelligence on El Shifa been right - this pharmaceutical plant allegedly produced precursors for chemical weapons (VX nerve gas) and had links to bin Laden - the bombing of it could perhaps have been justified as an act of self-defence in reference to Article 51 of the UN Charter, similar to the way in which the US justified its attack on Afghanistan after 9/11. Or it may have been justified as an act of reprisal. ${ }^{9}$ It was done in response to the terror attacks on the US embassies in Kenya and Tanzania. However, eight months later, the US admitted that it had made a mistake. "Guilty until proven innocent" is, anyhow, nowhere in the legal textbooks.

The actions have been marred by intelligence failures (admitted in the cases of Iraq and El Shifa); flawed diagnosis and failure to grasp the consequences of bombing in the case of Osiraq (the bombing of it accelerated the secret nuclear weapons programme that was discovered ten years later, and may even have triggered $\mathrm{it}^{10}$ ); waiting to be corroborated in the case of Al Kibar, where Israeli intelligence seems to have had it right. The target appears to have been a nuclear reactor built with the assistance of North Korea. All four actions were illegal under international law: three of the four were based on flawed intelligence.

The political implications have been detrimental to non-proliferation endeavours. Illegal acts of war trigger strong sentiments and much enmity, especially when based on claims that are unfounded. The case of Osiraq leaves a lesson that is pertinent to Iran and possibly also Syria. If Iranian nuclear facilities are 
bombed, Iran may try even harder the next time. If it was not going for nuclear weapons before being bombed, it would be more likely to do so afterwards. The Syrian case is more open to doubt, however. Its territory is much smaller than Iran's, and it is more vulnerable to Israeli intelligence and military capabilities than is Iran.

The bombing raid at Al Kibar was the second application of the Begin Doctrine, which holds that Israel will not tolerate acquisition of nuclear-weapon capabilities by its enemies (the bombing of Osiraq was the first). If the charges are correct - that Syria and North Korea were cooperating to build a nuclear reactor there - Syria had failed to declare the upcoming facility to the IAEA. Being a member of the NPT and having an INFCIRC 153 safeguards agreement in force, it should have provided design information to the IAEA when the construction works started in preparation of safeguards. Israel, which is well known for being critical of the effectiveness of international safeguards, did not inform the IAEA either. In a vote of no confidence in the Agency, it bombed instead. Unilateral action substituted for the way the non-proliferation regime is designed to handle such a matter, undercutting its international verification instrument.

The third requirement is therefore that preventive military action yields to legal, treaty-based approaches. However, military action to stop nuclearproliferation programmes is central to Israeli political and military thinking, and while President Obama upgraded the role of diplomacy and downplayed the use of force, unilateral military options are not ruled out. The security assurances announced by the US Nuclear Posture Review of 2010 do not apply in relation to NPT members that are not seen to be in good standing (see Chapter 3). Unilateralism is a structural phenomenon rooted in the superior position of the US in world affairs, and unilateral action is nearest at hand where it is strongest, i.e. in the military field. So the caveat is that for the NPT, the question is how best to co-exist with policies which, when enacted, may weaken it.

Playing on the assumption that differences do not necessarily amount to incompatibilities, but can be made complementary, the tensions between regime procedures and unilateral counter-proliferation policies may be alleviated and even transformed to become mutually supportive. In certain circumstances, the international regime may actually stand to gain because its own enforcement mechanisms are commonly recognised to be weak (see Non-proliferation and Counter-proliferation, pp. 90-91).

\section{Verification}

The original NPT verification standard was full-scope safeguards following all fissile materials in member states. The model agreement (INFCIRC 153) provided for more intrusive international verification than had previously been accepted by states. There were concerns in highly industrialised NNWS that industrial secrets might be revealed, but they were put to rest already by the mid-1970s.

To be taken seriously, any arms-control regime must have verification provisions that are considered adequate, and INFCIRC 153 was deemed adequate for 
the purposes of the NPT. When Saddam's secret nuclear weapon programme of the 1980s proved them inadequate, an Additional Protocol (INFCIRC 540) was elaborated that greatly improved the Agency's ability to look for activities and facilities that might not have been declared. Efforts are going on to make 153 plus 540 the new verification standard. The principle is adequacy: the operative meaning of it may have to be adjusted from time to time, and INFCIRC 540 is hardly the end of the road. To oppose the Additional Protocol on the ground that it was not a part of the original bargain is therefore misguided. NNWS refusing to accept INFCIRC 540 because the NWS do not live up to their obligations - to Article VI in particular - should reconsider their stance. This is the fourth requirement for reconfirmation of the basic bargain.

In 2003, the United States did not allow UNMOVIC to come to a conclusion. The war cut the inspections short. In Iran, verification is also in a bind. Recurrent demands that it should ratify the Additional Protocol; provide early design information; and offer voluntary transparency measures are made with the knowledge that nobody can prove the negative and in the hope that incriminating evidence will be found. As long as Iran is under military threat, it must be assumed to distribute its assets on many well-protected sites throughout the country and to keep them secret to not help its enemies update their target lists. ${ }^{11}$ On the one hand, it is obliged to provide information to the IAEA; on the other hand, it wants to minimise its vulnerability to attack. As long as this is the situation, transparency demands - ostensibly to enable Iran "to come clean" enhance suspicions rather than build confidence.

Cooperation between the IAEA and possessors of relevant national intelligence data has been mixed. Some governments have shared some information with the Agency, but there is no systematicity to it, and it is not always clear for what purpose it is done. In the later phases of UNSCOM's work, national intelligence agencies also infiltrated the Commission. Provision of national intelligence information to the IAEA was not a part of the original bargain, and it is fraught with difficulties. But to use national intelligence to complicate and obstruct the verification process was certainly not part of the bargain either.

Reconfirmation of the basic bargain means that member states should refrain from any activity or policy that may detract from adequate verification procedures. Those who are in a position to enhance the effectiveness of international safeguards should be encouraged to do so in good faith. INFCIRC 540 should be universally accepted. By January 2010, an additional protocol had not been ratified by more than 94 states, so it was too early to make it a condition for nuclear exports. ${ }^{12} \mathrm{~S} / \mathrm{Res} / 1887$ could only "encourage states to consider whether a recipient State has signed and ratified an additional protocol based on the model additional protocol in making nuclear export decisions" (para. 10).

\section{Balancing the rights and responsibilities of peaceful uses}

Reconfirming the basics is very much about re-establishing the balance between the three pillars of the NPT: non-proliferation, disarmament and peaceful uses of 


\section{The legacies of nuclear history}

nuclear energy. This is requirement number five. What has changed the original balance is, first of all, the failure to meet the disarmament obligation of Article VI, while imposing a number of supply-side measures restricting the right to peaceful uses under Article IV in the name of non-proliferation.

Article IV was deliberately written to avoid attempts to reinterpret the NPT in ways that would make peaceful utilisations more difficult. The only qualification was that international transactions must be in conformity with Article I and II, excluding acquisitions for weapons purposes. The right to peaceful uses includes the right to build national fuel-cycle facilities, i.e. plutonium and enrichment plants. ${ }^{13}$ The spread of such capabilities is undesirable from a proliferation point of view, but restrictions can best be promoted in conjunction with other measures in order to maintain the overall balance of rights and obligations. One type of trade-offs that has long been discussed is assurances of fuel supplies and access to nuclear technology in return for restrictions on national fuel-cycle programmes.

In 1971, the Zangger Committee was established to operationalise the NPT export control provision contained in Article III.2. In 1975, the Nuclear Suppliers Group (NSG) was established following India's nuclear explosion the year before, setting out to control the export of dual-use items. The NSG - a selfappointed group of supplier states originally referred to as the London Club, holding secret discussions in London - drew resentment right from the beginning. Critics recommended, instead, the negotiation of mutually agreed rules of international nuclear commerce between suppliers and recipients. These diverging approaches have existed ever since and they have been further accentuated recently.

Technology restraints may still be clarified, improved and consolidated. For instance, there are proposals for a division of labour between the Zangger Committee and the NSG, Zangger staying with nuclear items (especially designed or prepared (EDP) items) and the NSG with the dual-use list; for linking export control information with the IAEA verification system (current practices lack systematicity); and for negotiating a global export control convention to strengthen the standards and promote their universality and legitimacy. Clearly, there is merit to moves that can shore up present arrangements along such lines. However, the main agenda of the future should take a different tack with the problems, moving to a negotiated set of regulations between suppliers and recipients that would be more legitimate, comprehensive and universal than supplier restraints can ever be, and that would provide both assurances of nonproliferation and assurances of supply and access. ${ }^{14}$

\section{Balancing the pillars: the necessity to disarm}

Such a deal is hard to strike, however. In view of all the attempts that have been made to date, without success, it may only be achieved in a broader framework that sees a new understanding of Article IV in conjunction with progress on Article VI. Many NNWS object to restrictions on their Article IV rights as long 
as the NWS pay so little attention to their own obligations. In their view, the original balance of rights and obligations has shifted too much in their disfavour already.

Legally speaking, failure to take "effective measures relating to cessation of the nuclear arms race at an early date and to nuclear disarmament" does not necessarily amount to non-compliance by any particular state. Progress depends on the seriousness of all negotiating parties and is arguably beyond the powers of any single participant. Article VI fails, moreover, to specify which measures should be pursued. ${ }^{15}$ The principles and objectives of nuclear disarmament adopted by the 1995 NPT Review and Extension Conference, the Middle East resolution adopted on the same occasion and the 13 steps towards nuclear disarmament agreed by the 2000 Review Conference do not make up for this lack of specificity, for none of these documents qualify as "subsequent agreements" within the meaning of Article 31 of the Vienna Convention on the Law of Treaties. They are political commitments, not legally binding interpretations of Article VI (Ford 2007). The Article is simply too vague to provide benchmarks for legal assessments of compliance the way, for example, safeguards agreements do.

Seen in the political context in which the NPT evolved, as part of a larger political bargain, the meaning of Article VI looks different, however (Graham 2007). Right from the beginning of the NPT negotiations in the mid-1960s, disarmament was considered to be a quid for the non-proliferation quo. On 15 August 1968, one-and-a-half months after the NPT was opened for signature, the co-chairs of the Eighteen Nation Disarmament Committee - the USA and the USSR - presented an agenda for the Committee that struck a compromise between those NNWS that had wanted commitments to specific measures to be written into the NPT and those who were willing to leave it for follow-up action. ${ }^{16}$ The nuclear part of the agenda was essentially a package proposed by India and Sweden, who had argued for inclusion of specific measures in the Treaty text. A month later, the non-nuclear members of the Committee presented a comparable agenda. Both agendas included a test ban, a cut-off of all production of fissile materials for military purposes, security assurances for NNWS, and reduction and subsequent elimination of nuclear weapon stockpiles. The cochairs as well as the other members of the Committee emphasised that the viability of the Treaty depended on the results achieved in this field, and the review conferences were mandated to assure "that the purposes of the Preamble and the provisions of the Treaty are being realized" (Article VIII.3). Clearly, Article VI was conceived as part of a dynamic bargain to be implemented over time, erasing - in due course - the distinction between NWS and NNWS. Measures were identified, converging expectations were created, and a review mechanism was set up to facilitate the realisation of them. Although no timeline was given, "cessation of the arms race at an early date" left a sense of urgency.

Article VI therefore calls for negotiations in good faith. In the view of Judge Muhammed Bedjaoui, president of the International Court of Justice at the time its Advisory Opinion on nuclear weapons was issued (1996), "good faith" as 
applied in the NPT context means sustained negotiations and search for compromises; refraining from acts that are incompatible with the purpose of the Treaty; proscription of any initiative that would render impossible the conclusion of disarmament treaties; prohibition of unjustified termination of negotiations; no selectivity regarding which provisions to implement; and a general obligation to inform and communicate - mainly on the part of the NWS - since the pursuit of disarmament is an obligation on all parties and the status of the Treaty is a matter of global concern (Bedjaoui 2009). In short, the "good faith" provision was inserted to enhance the prospects of "systematic and progressive efforts to implement article VI". ${ }^{17}$ The ICJ Advisory Opinion therefore held that Article VI amounts not only to an obligation to negotiate, but also to an obligation to bring the negotiations to a conclusion (ICJ 1996).

In the years following signature (1968) and entry into force (1970) of the NPT, the Treaty became the backbone of an international regime comprising arms-control agreements, a growing number of nuclear-weapon-free zones, security assurances for NNWS, full scope safeguards, rules of international nuclear commerce and national export-control regulations. Commonly referred to as the international non-proliferation regime, it conforms to a classical regime definition in the study of international affairs: a set of explicit or implicit principles, norms, rules and decision-making procedures around which actor expectations converge in a given issues area (Krasner 1983). In the realm of declaratory policy, expectations clearly converged. Assurances were exchanged tying non-proliferation to disarmament.

National interests turned out to be a different matter. In her account of the negotiations, the Swedish negotiator and Nobel Peace Prize winner Alva Myrdal (1977) felt betrayed. The review conferences of 1980 and 1990 failed over Article VI issues, and the 1975 and 1985 conferences papered over profound divergences of views on the same issues. The period of opportunity after the Cold War brought enough progress for disarmament and non-proliferation to enable the 1995 Review and Extension Conference to extend the NPT indefinitely but, a few years later, the treaty architecture began to unravel: the US withdrew from the ABM Treaty; Russia dropped START II per consequence; the INF Treaty came under pressure; and START I was due to expire on 5 December 2009. Except for SORT (2002), which strictly speaking was not a disarmament treaty (Lodgaard 2003), no negotiations were conducted. The CTBT had not entered into force; negotiations for a Fissile Material Cut-Off Treaty had not started; and the security assurances for NNWS - always conditional - were further weakened. Clearly, the bargain of 1968 came apart.

Substantial progress in implementing Article VI, setting the world on a path towards a nuclear-weapon-free world, is requirement number seven for the original bargain to be reconfirmed. President Obama has taken a series of initiatives in this direction, but how far they will lead is an open question. 


\section{Security assurances}

Security assurances for NNWS were part of the NPT bargain from the beginning. In return for accepting a temporary division of the world into nuclear and non-nuclear-weapon states, the NNWS demanded assurances that they would not be subject to use or threat of use of nuclear weapons. The Soviet Union and the US/UK gave different kinds of assurances; France and China, which became members of the NPT only later, also offered their own formulas (SIPRI 1980). All of them were qualified in various ways, except the Chinese no-first-use assurances. Prior to the NPT Review and Extension Conference in 1995, the P5 summarised their assurances in Security Council Resolution 984.

Except for China, the assurances remained qualified in ways that limited their value. The NPT review conferences have therefore urged the NWS to do better. This century, however, the opposite happened: the national doctrines significantly widened the range of missions assigned to nuclear weapons, shedding doubt on the validity of the assurances contained in Resolution 984 (see Chapter 3). Only China remained true to its original policy of no-first-use. Reversing this development, extending assurances that are more forthcoming to the NNWS, is the seventh requirement for a new non-proliferation consensus.

This is what the Obama administration has begun to do. It will not use or threaten to use nuclear weapons against NPT members in good standing. Chemical and biological weapons will be deterred by conventional means, with reservations made for new scientific developments in the biological sector. In practice, this negative security assurance covers about 180 states. Exempt are the NWS and NPT members that, in the US view, do not comply with their NPT obligations, such as Iran and possibly Syria. Another Security Council resolution on security assurances based on the new US formula, replacing Resolution 984 of 1995, may be within reach (see Chapter 3).

NNWS are more vulnerable to use and threats of use than NWS. Where mutually assured destruction applies, resort to nuclear weapons is an ordained act of suicide, while in relation to NNWS, the aggressor may get away with it. Accordingly, the threats that have been made have mostly been addressed to NNWS (Ellsberg 2009). Non-aligned states have therefore called for an international convention committing the NWS not to use or threaten to use nuclear weapons against NNWS parties to the NPT, no qualifications added. This is more difficult to achieve than a Security Council resolution, especially because the convention would have to clarify the meaning of being an NPT member "in good standing". That question would certainly also be raised in connection with a Security Council resolution, but if the resolution is a collection of national assurances, the question does not require a uniform answer.

No-first-use doctrines, limiting the role of nuclear weapons to that of deterring others from using theirs, would meet the same concerns and, in addition, reduce the role of nuclear weapons in inter-NWS affairs to the passive one of deterring others from using theirs. ${ }^{18}$ Unqualified undertakings never to be the first to use nuclear weapons have, moreover, an important disarmament 
corollary: nobody would need them if nobody had them. In deep cuts and elimination scenarios, this proposition is therefore more relevant than extension of non-use assurances to NNWS.

Progressive restrictions on the role of nuclear weapons must go hand-in-hand with nuclear disarmament, for without disarmament the doctrinal restrictions would not be credible (see Chapter 10). However, no-first-use doctrines are harder to achieve than unqualified assurances of non-use to NNWS parties to the NPT. ${ }^{19}$

\section{Universality: the three-state question}

A new global consensus must also include the three states that never joined the NPT: India, Pakistan and Israel. They are all NWS. North Korea, which withdrew from the NTP in 2002, is in a category of its own. It has been a member of the NPT (1992-2003), and the objective must be to bring it back into the Treaty.

After the tests in 1998, India began to rework its nuclear diplomacy. From being the world's leading protestor against discrimination in the nuclear order, India transformed itself into a nation ready to support the existing order. It stepped up its support for incremental arms control, endorsed the objectives of the NPT and supported new US non-proliferation initiatives like the PSI (Mohan 2007) (see Chapter 5).

The nuclear deal with the United States rubbed some of these commitments in - the commitment to world-class export controls in particular. The deal also influenced India's decision to support the European resolution on Iran at the IAEA in September 2005, declaring Iran to have been in non-compliance with its safeguards obligations, as well as the resolution that sent the Iranian file to the UN Security Council in February 2006 (see Chapter 7). However, India is keen to preserve its independence in relation to other big powers, and its policy towards Iran is a litmus test of that (see Chapter 1).

India's orientation towards the existing order makes it easier to forge a new global consensus on non-proliferation and disarmament. To enhance and formalise its involvement in an emerging consensus, it should be asked to behave "as if" it was a member of the NPT (see Chapter 5). Concretely, this would oblige India not to assist others in acquiring nuclear weapons (Article I of the NPT), abide by the rules of international nuclear commerce (the safeguards requirement of Article III.2) and dedicate itself to nuclear disarmament (Article VI). Today, it is under no such international disarmament obligation (see Chapter 5). India has a strong tradition to uphold in the disarmament field, and a legacy from Rajiv Gandhi to honour. Influenced by the "gang of four" and President Obama, it has put renewed emphasis on its traditional pleas for nuclear disarmament. It maintains its support for a time-bound international convention for elimination of nuclear weapons. Therefore, an Article VI commitment is unlikely to be a big problem.

In principle, the "as if" formula is applicable to Pakistan and Israel, too. Israel's declaratory policy has always been the same: never to be the first to 
introduce nuclear weapons into the Middle East. The ambiguity of it has served it well. For the near term, efforts to extract non-proliferation commitments from Israel should therefore not be predicated on a change in declaratory policy. ${ }^{20} \mathrm{On}$ closer examination, this does not pose any problem: an Israeli commitment to behave "as if" it was a member does not have to clarify whether it is an NWS or an NNWS that undertakes it. Often criticised for being recalcitrant and arrogant and for blocking arms control in a region that desperately needs it, the merit of this for Israel would be to soften that perception.

De jure recognition of India as an NWS may have to wait until it undertakes a full "as if" commitment. Pakistan must live up to the same standards in order to be treated the same way. Pakistan is far from that standard today, but it is in the best interest of non-proliferation that it gets there. Another possibility would be a more comprehensive criteria-based approach applicable to all outliers, building on the elements that were highlighted by the NSG when the exemption was made for India and adding some more requirements such as a disarmament commitment equivalent to Article VI; signature and preferably accession to the CTBT; restrictions on fissile material production while waiting for a cut-off treaty to be concluded; and, possibly, a clearer separation line between civilian and military activities. Sooner or later, de facto nuclear weapon status will lead to de jure recognition, which is necessary in order to bring them into armscontrol and disarmament negotiations.

Could NPT members contemplating acquisition of nuclear arms prepare themselves under the umbrella of the Treaty, give three months notice of withdrawal, and then try to soften the pressure levelled on them by offering to abide by the provisions of the NPT "as if" they were members, replicating India? This is a substantial concern. There is no simple answer. However, unlike the three which never joined the Treaty, states attempting to do this would, first, violate an international legal commitment; second, none of them would have the weight of India, so they would be more vulnerable to international reactions; third, to further dissuade states from leaving the NPT, the Security Council could adopt a generic resolution explaining that if a state withdraws after having been found to be in noncompliance with its safeguards undertakings, this will be considered as a threat to international peace and lead to certain specified reactions, without necessarily being exhaustive in that respect: ${ }^{21}$ and, fourth, the withdrawal clause (Article X) should be tightened up to make withdrawal more difficult and give the parties more time to persuade the notifying state to maintain its membership (see Chapter 9). This, however, is unlikely to happen unless it becomes part of a broader package to redress the balance of rights and obligations under the Treaty.

Universality was always the ambition, reiterated at all review conferences of the Treaty. In this respect, the NPT has already been more successful than any other multilateral arms-control treaty. If North Korea can be brought back to the NPT as an NNWS, application of the "as if" formula to the remaining three would bring the Treaty as close to universality as is practically possible. Some version of this controversial proposition may be element number eight in a new consensus. ${ }^{22}$ 


\section{Non-proliferation and counter-proliferation}

Some elements of US policy remain at odds with the non-proliferation regime, with no prospect of radical change. In so far as this is the case, the strategy must be to reduce the incompatibilities and exploit potential complementarities between US positions and those of others whenever possible. For differences do not always amount to incompatibilities: they may also be complementary, reinforcing each other in the pursuit of common goals.

One such element is that of counter-proliferation - preventive action in some form or other - using military or non-military means to eliminate nuclear installations. Another related element is that of unilateralism: while the idea that there should be exceptional rules for the exceptionally strong - in high currency immediately after the occupation of Iraq - is more or less out, unilateralism is likely to stay for a long time. Counter-proliferation and unilateralism may change with changing administrations and there may be more or less of it, but the changes are likely to be variations of one and the same theme. For these policies derive from the superior status of the US in world affairs, and US military superiority, in particular, is unlikely to go away any time soon. The nonproliferation regime will have to co-exist with these elements of US policy.

Counter-proliferation and non-proliferation policies may be incompatible. When the IAEA reports a case of non-compliance to the Security Council, authorisation of the use of force in a counter-proliferation mode is not excluded - on questions of international peace and security the Council is free to decide; there is nobody above it - but it is unlikely to happen. Such action is more likely to be taken unilaterally or by "coalitions of the willing" and be conducted in defiance of the regime. For instance, bombing of nuclear facilities in Iran would be a violation of international law, for it could not be justified as an act of selfdefence in reference to Article 51 of the UN Charter, and the Security Council will not authorise it.

On the other hand, by extending credible threats of the use of force, US counter-proliferation policy may be a useful supplement to the non-proliferation regime. Such threats can have a deterrent effect which the international regime has little or no prospect of providing. Deterrence does not address the root causes of proliferation, and in that sense does not solve the problems, but it can affect the balance of incentives in favour of staying non-nuclear. For instance, a wouldbe proliferator may defer a decision to go nuclear, or refrain from weaponising the programme, seeking political solutions to security concerns instead.

For threats to be credible, there has to be a capability and a will to implement them. Actual use of force to destroy nuclear facilities may, however, do more harm than good. A topical case is that of Iran: if it is bombed, it would probably leave the NPT, refuse inspections and be motivated to pursue a nuclear-weapons programme in secret. Bombing would set the nuclear programme back, but in the long run it is more likely to become part of the problem than of the solution. Therefore, the relationship between counter-proliferation and non-proliferation is ambiguous and complex: counter-proliferation threats may supplement the 
regime in the best interests of non-proliferation, while actual use of force may undermine the same objective.

Requirement number nine is therefore to live with the differences between non-proliferation and counter-proliferation and exploit the opportunities to turn them into mutual advantage.

Against non-state actors, collective action is more easily agreed. Security Council Resolution 1540, dealing with measures to be taken against non-state proliferators, was passed by consensus under Chapter VII of the UN Charter. For the great majority of states, violent non-state actors are "hairs in the soup". Usually dubbed terrorists, they tend to be resolutely addressed, including by use of force if needed and at all possible.

\section{Leadership}

For international regimes to function properly, some important actor(s) must exercise leadership. The non-proliferation regime is no exception. During the Cold War, the depository states took responsibility for the NPT in their special way, disregarding the disarmament obligation of Article VI. In the beginning of this century, there was no leadership at all. A new global consensus on nonproliferation and disarmament depends on US leadership. This is requirement number ten.

Nuclear weapons are usually regarded as a source of strength, but they can also be seen as signs of weakness and vulnerability. The history of the nuclear age speaks to it. The Soviet Union built nuclear weapons to overcome its inferiority in relation to the US (see Chapter 2) and Russia has assigned a wider role to its nuclear forces to compensate for conventional weakness (see Chapter 3). For the UK and France, nuclear weapons served to underwrite their big power status, which rests on narrow grounds. China reacted to US and Soviet weapons. Currently, it modernises and probably also expands its arsenal in response to the US missile-defence programme. India - largely driven by status ambitions - justified its tests in reference to China, and Pakistan in reference to India. For North Korea, it is a matter of regime survival, and for Israel the nuclear arsenal is the ultimate national insurance premium. When considering how best to facilitate nuclear disarmament, this perspective is an indispensable guide to what to do.

While all parties - NNWS as well as NWS - are obliged to work for nuclear disarmament, US leadership is vital. The political chain reaction outlined above started in the US, and reversal of it also has to begin there. The logic of the argument rests on the fact that the nuclear weapon acquisitions of the other big powers can be fully understood only in reference to that of the US, i.e. coming back to the country of origin. The realism of it lies in the fact that the US is strong on so many dimensions and in a category of its own when it comes to conventional military strength.

Abolition has been proposed three times before (chapter 2). It came to the fore again in connection with the 20th anniversary of Reykjavik, in the form of the Hoover plan (Shultz et al. 2007). Three camps have shaped the US debate 
about it: the Shultz-Nunn-Perry-Kissinger camp, which holds out the vision of total disarmament; a "the vision is right but unrealistic" camp that wants smaller inventories; and a "this is a very bad idea" camp that fears a return to arms control. In the US House of Representatives, a bipartisan resolution was introduced in 2008 calling for a reduction of deployed US and Russian nuclear weapons to no more than 1,000 , and a total (including reserves) of no more than $3,000 . .^{23}$

In his April 2009 speech in Prague, President Obama outlined his vision of a world without nuclear weapons, and in September 2009 the Security Council summit meeting resolved "to create the conditions for a world without nuclear weapons". In a literal sense, this was nothing new, for the parties to the NPT had already undertaken an international legal obligation to work for an NWFW. The above quote from S/Res/1887 therefore adds "in accordance with the Treaty on the Non-Proliferation of Nuclear Weapons (NPT)".

Still, the resolution was important. First, because the Council's Heads of State reconfirmed the validity of the three pillars on which it is built - nonproliferation, disarmament and peaceful uses. The disarmament pillar got little attention in comparison with the non-proliferation dimension, and no mention was made of the 1995 Middle East Resolution- the initiators were consumed by the Iranian problem in particular - yet disarmament was more prominently addressed than in a long while. Second, it raised expectations that the discrepancies that had evolved between UN declarations and national strategy documents, between SC Resolution 984 on security assurances and national nuclear doctrines in particular, will be eliminated in favour of the former. Third, the summit was convened and chaired by a US President who had made nuclear nonproliferation and disarmament his number-one priority. ${ }^{24}$ New START, a new US NPR and a Washington summit on nuclear terrorism followed.

In the diplomatic process that led to the resolution, the negotiating sequence was unfortunate. It failed to properly reflect the shift of power to the east and south. The sooner the emerging powers are brought into disarmament diplomacy on a par with the US and other Western states the better (see Chapter 1). The Security Council is, moreover, often perceived as ignoring the interests of lesspowerful states while the veto protects the interests of the NWS and their allies. Resolution 1887 confirmed these concerns. Many non-aligned states found that their interests were poorly reflected. They see the Council as a means by which the NWS and their allies can short-circuit the international decision-making process where, in reality, there is no consensus among UN member states.

US leadership is essential. Tailoring the conduct of disarmament and nonproliferation affairs to evolving world order changes is no less important. 


\section{Part III}

\section{Proliferation problems and the role of nuclear disarmament}





\section{The three-state problem}

\section{The outliers}

India and Pakistan never joined the NPT and broke no international legal commitment by going nuclear. Neither did Israel, which is known to possess a nuclear arsenal, but which practices a policy of opacity and a declaratory policy of "not to be the first to introduce nuclear weapons into the Middle East" (Cohen 1998). North Korea, which became party to the NPT in 1985, but left the Treaty in January 2003 and conducted a test in October 2006 and another one in May 2009 , has on several occasions declared that it is ready to give up its nuclear capabilities in return for external assistance, security assurances and normalisation with the United States and the rest of the world. ${ }^{1}$ Efforts are still being made to find a political solution that will bring Pyongyang back into the fold of nonnuclear parties to the NPT. While the realism of this is open to doubt, the case of North Korea is, therefore, different from that of India, Israel and Pakistan. It can best be treated separately. All other states are parties to the NPT. No other armscontrol treaty has such a wide membership.

India, Israel and Pakistan are variously referred to as outliers or the "threestate problem". North Korea apart, universality for the NPT is a question of how to draw the outliers into the web of obligations that the Treaty harbours. All the others are on board. Except for Israel, whose nuclear arsenal is integral to the security problems of the Middle East, all NWS are looking at each other, justifying their acquisitions in reference to stronger adversaries: Pakistan to India, India to China, China to the United States and Russia, France and the United Kingdom to Russia, and Russia to the United States. ${ }^{2}$ The chain comes back to the point of origin, i.e. the United States. Two corollaries follow: (1) they are all in the same boat, and (2) US leadership is necessary to set the world on the course of disarmament (see Chapter 4).

\section{Framing the problem}

For many years, supporters of nuclear non-proliferation were caught between the unrealistic hope that India, Israel and Pakistan would abandon their nuclear weapons and the controversial prospect of accepting them as NWS. On the one 
hand, there is no particular reason to believe that these states will dismantle their nuclear arsenals any sooner than any of the five recognised NWS. The paternalistic language of the UN Security Council Resolution 1172 of 6 June 1998, adopted after the testing in South Asia that year, never had the intended effect. On the other hand, treating them for what they are has been anathema: the NPT recognises five NWS only; some NPT parties joined the Treaty on the understanding that no other states would openly declare a nuclear-weapon capability; ${ }^{3}$ and in 1992, the NSG guidelines made full-scope safeguards a precondition for nuclear transfers.

In Disarmament Diplomacy, ten ideas for how to deal with the three-state problem were examined (Nielsen 2007). None of them was found good enough. The author concluded that under the circumstances, status quo might be the best option. One year later, that option was no longer available, for at long last the US-India agreement was clinched. That agreement recognises the fact that India is an NWS, but stopped short of formal recognition. Subsequently endorsed by the 45-member NSG, it redefines the relationship between India and the rest of the world, making India a bona fide commercial partner in the nuclear field. Status quo would have been an untenable situation anyhow, just waiting for a better way to engage the outliers.

The failure of the 2005 NPT Review Conference (RevCon) and the failure of the September 2005 UN Summit to agree on anything regarding nuclear nonproliferation and disarmament fully demonstrated that the Treaty was in danger. In the following years, the crisis grew deeper. At the same time, the NPT proved its resilience. For the great majority of member states it remained important, so for them it was a matter of buying time for common ground to be re-established at a later stage when, hopefully, the situation would make that possible (Lodgaard 2007). Amidst all the conflicting interests and diverging policies, there was a growing realisation that it should be re-established as a matter of urgency. The best, and maybe the only, way to achieve it would be to reconfirm the validity of the old bargain and, in 2009, UNSC Resolution 1887 did so. A better approach to the three-state problem must be sought in that framework. Engaging the outliers must be part of the broader consensus effort.

Reconfirmation comes with an update. Some 40 years after the bargain was struck, this is to note the obvious. It applies to all three pillars of the NPT: nonproliferation, peaceful uses and disarmament. Also, it applies to the international system in which the non-proliferation regime functions. Two political-order observations rank above all others: (1) the United States remains the global power number one, so regime leadership - which no international regime can do without - is primarily up to the United States to exercise; and (2) the power shift from the West to the East and South and the rise of the "World Without the West" means that Brazil, China, India, South Africa and others should be more involved and have a greater say in shaping the disarmament and nonproliferation agenda.

The most important factors framing the approach to the three-state problem are therefore: (1) the implications of the US-India agreement and (2) the search 
for a new global consensus on non-proliferation and disarmament on the basis of an updated reconfirmation of the grand bargain of 1968, realigning the regime to ongoing power shifts in the international system. The first is India-specific, ${ }^{4}$ but influences considerations of how to engage the other outliers. The second is a world-order issue.

\section{The US-India agreement}

The origin of the US-India Peaceful Nuclear Cooperation Agreement goes back to the nuclear-weapon tests in 1998, when India began to rework its nuclear diplomacy. From being the world's leading protestor against discrimination in the international non-proliferation regime, India transformed itself into a nation ready to support the existing order. It stepped up its support for incremental arms control, endorsed the objectives of the NPT, declared its readiness to join negotiations for a Fissile Material Cut-Off Treaty (FMCT), endorsed the NSG guidelines without being a member of the NSG, issued a moratorium on testing, supported nuclear-weapon-free zones (NWFZ) elsewhere in the world, announced its willingness to seek substantive confidence-building measures $(\mathrm{CBM})$ with Pakistan and tightened export-control regulations. In addition, India supported US non-proliferation efforts such as the Proliferation Security Initiative (PSI) (Mohan 2007). The agreement with the United States, the safeguards agreement with the International Atomic Energy Agency (IAEA) and the NSG decision to give India access to the international nuclear market in reference to its non-proliferation commitments turn these undertakings - originally unilateral - into international obligations.

The deal therefore grew out of many years of pragmatic, concrete reorientation towards the existing arms-control order. In view of the fundamental change of Indian foreign policy that it amounted to, the gestation period - ten years - was surprisingly short. Too short for comfort when the deal was introduced and India began to debate it: the meaning of the turn-around had not been fully grasped and digested. The big political battle that followed can be fully understood only against this background. Indian right-wingers were concerned that the agreement would block further testing and constrain the nuclear arsenal; left-wingers feared that India would become too subservient to the United States. Access to modern technologies attracted them all. Since 1974, the United States had systematically denied broad categories of sensitive technologies to India, such as supercomputers, missile and space technology, satellites, advanced fighters, microelectronics and fibre optics; now, the door to those technologies was opening up. Access to nuclear technology was important both substantially and symbolically. Having developed a comprehensive nuclear programme since the 1950 s, largely on its own, utilisation of nuclear energy resonates well in Indian public opinion. On 22 July 2008, after a raucous debate, the government of Manmohan Singh won a vote of confidence tied to the nuclear deal by 275 votes to 256 .

For the United States, the agreement met a range of objectives. It opened an important market for US export industries; it helped meet India's rapidly 
growing energy needs and reduce carbon dioxide $\left(\mathrm{CO}_{2}\right)$ emissions in a country where almost 70 per cent of the electricity production was based on coal; and it paved the way for India to join global efforts to stop the proliferation of nuclear weapons. ${ }^{5}$ Also, it was seen as a catalyst of military cooperation including joint exercises, cooperation in multilateral operations, common efforts to fight terrorism, arms transfers both ways, research and development (R\&D) cooperation, technological transfers, cooperation on missile defence and intelligence collection, dialogues about defence strategies and military reform and strategic dialogue at the highest levels. ${ }^{6}$ In short, it freed the bilateral relationship from the limitations that were introduced after India's test of a nuclear device in 1974 and its nuclear-weapon tests in 1998. In the words of Nicholas Burns, the US chief negotiator, the nuclear agreement is the symbolic centrepiece of something much larger - a comprehensive engagement between the world's oldest and the world's largest democracy. ${ }^{7}$

In all of this there is a geopolitical dimension, variously characterised as "strategic" and "compelling". ${ }^{8}$ India was deemed ripe and ready to be a geopolitical partner. The US National Security Strategy of January 2006 emphasised it: "India is poised to shoulder global obligations in cooperation with the United States in a way befitting a major power" (National Security Strategy 2006). Twoand-a-half years later, when the agreement was clinched, the contours of a multicentric world had become clearer and the geopolitical importance of the Agreement more obvious. In view of the rise of China and of Islamic radicalism in Afghanistan and Pakistan, it was argued that the national security of the United States would be enhanced by a strong and enduring partnership with India.

More than anything else, it may have been the geopolitical rationale and the economic benefits of engaging a rapidly growing market of 1.2 billion inhabitants that made Congress pass the agreement so quickly ${ }^{9}$ and with such a wide margin: the House voted 297-117 and the Senate 86-13. The Indian-American community was vital in explaining the advantages of it both in the United States and in India. ${ }^{10}$ The US-India Business Council, representing 300 of the largest American companies investing in India, was particularly effective in arguing the commercial benefits. The geopolitical arguments were easily understood by the politicians themselves, irrespective of lobbies. In the United States, they were relatively uncontroversial. For weaker but rapidly ascending India they were troublesome, however. India cares very much about its sovereignty and independence, and the sceptics were critical to the point of suspecting that the government had reassured the United States by extending promises in secret.

\section{An "as if" kind of deal}

Some suggestions for how to get beyond the dilemma described above have addressed India, Israel and Pakistan in joint fashion. One such idea is to commit them to behave "as if" they were members of the NPT. This was French policy for quite a while, until it became a regular member in 1992. Concretely, the "as 
if" formula would oblige them not to assist others in acquiring nuclear weapons (Article I of the NPT); to abide by the rules of international nuclear transactions (the safeguards requirement of Article III.2); and to dedicate themselves to nuclear disarmament (Article VI). Unlike the NPT parties, they are not under any legal obligation to disarm. In addition, they should be asked to join other elements of the non-proliferation regime. ${ }^{11}$

The US-India Joint Statement issued after the meeting of President Bush and Prime Minister Singh on 18 July 2005 seemed to offer an "as if" kind of deal, but for India only. Emanating from the Next Steps in Strategic Partnership Initiative launched in January 2004, India would acquire the same benefits and advantages as other states "with advanced nuclear technology" (a euphemism for NWS). In return, it would assume the same responsibilities and practices. The statement treated India for what it is, a de facto NWS, yet without formally recognising India as a nuclear power. However, the end result - the US-India Peaceful Nuclear Cooperation Agreement, often called the "123 Agreement" stopped short of being a fully-fledged "as if" agreement.

\section{Rationale}

Having declared itself a nuclear-weapon power in May 1998, after years of hesitation and vacillation, India embarked on three basic foreign-policy transitions: from the normative to the pragmatic; from ideas of collective security to balance of power; and from the notion of disarmament to arms control. It turned around from being world champion in criticising the NPT for being discriminatory and the big powers for being hypocritical, to supporting and promoting the Treaty and the regime that it anchors. The 123 Agreement confirms and elaborates on it.

Basically, the non-proliferation rationale for the agreement is simple. To lean on India to eliminate its nuclear arsenal and join the NPT as a non-nuclearweapon state (NNWS) is unrealistic to the point of being counterproductive. Neither can it join as an NWS, for the NPT recognises five NWS only and, in practice, cannot be amended. Better, then, to treat India for what it is - an NWS - and to commit it to the non-proliferation regime on an "as if" basis. In the long run, policies are best when based on facts and not on fiction. In view of all the pressing proliferation concerns both in the state and non-state paradigms, the universality of the regime is more important than ever. The 123 Agreement is a step in that direction, breaking the stalemate surrounding the "three-state problem". It substitutes engagement of India and commitments to nonproliferation standards for isolation and top-down talk.

Did it effectively exploit the non-proliferation opportunities? Access to nuclear materials, equipment and technology on a par with NPT parties was a major concession to India. How much did it pay back in terms of nonproliferation commitments? 


\section{Strengths and weaknesses}

\section{The separation plan}

A plan was made to identify and separate civilian and military nuclear facilities and programmes in a phased manner and to declare them to the IAEA. The United States is committed under Article I of the NPT not to assist India in the development of its nuclear-weapon programme: ${ }^{13}$ does the separation plan square with that obligation?

The plan places 14 of India's 22 power reactors under safeguards. As of March 2006, when the separation plan was introduced, 15 reactors were operational and seven under construction (Squassoni 2006). A fast-breeder test reactor and a prototype breeder under construction at Kalpakkam are on the military side of the line and will, therefore, not be safeguarded. ${ }^{14}$ Eight heavy-water reactors (HWRs) are exempted from safeguards in order to provide plutonium for current and future breeders in their start-up phase. A breeder reactor can produce more plutonium than it uses. However, it takes some years to make the prototype operational, and a decade or two before it can start producing plutonium for weapons. Therefore, its plutonium potential has the character of a nuclear insurance premium for the long term. HWRs also yield plutonium of weapon quality and are used for that purpose, but at the cost of reduced efficiency in electricity production.

All new civilian reactors will be safeguarded. However, India itself will decide which reactors will be on the civilian side of the separation line (Nayan 2006). As for the research reactors, Cirus - which produced the plutonium for the test in 1974 - will be decommissioned in 2010 while the other two - Dhruva (Trombay) and Kamini (Kalpakkam, uses U-233) - are used for military ends. The core of the oldest reactor, Apsara, will be removed from the Bhaba Atomic Research Centre (BARC, Trombay) and submitted to safeguards in 2010.

India has an enrichment plant in Mysore (named Rattehalli), which enriches uranium for use in Indian submarines. This plant and all enrichment research programmes are exempted from safeguards. India will build a new reprocessing plant to make the distinction between civilian and military uses clearer. On the civilian side, all reprocessing will be done at this plant. The United States will then treat India the same way as Japan and the European Atomic Energy Community (Euratom), where the United States allows reprocessing of fuel of American origin.

Heavy-water production facilities - there are six of them - are not safeguarded on the basis of INFCIRC 153, but will be reported under the Additional Protocol (INFCIRC 540), to which India will accede. It remains to be seen how many plants will be placed on the civilian side and covered by safeguards.

The separation plan will be introduced gradually up to 2014. Without the Agreement, only six of 22 power reactors would have been safeguarded; ${ }^{15}$ under the Agreement, 14 will be covered. On the other hand, the Agreement permits India to import uranium fuel for its civilian reactors so that India's own uranium production, which did not allow all reactors to work at full capacity, can be used for military purposes instead. This is openly acknowledged on the Indian side as 
well. ${ }^{16}$ However, the bottleneck concerns the mining and processing of the uranium rather than the size of the reserves, and is about to be removed. Supporters of the Agreement claim that the reserves are big enough for India to produce as many nuclear weapons as it wants to without external assistance (Tellis 2006).

Irrespective of the sufficiency or insufficiency of domestic uranium reserves, transfers of nuclear material, equipment and technology to safeguarded activities are not in violation of Article IV of the NPT. The NSG provision of full-scope safeguards is, furthermore, a guideline for its 45 members, not a rule. India has received much safeguarded assistance over the years, subject to INFCIRC 66-type controls. As the Agreement was coming to a conclusion, Russia was building two power reactors in India along with assurances of fuel supply - the NSG guidelines notwithstanding- and without anybody raising any question about Article I of the NPT.

By and large, India can continue its nuclear-weapons programme according to existing plans. The 123 Agreement makes no significant difference in any direction, neither expanding nor constraining the programme. ${ }^{17}$ Therefore, the United States can hardly be criticised for violating Article I.

\section{Enrichment-, reprocessing- and heavy-water technologies}

The agreement says nothing specifically about the transfer of sensitive technologies, but it is the agreed interpretation of the NSG guidelines that sales of such technologies are not permitted. The United States, therefore, argued that it was unnecessary to repeat it in the Agreement. However, the guidelines are recommendations, sometimes referred to as a "gentlemen's agreement", while the 123 Agreement is binding on the parties.

Two exceptions to the prohibition are envisaged: first, for multinational facilities, which are more proliferation-resistant than national ones, and in which there is renewed interest; and, second, for research and development (R\&D) facilities of more proliferation-resistant technologies, especially for reprocessing.

\section{Access to reactor fuel}

This is crucial for India, and has met with full understanding by the United States. ${ }^{18}$ To avoid disruptions in the deliveries, the United States was ready to (1) write assurances of fuel deliveries into Section 123 of the US Atomic Energy Act; (2) negotiate, together with India, an agreement on fuel supplies with the IAEA; (3) support India in the establishment of a strategic fuel reserve; and (4) join India in organising a group of suppliers (including France, Russia and the United Kingdom) that would be ready to assist if all else failed.

\section{Safeguards}

In the United States, Russia and China, the IAEA applies safeguards to select facilities only, on a voluntary basis. France and the United Kingdom, on the 


\section{2}

\section{Proliferation problems}

other hand, have separated their civilian and military programmes, applying Euratom/IAEA safeguards to all civilian activities. The 123 Agreement follows the French/British model, precluding withdrawal of any plant or activity for national-security purposes and providing safeguards in perpetuity. Safeguards on all civilian facilities have the additional advantage of facilitating Indian participation in an international cut-off agreement. ${ }^{19}$

Knowing that the Additional Protocol is applied, suppliers can be all the more certain that their deliveries will not be misused for military ends. However, the Protocol was developed to help detect undeclared activities in NPT member states, so in the case of India the value of it is limited.

\section{The NSG guidelines}

According to the Guidelines for Nuclear Transfers agreed by the NSG, triggerlist items or related technologies can only be transferred to an NNWS when the receiving state has brought into force an agreement with the IAEA for safeguards on all source and special fissionable material in its current and future peaceful activities. That ruled out nuclear transfers to India. The 123 Agreement takes India out of the category of NNWS, places it on a par with "other leading countries with advanced nuclear technology such as the United States", and aims at "full civil nuclear energy cooperation".

Some years ago, the full-scope safeguards requirement for nuclear transfers was important in order to bring more countries into the NPT and NPT-type safeguards (INFCIRC/153). ${ }^{20}$ That objective has been fulfilled. All NNWS have joined the NPT and its safeguards system. There is, in other words, nothing more to achieve by stressing the full-scope safeguards requirement. It is by accepting India (Israel and Pakistan) as an NWS and applying safeguards to the civilian activities that the safeguards coverage can be further extended.

Today, the equivalent to the full-scope safeguards requirement - introduced by some suppliers already in the 1970s and adopted by the NSG in 1992 - is the attempt to make the Additional Protocol part of a new, enhanced safeguards requirement for nuclear transfers. There is a long way to go: by January 2010, protocols were in force in only 94 NPT member states. India's acceptance of the Protocol is a minor step towards universal application of the new requirement. Presumably, there is a tipping point at which the NSG might agree to make acceptance of the Protocol a condition for transfers, but that would be at a much higher number of acceptances.

India's record of compliance with the rules of international nuclear commerce sheds credibility on its commitment to go by the NSG guidelines and refrain from transferring fuel-cycle technologies to states that do not have them. It pledges, furthermore, to "support international efforts to limit [the] spread of enrichment and reprocessing technologies". This is a general expression of support for enhanced international efforts to constrain the proliferation of fuelcycle facilities in line with President Bush's proposal of February 2004 (White House 2004). 


\section{Export control}

The United States wants India to institutionalise world-class export controls. Under UNSC Resolution 1540, India is already committed to the strongest possible non-proliferation practices in this respect. Legally, the Agreement, therefore, does not add to the obligation already undertaken. Concrete export-control improvements can just as well be worked out on the basis of Resolution 1540 . However, the Agreement raises the awareness and stresses the importance of strict controls.

The commitment under Article I of the NPT is not limited to the governmental sphere. The governments must see to it that the private sector, too, complies with it. The same goes for the safeguards obligation under Article III.2. In order to live up to these commitments, effective export-control systems and proper reporting routines to the IAEA are needed. Under an international legal arrangement to this effect, other states can legitimately raise questions about export regulations and, also, offer their cooperation in establishing more effective domestic-control systems. The NSG guidelines do not have that status, but UNSC Resolution 1540 has.

\section{Fissile Material Cut-Off Treaty (FMCT)}

The commitment to work for an FMCT is not new either. It was part of the Indian policy package to soften the political shockwaves created by the 1998 tests, along with a moratorium on new nuclear tests, a no-first-use (NFU) pledge and a minimum deterrence posture.

The FMCT has been a non-starter. The Conference on Disarmament (CD) adopted a mandate for FMCT negotiations in 1995, but no negotiations have taken place. The prospects got even dimmer when the Bush administration stated that an FMCT would not be verifiable. There is an element of cynicism in this plea: India promises to work towards a treaty which is not expected to come about, or the negotiation of it may be marred by so many difficult problems that it would go on until a sufficient amount of materials has been produced. In the meantime, India's fissile-material production continues.

Four of the five recognised NWS have issued a moratorium on production of fissile materials for weapons. China seems to have stopped, too, but without announcing it. Critics of the Agreement see the lack of such a commitment by India as a serious weakness. However, had a cap on fissile-material production been made a condition, no agreement would have been possible (Mohan 2007).

\section{Nuclear testing}

India declared a moratorium on nuclear-weapon tests in 1998 and has an understanding with Pakistan not to be the first to resume testing. The 123 Agreement adds a bilateral commitment to the United States to that same effect. This was 
the least the Agreement could contain on the important matter of nuclear-weapon testing.

What will happen if India resumes testing? The Agreement is vague on this issue. US law entitles the administration to stop further cooperation, and this is the likely consequence if India is the first to break out of the current moratorium. If another NWS starts testing and India follows suit, the reaction is not so obvious. There might be no legitimate ground for leaning on India.

India's signature on the CTBT would have been an achievement. A party signing an international agreement commits itself not to do anything that may complicate the ratification of it. However, since the Bush administration had been looking for ways to erase Clinton's signature of the Treaty, it was not in a position to urge India to sign.

\section{Missile technology control regime (MTCR)}

India committed itself to follow the guidelines of this regime. The commitment is important, for India has an advanced missile programme. Similar to its nuclear export controls, India already has a good record of compliance with these rules.

\section{Disarmament}

This is an empty category. The Agreement contains no such commitment. While all members of the NPT are under an international legal obligation to work for nuclear disarmament, the non-members are not. In view of the dismal disarmament record of the NWS parties, the same undertaking by India would not necessarily make much of a difference. However, had it been committed in reference to Article VI, it could have been held accountable in the review process of the NPT and be asked to respond to questions in other settings where nuclear disarmament is discussed on a par with the other NWS. Today, there is no formal basis for such requests.

Similar to the test-ban issue, the United States could not be expected to press India to undertake a disarmament commitment that it itself belittled. The domestic debate about the agreement hardened India's opposition to it, the rightwing fearing that the nuclear arsenal would be unduly constrained. Traditionally, however, India has had a high profile on disarmament issues, and under the influence of recent US policies it revived that declaratory policy. It continues to support the proposal for a nuclear-weapon convention to abolish such weapons worldwide on an agreed timeline. As the controversies about it are put to rest, it may therefore see fit to make such a commitment, especially if, in the meantime, progress is made on disarmament and non-proliferation matters.

\section{Assessment}

If India exploits its capacity fully, it can produce in the order of 50 nuclear weapons per year without violating the Agreement. That would trigger an arms race with Pakistan and China. Pakistan tries to match India as best it can. 
China has shown impressive restraint over the decades. Challenged by the evolution of the US force posture, it modernises and expands its nuclear forces at the risk of provoking India, but with no special intention of doing so. China tries to maintain its retaliatory capabilities while avoiding steps that may lead to a more demanding security environment. This is a delicate balance, conducted in the best interest of domestic economic and political development and reform. India has never defined what "minimal deterrence" should mean. It justifies its force acquisitions in reference to China, but has no interest in triggering any arms competition with it. Its maximum production capacity is therefore of little or no practical interest. However, India also has a balancing act to conduct between China and Pakistan, building a nuclear arsenal that addresses both without being trapped into arms-racing.

For the Bush administration, a strategic partnership with India was a major foreign-policy objective. ${ }^{21}$ Widely criticised for its hard-nosed, militaristic foreign policy - and for the failures in Iraq and Afghanistan in particular - a diplomatic success was in high demand. A breakthrough in relations with one of the heavyweights on the Asian scene would be a major achievement. Critics, therefore, claim that the United States entered the negotiations at a disadvantage: if you fall in love with a commodity before the price is fixed, you end up paying more than is strictly speaking necessary. However, pressures for such a partnership had been building up in India, too. India worked hard to become a legitimate partner in international affairs, especially after the tests in 1998, and the nuclear deal lifted it from a lower tier of nations to a bona fide partner with the United States and other big and small nations. Much was therefore at stake on both sides. Both had a keen interest in closer relations. The fact that the Agreement was passed with the smallest of margins in India, while both Houses of the US Congress endorsed it with big majorities, suggests that if any of them could have offered more without risking defeat at home, it was the United States rather than India.

Non-proliferation critics charge that the United States gave priority to economic interests and geopolitical considerations at the expense of nonproliferation concerns. This impression is shared by many supporters, too. On the other hand, what more could the United States have obtained, given its own devaluation of many elements of the non-proliferation regime?

The critics seem to ignore India's new-won economic and political strength. Powers that are strong and about to grow even stronger usually have the confidence to pursue their interests with particular vigour, and India is no exception. India shows greater respect for international rules, norms and standards than the United States did at the time the Agreement was negotiated, but like so many other states in the East and South it cares very much about its sovereignty (see Chapter 1). In its current phase of rapid growth, India stiffly opposes external attempts to dictate its foreign policy. The United States never had a say in Indian affairs anywhere near its influence in, for instance, Pakistan and many countries in the Middle East and East Asia.

Still, in some respects the nuclear deal was important enough to warrant accommodation to US interests. US attempts to line India up against Iran were 
painful for India. On two occasions - in September 2005, when the IAEA Board of Governors declared Iran to be in past non-compliance with its safeguards obligations, and in February 2006, when the Iran file was sent to the UNSC India voted with the United States. On both occasions, it may have yielded to US and Western pressure not to jeopardise the deal. Had it not gone with the majority, it could also have complicated India's relations with Israel, its second largest defence supplier. ${ }^{22}$ Later, the Hyde Act underlined the importance of securing India's "full and active participation" in US efforts to block Iranian attempts to acquire weapons of mass destruction (WMD), and asked the administration to report on the steps that India took in this connection (Hyde Act, Section 103(4)). The United States also lent on India to cancel the plans for a gas pipeline from Iran via Pakistan. However, it was the security environment in Pakistan and Afghanistan that held it up: US pressure was rebuffed. While India had reasons of its own to oppose another NWS in the region, it kept stressing that it had friendly relations with Iran. ${ }^{23}$

Once the Agreement was clinched and the sanctions were lifted, India was free to pursue its own priorities with great determination. However, the Indian opposition remained suspicious of hidden concessions to the United States, and kept questioning the government about it.

Did the gains of the Agreement come at the cost of diminished commitments to non-proliferation by others? Many non-proliferation experts argued that the Agreement amounts to a reward for bad behaviour and that as a consequence, other states would feel less committed to the Treaty. They feared that some states would actively exploit it for objectives of their own other than nonproliferation. In particular, the critics argued that the Agreement left the door wide open for Israel and Pakistan to emulate it, using the Indian precedent to gain access to the international nuclear market, irrespective of their weapon acquisitions. Iran and other NPT members in dubious standing might see fit to do the same. Why should Iran be punished on mere suspicion of weapons intent when India, a non-member and a declared NWS, was granted full access? In the view of some, the cause of non-proliferation would have been better served by sticking to the full-scope safeguards requirement as a condition of supply, avoiding any exception to the NSG rules. In the view of others, the Agreement is flawed for lack of non-proliferation and disarmament commitments from India.

The worries about Israel and Pakistan are exaggerated, however. They are far from being in a position to benefit from the 123 Agreement. True, Pakistan wants an agreement with the United States similar to India's, and it has been speculated that China and Pakistan may emulate it. Israel has also explored the possibility of being exempted from the NSG guidelines. However, Pakistan has not reoriented itself the way India has, and does not enjoy the same status. It is not a state in proper export control standing: for years, it violated the rules of international nuclear commerce and governmental institutions remain weak. This is not the time, therefore, to invite the NSG to make an exemption for Pakistan. China did not try, anyhow. Its gigantic, domestic modernisation project depends on harmonious relations with the outside world, and provocative foreign-policy 
experiments are alien to the decision-makers in Beijing. China hardly appreciates the US-India agreement - certainly not its geopolitical aspects - but went along with it so as to not antagonise the United States and others. Israel does not admit to having nuclear weapons and is therefore not prepared to draw any separation line between civilian and military programmes. It follows that it is not in a position to claim exemption from the NSG guidelines in reference to India.

Iran criticised the NSG for making the exemption: "It is in the direct contravention with the Treaty [NPT] ... to engage in nuclear cooperation with any State whose nuclear facilities are not under IAEA full-scope safeguards" (NPT/ CONF2.2010/PCIII/WP.7, paragraphs 11 and 12). The criticism was muted, however. India is important for Iran and so are other Asian states. Russia and China, the Asian members of the P5, are holding back on UN sanctions, and India is a big potential customer of Iranian petroleum. Economically, Asia is about to become a comfort zone for Iran, compensating for the restraints that are imposed by the Western world. In the history of Iran, relations with countries to the East and North East have been at least as important as relations westwards. A reorientation in that direction therefore means resumption of long traditions.

Arab states strongly criticised the exemption and continue to do so, mainly out of concern for the potential implications for Israel. Other NAM countries likewise, although at the IAEA Board of Governors meeting on 1 August 2008, several NAM members gave broad support to the conclusion of the new safeguards agreement with India ${ }^{24}$ and, implicitly, to the NSG exemption. ${ }^{25}$ Some NSG members that argue for stricter non-proliferation provisions may have succumbed to pressure from the United States and others, but the great majority willingly supported the Agreement. States in the South (Argentina, Brazil, South Africa) as well as vendors in the North came out in favour. No NPT member has signalled reduced support for the Treaty because of the exemption, and no one has withdrawn from any other part of the international non-proliferation regime. In the future, those who favoured stricter provisions will shift their attention from criticising the Agreement to becoming first-line guardians of the nonproliferation commitments that were listed in the NSG decision and work for further restraints. The NSG decided to review the implementation of the Agreement on a regular basis.

In one way, the US-India agreement is stricter than the NPT; in another, more permissive. The permissive part concerns the disarmament commitment of Article VI. The agreement contains no commitments in this respect. The stricter part concerns the fact that, under the NPT, the NWS are free to assist each other in developing nuclear warheads and in testing them; to receive from any state the material necessary to pursue their nuclear-weapon programmes; and to decide by themselves whether, and to what extent, they should accept international controls over their peaceful activities.

The US-India agreement does not provide the same privileges for India. The United States wanted to ensure that India applies world-class export controls, blocking Indian contributions to any and all weapon-oriented programmes. Furthermore, by separating military and civilian activities and putting all civilian 
activities under safeguards, suppliers would know that they do not contribute to India's military programme, although the line between civilian and military applications is not watertight and probably never can be. The prohibition of enrichment, reprocessing and heavy-water technology transfers - in the NSG guidelines, but not explicated in the agreement - corroborates it.

In the long run, policies are best when based on facts and not on fiction. The fact is that India is an NWS and is unlikely to eliminate its arsenal any sooner than any of the five. Since it cannot become a member of the NPT, this means that the only way to commit it to the principles and practice of non-proliferation and disarmament is to urge it to behave "as if" it were a member of the Treaty and commit it to all other relevant parts of the non-proliferation regime. The US-India agreement is a step in that direction - a building block that may lead to full-scale involvement in the regime. The warnings of negative effects, so strongly propounded by alarmist non-governmental critics, were exaggerated.

Given the differences between the three outliers, there was always a case for addressing them separately, one by one. The US-India agreement, specific for India, confirms it. However, it suggests certain options for Israel and Pakistan as well. If they follow the Indian example and move closer to the international regime, similar agreements may sooner or later be agreed for the other outliers. For all of them, however, there is a point at which they cannot be brought deeper into non-proliferation and disarmament endeavours unless they are formally recognised - de jure - for what they are, i.e. NWS.

\section{Recognition}

Unless international law has a life of its own, disconnected from the realities of the world, de jure recognition of India is a matter of time. The question is not whether it will happen, but when and under what circumstances. Still, it is a touchy question that merits thorough examination. In the following analysis of arguments for and against recognition, "recognition" is used in the full de jure sense of the term.

First, representatives of some states have indicated that, if the nuclear club were to be enlarged beyond the five, they might have to reconsider their nonnuclear status. For instance, such voices have been heard in Japan, despite the difficulties that this would pose in the consensus-minded Japanese political system and the pain that nuclear issues evoke among the victims of nuclear bombing. In effect, however, India has been an NWS for a long time: if these states could live with the reality of Indian nuclear weapons, they should be able to live with the formality of it as well.

For Japan, like the United States, geopolitical factors favouring closer relations with India out of concern for China, and economic interests in the Indian market, played a role in this connection. In the end, the 123 Agreement did not trigger any national debate about Japan's commitment to the NPT. During the NSG deliberations, the countries urging India to enhance its non-proliferation commitments were non-proliferation stalwarts, such as Austria, Ireland, New 
Zealand and Norway, not states that acceded to the NPT on the ground that there would be five NWS only.

Second, none of the countries that entered the NPT on the understanding that there would be only five NWS - Algeria, Argentina, Brazil, Japan, South Africa and South Korea - can credibly claim that their security is jeopardised by the nuclear-weapon acquisitions in South Asia. As India acquires missiles of longer range, some of them may come within their reach. Still, it would be far-fetched to argue that the formal aspect - recognition of the nuclear facts - is a factor upsetting their security calculations. States base their security policies more on tangible facts than on formalities.

However, there is a category between tangibles and formalities - political perceptions of prestige and civilisational pride - that affect security policies. For instance, deterrence relies not only on tangible facts but also on impressions of willpower. Recognition would be a sign of success and strong will on the part of those who were determined to follow through on their nuclear ambitions. In a sense, recognition would not only recognise India's nuclear assets, but pay tribute to its assertiveness and willpower as well, leaving other states a bit inferior in comparison.

Third, while being harshly criticised in 1998 and for some time thereafter, the 123 Agreement took India off that hook. Clearly, this is a relief for Delhi. However, it should not be seen as a concession: to drop a policy that did not work is no reward to others.

Fourth, does recognition bring a bonus in terms of higher status in the international system? It probably does. At least in rudimentary terms, states distinguish between the mighty and the less mighty, and adjust their behaviour to that ranking order. Nuclear weapons have not been used since 1945, but they remain attractive because they translate into status and weight in the international system. As long as they are perceived this way, they function accordingly.

Higher status for some means lower status for others, so there is a feeling among some NNWS that higher status for India will leave them at a loss. For instance, India's nuclear programme may be invoked against a permanent seat in the UNSC, not to provide any reward for the 1998 tests and not to extend the unhappy combination of between permanent membership and nuclear weapon possession, but in the long run such arguments are likely to dissipate in favour of gross size and weight, to which its nuclear weapons contribute. So there is probably a bonus to be reaped both in absolute and relative terms.

Fifth, the agreement provides full access to civil nuclear technology in return for (marginally) stronger non-proliferation commitments. Some see this as a reward for imprudent behaviour; others consider it a win-win situation. If it leaves the impression that hereafter threshold countries could move ahead to test, gain access to nuclear technology and be recognised as NWS - on the Indian precedent - the implications are clearly unfortunate for the cause of nonproliferation. However, no other case is quite comparable to India (Israel and Pakistan). Should other states want to go nuclear, they would have to renege on their NPT commitment. 
Sixth, are there other ways in which recognition of India as an NWS would encourage other states to follow suit? Could NPT members contemplating acquisition of nuclear arms prepare themselves under the umbrella of the Treaty, give three months' notice of withdrawal, and then try to soften the pressure levelled on them by offering to walk in the path of India and abide by the provisions of the NPT "as if" they were members?

It is important to rule this possibility out. The 123 Agreement should be accompanied by intensified efforts to make the non-proliferation regime universal and further proliferation more difficult. New instruments and procedures should be devised to make it harder to leave the NPT. A variety of ideas have been aired in recent years (see Chapter 9). India should be asked to participate actively in the development of such measures to ensure that the 123 Agreement would not make proliferation less difficult.

Seventh, as noted above, recognition of India qua NWS would make it possible to draw it into arms-control arrangements from which it is now excluded. It could be asked to extend security assurances to members of NWFZ; a bilateral no-firstuse commitment between India and Russia might be possible, on the model of an existing exchange of letters between the leaders of Russia and China containing such a commitment; or a trilateral agreement to this end could be considered. If the United States and Russia were to reduce their arsenals to no more than 1,000 operative weapons while inviting the other NWS for multilateral disarmament negotiations, excluding India and others on the ground that participation would confer recognition on them would be absurd. Given that we are dealing with an NWS that has come to stay, it would be unwise not to extract commitments from it.

All told, the advantages outweigh the costs. The cost is, first of all, the enhanced status that recognition confers on India. This is nothing new, but reconfirmation of the status benefits of nuclear weapons is bad enough. The main advantage is that recognition allows for Indian involvement in arms control and disarmament agreements. Since India stands to gain from being recognised, it should be invited to undertake additional arms control and disarmament commitments, on the basis of a list of criteria to be applied to all three non-parties. All states - the members of the NPT as well as the non-parties - should be drawn into a new consensus on non-proliferation and disarmament based on the grand bargain of 1968 .

\section{Reconfirming and realigning the grand bargain}

What does it mean to draw the outliers into a new global consensus on nonproliferation and disarmament? What is required of them and how much do they have to change? Tying into the ten requirements of a new global consensus outlined in Chapter 4, eight of them have implications for one or more of the three non-parties.

First, in the NPT, it is the weapons that are the units of account, not their possessors. India and Pakistan follow the NPT in this respect, while the Israeli position is ambiguous. 
Second, negotiations must be reinstated as a bona fide modality of nonproliferation policy. The Obama administration set out to do so. India and Pakistan also favour negotiations, while Israel has little faith in such an approach towards Iran. Rather, it believes in the utility of military force.

Third, in international law, preventive attack against an opponent who may or may not become a real threat in the future is not permitted. Such attacks are at odds with the non-proliferation regime, which is part and parcel of international law. In Israel, preventive attack has been military doctrine for more than 25 years ${ }^{26}$ and advocated as a means of last resort to stop the Iranian nuclear programme. India and Pakistan do not favour preventive attack against the nuclear programmes of other states, and have agreed not to attack each other's nuclear facilities.

Fourth, in the field of verification, the principle is adequacy. The operative meaning of it has to be adjusted from time to time. ${ }^{27}$ India has accepted that standard for its civilian activities. Israel and Pakistan stay with pre-NPT facilityspecific INFCIRC 66-type agreements.

Fifth, reconfirming the basics is very much about re-establishing the original balance between the pillars of the NPT: non-proliferation, disarmament and peaceful uses of nuclear energy. Among the outliers, Pakistan is known to be one of the worst proliferators ever. On nuclear disarmament, India has been more vocal than the others. All of them would like to be admitted into the international market for nuclear material, equipment and technology, but for Israel this has been a lower priority than for the South Asian states. India and Pakistan have been world champions in criticising the NPT for being unbalanced and discriminatory, and the NWS for being hypocritical. After 1998, that criticism has abated, but it remains a significant undercurrent in both countries. Israel has been low-profile in this respect.

Sixth, all parties to the NPT are obliged to work for nuclear disarmament. India and Pakistan have criticised the NWS vehemently for their failure to disarm - the United States and the Soviet Union/Russia in particular. Today, the aggressiveness of their disarmament advocacy is gone. Instead, they are trying to fend off global measures to implement the first part of Article VI - "cessation of the nuclear arms race at an early date" - which includes a test ban and a cut-off. Israel was never very outspoken on behalf of nuclear disarmament, in reality being an NWS itself from the late 1960s, and has been wary of criticising its close partner and security guarantor, the United States.

Seventh, the relationship between counter-proliferation and non-proliferation is ambiguous and complex. Counter-proliferation threats may supplement the regime in the best interests of non-proliferation - adding a deterrent capability to a regime that is very weak on means of enforcement - while actual use of force may undermine the same objective. The aim must therefore be to live with the differences between non-proliferation and counter-proliferation as best one can, and exploit opportunities to make them mutually re-enforcing. This is a delicate challenge for non-parties as well as parties to the NPT.

Eighth, for international regimes to function properly, some important actor or actors have to exercise leadership. The roles of India, Israel and Pakistan can only be secondary in this respect, for the very reason that they are outliers. 


\section{Proliferation problems}

India's orientation towards the existing arms-control order makes it easier to forge a new consensus on non-proliferation and disarmament.

\section{Summary and conclusions}

The US-India agreement recognises the fact that India is an NWS. By endorsing the agreement and exempting India from the NSG guidelines, all NSG members did the same.

Sooner or later, de jure recognition of India as an NWS will follow. International law - which currently holds that there are only five nuclear powers - will have to be reconciled with the realities of the contemporary world. The question is: under what circumstances would it be appropriate to make that happen?

Except for the disarmament clause of Article VI, India has committed itself to the provisions of the NPT. It seems well on its way to an Article VI commitment, too. In October 2006, it outlined a set of proposals for nuclear disarmament, determined that its post-1998 alignment with the existing arms-control order should not erase its traditional push for disarmament. At the twentieth anniversary of Rajiv Gandhi's UN speech of 1988 outlining India's "Action plan for ushering in a nuclear-weapon-free world and non-violent order", Manmohan Singh (2009) expressed urgency with respect to the goal of an NWFW and stressed that measures to this effect would apply both to parties and non-parties to the NPT. At the Munich Conference in February 2009, India's national security advisor Mayankote Narayanan presented New Delhi's approach to nuclear disarmament, non-proliferation and arms control, stressing their interconnectedness and outlining a set of steps on the way to an NWFW. The pronouncements at the Rajiv Gandhi anniversary were clearly inspired by the American "gang of four", and the Munich speech, likewise, by President Obama's disarmament vision.

The new US policies have enabled India to revert to its pro-disarmament stance. To be fully recognised as an NWS, it plays on its disarmament credentials to curry favour both with the Western powers and with NAM countries. A formal Article VI commitment may, therefore, be near at hand. If and when it happens, India would have undertaken to behave "as if" it were a member of the NPT. One possibility, therefore, would be to wait for this commitment to come forward before extending de jure recognition to it, and let this be the standard that Pakistan must live up to in order to be treated the same way. Pakistan is far from that standard today, but for the sake of disarmament and non-proliferation NPT parties should encourage and assist Pakistan to get there. The prospect of an agreement similar to the Indian one could help it walk the last mile. ${ }^{28}$

Another possibility is a criteria-based approach applicable, in principle, to all outliers. It could build on the elements that were highlighted by the NSG when the exemption was made for India. They were:

- separation of civilian and military facilities and declaration of all civilian facilities to the IAEA, in accordance with the separation plan; 
- an agreement on the application of safeguards to the civilian facilities in accordance with IAEA standards;

- adoption of an Additional Protocol to the standard safeguards agreement;

- no transfer of enrichment and reprocessing technologies to states that do not have them, and support for international efforts to limit their spread;

- institution of a national export-control system capable of effectively controlling transfers of multilaterally controlled nuclear and nuclear-related material, equipment and technology;

- harmonisation of export control lists and guidelines with those of the NSG and a commitment to adhere to the NSG guidelines; and

- a moratorium on nuclear testing and a readiness to work with others towards the conclusion of a multilateral FMCT.

In addition, a disarmament commitment equivalent to Article VI; signature, if not accession, to the CTBT; limitations on fissile material production while waiting for a cut-off treaty to be negotiated, if not a moratorium; and, possibly, a stronger separation line between civilian and military activities may be required. ${ }^{29}$ This means a longer timeline for recognition than a mere "as if" requirement. So far, India has not been willing to sign the CTBT, and had the United States demanded a halt in the production of fissile materials there would have been no 123 negotiation. For Pakistan, which faces the same hurdles, it also remains to meet some of the criteria listed above, the export control requirement in particular.

For India, signature and ratification of the CTBT presupposes that the United States and China do so first. It may not be enough: in the domestic debate, some proponents of a thermonuclear capability claim that this cannot be achieved without further testing. But if other states in the "World Without the West" urge India to take responsibility for the global nuclear order by doing what the other NWS do, India's interest in being recognised as a global leader could lead it to cooperate - especially if the request is framed in India's long-standing quest for nuclear disarmament and addressed to a Congress Party government.

For an FMCT to be concluded, more will be required of the leading NWS, such as restrictions on ballistic-missile defence and militarisation of outer space. This may win enough time for India and Pakistan to acquire the fissile material stocks they deem adequate. India is unlikely to compromise on its ambition to build a minimum deterrent, and Pakistan will be no different. There is hardly any short-cut to nuclear arms control and disarmament in South Asia.

As for the separation line, the 123 Agreement fails to prohibit India from extracting tritium for weapons from its safeguarded power reactors, and permits free flow of personnel and information between safeguarded and unsafeguarded activities. This indicates that there is scope for further clarification.

Israel has signed the CTBT and may have enough fissile materials to agree to a cut-off. It probably finds it harder to accept the necessary verification arrangements. As long as it does not admit to being an NWS, there is no separation line to discuss and no recognition to consider. In this fundamental respect, Israel is 


\section{Proliferation problems}

unprepared for a criteria-based approach built on the US-India-type deal. However, its declaratory policy of opacity/ambiguity does not prevent it from making an "as if" commitment. For Israel, such a commitment would entail no significant sacrifice and no significant gain. It would be a gesture of good will.

As long as the outliers are not formally recognised for what they are, they cannot become parties to arms-control agreements qua NWS. For instance, they cannot be asked to extend security assurances to members of NWFZ. If they are to be involved in nuclear disarmament negotiations with a view to ambitious agreements affecting the arsenals of all NWS, de jure recognition of them is a sine qua non. Any serious pursuit of an NWFW must take them on board, so at some stage they have to be formally recognised as NWS.

The requirements for a new consensus on non-proliferation, disarmament and peaceful uses show that much more than Articles I, III.2 and VI is involved. There are fundamental modes of behaviour to be respected (unit of account, negotiations, commitment to international law); a proper balance between the pillars to be re-established; a delicate co-existence between non-proliferation and counter-proliferation to be managed; and a leadership role to be filled. Among the outliers, India is closest to the requirements for a new consensus, while Pakistan and Israel, in particular, are at a great distance from it.

When the US-India agreement entered into force, there was no similar agreement in the making. If there is another agreement, it may have to wait a long time. For India to comply with the demands of a criteria-based approach may take a long while as well, depending on where the bar is set. For some time ahead, the best approach may therefore be a pragmatic, incremental one, sensitising and committing both parties and non-parties to the requirements for a new consensus. 


\section{Rollback experiences}

\section{The concept}

Proliferation is about moves towards weaponisation. Rollback is a process in the opposite direction, reversing intentions and/or capabilities to acquire nuclear arms. ${ }^{1}$ Some states have rolled back to stable non-nuclear status. Others have kept a certain preparedness for going nuclear if changing circumstances so suggest. Yet others have rolled back and forth between different degrees of interest in the nuclear option and different degrees of material preparedness to exercise it. This is sometimes referred to as "nuclear latency".

Ariel Levite (2002-2003) defines rollback as "a governmental decision to slow or stop altogether an officially sanctioned nuclear weapons programme". Unauthorised weapon-related activities and private-sector research and development in weapon-related fields are not included in the definition. The distinction between sanctioned and unauthorised activities is not clear-cut, however: when scientists have had ample resources at their disposal and felt free to use them, they have sometimes "strayed off" into weapons-related experiments. Inadvertently or deliberately, the authorities may not have given accurate guidance, leaving a grey area that experts felt they could legitimately explore. Some such cases were discovered when the IAEA began to implement the Additional Protocol, among them South Korea, which conducted enrichment experiments as late as 2000. The Protocol enables the Agency to undertake a more comprehensive examination of the nuclear history of member states, inducing stricter governmental guidance of nuclear activities.

The definition includes cases where no explicit decision has been made to pursue the bomb, or where a governmental decision to acquire the bomb could not be ascertained. Because the lead times are long, such decisions are rarely made at early stages of a nuclear programme. It simply serves no purpose because, largely, preparations can be done under dual-use cover. ${ }^{3}$ Non-nuclear components of nuclear-weapon systems can, moreover, be developed in secret because the Additional Protocol does not allow the Agency to go beyond fissile materials and fissile material-related activities. If an early decision is leaked well before the weapon is in hand, it would be a major inconvenience. ${ }^{4}$ Better, therefore, not to run such a risk and conduct the programme under other headings, 


\section{Proliferation problems}

waiting to see how things unfold. Similarly, rollback processes often begin slowly and hesitantly and proceed incrementally. Clear-cut conclusions are seldom drawn until the trade-offs are apparent and the risks are minimised (Levite 2002-2003).

At the core of this wide definition is the distinction between states that have "done something" in the direction of the weapons option and then abandoned it, and those that have shown no interest. It leads to a list of 36 cases where some weapon-oriented activity or other has been conducted: 23 of them tried but gave up; four produced weapons or had them on their territories, but decided to eliminate and remove them (South Africa, Ukraine, Belarus and Kazakhstan); and nine became NWS (Muller and Schmidt 2010).

For the purpose of analysing proliferation and rollback, states may be grouped in five categories: rejection, hedging, restraint, active pursuit and acquisition. Three of them pertain specifically to rollback: rejection, hedging and restraint.

"Rejection" means that the option to acquire nuclear weapons has disappeared from the political agenda. Similar to the use of force in security communities, it is no longer being considered. It is not that the weapons option is discussed from time to time, but turned down: it has disappeared from the screen. Rejection means that weapons acquisition has become a non-issue.

Rejection may or may not be combined with dismantlement of relevant infrastructure. To roll North Korea back to stable non-nuclear status, dismantlement of most, if not all, of its nuclear facilities would be required. Even so, given the deep distrust in the North Korean government, a credible rejectionist posture can only evolve over time, or full confidence can be obtained by a change of regime - in North Korea or in the form of a reunified, non-nuclear Korean peninsula. In highly industrialised states, on the other hand, dismantlement may not be a practical option because a variety of dual-use technologies already exist in civilian sectors. There, the credibility of rejectionist postures rests on a national political consensus to disregard the nuclear option.

"Hedging" means maintenance of an indigenous capacity to produce nuclear weapons on relatively short notice, ranging from several weeks to a few years. A hedging strategy may be more or less sensitive to changes in the factors that condition it. It may be actively adapted to changing circumstances or it may be linked to a certain capability that is passively maintained irrespective of contextual changes. Hedging is a choice of strategic posture ranging from active to passive preparedness for nuclear-weapon production.

"Restraint" falls short of reversal but keeps states from proceeding to prominent nuclear activities such as testing of nuclear explosive devices, production of weapon-grade materials and construction of fuel-cycle facilities that may be used for military ends. For many years, India and Pakistan exercised various kinds of restraints. In terms of testing, India held back for almost 25 years: it tested a nuclear device as early as 1974, but did not proceed to weapons tests until 1998. South Korea and Taiwan have also been persuaded - by the United States - to exercise restraint. On other occasions they have been pressed to roll back. ${ }^{5}$ 


\section{The cases}

Using Levite's categorisation and Muller and Schmidt's update as of 2010, the history of nuclear rollback and nuclear proliferation looks as follows:

Sweden is a case of complete rejection. In the 1960s, after having built two plutonium production reactors and after a period of slow decline in the government's interest in the weapons option, Sweden concluded that regardless of what the NWS were doing, it would not be in Sweden's interest to acquire nuclear weapons. The conclusion was virtually unconditional. The only reservation was in reference to possible long-term developments making "nuclear weapons standard equipment of ordinary states" (Prawitz 1995; Cole 1997; Jonter forthcoming). Widely known as the "Swedish example", it inspired other governments to draw similar conclusions and join the NPT.

South Africa is the only state to have eliminated an indigenously developed, ${ }^{6}$ ready-made nuclear arsenal. When President de Klerk halted weapons production in 1989, seven gun-type uranium weapons had been built and number eight was under construction. The dismantlement of them began in July 1990 and was completed by June 1991, when all HEU had been removed from the weapons and transported to Pelindaba. South Africa signed the NPT on 10 July 1991; the safeguards agreement entered into force on 16 September; and the IAEA began its inspections in November. South Africa provided full disclosure - on a formula allowing the IAEA to go "anywhere, at any time, but for a reason" - enabling the Agency to confirm beyond doubt its reversal to non-nuclear status. ${ }^{7}$

The NPT permits the non-nuclear parties to move close to nuclear-weapon possession, first of all by allowing national fuel-cycle facilities. Only activities unambiguously related to weapon acquisition - such as work on warhead design, trigger mechanisms and other non-nuclear components of nuclear weapons - are prohibited. Advanced industrial states can cut these obstacles short, for relevant know-how exists in civilian sectors. They may come within a few weeks of ready-made weapons without doing anything illegal. In such cases, it is doubtful whether the safeguards system can provide any meaningful warning.

This leaves a wide range of hedging options. Japan is at the advanced end: it has high-capacity fuel-cycle plants, huge stocks of fissile materials, electronic trigger technology and the human expertise to build a large arsenal in a short period of time. Despite its "three nuclear principles" 8 and the constitutional prohibition of nuclear weapons, Japanese officials have emphasised that the principles may be revisited and the constitution reinterpreted. ${ }^{9}$ Germany is comparable to Japan capability-wise, but has no hedging strategy. Other European states, as well as Canada and Australia, are in a similar position, possessing advanced nuclear industries but with no intention to mobilise them for military ends. They are closer to Sweden than to Japan, and are usually considered rejectionist. Argentina and Brazil are parties to the Tlatelolco Treaty and the NPT and may be considered in a state of passive hedging, while South Korea and Taiwan which have rolled back and forth a couple of times - may be labelled cases of 


\section{Proliferation problems}

Table 6.1 Nuclear rollback and nuclear proliferation, country by country ${ }^{\mathrm{a}}$

\begin{tabular}{|c|c|c|c|c|}
\hline $\begin{array}{l}\text { Never tried } \\
\text { (nuclear } \\
\text { abstinence) }\end{array}$ & $\begin{array}{l}\text { Tried but gave up } \\
\text { (rollback) }\end{array}$ & $\begin{array}{l}\text { Attained but } \\
\text { gave up }\end{array}$ & Trying? & $\begin{array}{l}\text { Attained and } \\
\text { maintained }\end{array}$ \\
\hline $\begin{array}{l}\text { All other states } \\
(?)\end{array}$ & $\begin{array}{l}\text { Algeria }^{c} \\
\text { Argentina } \\
\text { Australia } \\
\text { Brazil } \\
\text { Canada } \\
\text { Chile }^{\mathrm{d}} \\
\text { Egypt }_{\text {Germany }} \\
\text { Indonesia } \\
\text { Iraq } \\
\text { Italy } \\
\text { Japan } \\
\text { Libya } \\
\text { The Netherlands } \\
\text { Nigeria } \\
\text { Norway } \\
\text { Rumania } \\
\text { South Korea } \\
\text { Spain } \\
\text { Sweden } \\
\text { Switzerland } \\
\text { Taiwan } \\
\text { Yugoslavia/Serbia }\end{array}$ & $\begin{array}{l}\text { Belarus }^{\mathrm{b}} \\
\text { Kazakhstan }^{\mathrm{b}} \\
\text { South Africa } \\
\text { Ukraine }^{\mathrm{b}}\end{array}$ & $\begin{array}{l}\text { Iran? } \\
\text { Syria? } \\
\text { Myanmar? } \\
\text { Others? }\end{array}$ & $\begin{array}{l}\text { USA } \\
\text { USSR/Russia } \\
\text { UK } \\
\text { France } \\
\text { China } \\
\text { Israel } \\
\text { India } \\
\text { Pakistan } \\
\text { North Korea }\end{array}$ \\
\hline
\end{tabular}

Notes

a Turkey often figures in discussions of proliferation risks in the Middle East, both in reference to Iran and to European reluctance to let Turkey into the EU, but there is no evidence of specific moves in this direction. Also, there have been assertions, but no publicly available evidence, of nuclear aspirations in Finland and Greece. These cases have not been listed for lack of documentation.

b Ukraine had Russian nuclear weapons in its custody, although apparently not the codes to use them. The missile launch codes were in Russian hands as well. In Belarus and Kazakhstan, the weapons remained under Russian control while being on their territories.

c While it has been in the spotlight, little is known about the degree and circumstance of Algerian interests in nuclear weapons.

d Chile had a significant nuclear research programme and did not accede to the NPT until Argentina did. The two countries nearly went to war in the late 1970s. Muller and Schmidt (2010) nevertheless acknowledge a lack of conclusive evidence.

e North Korea tested a nuclear device in the autumn of 2006 and another device in the spring of 2009. It is not known whether it has deliverable nuclear weapons.

f Levite describes Spain as an uncertain case; Jo and Gartzke (2007) do not include it in their list of reversals.

active hedging. If there is a crack in the non-proliferation dam in East Asia, more states may reconsider their current status.

Rejection is not to say that nuclear weapons are out forever. The predictability of international relations is too low for guarantees to be issued..$^{10}$ However, for many states on the nuclear rollback list of Table 6.1 - Australia, Canada, 
Germany, Italy, the Netherlands, Norway, Romania, Spain, Sweden, Switzerland and Serbia - it will take major world-order changes to regenerate an interest in nuclear weapons.

Among those who attained nuclear weapons but gave them up - Belarus, Kazakhstan, South Africa and Ukraine - none show signs of rolling forth again (Potter 2009; du Preez and Maettig 2010). In the Middle East, Egypt's nuclear programme is rudimentary and in Saudi Arabia there is not much to build on. However, as Iran proceeds with its nuclear programme and as interests in nuclear power are growing, some states may adopt active hedging strategies (Egypt, Saudi Arabia, Turkey) (Dunn 2007; Varnum 2010).

\section{Theoretical approaches to proliferation and rollback}

\section{Realist assumptions}

The realist perspective on international affairs accounts for much of what proliferation and rollback is about. In an international anarchy, states need to deter potential attackers, and the gold standard of deterrence is nuclear. To turn states back from weapons pursuits, their security concerns have to be alleviated, either by reducing the threat or by enhancing deterrence in one or both of its basic modes, i.e. deterrence by defence and deterrence by retaliation. During the Cold War, the superpowers threatened each other's clients and responded by beefing up their extended deterrence postures, holding the clients under strict control and keeping proliferation at bay both in Europe and in East Asia. However, the dominant motivation was not fear of proliferation, but fear of the other side and competition for influence worldwide. The non-proliferation gains followed per implication, virtually free of cost. ${ }^{11}$ Neither the US nor the Soviet Union really confronted the question of what to pay to prevent proliferation (Dunn 2006). How much the big powers are willing to pay today remains unclear.

The one-dimensional nature of realist logic - of neo-realism in particular has a tendency to lead from anarchy to "life in a nuclear crowd". ${ }^{2}$ All nuclearweapon programmes have been justified in reference to security concerns, but the realist perspective exaggerates their importance and overrates the propensity to proliferate. Realists were quick to predict proliferation to tens of states, but although tens of states have the economic, technological and industrial potential to make weapons, there are only nine NWS to date. Realism fails to explain the gap between the large and fast-growing number of nuclear-weapon-capable states and the small and slowly growing number of actual NWS. ${ }^{13}$ It does not explain under what conditions security concerns trigger nuclear programmes and under what circumstances they lead to conventional responses, new alliance formations or other policy responses, nor does it explain the timing of policy shifts, for it tends to ignore national political cultures, shifting national economic and political trade-offs and individual preferences. ${ }^{14}$ In these respects, the idealist perspective, capturing domestic factors and individual mindsets, does better (Lavoy and Walker 2006). 
Realism comes in different versions, though. In the history of nuclear proliferation, the French rationale for nuclear weapons is the arch-realist one. De Gaulle stressed that the US would not sacrifice Chicago for Paris. Only a national finger on the trigger would do. This logic - fortunately not tested, but quite possibly valid - invited proliferation. It was underwritten by the fact that friends are not forever: the allies of today may be enemies tomorrow. The French doctrine was therefore tous azimut, i.e. the weapons were in principle turned in all directions.

During the Cold War, worst-case assumptions were notorious for their influence on security policies. In the 1990s the strongest physical manifestations of Cold War thinking were eliminated, yet worst-case assumptions remained important in the security policies of states. This century, threat-based policies were brought to new heights in reference to state as well as non-state actors. Even so, the pros and cons of nuclear-weapon acquisition are numerous and states are weighing the arguments. For instance, Iran is widely considered to be a rational actor susceptible to external incentives as well as domestic interests. Only when national existence is threatened (Israel) or regime survival is at stake (the communist regime in North Korea, the apartheid regime in South Africa) may it be attractive beyond doubt to possess the strongest of all weapons as an ultimate insurance premium. This is a softer type of realism: states that acquire the bomb may be buying themselves problems as well as opportunities, but if they are faced with existential threats and cannot rely on the help of a nucleararmed ally, they will ignore the potential difficulties and go nuclear (Ericsson 2001; Hymans 2006a).

In yet another version, T.V. Paul has introduced the notion of "prudential realism", which substitutes "most probable" threat assessments for the worstcase thinking of hard-nosed realists (Paul 2000). Prudential realism means that states "balance their interests and capabilities so as to minimize the security challenges they pose to others and in expectation of reciprocal benign behaviour in return". However, Paul did not offer prudential realism as the key to understanding nuclear rollback, but emphasised that there is no single overarching explanation of this many-faceted phenomenon.

Realists defend their alarmism partly in reference to proliferation as a continuum, ranging from different degrees of preparedness to ready-made operative arsenals. Even if the number of NWS remains in the one-digit range, many more states have moved closer to nuclear-weapon status. Overall, there is a proliferation slide which is not captured by the exclusive focus on testing as the defining criterion of an NWS (Hymans 2010). National capabilities are proliferating; hedging is widespread in East Asia and may become increasingly so in the Middle East; some cases are ambiguous as regards intent; and in two cases significant arsenals have been built under a strategy of opacity, without any confirmed testing (South Africa, Israel). ${ }^{15}$ However, the great majority of industrialised states possessing significant nuclear capabilities are rejectionist. Others are hedging.

Realists also defend themselves in reference to the NPT and the supply-side measures that they see as the core virtue of the non-proliferation regime. The 
NPT has been a success, and the regime has been heavily tilted towards export denials, export controls and safeguards. Supply-side policies have been useful, and when they have been shown to be ineffective and inadequate they have been heavily criticised by realists and others for that. However, realists are also responsible for the relative ignorance of other parts of the regime, notably the disarmament commitment of Article VI, and the combination of technology denial and failure to disarm undermines the trade-off on which the NPT is built.

\section{Idealist perspectives}

The importance of ideas manifests itself at three levels. At the international level, it is evident in the non-proliferation norm. As the NPT got more and more members, states found it increasingly important to subscribe to the norm in order to be in good standing (Rublee 2009). After a while, the Treaty got more parties than any other arms-control agreement. Except for India, Pakistan, Israel and North Korea, it has become universal. The NPT may have been more or less important in tilting states towards non-nuclear status, but once they have joined the Treaty they have taken a keen interest in ascertaining that other parties remain true to their Treaty obligations.

This century, the commitments to the NPT were weakened. A weaker NPT means a weaker non-proliferation norm, for the Treaty is the main standardsetter in the global nuclear realm.

Fortunately, the norm also rests on grounds other than the NPT, among them nuclear-weapon-free zones (NWFZ), which entail more comprehensive nonproliferation commitments than the NPT. ${ }^{16}$ Also, the norm is underwritten by the likelihood that those going for weapons will fall into disgrace. Even if the enforcement mechanisms are weak, states proliferate at the risk of becoming international pariahs. Being subject to sanctions at first, India was soon forgiven for what it did in 1998, but any future proliferator will be small in comparison and much more vulnerable to international reactions. A future proliferator would also have to violate the NPT, or withdraw in orderly fashion, whereas India never joined the Treaty and therefore broke no legal commitment.

At the national level, Etel Solingen (2007) finds a difference between proponents of openness towards the outside world and those who prefer to shut the world out. Not surprisingly, the former is more likely to turn the nuclear option down, while the latter are more inclined to keep it open or even to exercise it. Peter Lavoy (2006) homes in on the "nuclear mythmakers". Are there strong believers in the utility of nuclear weapons for national security and national status? How able are they to legitimise and popularise those assumptions among fellow elites and political leaders? To what extent are they able to integrate their views and preferences into governmental institutions and budget priorities? The focus on "national mythmakers" does not disregard external influences and challenges, and so does not belittle the relevance of realist perspectives. The difference lies at the level of analysis: where neo-realists operate at the systemic level, focusing on external developments that may trigger national responses, the 


\section{2}

mythmaker approach links those developments to policy debates and reorientations in the national political system.

Transitions between civilian and military rule crystallise the difference between openness and isolation. The nationalistic orientation and dubious legitimacy of military rulers tend to turn them into outcasts. If economic, technological and industrial capacities enable them to conduct a significant nuclear programme, they may try to solidify their positions by going nuclear. Such rulers may be favourably disposed for the nuclear option from the outset, and the negative feedback they receive from the surroundings may tempt them to exercise it.

The Swedish experience highlights the importance of military strategy in national debates. The leading opponents of nuclear weapons - Alva Myrdal and Inga Thorson - deemed it particularly important to do better than the military officers in strategy discussions. They were keenly aware that, while the listeners might not understand all of the arguments - some of them too complex to be grasped by non-professionals - they sensed very well who won the debates. If they could beat the military on their home ground, the rest would be easier to manage. They therefore prepared particularly well for debates about military strategy.

At the individual level, case studies of leaders from France, Australia, Argentina and India suggest that leaders with definite nuclear-weapon ambitions differ from the great majority of others in their conception of national identity. Seeing their nation as "both naturally at odds with an external enemy, and as naturally its equal if not its superior", they have been dubbed "oppositional nationalists" (Hymans 2006b). Driven by fear and pride - i.e. a combination of security and status motives - oppositional nationalists go for nuclear weapons not merely as a matter of calculation, but as a matter of self-expression. Unlike most of their peers, who find it hard to make a rational assessment of the pros and cons of weapons acquisition given all the uncertainties about the consequences, for oppositional nationalists the choice of nuclear weapons is neither a close call nor a possible last resort, but a matter of necessity.

On the rollback list, de Klerk was the right man at the right time in South Africa. The December 1988 agreement which provided for the withdrawal of 50,000 Cuban troops from Southern Africa presented an opportunity to place South Africa's identity anchor in the Western community of nations. As the security concerns receded, de Klerk grabbed it and spearheaded the decisions that made South Africa a bona fide entity in international affairs: transition to majority rule and elimination of nuclear weapons. Some 15 years later, Colonel Gaddafi of Libya made a similar choice, burying all efforts to acquire nuclear weapons and earning goodwill from the US, the UK and the rest of the Western world. From the mid-1980s, the presidents of Argentine and Brazil held converging views on the importance of building confidence between their nations, leading to the Common System of Nuclear Materials Accountancy and Control and its implementing agency ABACC, accession to the Tlatelolco Treaty and membership of the NPT (Brigagao 2009). 
Both realists and idealists have to attend to the technical, economic and political feasibility of nuclear-weapons acquisition. In South Africa, scientists demonstrated the feasibility of building nuclear weapons at a time when the country felt increasingly threatened by enemies both in the region and internationally. Security concerns merged with the practical feasibility of a focused, costeffective programme that produced half-a-dozen bombs. In North Korea, an indigenous programme developed with Soviet assistance reached the point where it could produce significant amounts of plutonium right at the time the Cold War came to the end and the Soviet Union and the security guarantees it had issued disappeared. From then on, the nuclear programme became the lifeline of the communist regime in Pyongyang, leading to a first nuclear test in 2006. In Libya, on the other hand, Colonel Gaddafi tried and failed to purchase nuclear weapons from China and bomb production materials from India, Pakistan, the Soviet Union, Argentina, Brazil and Belgium during the 1970s and 1980s and from the Khan network in the 1990s and 2000s, but gave up in favour of integration into the existing Western economic and political order.

\section{Quantitative analysis}

In a quantitative analysis of the 36 cases listed above, Muller and Schmidt examine existing propositions in the field, adding to our understanding of proliferation/de-proliferation dynamics.

Comparing the building of research reactors with the conduct of weaponrelated activities, they find no support for the hypothesis that proliferation is technology driven. A growing number of states have such reactors, but a decreasing number are using them for nuclear-weapon activities. The hypothesis is further refuted by the fact that more states started nuclear-weapon activities before they acquired research reactors, and more finished them after they did so.

Neither do they find support for the hypothesis that an alliance with an NWS prevents NNWS from embarking on weapon activities. ${ }^{17}$ If anything, there is a tendency in the opposite direction. The strength of alliance guarantees does not seem to matter either. This is not to deny that, in single cases, alliances have played a key role in the renunciation of nuclear-weapon options. In East Asia this is documented beyond doubt. Statistically, however, the relationship is not significant.

Another realpolitik assumption - that states do not dare to proliferate if the big powers are strong enough and flex their muscles; the "high posture" hypothesis (Schoettle 1979) - is refuted as well. Rather, there has been a tendency in the other direction: after the Cuban crisis and the conclusion of the Partial Test Ban Treaty in the early 1960s, proliferation stagnated; the stagnation continued during the détente of the 1970s; there was a slight change of trend during the new wave of Cold War in the first half of the 1980s; and with the relaxation of tensions from the mid-1980, terminations accelerated.

The most important finding relates to the international non-proliferation norm, which can be traced back to the so-called "Irish Resolution" adopted by the UN 
Table 6.2 Initiation and termination of nuclear-weapon activity before and after 1968

\begin{tabular}{lll}
\hline & Before NPT & After NPT \\
\hline NWA Start (\%) & $41(24$ of 58) & $16(13$ of 83) \\
NWA Stop (\%) & $13(3$ of 24) & $68(23$ of 34) \\
\hline
\end{tabular}

General Assembly in December $1961 .^{18}$ The norm was harnessed by the entry into force of the NPT in 1970. Distinguishing between states that were independent before 1960 and states that gained their independence later, the emerging norm had a distinct impact on the way the new states conceived of proper behaviour in the security field. For the old states, the impact was lower. In the words of the authors, "the Irish resolution appears to have influenced the stagnation of proliferation in relative terms, ${ }^{19}$ [and] with the conclusion of the NPT negotiations the stagnation of proliferation began also in absolute terms."

The significance of the NPT is borne out by the following table showing initiation and termination of nuclear-weapon activity before and after the conclusion of the Treaty: ${ }^{20}$

Not surprisingly, the authors also find that democracies are more sensitive to the non-proliferation norm than other forms of government, and that democratisation - the transition from authoritarian to democratic systems - contributes to norm conformity. Democratising states feel a particular need to posture as normabiding.

Finally, little support is found for the hypothesis that governments that open up to the outside world are less proliferation prone than those that shut the world out. The liberalisation thesis advanced by Etel Solingen is not refuted, but each case must be examined on its own merits. ${ }^{21}$

\section{Lessons from Iraq, Libya and Syria}

Recently, there have been three prominent cases of nuclear rollback: Iraq, Libya and Syria. What are their experiences, and how relevant are they for other rollback efforts?

\section{Iraq}

Iraq was effectively disarmed by UNSCOM (the UN Special Commission in Iraq) and UNMOVIC (the UN Monitoring and Verification Mission Commission). Shortly after the first Gulf War in 1991, elimination of the secret Iraqi nuclear-weapons programme of the 1980s had been accomplished. Saddam gave up, and never tried to bring any part of the programme back on track (Blix 2004; Cirincione et al. 2005).

The background for the UN disarmament mission in Iraq was very special. The 1991 war and ceasefire Resolution 687 of the UN Security Council set the stage for it. The air prohibition zones over northern and southern Iraq further 
restricted Saddam's freedom of action. Except for a brief period of time immediately after the Second World War, this was the first and only time in the history of the UN that the Security Council functioned more or less the way the authors of the UN Charter had hoped. It did not last long - by the mid-1990s, big power cooperation was once again on the decline - but the liberation of Kuwait and the constraints on Saddam happened in the cooperative spirit of that period. Not only were the conditions for UNSCOM dictated by force: there was agreement on them at the UN. This was special to the point of being unique.

The Iraqi experience had a number of constructive spin-offs. When the nuclear-weapon programme of the 1980s came to the fore in the aftermath of the war - the IAEA had failed to discover it - this became the impetus to the Model Additional Protocol to the standard NPT safeguards agreement. In the years that followed, UNSCOM and UNMOVIC became rich sources of verification experience, inspiring new ideas of how effective verification could best be organised and implemented.

After the second Gulf War in 2003, the inspectors were proven successful. They had been right and US and other national intelligence agencies woefully wrong. Obviously, big power disinformation campaigns had not disappeared with the Cold War, giving a major boost to the standing of international inspections. To the extent that reliable information is important for the progressive conduct of nonproliferation policies, international inspections are vital. They must be allowed to run their course, however lengthy and tiresome the process must be, and international institutions should be used and empowered, not bypassed by unilateral action. These may be the main lessons of the Iraqi experience.

\section{Libya}

What can we learn from the case of Libya? Can anything be generalised and applied elsewhere, or is this another unique case?

Rollback did not occur by a major change in the Libyan political system, as was the case in South Africa, Brazil, Argentina, South Korea and Taiwan. Nor was it the result of public diplomatic campaigns and economic assistance, as was the case with Belarus, Ukraine and Kazakhstan. Sanctions seem not to have done the trick either, as the turnaround came in a period when the peak of sanctions had already passed. In other words: it happened in a period of systemic continuity (Bowen 2006; Muller 2007; Braut-Hegghammer 2008).

Rather, it seems that the turnaround was part of a major reconsideration of the utility of military-based power politics. Libya shifted from power to economic growth and welfare as the best way to keep the regime in power. In this respect, Colonel Gaddafi seems to have been under the influence of a younger generation of leaders, notably one of his own sons. In part, the long-standing diplomatic efforts by the EU to entice Libya into more cooperative relations with the Western world also account for the reversal, as do the determined rollback efforts by the USA and the UK (Muller 2007). The end result was a complete, supervised dismantling of WMD stocks and facilities. 
The Libyan case is reminiscent of the South African one. Like de Klerk, Gaddafi gave priority to normalisation with the West, abandoning his nuclear programme and aligning himself with the existing international order. Also like South Africa, Libya opened its nuclear programme for international verification, full-scale. It skipped its weapons programme in return for normalisation with the US and the rest of the world - similar to what North Korea says it would be willing to, on and off, without any change of government. Five years later, the Libyan political system remains much the same, while in North Korea it is commonly assumed that far-reaching normalisation will trigger major changes in the system of government.

\section{Syria}

In the night of 6 September 2007, Israeli fighter jets bombed a building complex at Al Kibar, Syria, next to the Euphrates river. Israeli and American intelligence had concluded that the target was a camouflaged nuclear reactor under construction, built in cooperation with North Korea. A photograph released by the intelligence agencies showed the head of the Syrian Atomic Energy Commission and a senior official of the North Korean nuclear programme standing together at the site.

Later, the IAEA confirmed that the complex bore features resembling those of a nuclear reactor; ${ }^{22}$ that the imagery of the site showed similarities with the graphite reactor building at Yongbyon; and that traces of uranium and graphite had been found on the site despite the fact that Syria had removed the debris from the bombed facility and covered the entire site with concrete. The Syrians said the complex was a conventional military factory, arguing that the uranium traces were of Israeli origin and that no foreigners had been involved at $\mathrm{Al}$ Kibar. However, they provided no documentation in support of their claims. By the turn of 2009/2010, much remained to be understood regarding the relationship to other nuclear activities in and out of Syria and about the procurement activities and the financial aspects of it all, but in essence, national intelligence seems to have had it right on this occasion.

Assuming that the target of the bombing was a nuclear reactor in the making, Syria had violated the safeguards agreement with the IAEA. The agreement obliged it to notify the Agency as soon as construction of new nuclear facilities starts. Israel in effect reiterated that it does not tolerate other nuclear-weapon states in the Middle East, but in so doing violated international law. The IAEA emphasised that as soon as the Israelis and the Americans had information about an illegal nuclear facility coming up, they should have notified the Agency. Instead, the IAEA learned about the bombing from the media, and was asked to search for evidence in the rubble.

To maintain its nuclear monopoly in the Middle East, Israel seems determined to take preventive action. This is the so-called Begin doctrine, named after Prime Minister Menachem Begin, who authorised the 1981 strike on the Frenchsupplied reactors in Iraq. The question is where the outer limits of the doctrine 
go, i.e. if it is applicable in the case of Iran. In large measure, the answer comes in terms of military capability: had the Iranian facilities been closer at hand and easier to destroy, they would have been bombed a long time ago. The nonproliferation regime is weak when it comes to enforcement, and Israel has no confidence in it.

\section{Lessons learnt}

Summing up, what are the lessons for policies of nuclear rollback? What does it take to turn would-be proliferators away from nuclear arms? What is the state of the art?

In the social sciences, all theses are conditional in one or more ways ( $x$ relates to $y$ in a certain way provided that $a, b$ and $c$ apply). The following is a list of propositions - i.e. hypotheses for which there is some evidence - that are all qualified in various ways. The qualifications, discussed at some length above, are only hinted at here.

\section{Alleviate security concerns}

All proliferators have invoked security concerns to justify their weapons acquisitions - even if, in reality, other factors may have been as or more important. Sometimes, threat perceptions have been alleviated through alliances, extended nuclear deterrence, other kinds of security assurances and improved conflict management.

South Africa traded its nuclear programme for normalisation with the West and bona fide status in international affairs. Libya's way out of the squeeze was similar. First, it tried to become a legitimate member of both the Arab and the African community of nations, but felt rejected and sought a stronger platform for itself by embarking on a nuclear-weapon programme. When that did not pay off, it dropped the nuclear programme altogether in return for acceptance by the Western world. In the South African case, regime change was another condition for universal acceptance, whereas in the case of Libya, state security was solidified without any change in the system of government. If Myanmar is doing something in the direction of a weapons option, these experiences may be useful in crafting policies to roll it back.

During the Cold War, the superpowers threatened each other's clients and responded by tying them closer to their own camps, thereby suppressing inclinations to proliferate. These non-proliferation gains were spin-offs of Cold War dynamics - in essence, non-proliferation for free. Much the same goes for the US-Japan alliance: while being a counterweight to China, it helps to keep Japan non-nuclear. Presumably, the US is willing to enhance the defences of South Korea and Taiwan - over again - if this is what it takes to prevent them from building nuclear weapons. However, as illustrated by Iran and North Korea, today it is unclear how much the big powers are able and willing to do to prevent proliferation. 


\section{Play status gains down/play status substitutes up}

Status ambitions do not always play any important role when states consider the nuclear option. For small and medium-sized states, strong security concerns can make status considerations next to irrelevant. For de facto NWS shying away from documenting and demonstrating their capabilities, rank in the international system obviously plays little or no role (Israel, South Africa). However, for the majority of NWS, the status gains have been quite important. For India, crossing the nuclear threshold may first and foremost have been a matter of status (Perkovich 1999).

The best way to reduce the status value of nuclear weapons is to scale the arsenals down and introduce doctrines that limit their functions. Unqualified assurances not to use or threaten to use nuclear weapons against NNWS are significant steps in that direction. No-first-use postures, limiting the functions of nuclear weapons to that of deterring others from using theirs, have an intriguing disarmament corollary as well: nobody would need them if nobody else had them (Halperin et al. 2009; Sagan 2009a). These are approaches that may work over time in a general fashion. They are not flexible enough to be of use in particular cases.

For less-industrialised countries, civilian nuclear programmes can be powerful expressions of technological sophistication yielding significant status benefits, especially if they include fuel-cycle elements that make them self-sustainable (Argentina, Brazil). In Iran, the national consensus on nuclear issues is built around an allegedly civilian high-technology prestige programme. Iran also wants to be recognised as an important actor in Middle Eastern affairs (see below, p. 130). Playing status substitutes up - applying imagination to such options across technological sectors, nuclear and non-nuclear, and in the structuring of international affairs - is therefore another, complementary approach to playing the status value of nuclear weapons down. ${ }^{23}$

\section{Diplomatic involvement to buy time}

This has been an element in many rollback campaigns. It may go on for years, waiting for external and/or internal constellations to offer special opportunities for diplomatic breakthroughs. In the end, this brought good results in Argentina and Brazil. In the case of North Korea, China and others have played for time and still do, hoping for propitious moments to appear.

The first steps away from the nuclear brink tend to be slow and incremental and sometimes non-linear. Continuous engagement and patience - watching the relative strength of different points of view and assessing the direction in which national debates are moving - is critically important in any diplomatic effort to influence the outcome. 


\section{Technology denials}

The International Nuclear Fuel Cycle Evaluation of 1979 predicted that, beyond the turn of the century, technology denials would no longer be effective. By then, nuclear technologies would be too widely spread for supply restraints to have much effect.

This prediction turned out to be premature. Even if proliferation cannot be stopped by technology denial, valuable time can still be bought this way. Over the years, technology transfers have been tightened and export controls enhanced. In particular cases, denials have been extended into broader sanctions regimes. Beyond winning time, however, the effectiveness of such measures is questionable. They may as well isolate the state of concern and harden its will to carry the weapons ambition through. There seems to be no general prescription: specific cases call for special measures.

\section{Individual mindsets}

Individual mindsets are important. When the Cold War ended and the Cubans withdrew from Angola, de Klerk seized the opportunity to take South Africa back from nuclear to non-nuclear-weapon status. In Argentina and Brazil, presidents Alfonsín and Sarney, Menem and Collor held converging views on the importance of confidence-building between their countries, resulting in full coverage for the Tlatelolco Treaty and accession to the NPT. Usually, a change of mindset takes a change of government, but not always: Libya's turnaround all happened under Gaddafi's leadership.

\section{Attend to the activities of mythmakers}

Myths grow out of strong convictions and are therefore hard to change (Lavoy 1993). Pro-nuclear mythmakers tend to argue the case for nuclear-weapon acquisition irrespective of changes in their environment. Zulfikar Ali Bhutto wanted nuclear weapons even if the Pakistanis had to eat grass (Time, in partnership with CNN 1985). Egypt's Nasser and South Africa's Vorster were also carriers of strong beliefs. To succeed, however, more is needed: how strong are their constituencies? How effective are they in converting their convictions into budgetary priorities? Mythmakers cannot be expected to change their minds, so they can only be stopped by technical, economic and political obstacles, or by removing them from power. At any given time and in any given country, multiple strategic myths may co-exist and compete with each other, widening the potential leverage of external actors.

\section{Beware of nationalistic governments}

Countries that abandoned nuclear-weapon programmes in the past, but maintain some significant capability, are cases of continued concern. South Korea and 
Taiwan have higher capability levels today than at the time of rollback 20-30 years ago. These countries remain sensitive to changes in the international security environment, and their policies may change with changes in their ruling elites. In India, it was a nationalist government that went ahead to test. In Argentina and Brazil, nationalist governments that claim a stronger role for themselves in international affairs may once again turn their countries towards the nuclear option.

\section{Pay special attention to oppositional nationalists}

Jacques Hymans has identified a particularly potent proliferation mindset: that of so-called oppositional nationalists combining fear and pride, security and status concerns. When leaders fear for the security of their nation and/or their own regime while thinking at least as highly of themselves as of their opponents, the temptation to correct this anomaly by launching a nuclear-weapons programme may be strong. Such cases are therefore among the hardest ones to roll back. Effective measures may be needed both to alleviate the security concerns and to satisfy national and personal pride. Iranian leaders illustrate this predicament. Iran is under threat, first of all from Israel and the US; in the nuclear field, the rich Persian civilisation is inferior to the young and shaky Pakistani neighbour, which is an NWS; and in the shia-sunni context the large Iranian nation represents the traditional underdog. These are strong asymmetries waiting to be corrected. To pin Iran down to non-nuclear status, a more secure Iran must be accepted as a regional player of significance in the Middle East (see Chapter 7).

\section{Eliminate the role of the military in nuclear programmes}

For reasons explained in organisation theory, the military, too, want to maintain and expand the role of their own organisations (Niskanen 1971). In Taiwan, Argentina and Brazil, the transition from military to civilian rule was crucial in steering their nuclear programmes away from weapons acquisition. In South Korea, General Park pursued the nuclear weapon option but opened the economy to the outside world (see below). Eliminating the role of the military means eliminating military rule: no military government is likely to delegate authority over any nuclear programme of significance to others.

\section{Encourage openness to the outside world}

Statistical support for the liberalisation thesis is meagre, but qualitative analyses of specific cases suggest that proponents of openness are less likely to seek nuclear weapons than governments wanting to shut the world out. One explanation may be that in a globalised environment where everything moves easily across borders, closed societies stand out as an aberration. The governments of such countries risk being beleaguered and may turn to nuclear options in response. 


\section{Encourage democratisation}

Democracies are more sensitive to the non-proliferation norm than other forms of government, and countries undergoing democratisation often find it particularly important to be seen as norm-abiding. Democracy means openness to the outside world: the root cause of the liberalisation hypothesis may therefore lie in democratic practice. $^{24}$

\section{Diplomatic and economic inducements may work}

For the three former members of the USSR - Belarus, Kazakhstan and the Ukraine - diplomatic engagement, security assurances and economic inducements were enough to make them drop whatever weapon ambitions they might have had. Economically, they received assistance roughly proportional to the difficulties they posed: Ukraine most; Belarus least.

Knowing that the US and its Western partners may be willing to buy wouldbe proliferators off, nuclear aspirants have sometimes played their ambitions up in order to maximise the compensation they might receive for pulling back. North Korea is famous for this tactic, demanding compensation for crises of its own making. At times, Italy, Pakistan, South Korea and Taiwan have also moved ahead on the nuclear-weapons path to raise US rewards for rollback (Levite 2002-2003).

\section{Apply the Additional Protocol}

Nuclear programmes are made up of hundreds of decisions, some of which may escape political control. If for no other reason, scientists and engineers may be tempted to take their research in new directions out of curiosity, without any long-term objective in mind. Application of the Additional Protocol, which goes beyond fissile materials to cover a wider set of fissile material-related activities, can help to institute a stricter non-nuclear-weapon culture.

\section{Nuclear disarmament}

During the Cold War, there were indications that big power détente and arms control were conducive to non-proliferation. Today, disarmament is high on the agenda along with arms control, but single steps towards disarmament may have little or no impact if there is nothing more on the cards. For instance, states of proliferation concern would hardly be impressed by further reductions in US and Russian arsenals as long as three-digit numbers remain, other NWS are caving in and modernising their systems, and the Chinese, Indians and Pakistanis are expanding their arsenals. However, if there is a dynamic interplay between the vision of an NWFW and specific measures towards that end, drawing all NWS into systematic and progressive reductions, would-be proliferators would find it harder to go ahead and be more easily targeted for countervailing action. It is 


\section{2}

more costly to work against an established trend than to work with it (for elaboration of the relationship between disarmament and non-proliferation, see Chapter 9).

\section{The non-proliferation norm}

The non-proliferation norm anchored in the NPT is essential for the cause of non-proliferation. Ensuring the viability of the NPT may be the single most important way to stem proliferation. Better and more balanced implementation of the Treaty is therefore of cardinal importance.

The non-proliferation norm is upheld by the nuclear-weapon-free zones (NWFZ) as well. Paradoxically, members of such zones can, nevertheless, present a particular challenge to the integrity of the NPT. They may withdraw from the Treaty, protesting the imbalanced implementation of rights and obligations, and do so with relative impunity, for they would still be under an international legal obligation to stay non-nuclear and be subject to NPT-type safeguards. If a number of NWFZ members were to do that, others may follow suit and the NPT unravel. The probability that this would happen may be low, but should US-Russian disarmament negotiations get stuck and the US disarmament ambition falter, it is worth watching.

\section{The crucial role of the $U S$}

The US has been effective in its rollback endeavours when it has been in a position to offset security threats facing potential proliferators. In Europe, alliance commitments contained and marginalised proliferation interests. In East Asia, enhanced security assurances rolled South Korea and Taiwan back. ${ }^{25}$ When the US itself has issued threats, such as in the ongoing disputes with Iran and North Korea, its policies have been dysfunctional. When the objective has been to overthrow another regime, that regime has had little incentive to negotiate.

For an international regime to function properly, somebody has to exercise leadership. The non-proliferation regime is no exception. While the Bush administration took a selective view of the NPT, the Obama administration is mindful of the totality of the regime and has assumed a high-profile leadership role. $\mathrm{S} / \mathrm{Res} / 1887$ went a long way to forge a renewed global consensus on nonproliferation and revived the NPT commitment to seek an NWFW (for criticism of the Resolution, see Chapter 4). 


\section{Challenge from within The case of Iran}

\section{Real and virtual arsenals}

The Nuclear Non-Proliferation Treaty (NPT) defines a nuclear-weapon state (NWS) as a state that had tested a nuclear explosive device before 1 January 1967. The five permanent members of the UN Security Council (P5) had done so: the Treaty therefore recognises them as NWS. All others should forego acquisition of nuclear arms.

By the testing criterion, another three states have become de facto NWS: India (1998), Pakistan (1998) and North Korea (2006). In addition, Israel is known to have a nuclear arsenal without any confirmed testing. North Korea acceded to the NPT in 1985, but left the Treaty in 2003 as the only country to have done so. Israel, India and Pakistan never joined. All other UN member states are parties to the Treaty.

Some non-nuclear-weapon states (NNWS) can build such weapons in a matter of weeks or a few months if they decide to do so. While the number of states possessing ready-made weapons has increased only slowly, there is concern that "virtual arsenals" may now be growing faster, nurtured and legitimised by the growing interest in nuclear power. The key to virtual capabilities is national fuel-cycle facilities and fissile materials on stock. Iranian leaders have indicated that they may seek such a status, similar to that of Japan. However, while "creeping in" under the testing criterion may be legal under the NPT, it is not necessarily legitimate. ${ }^{1}$

Proliferation is about moves towards weaponisation. Rollback is a process in the opposite direction, reversing intentions and/or capabilities to acquire nuclear arms. Throughout the nuclear age, more than 20 states have "done something" in the direction of a weapons option and then abandoned it. Another four have produced weapons or have had them on their territories, but have decided to eliminate and remove them (South Africa, Ukraine, Belarus and Kazakhstan). Some of the lessons from this underpublicised part of the proliferation/nonproliferation story shed light on the Iranian situation and what it may take to keep it an NNWS. 


\section{Reining in a virtual arsenal}

Non-proliferation policies should therefore aim at more than stopping states and non-state actors from actually acquiring the bomb. Virtual arsenals have a destabilising effect, especially in regions of conflict such as the Middle East, calling for transparency and constraints on such capabilities.

\section{Verification}

One such measure is implementation of the Additional Protocol (INFCIRC 540) to the standard NPT safeguards agreement. ${ }^{2}$ The Additional Protocol enables the IAEA to search for items that may not have been declared. Without it, the Agency can only verify the non-diversion of declared nuclear material and activities. Application of the Protocol may deter states from developing weaponoriented capabilities in secret, and make others more confident that they know what is going on. It limits the scope of uncertainty and the potential for suspicions and misunderstandings.

From November 2003 to February 2006, Iran allowed the IAEA to apply the Additional Protocol. In addition, it offered access to certain sites on a voluntary basis. In that period, there were more comprehensive inspections in Iran than in any other country in the world. Since February 2006, when the Iran file was transferred from Vienna to New York, Iran has not accepted the Protocol and declines Agency requests for voluntary transparency measures providing access to locations that may be related to the manufacturing of centrifuges, R\&D on uranium enrichment, and uranium mining and milling. Also, it no longer provides early design information of upcoming facilities. ${ }^{3}$ Gradually, the IAEA is therefore losing its overview of the programme. Presumably, Iran has spread nuclear equipment, materials and technology throughout the country, if for no other reason than as a precautionary measure in case it is attacked. ${ }^{4}$

Recurrent demands that Iran agrees to the Additional Protocol, provides early design information and offers voluntary transparency measures are made with the knowledge that nobody can prove a negative and in the hope that incriminating evidence will be found. Ostensibly requested in order to enable Iran "to come clean", they enhance suspicions as much as they build confidence. As long as Iran is widely suspected of having weapons intentions, and as long as it is under threat of military attack, there is not much hope of changing this predicament. The situation is increasingly untenable, because the closer Iran comes to a nuclear-weapon capability, the more important it is to place those capabilities under the best possible safeguards.

\section{Multinational fuel-cycle facilities}

Another possible restraint is multinationalisation of fuel-cycle facilities. This option, which comes in many versions, was thoroughly examined at the end of the 1970 s and once again by an IAEA study group in 2005, but never material- 
ised in regions of proliferation concern (SIPRI 1980; IAEA 2005). Multilateral facilities are intuitively attractive because they can be run in a joint decisionmaking mode and operated with "black boxes" that limit the transfer of advanced technologies. On his first visit to the UN, President Ahmadinejad mentioned the possibility of multinational fuel-cycle facilities in Iran. However, such proposals raise complex technological, organisational, financial and political questions and may lead to long and arduous negotiations. Far from being any quick fix, they can be excellent vehicles for buying time.

\section{Internationalisation of the fuel cycle}

From a regime point of view, internationalisation of all fuel-cycle facilities, existing ones included, would be better than occasional, multilateral ones. Special treatment of special cases may be warranted, but equal treatment is the regime norm. If backed by the big powers, which have such facilities themselves, other states would find it hard to resist. It may materialise as an adjunct to a Fissile Material Cut-Off Treaty (FMCT) stopping all production of fissile materials for weapons purposes: internationalisation would then apply to all the rest. Without an FMCT, a line would have to be drawn between military and civilian activities in the NWS. So far, that has been done in the UK, France and India, but not in the other NWS. However attractive, this is another long-term proposition that may consolidate a solution to the Iranian problem, but hardly something that can be implemented in time to help create it.

\section{Supply assurances to forego national facilities}

Yet another possibility is assurances of fuel supply, solid enough to convince states to forego national fuel-cycle facilities. Preparations for an international fuel bank are being made, centred on the IAEA. ${ }^{5}$ The flaw of such assurances is that they tend to preserve another distinction between haves and have-nots (in addition to that between NWS and NNWS), i.e. between those who possess fuelcycle plants and those who are encouraged and urged not to build them. This is objectionable on political grounds, and for states that have big deposits of uranium on their territories, enrichment may also be an attractive business proposition.

The Framework for a Long-term Agreement offered by the E3/EU on 5 August 2005 contained fuel assurances to Iran in return for halting all fuel-cycle activities there. The Europeans committed themselves to assist in the establishment of a buffer store of fuel, sufficient to maintain supplies for a period of five years. While international supply arrangements can never be as reliable as domestic sources of supply, and the buffer store would be located outside Iran, the credibility of these assurances were high. They were made by a group of states and communicated to all interested parties through an international organisation (the IAEA), and so could not be withdrawn by any single government. The IAEA was invited to monitor and certify the operation of it "on objective 
principles". The fuel assurances were the best part of the European offer. On other accounts, however, the offer fell short of expectations and was summarily rejected by Iran. ${ }^{6}$

\section{Limiting the scale of fuel-cycle activities}

Finally, a broader separation of civilian and military applications could be established by limiting the scale of fuel-cycle activities to a level below that required for weapons production. A compromise of this kind would allow for research and development on enrichment and/or reprocessing, and provide a mobilisation base for rapid construction of national industrial plants in case fuel supplies were interrupted. More than once, Iran has reportedly been ready to accept such a cap on its enrichment programme, but without anybody picking them up on it. $^{7}$ Believing that Iran would buckle under pressure, the Western demand was always that Iran should give up any and all fuel-cycle activities.

By August 2009, more than 8,000 centrifuges had been installed in Natanz (IAEA 2009). ${ }^{8}$ Second-generation centrifuges (IR-2), enriching uranium two-tothree-times faster than the first generation, were being tested. Iran insists on exercising its sovereign rights under the NPT and has made mastery of the entire fuel-cycle a matter of national pride. ${ }^{9}$ The nuclear programme is elevated above factional politics in Iran.

For Iran, the right to enrich on its own territory is a red line in any forthcoming negotiation. Anything less is unacceptable (ICG 2009). An opinion poll shows that 89 per cent of the population believe that Iran should master the uranium-enrichment process. Since President Obama took office, Iranian officials have also begun to argue that the Iranian nuclear issue is closed except for activities within the framework of the IAEA, and that the world has to come to terms with a nuclear Iran. ${ }^{10}$

\section{The politics of rollback}

Rollback is a process reversing intentions and/or capabilities to acquire nuclear arms. From a longer list of lessons from rollback experiences, ${ }^{11}$ the following appear relevant to the Iranian case.

\section{Alleviation of security concerns}

All proliferators have invoked security concerns. Other factors may have been more important, but security considerations have always been used to legitimise nuclear-weapon ambitions. Non-nuclear Iran is surrounded by NWS - Israel, Pakistan, Russia and the US - and therefore very conscious of the imbalances that this creates. ${ }^{12}$

At various points in their histories, the leaders of Israel and Pakistan became convinced that the possession of nuclear weapons would deter attacks on them, or limit how far an attacker would dare to go. Iranian leaders are of the same 
view, although in their overall assessment of the issue they may or may not favour nuclear weapons.

The Iranian programme was restarted in the midst of the Iran-Iraq war, when the country suffered very high casualties and was attacked with chemical weapons. Whether Iran knew of Saddam's secret nuclear-weapon programme is unclear, but if it did, this would have been another reason to bring the programme back up to speed. There is little doubt that it was the security arguments that made Ayatollah Khomeini - who originally turned his back on the Shah's nuclear ambitions - change his attitude in favour of resuming the programme.

These arguments were reinforced by the first Gulf War, which demonstrated that nobody could match US high-tech conventional power. Nuclear weapons were widely perceived to be the only "equaliser". Later, North Korea and Iraq confirmed the deterrence value of nuclear weapons: Iraq was believed to possess chemical and biological weapons but had no nuclear arms and was occupied, while North Korea had nuclear weapons and was not attacked. The conclusion appeared obvious: nuclear weapons are effective deterrents, but chemical and biological ones are not.

In recent years, the strong US military presence on Iran's doorstep and the cascade of security-related developments in the aftermath of 9/11 have accentuated the relevance of nuclear weapons. The US Navy has extensive support and logistical facilities in Qatar, Bahrain, the UAE and Oman, and there is a major American airbase in Qatar. There are a large number of well-supported US troops in Iraq and Afghanistan; there is a close partnership, however problematic, between the US and Pakistan and a minor US foothold in Azerbaijan; and Israel, the only resident NWS in the Middle East, enjoys staunch US support and cooperates with Turkey and India. Iranian perceptions of encirclement are therefore based on stark realities. In periods of dire threat such as in the aftermath of the occupation of Iraq, when it was feared that Iran would be next, and under the impact of recurrent US and Israeli bombing threats, security concerns cannot but strengthen the interest in nuclear weapons.

There is no doubt that Iranian security concerns bring the nuclear-weapon option to mind, and that alleviation of threats and formal security assurances are important to put it to rest. For some analysts, this is the primary motivation for Iran's nuclear drive. ${ }^{13}$ Others argue that status ambitions are more important. ${ }^{14}$

\section{Resolve status concerns}

Karl Marx said that the most effective power is the structural one that functions without being used. In international affairs, this is military force, nuclear weapons being the ultimate expression of destructive power. States have a fine eye for who is more and who is less powerful and tend to adjust, consciously or subconsciously, to the perceived distribution of power in their surroundings. In this way, nuclear weapons are important in order to gain political influence and higher international standing. 
Iran seeks higher status and a greater role in the Middle East and the wider Asian setting. In the Middle East, it has gained greatly from US actions in Iraq and Afghanistan, and in the Arab streets its opposition to Israel and the US has paid off. Egypt is intensely aware that Iran is undermining its traditional political leadership role in the region. For the neo-revolutionary factions, enhanced regional influence is a matter of fulfilling "Iran's historic mission to lead the region and the wider set of Muslim countries to a just world" (Ehteshami 2009). For others, it is a matter of ordinary national interest. Nuclear capabilities are signs of technological advancement and potential nuclear-weapon status, and may be used to this avail, although it is no simple way of projecting power. In response to Iran's ascendancy, members of the Gulf Cooperation Council (GCC) are launching their own nuclear programmes while seeking military partnerships with the US and other Western countries. Saudi Arabia and others are trying to counter Iranian influence in Lebanon, Palestine and Syria.

In the wider Asian context, Iran's economic power base is unimpressive, but its oil and gas deposits make it attractive for rapidly expanding Asian economies. Traditionally, Iran has been oriented at least as much to the North and East as to the West and has developed its relations to a great many Asian states, North Korea included. The secretariat and cultural department of the Economic Cooperation Organisation (ECO), involving ten Eurasian nations, are in Tehran; Iran is a member of the D8 group of eight Muslim countries promoting economic and technical cooperation; and it is an observer to the Shanghai Cooperation Organisation (SCO) and would like to become a full member. ${ }^{15}$ In the face of sanctions from the Western world, Asian countries may provide a "comfort zone" for Iran.

Status motivations for going nuclear can be modified and reversed in two ways: by implementing Article VI of the NPT in its software (doctrines) as well as hardware (weapon systems) dimensions, thereby reducing the political value of nuclear weapons in general, and by allowing a greater Iranian role in the Middle East in return for constraints on its nuclear programme. Single reductions of US and Russian nuclear arsenals to, say, 1,000 deployed strategic weapons for each with no promise of further cuts will hardly impress Iran or any other potential proliferator. But if disarmament becomes a trend encompassing both weapons systems and doctrinal limitations on their use, and involving other NWS in addition to the leading ones, the costs of contravening it will be higher.

Status gains accrue not only from military applications of nuclear energy. Civilian programmes can also be powerful expressions of technological sophistication and yield significant status benefits, especially if they cover the entire fuel cycle. In Iran, the national consensus on nuclear issues is built around an allegedly civilian high-tech prestige programme. Today, the enrichment works in Natanz and the construction of a big research reactor in Arak have reached such an advanced stage and enjoy so much support all across the political spectrum that it will be hard to reverse them. However, the stability of such decision points, stopping just a little short of weaponisation, is doubtful. To reassure others that the nuclear-weapon option is not being pursued, constraints are necessary. 


\section{Pay special attention to oppositional nationalists}

Iran is fertile ground for "oppositional nationalism" combining fear and pride, security and status concerns. ${ }^{16}$ When leaders fear for the security of their nation and/or their regime, while thinking at least as highly of themselves as of their neighbours and opponents, there is an asymmetry that cries out for correction. In the nuclear field, the asymmetry is most striking in relation to Pakistan: Pakistan is a nuclear-weapon state while Iran is not, yet Pakistan is a young and unstable state while Iran represents a distinguished age-old civilisation. Status asymmetries are powerful drivers of policy: Teheran's most oft-repeated demand is that the US must change the way it sees and treats Iran, its regional role and aspirations. To help constrain the nuclear programme, the status asymmetries must be alleviated as a matter of priority.

Over and over again, Iran has asked to be treated with fairness and respect. In his video message of 20 March 2009, addressed both to the Iranian people and to the Islamic Republic of Iran, President Obama did so: instead of policies of threat, "we seek ... engagement that is honest and grounded in mutual respect". "The United States wants the Islamic Republic of Iran to take its rightful place in the community of nations." "You have that right - but it comes with real responsibilities." $" 17$

Talks have taken place - about Afghanistan after 9/11, and three rounds about Iraq later on - but they were grounded in specific American needs and separated from Iran's broader regional role. For Iran

that kind of dialogue symbolizes the unequal relationship the US has sought to impose under cover of mutual respect. Iran was invited to participate only to the extent it had something to offer to the US - not because it had something to say. ${ }^{18}$

Iranians are therefore wary of invitations to discuss specific issues that emanate from Washington's failures and needs without a new overarching strategic framework that recognises Iran as a full-fledged regional player. For instance, annoyed by questions about what it is doing in Iraq, it claims respect for its intrinsic religious, economic, cultural, political and historical presence and influence there. With Afghanistan, Iran has a 930-kilometre-long border; a strong common interest with the US in fighting al-Qaeda and keeping the Taliban at bay; there are a million Afghan refugees on Iranian soil; and narco-trafficking is heavy. The scope for cooperation is quite considerable provided that the role of the regional power (Iran) is respected as much as the role of the major power on the other side of the globe (USA).

The fax that the Swiss caretaker of US interests sent to Washington in May 2003 also offered to stop material support to Hamas, Islamic Jihad and Hezbollah and to help turn them into political organisations, along with acceptance of a two-state solution of the Israeli-Palestinian conflict. ${ }^{19}$ This is a prerequisite for full normalisation of US-Iranian relations. Textbook logic suggests that the 
nuclear issues can best be solved in a framework of comprehensive normalisation, because the deeper the mutual confidence, the less need there is to constrain the nuclear programme. A high level of overall confidence would make tight constraints beyond international regime standards superfluous. However, unwavering US support for Israel, and Iranian aspirations to lead the Muslim world in its fight against Israel and in support of the Palestinians, make this a distant prospect.

In one key respect, Iran and the West see each other through the same lens: the attitude towards the nuclear programme is a litmus test of where the other side is heading and how far the dialogue can go. The West does not accept Iran becoming an NWS, and political reconciliation is unlikely to evolve fast enough to make it live comfortably with an advanced Iranian virtual arsenal. For Iran's oppositional nationalists, the nuclear programme is at the core of its demands: it is key to higher status, enhanced security and a stronger regional role, i.e. the alleviation of the painful asymmetries they have had to labour under. The programme strengthens national independence and self-sufficiency, and raises Iran's international standing in a way reminiscent of the role that nuclear weapons played in the revival of France as a big power with an independent foreign policy in the 1960s, yet without necessarily turning Iran into an NWS.

\section{Attend to the activities of nuclear mythmakers}

Myths grow out of strong convictions and are therefore hard to change. Pronuclear mythmakers tend to argue the case for nuclear-weapon acquisition irrespective of changes in their environment (Ali Bhutto, Nasser, Vorster) (Lavoy 2006). In Iran, some clerics remain true to Ayatollah Khomeini's negative attitude towards "the atom" and now and then go public as anti-nuclear mythmakers. ${ }^{20}$ In September 2003, this position was expressed in a fatwa by conservative ulama in Qom, reiterating that "nuclear weapons are un-Islamic because they are inhumane" (Bar 2009).

In the public domain, there are few mythmakers of any significance - no Iranian Ali Bhutto who said he would push for nuclear weapons even if the Pakistanis had to eat grass. Still, it is not far-fetched to assume that in the Iranian Revolutionary Guard Corps (IRGC, the Pasdaran) and among second-generation revolutionaries, pro-nuclear mythmakers do exist, but that they do not find it opportune to go public or are not allowed to do so. At any time and in any given country, multiple myths may co-exist and compete with each other: that appears to be the case in Iran, too, although by and large Iranians do not seem to hold strong, unqualified positions. Rather, they are sensitive to changes in their surroundings. Also, the role of religion and of the religious mythmakers is debatable. One interpretation holds that it is no different from the role that religion has played in so many other countries in human history, i.e. that of legitimising political interests. ${ }^{21}$

Important decisions on nuclear and foreign policy have been made by consensus among the major factions. For instance, the decision to restart nuclear 
activities in Esfahan at the end of July 2005 was made by a group comprising Khamenei (the supreme leader), the outgoing president Khatami (reformist), the incoming president Ahmadinejad (radical), former prime minister Moussavi (moderate conservative) and former president Rafsanjani (conservative).

Multiple mythmakers, few principled ones and decisions by consensus: this amounts to a political system where external factors are weighed and debated between the factions, but which may be less flexible and less effective than many other systems because of the time it takes to forge consensus. The US National Intelligence Estimate (NIE) of November 2007 also emphasised the rationality of the system and that Iran is susceptible to foreign influence. The government of Iran was willing to and capable of adapting to changes in its environment and to being a partner in real negotiations. However, after the presidential elections in the summer of 2009, the leadership group got embroiled in internal conflicts and fell apart.

\section{Reduce the role of the military}

One of the most solid theses in organisation theory is that big organisations try to maintain and expand their own status and influence. The military is no exception. In Iran, the military organisation to be watched is primarily the IRGC/ Pasdaran. The Army and the Iranian Atomic Energy Organisation (IAEO) were inherited from the shah and play more modest roles. The election of Ahmadinejad brought people from the Pasdaran into high government offices - so much so that to refer to the leadership in Teheran as "the priesthood" is inaccurate. It is commonly assumed that the interests in military applications of nuclear energy reside first and foremost with the Pasdaran, and that the closer the nuclear programme comes to a weapon capability, the greater the influence of the Pasdaran will be. To make Iran refrain from weapons pursuits, it is therefore important to constrain the influence of this organisation and the second-generation revolutionaries who liaise with it. The ups and downs of Pasdaran are, however, first and foremost a function of domestic political dynamics. There is not much that external actors can do to change it, except indirectly.

\section{Encourage openness to the outside world}

The hypothesis has been advanced that proponents of openness are less likely to seek nuclear weapons than governments wanting to shut the world out (Solingen 2007). Quantitative analysis does not refute it, but suggests that each individual case must be examined on its own merits (Muller and Schmidt 2010).

The Iranian regime has had few problems living with US sanctions. Using US hostility to legitimise and enhance its own position, it has even turned them to its own benefit. UN sanctions have been harder to swallow, not because they have been biting - they have actually been modest - but because Iran seeks recognition as a regional power and legitimate partner in international affairs and that ambition does not square with international condemnation. For some time, Iran 


\section{2}

has drawn distinctly unfavourable reactions from many parts of the world, making many Iranians ask what is wrong with their foreign affairs. Policies that allow it to become a bona fide partner in international cooperation provided that the non-proliferation norm is respected may therefore be instrumental in keeping it away from nuclear weapons.

Openness to the outside world is positively correlated with degree of democratic practice. Countries undergoing democratisation often find it particularly important to be seen as norm-abiding. Iran is in many ways more democratic than most other countries in the Middle East, although the chaos following the 2009 elections significantly curtailed civil liberties. Factions compete for influence and their relative importance is changing back and forth. There is nothing unidirectional about it - no signs of a well-functioning democracy at the end of any tunnel. Deeper involvement in international economic, cultural, scientific and political affairs therefore has to be stimulated in other ways. Sanctions are standing in the way, whereas membership in the WTO and other organisations may turn it into a stakeholder in organised international cooperation.

\section{Enhance the non-proliferation norm}

A strong non-proliferation norm may be among the most important factors in stemming proliferation and inducing rollback. ${ }^{22}$ Better and more balanced implementation of the NPT is therefore fundamentally important.

Implementation of Article VI of the Treaty - the disarmament article - is of vital importance in this connection. If a dynamic interplay evolves between the vision of an NWFW and specific measures towards that end, drawing all NWS into systematic and progressive reductions, the original bargain between nonproliferation, disarmament and peaceful uses will be much healthier. If this were to happen, potential proliferators will find it harder to go ahead and be more easily targeted for countervailing action. It is more costly to work against an established trend in the international system, especially if it is jointly developed by the big powers.

Calling for an NWFW, President Obama easily wins the war of words over big power hypocrisy and discrimination charges. He acknowledges the protests of double standards and wants to eliminate all nuclear weapons. To make a real difference, however, declaratory policies must be followed by action.

\section{Buy time}

Diplomatic involvement to buy time has been an important element in many rollback campaigns. It may be applied for years, waiting for external and/or internal changes to offer special opportunities for breakthrough. In the end, this brought good results in Argentina and Brazil.

In the case of Iran, the talks with the EU3/EU bought time in so far as Iran suspended its enrichment works between 2003 and 2005. Beyond that, however, making suspension a condition for negotiations meant time lost. For the Bush 
administration, negotiations were a reward granted to foreigners for good behaviour. ${ }^{23}$ It did not want to negotiate with evil, but to remove it. Means and objectives were turned upside down: the objective - curtailing the fuel-cycle activities - was made a precondition for talks about it. Both time and opportunities were lost.

When Obama entered the White House he put it straight, offering negotiations without preconditions. The timelines were critical, for the risk was that the nuclear programme would be racing ahead of progress in the negotiations. At that juncture, a formula for buying time was a double freeze, i.e. a halt to further enrichment and to further sanctions while new opportunities were explored.

\section{US and Iranian strategies for conflict management}

\section{US strategy}

In the spring of 2009, the contours of the new US strategy were coming into focus. The US was ready to participate in multilateral nuclear talks in the P5+1 framework and to initiate a dialogue with Iran without preconditions. The sanctions would be maintained, and efforts were made to build broad coalitions with a view to increasing the pressure on Iran if the negotiations were to fail. No "artificial" deadlines for progress were set, but a review would be made by the turn of 2009/2010.

The coalition-building aimed at making Russia more cooperative and at mobilising Arab support for US policies. European support seemed assured. The message to Russia was that if it joined the US in a successful attempt to keep Iran non-nuclear, there might be no need for a missile shield on its borders in Eastern Europe. Originally understood to be an exercise in linkage politics, this was later said to be a statement of fact. Cancellation of the missile shield plans for Poland and the Czech Republic would in turn facilitate disarmament negotiations between the US and Russia, possibly leading - in due course - to multilateral disarmament talks. If successful, it would put broader, concerted pressure on Iran not to rock the boat by acting in contravention to the joint US-Russian efforts. The plans for Poland and the Czech Republic were subsequently abandoned, paving the way for another disarmament agreement to replace START I, but Russian cooperation on Iran remained open to doubt.

Ten years ago - when Russia had to swallow a series of humiliating political defeats at the hands of the US and the West - its relationship to Tehran became a litmus test of the continued existence of an independent Russian foreign policy. Russia was selling weapons to Iran; cooperated with Iran on peaceful uses of nuclear energy; and wanted to cooperate with Iran on issues of petroleum policy. A closer Iranian alliance with the West could jeopardise its role as the main gas supplier to Europe. Russia does not want Iran to fall back into the Western sphere of interest. In key respects, Russia, China and Iran are supporting each other: Russia and Iran support China on the Taiwan issue; China and Iran support Russia in Chechnya; and for Russia and China, Iran is an important 


\section{4}

\section{Proliferation problems}

geopolitical entity that should stay where it is and pick up on its historical orientations towards the North and the East. Asia's rapid economic development and growing political influence provide an impetus in that direction. Therefore, US cooperation with Russia on Iran will not come easily.

To get the Arabs on board, the US was leaning on Israel to be more forthcoming towards the Palestinians. President Obama's insistence that Israel stop building new settlements, natural expansion of existing settlements included, was another go at something previous presidents failed to achieve. In effect, his coalition-building with moderate Arab regimes (euphemism for regimes that are on friendly terms with the US) was a follow up of President Bush's Annapolis exercise, which ostensibly set out to improve Israeli-Palestinian relations, but which had the same subtext: moderating the Arab-Israeli relationship with a view to concerted pressure on Iran. The US took care to brief moderate Arab states about its policies and diplomacy towards Iran, and extended a hand to Syria, Iran's only ally in the Middle East. A better relationship with Syria might weaken Syria's ties with Iran.

This was a tall ambition as well, too tall to be realised: Israeli politics had moved distinctly to the right, and Obama failed to stop the expansion of settlements. Iran's vocal opposition to Israeli and US policies and material support for Hamas, Islamic Jihad, Hezbollah and other groups fighting Israel had earned it much support on the Arab streets. The nearer one came to Iran, the more the Arab states feared the consequences of a war with it. The closer to Iran, the cooler was also the support for sanctions. However, Egyptian, Saudi and other Arab leaderships were deeply worried about the bomb potential of the Iranian nuclear programme, and many Arab states were launching programmes for civilian applications of nuclear energy.

Generally, US efforts to gain Arab, Russian and other countries' support for more severe sanctions in case engagement with Iran does not yield satisfactory results will therefore be hard-won. However, President Obama is in a better position to rally support for his policies than George W. Bush was. With the war in Iraq winding down and oil prices being well below 100 dollars a barrel, he is also better placed to threaten Iran with economic pain, although he stopped short of a cut-off. The single most biting sanction would be a cut-off of refined petroleum products, for which Iran still depended on import to almost 40 per cent of its total consumption. ${ }^{24}$ For Tehran, Obama promised to be a demanding interlocutor.

The US might go far in the direction of accepting the nuclear programme, some degree and form of enrichment on Iranian soil included, in return for full transparency. As for the negotiating procedure, there was a choice between a step-by-step approach and a comprehensive bargain, both with shortcomings and dangers. Any approach was subject to tight time constraints.

\section{Iranian strategy}

Iranian leaders were not content with US respect for Iran's sovereignty and territorial integrity and for its Islamic regime. After all, this is no more than a return 
to general code of conduct in inter-state affairs. Iran wants a negotiating framework that is conducive to recognition of its wider role in the Middle East. Negotiation of the nuclear issues and parallel talks about Iraq, Afghanistan and other problems, under a cloud of penalties if agreement is not reached within relatively tight time frames, do not meet that desire.

The Iranians want to have an overarching strategic framework that enables them to discuss regional issues with the American superpower across the board. In practice, it is far from clear what this means: Iran has learnt much about how to manage isolation and how to split big and small powers in their conduct of Iranian affairs, but it has little experience dealing with international openings. However, while the demands are vague, they are nevertheless central to the management of the Iranian problem in general and the nuclear issue in particular.

The nuclear programme is elevated above factional politics in Iran. It has many functions beyond providing nuclear power and a nuclear-weapon option. It symbolises what the Iranian civilisation can achieve; it can be used to offset domestic discontent, for the leaders can always count on widespread nationalism in support of their defiance towards the West; and it is one of Iran's main levers for being treated with respect and justice.

Enrichment is first and foremost a national undertaking, although there is a crack in the door for multilateral/international organisation of fuel-cycle operations. Multinational and international solutions are attractive, but timeconsuming to implement. A possible compromise may include comprehensive verification, solid supply assurances, constraints on the fuel-cycle programme, and exploration of multilateral/international options for the long term.

For the time being, verification is less than meaningful. The Western big powers are looking for incriminating evidence. Iran refuses to re-introduce the Additional Protocol. In the face of military threats from the US and Israel, it stands to reason that it has hidden materials, technology and equipment at many different locations. How can that Gordian knot be cut? It is hard to imagine a solution in the narrow framework of nuclear issues. It probably takes a degree of normalisation of US-Iranian affairs and acknowledgement of Iran's regional role to do it.

If Iran is serious about developing a weapon capability, it probably plans for enrichment somewhere other than Natanz, out of reach of the safeguards system. To turn Natanz to the production of highly enriched uranium, or divert material from there for upgrading at another site, will make alarm bells ring everywhere. That would mean publicity before consumption and more trouble than is, strictly speaking, necessary. There is little doubt that for some oppositional nationalists, security threats and status ambitions mould into a thought that meets both concerns: "If Iran becomes atomic Iran, no longer will anyone dare challenge it, because they would have to pay too high a price" (Clawson and Eisenstadt 2008). 


\section{Resumption of negotiations - and resumption of sanctions}

On 1 October 2009, negotiations between Iran and the P5+1 started in Geneva, with full US participation and without preconditions. The run-up could have been smoother: the unrest in Iran after the presidential elections in June, and the revelation of another enrichment facility under construction near the holy city of Qom - named Meshkat - only ten days before the meeting convened, put the diplomatic track under pressure. ${ }^{25}$

The standard safeguards agreement from the 1970s said that new facilities had to be notified to the IAEA at least 180 days before becoming operational. Later, this was changed to notification as soon as a decision to build a new facility had been made. ${ }^{26}$ In February 2003, Iran accepted that change, as the last country to do so, but in March 2007 it reverted to the 180 days provision. However, an agreement with the IAEA cannot be changed unilaterally. Work on the Meshkat facility did, moreover, start before March 2007. It was therefore done in violation of the safeguards agreement. ${ }^{27}$

Meshkat is well protected in hard rock. Naturally, a state that is under threat of being bombed would do so and distribute valuable equipment throughout its territory. ${ }^{28}$ Iran plans to build ten new uranium-enrichment plants inside mountains to protect them from military attacks. ${ }^{29}$ Therefore, if more locations become known, it is not necessarily a sign of weapons ambitions: it may just as well be mere defensive arrangements. To date, there is no proof that Iran is trying to build bombs, only plenty of suspicions.

In the run-up to the Geneva meeting, the US made it clear that, at that juncture, there would be no talk of sanctions. More comprehensive sanctions would come later, if the negotiations did not bring satisfactory results. A concrete confidence-building measure, advanced by IAEA Director General Mohammed ElBaradei, was tabled: Iran would send LEU from Natanz to a third country (Russia, France) for fuel enriched up to 20 per cent in order to continue production of isotopes for medical use at the Tehran research reactor (TRR). Nearly all the fuel that Argentina provided in the 1990s had been spent. The US and Iranian chief negotiators met in between the plenary sessions - the first such meeting in 30 years.

The US demanded that Iran document its peaceful intentions. The bar is high in this respect and the problems run deep, for even if Iran does not plan for production of nuclear weapons, it would obviously not like to provide information that may help Israel and the US to update their target lists. The Israelis are well known to prefer bombing, and the Americans have not written that option off.

In a comment, President Obama emphasised that Iran would not be singled out. The same standards should apply for all members of the international nonproliferation regime. His vision of an NWFW, and the UN Security Council summit meeting on nuclear disarmament and non-proliferation that he convened in September 2009, enabled him to refute assertions of double standards. He reiterated that Iran has the right to use nuclear energy for peaceful purposes, but that with the right comes responsibilities, and now Iran had to deliver (Sanger 2009). 
The continuation was deplorable. Iranian leaders reacted differently to the proposal and openly criticised each other, in a reflection of the chaotic governance situation in Tehran. The common denominator was a concern that they would not receive fuel for the TRR after fulfilling their end of the deal, so they put forward their own alternatives - exporting the LEU in batches or arranging swaps of LEU and fresh fuel on Iranian soil. ${ }^{30}$ The United States insisted on specific conditions for any deal to be agreed - 1,200 kilograms of Iranian LEU had to be removed from Iranian territory in a single batch before the end of 2009 which effectively blocked diplomatic progress on the issue. In effect, the TRR fuel issue was turned into a "take it or leave it" proposition. The impression was that Iran was buying time: now, at long last, it had to demonstrate good intent and readiness to do business. The announcement of negotiations without preconditions and the promising first meeting between Iran and the $5+1$ boiled down to stalemate over a modest measure to improve the atmosphere for substantive talks.

Facing prolonged impasse over the issue, the United States, France and other Western countries geared up for another round of sanctions, some of them in the belief that the domestic unrest had made Iran more vulnerable to external pressure. In Washington, Congress was ready for tougher application of US secondary sanctions on European and other companies doing business with Iran, while the administration seemed to prefer the UN route. Germany and other European countries warned against additional US sanctions because it might simply let Chinese companies replace European ones. The emphasis was on targeted sanctions, primarily against the IRGC: ${ }^{31}$ Israel demanded crippling sanctions as soon as possible. In February 2010, Iran started enrichment tests to 20 per cent with a view to producing the TRR fuel itself.

At that juncture, the headline was renewed focus on sanctions. The negotiating track had been reduced to a subtext.

\section{Assessment}

President Obama's coalition building is a new twist to long-standing US policies to contain Iran, running counter to Iranian efforts to correct prevailing status asymmetries. The coalition building may not be very successful: as Obama failed to deliver on the settlement issue and got nowhere with Iran, there was diminishing Arab enthusiasm for a common front against the Islamic republic. However, continued attempts to bring them on board did not augur well for settlement of the US-Iranian dispute. To the extent that the purpose is to elicit broader support for stronger pressures on the Islamic Republic - Hillary Clinton and Dennis Ross have advocated such an approach - the immediate consequence will be conflict escalation, not conflict settlement. For as long as Obama's conciliatory words do not translate into real prospects of being acknowledged as a regional actor in the wider Middle East, Iran is unlikely to yield very much on the nuclear issue. A high-level Israeli-American working group was set up to identify more coercive options if Iran does not meet US conditions. ${ }^{32}$ 
The covert operations initiated and conducted inside Iran by the Bush administration may be another impediment. ${ }^{33}$ Hundreds of millions of dollars were invested to destabilise the Islamic Republic. When Richard Nixon started his triangle diplomacy with the Soviet Union and China, he stopped the CIA's covert operations in Tibet. Did Obama do likewise in Iran? The new declaratory policy, substituting respect for the Islamic republic for regime change, suggests that the covert programmes have been cancelled. The reality may nevertheless be different. Covert operations have, moreover, also been conducted by other states, and may still be. To the extent that Iran is aware of them, it may be hard to determine who is responsible.

President Obama reached out to the governments of the Middle East and competed for sympathy among ordinary citizens. In response, the 2009 Iranian presidential candidates were keen to present themselves as best suited to handle the new challenges and opportunities. When the US offered unconditional negotiations both multilaterally and bilaterally, Iran was in no position to decline. However, because of the leverage that Obama tried to build and use in case Iran was not forthcoming enough, the new opportunities were fraught with great risks for the government in Tehran. Not only would Obama be more effective than his predecessor in gaining support for severe sanctions, but Democratic administrations also have a stronger interventionist record than Republican ones, George W. Bush aside. All the time, the Israelis can be counted on to lean on the US to take military action or to give a green light for Israeli bombing. Since they do not believe in diplomacy, they will try to limit the diplomatic window of opportunity as much as possible.

This goes to the heart of political realities and power politics. Israel is convinced that Iran is going for the bomb; Iranian nuclear weapons are unacceptable both to Israel and to the US; domestic US pressure in support of Israel is known to be very strong; so, to avoid more severe sanctions or being bombed, Iran will have to go out of its way to provide credible assurances of non-nuclear status. Never mind that the choice between accepting Iran as an NWS or bombing it is a false one: if Iran had not decided to go for nuclear weapons before being bombed, it would most probably do so in the aftermath. Israel does not see it that way, nor do many Americans.

Under what circumstances would Iran accept the Additional Protocol and offer the transparency measures that are necessary to reassure the US, Israel and others?

To convince Israel seems next to impossible. It will be hard enough to convince the United States, even if the 2007 NIE concluded - with a high level of confidence - that the Iranians stopped the military parts of the programme by the end of $2003 .^{34}$ Even if Iran were to meet the transparency requirements of the IAEA, the concerns about a virtual Iranian arsenal are such that restrictions on the fuel-cycle capabilities would be necessary to lay the security concerns to rest.

Iran may not be prepared for that. Anti-nuclear mythmakers claiming that the bomb is anti-Islamic are known neither to have protested the abandonment of the 
Additional Protocol in February 2006 nor to have argued for its re-introduction. The role of the IRGC is distinctly negative. Its officials are hardliners limiting the scope of conflict settlement. Their influence changes with changing political constellations: radical conservatives like Ahmadinejad, reaching back to the ideals of 1979, give it a boost; moderate or reformist presidents tend to constrain its influence. However, the more advanced the virtual arsenal becomes, the greater its influence is likely to be.

Much hinges on whether the discrepancies between Iranian self-perceptions and the way others see and treat them can be alleviated. Iran's security concerns should certainly not be underestimated either. What is more important in its nuclear drive - to negate the threats to its security or to overcome the frustration over not being properly treated - may be the wrong question to ask. Like apples and oranges, they are hard to compare, but they both translate into the nuclear programme as a favoured vehicle of change.

To be more forthcoming to Iran without jeopardising the interests of Arab states is in large measure a matter of exploiting the potential for win-win arrangements. One example is the proposed Iranian-Saudi/GCC mutual defence pact: Iranians have been saying that if the US is behind the proposal, it shows that US policy is changing (in a positive direction). Another example might be a free-trade arrangement comprising all the countries around the Persian Gulf. A third example is a Conference on Security and Cooperation in the Middle East, an idea that was discussed during the Madrid process of the early 1990s and that is inspired by the Helsinki Final Act and the Conference on Security and Cooperation in Europe. In effect, Obama's speech in Cairo on 4 June 2009 had important components in common with the Helsinki Final Act. ${ }^{35}$

The Nixon administration worked with the Chinese leaders to define what the long-term strategic realignment between their countries should be about. Without it, the realignment may not have happened (Leverett and Leverett 2009). The US and Iran have not come to anything of that kind. Washington has not outlined its strategic goals, and Tehran is even less capable than before of explaining its overarching objectives in the Middle East. By the beginning of 2010, another opportunity for a political solution therefore seemed to be lost.

\section{Implications for the NPT}

Should Iran become an NWS, proliferation pressures would grow throughout the Middle East - in Egypt, Saudi Arabia and Turkey first of all - although contrary to widespread beliefs, there is no automaticity to it. If the development of an Iranian virtual arsenal is not corrected, the effect will be much the same, tempting others to go down the same road. The impact on the NPT therefore goes beyond Iran.

The impact of a successful resolution of the conflict may also go much beyond Iran. If a multilateral fuel-cycle venture is set up, it would be the first of its kind in a region of proliferation pressure. If the case of Iran can be used to push internationalisation of all fuel-cycle facilities, existing ones included, the 


\section{Proliferation problems}

non-proliferation regime will be significantly enhanced. The Iranian problem, which highlights the untenable division of the world into haves and have-nots and the double standards that have been applied by the NWS, can also be invoked in support of nuclear disarmament, the way President Obama set out to do.

The outcome of the Iran conflict is therefore rich on consequences for the non-proliferation regime - for better or worse. 


\section{How to understand North Korea}

\section{The one and only withdrawal from the NPT}

North Korea acceded to the NPT in 1985; entered a safeguards agreement with the IAEA in 1992; and withdrew from the NPT in 2003, as the only country to have done so.

The validity of the withdrawal has been questioned on legal grounds. North Korea had announced its intention to withdraw once before, on 12 March 1993, but went back on that notice on 11 June, one day before it would have taken effect. On 9 January 2003, it stated that it would leave the Treaty the next day in reference to the 89 days' notice ten years earlier, which had merely been suspended. This procedure was controversial, since the reasons given in 2003 were different from the ones given in 1993. ${ }^{1}$ Once Pyongyang linked its withdrawal to the earlier notice, the legal basis for the final withdrawal arguably rested on the original grounds.

However, while the withdrawal was put before the UN Security Council, the Council failed to take any action because of disagreements among the P5, notably China and the United States. In effect, it was left to the withdrawing state, i.e. the DPRK, to define "the extraordinary events [that had] jeopardized its supreme interests". ${ }^{2}$ The facts on the ground were that the IAEA had to terminate all safeguards activities in the DPRK. By that yardstick, North Korea had for all intents and purposes left the Treaty.

\section{Denuclearisation: is it realistic?}

In 2003, North Korea openly declared its pursuit of nuclear weapons. In 2005, it said it had weaponised its nuclear programme (Hecker 2005). In October 2006 it tested a nuclear explosive device, followed by another test in May 2009. Can it be turned back to non-nuclear status? How realistic is it?

Some take the view that North Korea is determined to be a nuclear-weapon state (NWS) and that, in the time ahead, it will seek international acceptance of it. $^{3}$ Nuclear weapons are essential for North Korean security, and military might is the only source of its diplomatic power. Others believe it has been willing to trade its nuclear capabilities for a fundamentally new political relationship with 


\section{2}

the United States and other countries, including a peace treaty ending the Korean war, security assurances, economic aid and investment and normalisation, and that it still could be. Yet others believe limitations can be negotiated, but that elimination is out of reach or at least unlikely any time soon.

In large measure, the differences and uncertainties of interpretation stem from the fact that North Korea is a closed society - more so than any other country in the world. China and South Korea may have better intelligence on the internal workings of the North Korean regime than other states, but they, too, seem to have very limited access. North Korea's attitudes and intentions must therefore be judged on the basis of its conduct of external affairs. Efforts to link them to domestic factors like leadership changes, the effects of economic sanctions, food shortages and changes of economic policy may be interesting, but highly speculative.

Leon Sigal has pointed out that those who believe North Korea was always headed for nuclear weapons fail to explain significant anomalies in its nuclear efforts over the past two decades. North Korea stopped reprocessing in 1991 and did not resume until 2003. It stopped again in 2007 and did not resume until the spring of 2009. It fabricated a limited amount of fuel rods before 1994 and has yet to make more. It has therefore produced significantly less plutonium than it could have done so far. Siegfried Hecker (2010) assesses that, with the capabilities it had or was soon to complete by the early 1990s, Pyongyang could have had an arsenal of 100 or more nuclear weapons today. Instead it has enough plutonium for four to eight weapons and is currently not producing more. Plutonium from the $5 \mathrm{MWe}$ reactor in Yongbyon remains the only source of fissile material, but by 2009/2010 it had been shut down for a while. If North Korea was determined to become an NWS, why stop (Sigal 2009a)? Why did it take the starkly confrontational policy of the Bush administration to trigger another reprocessing campaign after 12 years of recess?

To get Washington's attention, to get negotiations going and to speed up implementation of accords that have been struck, missile and nuclear tests have been conducted and threats issued. In a sense, North Korea had no better choice, for absent dramatic actions the reclusive regime is off the radar screen, and its only means of alerting others to its needs and objectives are the nuclear and missile programmes. In contrast to Iran, which may have seen negotiations as a way of buying time for the nuclear programme to materialise, ${ }^{4}$ North Korea has taken action when implementation of agreements has been slow or absent. It has accepted agreements that have brought significant nuclear activities to a halt, and it has been angered when they have not been complied with. North Korea has practised tit-for-tat - cooperating when Washington cooperates and retaliating when Washington reneges. In game theory, such a strategy is known for its ability to turn conflict into cooperation. ${ }^{5}$ If this is a fair reading of North Korean thinking, there is realism to the disarmament ambition. Whether it applies all the way back to non-nuclear status is uncertain, however.

It follows that the North Korean challenge is different from the three-state problem. None of the three - Israel, Pakistan and India - seem prepared to 
relinquish their nuclear arsenals any sooner than any of the P5. Since in practice they cannot become members of the NPT, they are long-term outliers, awaiting comprehensive nuclear disarmament. North Korea, on the other hand, is a separate case that may be persuaded to limit its nuclear activities and even go back into the non-nuclear fold more or less irrespective of big power readiness to disarm.

Even if this reading fits past behaviour, how do we know that it remains valid? How do we know that the missile tests and the second nuclear test in the spring of 2009 is a wake-up call for renewed negotiations and not a farewell to the idea of disarmament for normalisation? In the past, it always wanted to revive negotiations, but will it happen this time? If it does, how do we know that it is sincere about a disarmament/reconciliation trade-off? Since we are unable to look inside North Korean politics, there is always the possibility that Pyongyang has given up on that option in favour of nuclear-weapon status for the foreseeable future, and that with some delay this will be clear. The foreign policies of the United States and others are not constant, and the domestic politics of the DPRK may certainly also be shifting.

When the Security Council issued a presidential statement condemning the long-range missile test in the spring of 2009 and imposing sanctions on three North Korean firms involved in missile trading, a DPRK Foreign Ministry spokesman stopped short of abandoning six-party talks forever. He characterised sixparty talks as "an arena that infringes on our sovereignty" (by opposing its missile launch) and "which only aims at disarming us and overthrowing our system", and said that "we will never participate in such talks and will no longer be bound to any agreement". The statement was similar to the March 1993 statement threatening to renounce the NPT. It called into question the commitment to "abandon all nuclear weapons and existing nuclear programs" in the September 2005 joint statement from the six-party talks in Beijing. That statement also reconfirmed the validity of the denuclearisation agreement between the two Koreas of $1992 .^{6}$

Only the North Korean leaders themselves know what they are going for, and even that cannot to be taken for granted: the objectives may not always be clearcut for them, either. The only way to find out is to probe through systematic give and take, offering North Korea a peace treaty, security assurances, normalisation of relations and economic assistance in return for denuclearisation. The Clinton administration did so only half-heartedly, dragging its feet in implementing the Agreed Framework of 1994 and being hampered by a recalcitrant Congress. The Bush administration closed the door at first, and when it opened it in Berlin in January 2007, it was split on how to proceed. In 2008 it moved the verification goalposts up in contravention to the 3 October 2007 agreement on "SecondPhase Actions for the Implementation of the Joint Statement", 7 leaving the Obama administration with a process that had veered off course. It remains, therefore, to undertake a thorough and systematic probe, true to the letter and spirit of existing agreements.

The North Koreans are known for their offensive diplomatic language. Over and over again, provocative statements have been made in response to what they 
have seen as broken promises and threats from the US and others. Many times, they left the table. So far, however, they have always come back. Once more, we have to ask: is it different this time? Are they burning bridges behind themselves?

\section{North Korea's nuclear history: the early years}

Under a cooperation agreement between the USSR and the DPRK, a nuclearresearch centre was established in Yongbyon in the mid-1960s. The USSR supplied a 2-4MWe research reactor which ran on 10 per cent enriched uranium, later upgraded to $8 \mathrm{MWe}$ and converted to the use of HEU ( 80 per cent). This reactor was not a good source of plutonium. However, in combination with Soviet training of North Korean scientists and engineers, it kicked off a nuclear programme that became increasingly self-sustained in line with North Korea's Juche ideology. ${ }^{8}$

The security motive was important from the beginning. In 1957, the United States deployed nuclear weapons in South Korea, and in the following years it conducted military exercises there involving nuclear-capable artillery, fighterbombers and carrier aircraft. In the early 1970s, enhanced North Korean nuclear efforts coincided with South Korean interests in nuclear weapons. To keep the South non-nuclear and to thwart competition between the two Koreas, the United States intervened to stop deliveries of a reprocessing facility from France, a "Cirus line" reactor from Canada and a fuel fabrication plant from Belgium, and induced Seoul to ratify the NPT in 1975. In 1977, the Soviet Union persuaded North Korea to join the NPT (which it did in 1985) in order to be in a position to receive lightwater reactors (LWR), only to have South Korea resume its nuclear programme. Once again, the United States persuaded the South to stop, but the North did not.

In the early 1980s, North Korea began constructing a 5 MWe gas-graphite reactor in Yongbyon, well-suited for plutonium production, along with facilities for uranium fabrication and conversion. The reactor became operational in 1986. Construction of a $50 \mathrm{MWe}$ and a $200 \mathrm{MWe}$ reactor started, but were never completed. At this time, the South was outpacing the North economically and militarily, and the North had growing doubts about the reliability of its allies, i.e. the USSR and China. Towards the end of the decade, the building of a reprocessing facility near the $5 \mathrm{MWe}$ reactor became public knowledge. In 1989 the reactor was shut down and the first load of fuel rods removed. When the safeguards agreement with the IAEA took effect in 1992, the Agency found that spent fuel had been reprocessed not only in gram quantities in 1990 - ostensibly from damaged reactor fuel as part of an experiment - but in 1989 and 1991 as well. North Korea seemed unaware that by collecting dust from the remote control rods at the reprocessing plant and analysing the isotopic decay, the Agency could prove this beyond doubt. At this time, North Korea may have had enough plutonium for one or two nuclear-explosive devices. ${ }^{10}$

When the Soviet Union fell apart and China improved its relations with South Korea, the United States and Russia, North Korea was left on its own. Trade 
with Russia was down, and China's market economy pushed Beijing in every direction but North Korea. China could be relied upon only if North Korea was attacked; Russia not even then. In the end of the 1980s, Kim-Il-Sung therefore reached out to North Korea's enemies - the United States, Japan and South Korea - in an effort to turn conflict into cooperation and reduce the dependence on China. International affairs were in such a state of flux that hedging against further Chinese moves to Pyongyang's detriment seemed appropriate. In 1991, the US withdrawal of tactical nuclear weapons from South Korea encouraged the adoption of a broader security strategy that emphasised threat reduction as well as military preparedness.

This led North Korea to sign two agreements with South Korea: an Agreement on Reconciliation, Non-Aggression, Exchanges and Cooperation ${ }^{11}$ and a Joint Declaration on the Denuclearisation of the Korean Peninsula. The Joint Declaration, which was signed on 19 February 1992, states that the two sides "shall not test, manufacture, produce, receive, possess, store, deploy or use nuclear weapons" and that they "shall not possess nuclear reprocessing and uranium enrichment facilities". In a move similar to the Argentina-Brazil Agency for Accounting and Control of Nuclear Materials (ABACC), the Declaration called for a Joint Nuclear Control Commission to verify the denuclearisation. On 30 January 1992, the DPRK also signed - at long last - a safeguards agreement with the IAEA, which it had been obliged to conclude much earlier following ratification of the NPT in $1985 .^{12}$

North Korea reprocessed plutonium for weapons while committing itself to disarm: these moves were open to interpretation, but not necessarily contradictory. It is not unusual that negotiating parties beef up their bargaining positions in the run-up to negotiations. However, the North-South dialogue stalled in the autumn of 1992. South Korea announced that full North-South economic cooperation would not be possible without resolution of the North Korean nuclear issue, and on that score there was little movement. The negotiation of a bilateral inspections regime made little progress, and when the IAEA asked for special inspections of nuclear-waste sites in order to come to grips with the nuclear history of the DPRK, North Korea refused. ${ }^{13}$

The South Korean demand concerning the sequence in which cooperative steps should be taken accentuated a point that was properly addressed only much later. It took another 13 years for the principle of parallel moves - "commitment for commitment, action for action" - to be agreed at the six-party talks in Beijing. ${ }^{14}$

\section{Twenty years of overt nuclearisation: the rationale}

By 2010, North Korea had conducted two nuclear tests and had perhaps 4-8 Nagasaki-like nuclear weapons stockpiled. ${ }^{15}$ What are the functions of these weapons? How do they serve North Korean interests?

Four motives deserve closer examination: to deter attack; to build bargaining leverage; to inflate crises in order to raise the compensation for defusing them; 
and to obtain hard currency and material favours by exporting nuclear and missile technologies.

\section{Deterrence}

Nuclear weapons are deemed important to deter attack. As the Cold War drew to an end and international constellations shifted and traditional allies were lost, North Korea was quick to conduct the first reprocessing campaigns. It is not known how much plutonium those campaigns yielded, nor is it known when the programme was weaponised - if indeed it has been. However, the international community had to entertain the possibility that North Korea was acquiring one or two nuclear devices.

What North Korea may have said and done in the name of deterrence, surrounding states have often perceived as threats of aggression. Being shrouded in secrecy more than any other nation, the scope for misperceptions is exceptionally great. Under conditions of opacity, worst-case assumptions are well-known to be thriving. The debate between those who see a consistent North Korean pattern of tit-for-tat, cooperation when the US cooperates and retaliation when it reneges, and those who believe that North Korea has long been determined to become an NWS, remains unresolved.

However, deterrence has not reigned supreme in North Korean security policy. Following the adoption of Kim Il Sung's comprehensive security strategy, repeated attempts to trade nuclear and missile capabilities for security assurances, normalisation and economic assistance were made without any addition to the plutonium stock. It was not until the Bush administration terminated the Agreed Framework in reference to North Korea's alleged enrichment programme and declared North Korea a member of the axis of evil that another load of spent fuel was reprocessed. During the Bush presidency, North Korea probably produced enough plutonium for another five-to-eight weapons and it conducted its first nuclear test in October $2007 .{ }^{16}$ In its declaratory exhortations, it has used its nuclear capabilities to the hilt, threatening to turn the Korean peninsula into a sea of flames if attacked.

\section{Bargaining leverage for normalisation and economic assistance}

North Korea's refusal to allow special inspections and lack of progress on the implementation of the North-South denuclearisation accord, triggered actions on both sides that led North Korea to announce its withdrawal from the NPT on 12 March 1993. The US responded by inviting high-level talks, which led North Korea to call off the threat of withdrawal. The parties also agreed on basic principles for continued dialogue. However, as Seoul resisted and Washington deferred to its ally, those talks were slow in materialising.

In response, North Korea shut down the plutonium-production reactor and removed the fuel. When the US turned to the Security Council for sanctions, the parties came close to war. It was at this point that President Carter went to 
Pyongyang to see Kim Il Sung. His mission was a breakthrough that turned confrontation into cooperation. A skeleton agreement was outlined and fleshed out in the course of four months to become the October 1994 Agreed Framework. ${ }^{17}$ Under this agreement, North Korea would freeze and eventually dismantle its $5 \mathrm{MWe}$ reactor, the reprocessing facility and the $50 \mathrm{MWe}$ and $200 \mathrm{MWe}$ reactors under construction. In return, it would receive two 1,000 MWe light-water reactors (LWR) and an interim supply of 500,000 tons of heavy fuel oil per year. The agreement also pledged to normalise US-DPRK relations and lift the sanctions, and committed the DPRK to North-South dialogue (Wit et al. 2004).

At the time, the LWR were estimated to cost about $\$ 4$ billion, later revised to more than $\$ 5$ billion. The value of the heavy fuel oil to be supplied while waiting for the LWR to become operational was of the order of $\$ 150$ million per year. In comparison, Belarus, Kazakhstan and Ukraine received less than one-tenth of this offer for giving up the nuclear weapons that were left on their soil when the Soviet Union fell apart. The North Koreans "framed" the deal themselves: they were the ones to propose two LWR, and the Americans accepted - on the assumption that South Korea, Japan and others would pay for it. ${ }^{18}$ The Framework Agreement proved that the bargaining value of the nuclear programme could be quite significant.

Ever since, economic compensation has been an important, integral part of the disarmament talks. In the spring of 2009, when North Korea said it would never go back to the six-party talks in Beijing, it may have had the Agreed Framework in mind, preferring bilateral talks with the US and an update of the 1994 agreement. ${ }^{19}$ The Agreed Framework offered much higher economic quids for the disarmament quo than the six-party deal offered.

\section{Compensation for crises of their own making}

Implementation of the Framework Agreement quickly ran into South Korean criticism as well as opposition from the US Congress after the Republican victory in the 1994 elections. In the following years, Congress interrupted fuel oil deliveries by holding back money for them. Also, the Clinton administration and other members of the Korean Energy Development Organisation (KEDO) were slow in implementing the LWR part of the deal. The problems lay in US domestic politics and alliance relations. Some officials may also have waited for the North Korean regime to disappear. In the wake of the Cold War, many regimes that had been in the Soviet sphere of influence collapsed or were expected to fall apart. In the view of many, North Korea had long been destined for the dust bin. Historical experiences showing that full-fledged dictatorships can be managed for very long periods of time were ignored. Delays in the implementation of the Agreed Framework were also caused by special North Korean demands such as its initial refusal to accept South Korean-designed LWR models $^{20}$ and its salary demands for North Korean workers.

In another interpretation of North Korean behaviour, Pyongyang turned these early negotiating experiences into a strategy to maximise compensation for 


\section{8}

crises of its own making. Over and over again, it has tried to sell the bargaining cards at its disposal, i.e. the nuclear and missile programmes. The prelude was the notification of withdrawal from the NPT in 1993, which led to the agreement on basic principles for continued dialogue and preliminary discussions of LWR for North Korea. One year later the Agreed Framework promised ample remuneration for Pyongyang's willingness to help defuse the crisis it had created by removing another batch of fuel rods, threatening to produce more plutonium and heightening military tension. Later examples are the testing of a long-range Taepodong missile in 1998 in an effort to speed up delivery of the goods that the Agreed Framework offered, and the nuclear and missile tests in 2006, which made the Bush administration do what it had said it would never contemplate sitting down with the North Koreans in Berlin to negotiate what became the sixparty agreements of 2007. When North Korea resumed its plutonium programme in 2003, it made no effort to trade cancellation for compensation in the belief that the Bush administration was not available for deals of any sort.

There is some circumstantial evidence to support this interpretation. In all likelihood the North Koreans considered the Agreed Framework to be a big diplomatic success, much as the disarmament part of it was a big step ahead from the American point of view. Later, they have therefore tried to use the assistance provisions of this agreement as standards for new deals. The main part of the 1994 offer was the LWR, which North Korea kept asking for in the six-party talks, and the 2005 South Korean offer of 2,000 MWe from the South Korean grid was tailored to the provision of two 1,000 MWe LWR in the Agreed Framework. North Korea pursued its nuclear and missile programmes in order to achieve remuneration of the magnitude envisaged by the Agreed Framework.

\section{Sources of hard currency}

The nuclear and missile programmes have also been sources of much-needed hard currency. Missile technology has been sold to Pakistan, Myanmar and countries in the Middle East, and nuclear assistance has probably been rendered to Syria and possibly Libya and Myanmar. ${ }^{21}$ The Syrian reactor building that Israel bombed in 2007 was strikingly similar to the $5 \mathrm{MWe}$ reactor in Yongbyon. Except for minerals and some other items that North Korea is selling to China and South Korea, these are the only commodities of interest to (some) others.

Efforts to obtain much-needed hard currency by selling nuclear and missile technologies to potential proliferators tap very well into the bargaining strategy, especially after 9/11 and the exposure of the Qadeer Khan network. Qadeer Khan is reported to have gone to North Korea 13 times. His network provided some 20 centrifuges for reverse engineering. Benazir Bhutto also paid a visit to North Korea in what may have been a missile-for-nuclear-technology barter deal. Other "liebhabers" of North Korean technology are Iran and - possibly terrorist networks wanting to harm the United States. A regime fighting for survival, with its back against the wall, hardly shies away from providing mass-destruction technologies to others if the price is right. 
On 5 April 2009, North Korea tested a missile that went 3,800 kilometres, longer than any previous missile test. Had the third stage functioned properly, it would have had intercontinental range. A little later, North Korea conducted another nuclear test. The yield was of the order of 2-4 kilotons. The tests hit at the core of US threat perceptions. They were reminders that North Korea has interesting technologies to offer potential proliferators. For Washington, North Korea's own capabilities are worrisome, but proliferation of nuclear and missile technologies to other states and non-state actors that may use them to attack US assets is of even greater concern.

\section{Assessment}

None of these theses can be written off. To a smaller or larger extent, they may all help explain North Korean behaviour. There is no doubt, however, that security is the main driver. Nuclear weapons are deterrents as well as bargaining chips for normalisation and security assurances. A related motive is bargaining leverage for elimination of sanctions and economic assistance. The nuclear and missile programmes are invoked across the board for economic and political goals as well as for security purposes. Secluded and impoverished, North Korea has no other instruments of significance in the conduct of its foreign policy. In the joint six-party statement of 2007 that paved the way for disablement of the Yongbyon facilities, North Korea reaffirmed its commitment not to transfer nuclear materials, technology and know-how, but went back on that and other commitments when the Security Council condemned the 5 April 2009 missile test. In the first half of 2009, its moves had the character of diplomatic posturing with a view to forthcoming talks with President Obama, who in principal terms had underlined his readiness to talk with US adversaries.

Compensation for crises of its own making is a controversial proposition. When cycles of crises and cooperation evolve repeatedly over the years and decades, it matters less and less when and how it all started. Conflict manifestations degenerate into incessant disputes about the distribution of responsibility and blame, like in the Israeli-Palestinian conflict. Different starting points lead to different readings of events. The impression that North Korea actively creates crises in order subsequently to claim remuneration for helping to defuse them starts from provocative North Korean behaviour - ousting of inspectors, withdrawal from the NPT, nuclear explosives tests and missile tests, threatening statements etc. The other side of the coin - that sometimes US failure to live up to commitments, insertion of new demands, inaction where action has been promised, military exercises and threatening statements instigated the provocations - is often ignored.

It is all too easy to get away with partisan narratives because in the media world, North Korea is easy prey. Its opponents are immensely more powerful. North Korea is a pariah state, both enemy and outcast. For good reasons, it is an international "prugelknabe": its Stalinist political system is hardly less repressive than the original; its human rights record is dreadful; criminal activities to 
obtain hard currency are well-documented; and abduction of Japanese citizens likewise. Its foreign policy tends to be seen in the same perspective of repugnant behaviour, confirmed and highlighted by the special brand of provocative language that the regime uses. There is a distinct tendency to blame North Korea for each new crisis that occurs, also when it its opponents fail to comply with agreements that have been entered into.

A comprehensive analysis of North Korean foreign policy from the early 1990s until today puts the "compensation for crisis" proposition into a different perspective. All the time, North Korea has been keen to reciprocate in kind. In the autumn of 2008, when the United States announced that it had delayed delisting of the DPRK as a state sponsor of terrorism until there was agreement on an intrusive verification protocol, North Korea suspended the disablement of the Yongbyon facilities and started to restore them: when President Bush nevertheless took it off the list a couple of months later, disablement resumed. North Korea has taken care to phrase this message in clear-cut terms, such as "dialogue with dialogue and strength with strength"; "a slap for a slap": "sword to sword, rice cake to rice cake" (Sigal 2009a). Seen in this perspective, "compensation for crisis" is not something North Korea has been initiating from scratch, but rather a spin it has given to retaliatory measures when the US failed to cooperate. Its brinkmanship diplomacy seems based on the assumption that the more serious the crisis, the higher the price for defusing it.

The sequence of cooperation and conflict that unfolded in 2008/2009 is as good an illustration as any. In accordance with the six-party agreement of September 2007, North Korea set out to disable its plutonium facilities in Yongbyon under international supervision ${ }^{22}$ and submitted a declaration of its plutonium programme. ${ }^{23}$ In a side agreement, it committed to disclose its uraniumenrichment and proliferation activities. That same day, the US announced its intention to cut back on the sanctions and remove North Korea from the list of states sponsoring terrorism, but with the proviso that the declaration would have to be verified. The problem was that in this phase of denuclearisation, there was no provision for verification: the US was moving up an issue that had been scheduled for the next phase. ${ }^{24}$ North Korea nevertheless agreed with the US to set up a verification mechanism, but after a couple of turns back and forth, President Bush yielded to hardliners in Japan, South Korea and Washington who wanted to have the commitment in writing. On 11 December 2008, they threatened to cut off energy aid unless North Korea accepted a formal six-party verification protocol. In response, North Korea stopped disabling and began preparations for another Taepodong-2 missile test. The test was made in contravention of Security Council Resolution 1718, issued after the nuclear test in 2006, which prohibited further testing of long-range missiles. The prohibition was tailor-made for North Korea, for there are no strong international norms in this field and some 20 states have been launching long-range missiles, among them Japan and South Korea. The Security Council condemned the launch and approved new sanctions. North Korea protested fiercely and staged its second nuclear test in yet another demonstration that the Western crime-and-punishment 
approach does not function. From mid-2009, in a repeat of previous cycles of crisis and cooperation, North Korea once again signalled interest in resumption of negotiations while the Obama administration, reacting to events without any comprehensive policy review, stuck to the sanctions and played for time.

\section{Current status}

\section{Nuclear profile}

On 14 April 2009, one day after the Security Council condemnation, North Korea expelled the US technical experts and the IAEA inspectors. The US specialists had then lived on the site in Yongbyon for 18 months to monitor the disablement, and the IAEA had had three inspectors on site full-time. North Korea said it would restore the facilities to their original state for normal operation and that the spent fuel rods that had been removed from the reactor in the disablement process would be reprocessed. In addition, it said it would actively examine the construction of an LWR on its own. ${ }^{25}$ Although the economic and technical capacity to build such a reactor is highly questionable, this may allow it to reveal its uraniumenrichment programme, presenting it as a source of LEU for power reactors.

The North Koreans have told the Americans that they had a pilot uraniumenrichment programme in the beginning of the 1990s, but that it was terminated. It seems to have been brought back to life around 1998, drawing on the Qadeer Khan network. Some significant undeclared enrichment activities have obviously been going on and may still do, most likely outside Yongbyon. The alleged export of hexafluoride to Libya, and possibly also uranium products to Syria, points to the existence of a uranium programme, though none has ever been located in North Korea.

When the inspectors left, past plutonium production had not been verified, for North Korea had neither allowed sampling of the reactor's graphite core nor of the reprocessing facility and waste sites. There are significant discrepancies between Pyongyang's declaration and US estimates. In 2008, North Korea declared that it had separated and weaponised $26 \mathrm{~kg}$. In 2009, it reprocessed an additional $8 \mathrm{~kg}$. US estimates of the plutonium inventory were higher, but Siegfried Hecker (2010) did not exclude that the declared amount could be correct. No progress had been made on the declaration of weaponisation facilities outside of Yongbyon, the nature of the uranium programme or the extent of nuclear exports.

Nearly all of the actions specified by the disablement agreement were completed. However, the $5 \mathrm{MWe}$ reactor, the reprocessing facility and the fuelfabrication plant can all be restored and returned to plutonium production. On 24 April 2009, North Korea announced that it had restarted the reprocessing facility. However, beyond the fuel rods that were removed during the disablement process and then reprocessed, it would take at least three years before another load of reactor fuel would be ready for reprocessing once the reactor is refuelled and restarted. 


\section{Negotiating profile}

After the North Korean missile test of 5 April 2009, the United States sought a punitive sanctions resolution in the UN Security Council. Japan and South Korea were pressing for it, while China and Russia were opposed. China believed another round of condemnation and sanctions would prompt retaliation by Pyongyang and endanger the six-party talks, but it was not ready to block Security Council action. Obama, who had stressed the need to repair America's alliances in the election campaign, lent an ear to his Asian partners, but did not want to confront China. The result was a presidential statement condemning the launch in reference to Resolution 1718, and sanctions on three North Korean firms involved in missile trading.

In response, North Korea backed out of the six-party talks and the agreements reached in that forum. The rejection may have been caused by the hardliners in Japan and South Korea. They had been the ones to insist on a written verification protocol in phase two of the denuclearisation agreement, and they had been holding back on previous occasions as well. Japan was the only six-party participant not to provide fuel oil, pending a satisfactory conclusion of the abductions issue. Indeed, a North Korean foreign ministry spokesperson said that "Japan is primarily responsible for the break-up of the six-party talks" (Sigal 2009b).

Lingering dissatisfaction with the terms of the 2007 agreements may have led to the same conclusion. North Korea is deeply committed to nuclear power and never dropped its demand for LWR. The South Korean equivalent of 2,000 MWe from the South Korean grid did not have the same attraction, because it would make the North dependent on the good will of the South. The Juche ideology deprives the US and its allies of the leverage to press it to do what they want and, in the view of the North, the lessons from the crises in 1998, 2003 and 2006 corroborate it. Its economic interactions with other countries are so modest that there is little that others can do to punish it for its transgressions.

At the fourth round of six-party talks in 2005, North Korea asserted that it would not agree to dismantle its nuclear-weapons programme unless the LWR project was re-established. The other five parties said they were willing to consider the LWR issue "at an appropriate time". Clearly, in the 2005 joint statement of principles, the commitment to supply LWR is weaker than in the Agreed Framework. The fuel oil deliveries were also miniscule in comparison with the Agreed Framework: 50,000 tons at the value of $\$ 15$ million during the first 60 days (the initial phase) and 950,000 tons in return for disablement. ${ }^{26}$ North Korea may also have wanted to go back to the Agreed Framework for this reason and negotiate an updated version of it with the US.

However, there is no way that DPRK-US negotiations can be segregated from the interests and influence of DPRK's neighbours. The US alliance with Japan seems stronger than ever and, unlike the previous Japanese government, which tried to block negotiations, the Democratic Party government will move to negotiate. South Korea's economic contribution is crucial in any deal with North Korea. The US is sensitive not only to its Asian allies and partners: it 
would not like to undercut China either, which was offended by the North Korean rejection of the Beijing talks.

Throughout 2009, Bill Clinton's successful visit to Pyongyang, the North Korean visit to New Mexico to see Governor Richardson, the invitation to Obama's point man on North Korea - Ambassador Stephen Bosworth - to visit Pyongyang and conciliatory gestures to South Korea signalled North Korea's interest in new talks. A 2010 New Year message issued jointly by the Party and the Army said that North Korea "remains consistent in its efforts to establish a lasting peace system on the Korean Peninsula and make it nuclear-free through dialogue and negotiations". The US noted that the North Koreans were "saying the right things". ${ }^{27}$ The North Korean nuclear negotiator Kim Kye-gwan was dispatched to Beijing to discuss the resumption of talks and Kim Jong-Il was invited to China. The six-party talks have always been a hybrid of bilateral and multilateral diplomacy, and the next round is also likely to entail a combination of both, maybe in a different mix. But is Pyongyang ready to commit to a disarmament/ normalisation deal, or do they seek international acceptance as an NWS?

\section{Rollback experiences: lessons for North Korea}

Many of the lessons from previous cases of nuclear rollback relate to domestic politics. They may or may not be relevant for the case of North Korea, but as long as North Korean politics is so opaque, it is difficult to tell. Individual mindsets, the role of nuclear mythmakers and nationalistic tendencies defy assessment. The military is known to be very influential, most probably also on nuclear and missile issues, but the relationship between the party and the military is hard to grasp in any detail.

Other lessons appear to be of little relevance. There is always a status aspect to nuclear weapons and underdogs in the international system can improve their status by engaging top dogs, but in the case of North Korea the status motive pales in comparison with security concerns. In other cases of proliferation concern, the international non-proliferation norm upheld by the NPT has been important in arresting weapons ambitions, but it hardly took root with any significance in the DPRK. Global disarmament does not matter much, either. A dictatorship fighting for its survival does not pay much attention to the norms and provisions of global regimes and global initiatives for nuclear disarmament except selectively for its own parochial purposes. Had nuclear disarmament become a trend supported by all the big powers, heading for a nuclear-weaponfree world, it may have also had an impact on North Korea, but less so than on other proliferators (with the possible exception of Israel, whose arsenal is inextricably tied to regional conflict formations). The North Korean regime has quite enough figuring out how to cope with its existential problems.

What remains from the list of rollback experiences are alleviation of security concerns; economic inducements; engagement with a view to gain leverage and encourage openness; diplomatic involvement to buy time; and the role of the US and North Korea's neighbours. 


\section{Alleviating security concerns}

North Korea has been quite explicit about the reasons for seeking nuclear weapons: military, political and economic insecurity caused by the hostile policy of the United States. Militarily, it fears attack by conventional forces, and it has been the object of nuclear threats several times over. ${ }^{28}$ Politically, it is concerned about efforts to undermine the regime. Economically, it is worried about the sanctions that are levelled at it, although the policy of self-sufficiency reduces its vulnerability to a minimum. Its insecurity relates both to the United States and to its Asian neighbours, Japan and South Korea in particular.

Since the end of the 1980s, when North Korea could no longer rely on its erstwhile allies, it has pursued a dual strategy of deterrence and threat reduction through reconciliation with its neighbours - deterrence underpinned by new weapons acquisitions; threat reduction by using the same weapons as bargaining chips for normalisation with the United States and negative security assurances. North Korean leaders have even indicated that US forces could stay in Korea as part of a comprehensive peace agreement on the peninsula. Surprising at first, this is classical international political logic: small states are best served by spreading their dependence on many others, and a US presence in Korea may be invoked to keep China and other neighbours at arm's length.

That a small, impoverished and dictatorial adversary would try to use nuclear weapons to forge a security partnership with the United States is hard for Americans to understand and even harder to accept (Hayes 2007a, b). Yet this is what senior North Koreans have consistently said that they want, and there is no reason to disbelieve them. During the Cold War, the US developed special understandings with its major communist adversary (i.e. the Soviet Union), which was of about the same military rank, but to go along with North Korean attempts to trade its rudimentary nuclear and missile capabilities for a special strategic relationship with the one and only military superpower is quite another matter. Short of a special partnership, North Korea may be content with normalisation, but for the US and others this is also hard to swallow. Some segments of the American political system have even been against talking to the North Koreans for fear that it would legitimise an outcast.

Reconciliation means full diplomatic relations, no sanctions, security assurances and a peace agreement on the Korean peninsula, which is a demanding proposition when, at the receiving end, there is a regime with almost no commitment to international norms of political and inter-state behaviour. However, unless North Korea's security concerns are effectively addressed, there is no hope of rolling it back to the NPT fold as an NNWS. ${ }^{29}$

\section{Economic inducements}

In the Agreed Framework, the economic inducements were quite significant. In the disablement phase of the six-party denuclearisation agreement they were tiny in comparison. However, North Korea would almost certainly have pressed for 
LWR reactors in the disarmament phase had it come to that. In principle, the other parties to the Beijing talks held the door open for it.

Judged on the basis of the Agreed Framework, North Korea values its nuclear arsenal to at least \$4-5 billion (Hayes 2007b). Still, it seems that economic inducements matter less than a peace treaty, normalisation and security assurances. The collapse of the Agreed Framework can be interpreted that way: when North Korea took an active interest in uranium enrichment in cooperation with the Khan network, contrary to the spirit of the Framework, and later left the NPT and resumed plutonium production protesting against the military policies of the Bush administration, it sacrificed the assistance package. The security considerations were in the driver's seat. The six-party agreement of 2007 indicates the same: modest economic assistance did not block agreement on freeze and disablement for deletion from the list of state sponsors of terrorism and gradual normalisation. Economic inducements are important - the modest provisions of the Beijing agreement is probably among the reasons why North Korea left Beijing - but less important than progress on the politico-military dimension.

\section{Engagement, leverage and openness}

In relation to North Korea, which has minimum interaction with the outside world, engagement is the way to leverage. Today, there are few items of value that the United States and others can deny to North Korea, especially as long as China is holding back on sanctions. Engagement, on the other hand, brings both sticks and carrots. The more the parties get involved in interactions of value to both sides, the greater the harm if they are terminated, especially for the weaker party, i.e. North Korea.

In a globalised world, closed societies are aberrations. They draw unfavourable reactions from others and risk being beleaguered. Even if an isolationist regime has no nuclear weapon ambitions at the outset, international hostility may bring the idea to the fore. Myanmar is worth watching from that perspective. North Korea is a pariah state, more isolated than any other country and probably also feeling more beleaguered than any other state. Instead of sanctions, which seldom function as intended against closed dictatorships, engagement is all the more important to break such vicious cycles.

Engagement is also a way to openness. Normalisation is bound to create some avenues into North Korean society. The advantages of engagement are manifold: greater leverage, better insights into North Korean affairs, more transparency, human contacts and - possibly - elimination of nuclear weapons in the end. The question is how far North Korea is willing to go. It brings to attention de Tocqueville's classical observation that when a fully-fledged dictatorship begins to open up, it is difficult to control the processes that are set in motion. 


\section{Diplomatic involvement to buy time}

China and South Korea take the long view, waiting for propitious moments to appear. Time is not on North Korea's side. Pyongyang's impatience with Washington and other negotiating partners indicates that it sees it that way itself.

This is not the same as waiting for the communist regime to implode. Six years of inaction under the Bush administration showed the futility of that. The relevant lesson from other cases of reversal recommends sustained diplomatic involvement in order to be in the best possible position to exploit new opportunities that may arise.

\section{The role of the United States}

US administrations have been split on how to deal with North Korea. In the Clinton administration, there were advocates of immediate freeze and dismantlement supporting reassurance and cooperative engagement with the DPRK, more or less in line with North Korea's claim that the role of the IAEA was to verify compliance with the freeze provisions of the Agreed Framework. Clearly, North Korea tried to use the safeguards issue to put pressure on the United States, emphasising that implementation of IAEA safeguards would depend on US implementation of the Agreed Framework. Others wanted North Korea to go by the NPT book, accepting NPT safeguards (INFCIRC 153) and allowing the Agency to reconstruct North Korea's nuclear history.

Divisions within the Bush administration were more serious. Some held that North Korea was bent on getting nuclear weapons and that it would never abandon that objective, arguing that the US should carry a big stick and wait for the regime to collapse. Others believed it was possible to negotiate a reversal of Pyongyang's nuclear programme at an acceptable cost, offering carrots while carrying a big stick. The 2005 Declaration of Principles was signed in that spirit, but only to be followed immediately thereafter by new sanctions that had been prepared by the proponents of confrontational policies. North Korea's nuclear negotiator concluded that the Bush administration was "dysfunctional". ${ }^{30}$ It was seriously split to the end, wavering back and forth over the disablement/normalisation issues throughout 2008.

The Obama administration has been torn between its preference for negotiations and Japan's and South Korea's desire to punish Pyongyang if it went ahead to test another long-range missile - which it did. After the launch, the administration deferred to Japan and South Korea and went for punitive Security Council actions, triggering another full-blown crisis in relations with North Korea. It left a gap between declaratory policy and action policy, between principle and practice, between engagement with North Korea and allegiance to Japan and South Korea.

The uncompromising Bush administration policy - carrying a big stick while waiting for the dictatorship to collapse - proved self-defeating. Confrontational policies usually make it easier for dictatorships to stay, and China would not let 
North Korea collapse anyhow. Waiting for collapse is, moreover, not a strategy. While Bush waited, Pyongyang used the time well to produce another half-adozen nuclear bombs.

Sustained engagement with a view to gradual change has a better chance of succeeding, and it may be the only chance to get rid of North Korea's nuclearweapon capabilities. Confrontational policies have proved counterproductive and nobody wants to go to war. To let the matter drift is not a viable option, either. Critics ask: has it not been tried before - through the Agreed Framework and the six-party talks - and failed? The answer is that it has been tried, but only halfheartedly. If the Obama administration can unite behind a consistent policy of "cooperation for cooperation", sticking rigorously to the agreements that are made, it will do something that has not been done before. Will it be able to? At home, it is hard to rally broad support behind it. Abroad, it has to be compatible with the alliance bonds to Japan and South Korea. Those bonds are too important to be jeopardised by splits over North Korea. But there is no alternative to a cooperative approach.

\section{Negotiating strategies and objectives}

Clearly, the negotiating modalities have to be agreed anew. The principles from 2005 and the experiences from the Agreed Framework and the six-party talks left much to build on, but similar to the Oslo agreements on the Middle East, time-consuming action-for-action strategies have proven vulnerable to misunderstandings, unforeseen circumstances and foul play. In the Middle East, the lesson drawn was that it would be better to go straight to a comprehensive, final settlement. A comprehensive package deal might also be better in the case of North Korea. The parties may therefore want to move faster than before to reduce the time and opportunity for spoilers. Nevertheless, given that both sides are seeking reassurances about the other side's intentions, and that complete and verifiable disarmament cannot happen overnight, there would have to be an element of gradualism.

But will North Korea be willing to abandon its weapons? The only way to find out is to engage them to see how far disarmament can go. If the answer is no, there may still be scope for significant partial agreements to limit North Korea's nuclear activities. For the United States, horizontal proliferation out of North Korea is at least as dangerous as further vertical proliferation in North Korea. In return for steps towards normalisation and economic assistance, North Korea may still be dissuaded to bring all exports of nuclear and missile technologies to a halt. If the answer is yes, the price will no doubt be high, but may be worth paying. 


\section{The relationship between disarmament and non-proliferation}

This chapter winds up Part III by addressing the political and military dimensions of the relationship between disarmament and non-proliferation. Is disarmament important to align the three outliers to the non-proliferation regime? Is it important for purposes of rollback? Does it matter for North Korea and Iran? The other way around, how important is non-proliferation for disarmament? How can the non-nuclear-weapon states (NNWS) contribute to nuclear disarmament by making their non-nuclear status more convincing? Special attention is paid to the distinction between disarmament as a process and disarmament as a state of affairs, and to the concept of rank disequilibrium, which appears to have great explanatory power in cases like Iran and India.

\section{Introduction}

To each of the previous chapters, a disarmament question is pertinent: how important is disarmament in order to bring the three outliers into the nonproliferation regime? How important is it to sustain nuclear rollback? And how much does it matter for the outcome of cases of immediate non-proliferation concern such as Iran? To the extent that the answer is affirmative, the primary responsibility for progress rests with the NWS.

But the responsibility does not stop there, for Article VI of the NPT commits all parties to the Treaty to work for nuclear disarmament. So how can the NNWS contribute? For one thing, they can lean on the NWS to do more, in the name of international security and in reference to international norms. In the face of arms-racing during the Cold War, and of modernisation and widening of the roles assigned to nuclear weapons in this century, this is first of all what they have been doing.

However, the new disarmament initiatives present new challenges and also opportunities for the NNWS. Beyond urging the NWS to enhance their disarmament efforts, they may facilitate disarmament by deepening their own commitments to stay non-nuclear. The more convincingly non-nuclear they become, the easier it will be for the NWS to go to zero. The NNWS may contribute by using carrots as well as sticks: working with the NWS to reduce their proliferation concerns while leaning on them to expedite arms reductions. 
More than anything else, the NPT review process has centred on the relationship between disarmament and non-proliferation. All parties to the Treaty are obliged to pursue both objectives in good faith (on the meaning of "good faith", see Chapter 4). On three occasions, efforts have been made to clarify the disarmament commitment of Article VI and make it more explicit, more binding and more tangible: in 1995, when the Review and Extension Conference adopted "Principles and Objectives for Nuclear Non-Proliferation and Disarmament"; in 1996, when the International Court of Justice issued an Advisory Opinion on the meaning of Article VI; and in 2000, when the Review Conference adopted an agreed roster of steps to implement Article VI, known as the "thirteen steps". All the time, there has been bitter disagreement about the precise contents of the obligations and how well they have been fulfilled. The sources of the disagreements and the clarification efforts have been examined elsewhere. ${ }^{1}$ In the following, the focus is not on the legal-political issues of rights and obligations, but on the political and military dimensions of the disarmament - non-proliferation relationship.

\section{General observations}

From time to time, it has been argued that acquisition of nuclear weapons by more states is a regional matter, driven by regional conflicts and security concerns. The claim absolves the NWS of responsibility for nuclear proliferation. It is fundamentally flawed.

The policies of the NWS affect proliferation/non-proliferation in many ways. First, they shape the security environment of potential proliferators. Recently, the main antagonists of the Cold War have geared their military policies less to each other and more to regional settings, notably to the Middle East, Central Asia and East Asia. This century, all P5 except China changed their doctrines to enhance the utility of nuclear weapons in regional contexts. The focus has first of all been on the Middle East, where Israel had acquired nuclear weapons by the end of the 1960s in response to Arab threats. There, the nuclear proliferation issue has been embedded in regional-conflict dynamics ever since, and it has become increasingly intertwined with big power politics. Also in other parts of Asia, there is an international as well as a regional dimension to the proliferation problem. The NWS have it in their power to twist the proliferation problems for better or worse.

The same powers influence the political environment of potential proliferators by projecting the status value that they attach to nuclear weapons. They have done so by maintaining and modernising big nuclear arsenals and by underlining the importance of nuclear weapons in their doctrines and statements. Some of them have been outspoken about the pride they take in their nuclear-weapon achievements (see Chapter 3). This century, their policies endangered the entire non-proliferation regime. The US, in particular, weakened the non-proliferation norm by buying selectively into the provisions of the NPT. The Obama administration changed that in support of the NPT and its disarmament dimension, and 
to the extent that it succeeds, it projects a diminishing belief in the political value of nuclear arms.

Whatever happens to the call for a nuclear-weapon-free world (NWFW), the thesis that proliferation is driven by regional conflicts and has little or nothing to do with the nuclear policies of the big powers is wrong. It was wrong in the past, and the growing focus on regional politics has made it even more so in recent years. To claim, as NWS sometimes do, that all of this "is inconsequential in the difficult and agonising deliberations of a government to go nuclear is far removed from political realism" (Muller 2008).

\section{Making disarmament credible}

Both governments and non-governmental actors are waiting to see what comes of Obama's disarmament initiatives. Will they materialise and progress towards the goal of an NWFW, or will they come to naught? Reykjavik failed to rid the world of nuclear weapons, but it was not a fizzle: it inspired substantial nuclear disarmament agreements, in casu the INF Treaty and START I. Obama's call for an NWFW is also bringing results, but how far will it go?

There are concerns that it will boil down to a non-proliferation tool stopping well short of elimination of nuclear weapons, and that to the extent that it succeeds and the NPT is strengthened, more restraints on peaceful utilisation of nuclear energy will follow. Modest single steps with no convincing promise of follow-on action may leave that impression, and the broken expectations of the 1990s are close enough in time to be remembered. Then, the NPT was extended indefinitely in the expectation that global disarmament would continue and that progress would be made towards a zonal arrangement in the Middle East (see Chapter 4). If this reading takes hold, the cooperation of many NNWS will be half-hearted at best.

Similar to integration theory, which distinguishes between integration as a process and integration as a state of affairs, disarmament may also be viewed as a process where one step leads to the next, or it may be seen in a static perspective where measures are introduced without any particular promise or expectation of further steps. The neo-functionalist school in integration theory assumed that integration could develop its own dynamic or "spill-over" effect from one sector into related fields (Haas 1958). Later studies have questioned this, emphasising the importance of governmental decisions for successive deepening of integration. Disarmament, if it proceeds, will also rest on governmental decisions. Still, the question is whether the governments will be willing to commit themselves from one step to the next, and whether a disarmament process can develop some momentum of its own.

Single steps towards nuclear disarmament may have little or no impact on governments contemplating going nuclear. For instance, if the US and Russia were to reduce the number of deployed strategic nuclear weapons to 1,000 each with no commitments to further reductions while all NWS modernise their weapon systems, the non-proliferation impact would at best be uncertain. As 
long as the continuation is open to doubt, states of proliferation concern would hardly be impressed.

This would be different if expectations were created that more would follow. Then, proliferators would be singled out as exceptions to a trend of improved compliance with Treaty obligations, Article VI included, and it is always more difficult to act against an existing trend, especially if it enjoys broad support from both nuclear- and non-nuclear-weapon states. If such a trend takes hold, the non-proliferation norm would be enhanced; the states that have rolled back would find it harder to roll forward again; and the international environment for management of critical contemporary cases of proliferation concern would be more benign. In the UN Security Council, decision-making in support of the trend would be easier.

The opposite of single steps in a static perspective is a convention with a timeline for nuclear disarmament to zero. However desirable it may be, the big powers are unlikely to accept it. Big powers are less willing to tie their hands to international rules, norms and standards than smaller ones. Precisely because they are powerful, there is much to gain from being free to exercise the power. So far, the convention proposals have therefore met consistent opposition from the P5. There is, furthermore, something simplistic about reducing the complexities of nuclear disarmament to a timeline.

Are there other ways of committing the NWS so that disarmament becomes a likely prospect in the eyes of the great majority of states? Reintroducing the declaratory policy of the $1990 \mathrm{~s}$ - commitments to systematic and progressive efforts - is not enough. These promises have already been made and broken. However, it is widely assumed that a START follow-on agreement will be followed by negotiations for deep cuts, although Obama and Medvedev have not been explicit about it. Commitments to follow up on one disarmament measure by negotiating another is a first step towards a dependable disarmament trend. Generally, the impact of disarmament on non-proliferation depends very much on where disarmament is perceived to be on the scale between single steps in a static perspective and a disarmament convention with a timeline: the more credible and dependable it becomes as a long-term trend, the stronger the impact.

For almost 50 years - ever since nuclear arms control was introduced in the early 1960s - disarmament measures have been discussed back and forth in great detail. Technically, virtually all stones may have been turned - except perhaps for how to make disarmament a reliable prospect short of using the calendar. In that regard, more options may exist. The NPT is a framework for disarmament to zero, but if and when the world approaches that point, a much more detailed description of the final steps and of what kind of NWFW one should go for must be agreed. The parameters of that discussion will most certainly be different from the ones that apply at present, so the question of timelines may also look quite different.

The bottom line is that as long as some states possess nuclear weapons, others will seek them too. The best way to prevent proliferation is therefore to reduce existing arsenals to zero. The same recipe applies to the danger that nuclear 
weapons might be used. The best, and quite possibly the only, way to avoid it is to do away with them all.

\section{How is disarmament important for non-proliferation?}

There are two broad categories of answers to this question. First, a credible movement in the direction of nuclear disarmament would facilitate the management of the non-proliferation regime. Second, it would affect the nuclear decision-making of states in a non-nuclear-weapon direction.

\section{Disarmament and regime management}

Failure to implement Article VI of the NPT has been a chronic source of friction in the regime. The NPT review conferences have been blighted by disputes over the disarmament obligation; the willingness of NNWS to support and participate in NWS calls for stricter enforcement of the Treaty has been undermined as the NWS have been widely viewed as ignoring their own NPT obligations; and NNWS willingness to support and accept measures to strengthen the regime which often require them to accept additional obligations and constraints - has been weakened for the same reason. Credible nuclear disarmament promotes the cause of non-proliferation because it is a key to improved regime management. This is a familiar point which has been elaborated upon in Chapter 4 and discussed more extensively elsewhere (Miller 2007a).

A similar situation exists at the regional level in the Middle East, where armscontrol and disarmament policies are conditioned by deep-seated regional conflict formations. As long as the Israeli arsenal is untouched, Egypt and other Arab states are generally unwilling to undertake more arms-control obligations. For instance, Egypt has not acceded to the CWC, the BWC, the CTBT, the Additional Protocol on safeguards and the Pelindaba Treaty declaring Africa as an NWFZ. In the Middle East, the nuclear arms-control and disarmament approach is an NWFZ or a zone free of all WMD. UNSC Resolution 687 - the 1991 ceasefire resolution for Iraq - explicitly linked the disarmament of Iraq to the establishment of a zone free of WMD in the Middle East, and in 1995 the NPT Review and Extension conference adopted a Resolution calling for such a zone and for Israeli accession to the NPT. ${ }^{2}$ This facilitated Arab acceptance of the decision to extend the NPT indefinitely. As no progress has been made in implementing the Resolution, Arab states feel that their NPT commitments have been met by broken promises. They are therefore holding back on additional arms-control commitments. The Iranian challenge reinforces this attitude and inspires hedging policies.

It follows, conversely, that if the NWS move to disarm and if Israel's nuclear capabilities are effectively addressed and constrained, global and regional frictions within the regime will be reduced, the review process will be more constructive, and the opportunities to strengthen the regime and enforce its provisions will be improved. These are important links between disarmament and non-proliferation. 


\section{Disarmament and nuclear decision-making in states}

\section{Disarmament and the devaluation of nuclear weapons}

Disarmament is not only about the weapons but also about the doctrines that define their roles. The doctrines have been variations of nuclear deterrence: deterrence by mutually assured destruction; deterrence of conventional forces; deterrence of chemical and biological weapons; and extended deterrence in cooperation with allies in Europe and East Asia. The nuclear war-fighting doctrines of the Cold War were also spins on deterrence. Since deterrence rests on the credibility of nuclear-weapon use, it was argued that the best way to convince the adversary about it would be to plan as if nuclear war could be similar to conventional war and be lost or won (see Chapter 3).

Nuclear history may be read as a political struggle over the utility of nuclear weapons for the security of states, and over the viability of nuclear deterrence in particular. On the one hand, there is the creeping norm of non-use that tends to undermine deterrence: the more time that passes without nuclear weapons being used, the stronger the norm of non-use. On the other hand, vested interests and believers in the utility of nuclear arms have made recurrent efforts to stem that norm. New weapons were developed that would be more thinkable to use, and that would therefore also more likely be used. Ships and other nuclear-weapon platforms were sent to hot spots around the world in shows of force instilling respect and awe. When these options were curtailed by the moratoria on nuclearweapon tests, which made it hard to introduce new types of weapons, and by the US-Soviet/Russian presidential initiatives that removed tactical nuclear weapons from ships and other platforms, the doctrines were expanded to include a wider range of situations in which nuclear weapons might have a role. More than 20 times, the United States has issued nuclear threats in some shape or form, apparently in the belief that they might function as intended, and all the time the importance of nuclear weapons has been emphasised in speech acts by state leaders. From a non-proliferation point of view, the problem with these efforts to sustain the credibility of nuclear deterrence is that they have kept telling others how important nuclear weapons are. In upholding the utility of nuclear weapons for themselves, the NWS have been teaching others the same lesson.

The problem is also that, in trying to show what nuclear weapons can do, their utility has been much inflated. Fortunately, some of the most glaring exaggerations are now receding. The nuclear war-fighting doctrines were among the most bizarre products of the Cold War: they have been toned down, if not totally laid to rest. The credibility of US extended deterrence doctrines for Europe and Asia were always in doubt: they are now ripe for revision. Shows of force and threats of nuclear-weapon use may or may not have worked: in most cases the effects can neither be proved nor disproved. Realistic reviews of nuclear history in these respects, deleting the propagandistic arguments to uphold deterrence and justify investments in huge arsenals, therefore reduce the attractiveness of nuclear weapons and so contribute to non-proliferation. In reality, the inhibitions 


\section{4}

\section{Proliferation problems}

against nuclear-weapon use - the nature of the weapons and the norm of non-use - probably leave a very narrow range of situations where employment is feasible and credible (Berry et al. 2010).

One such situation concerns the use of nuclear weapons where national survival is at stake. In its Advisory Opinion of 1996, the International Court of Justice was split on this issue. The prime example at the time was Israel. Today, Pakistan could be added, and possibly Russia and even China. The Russian doctrine of 2010 appears to tighten the criterion for use of nuclear arms, but allows for employment when "the very existence [of Russia] is under threat" (Sokov 2010). China's no-first-use policy may not apply if its own territory, or territories that it claims as its own (such as Taiwan and Arunchal Pradesh), are under threat. The fear in these huge state conglomerations is that dismemberment, even on a small scale, might be the beginning of national breakdown. ${ }^{3}$ The role of nuclear weapons as an insurance premium of last resort for national survival speaks to the obstacles that have to be overcome for an all-encompassing international agreement on no-first-use to be reached.

The treaties prohibiting chemical and biological weapons were preceded by the Geneva Protocol of 1925 which prohibited the use of these weapons. First, the use of the weapons was delegitimised and outlawed, and then they were banned. The same approach also has traction for nuclear disarmament. The Court found it hard to contemplate a use of nuclear weapons that would be compatible with international humanitarian law. Certainly, nuclear weapons are no less inhumane than chemical and biological weapons.

In effect, the Geneva Protocol was a no-first-use agreement, and an agreement banning the use of nuclear weapons would also allow for nuclear retaliation. Such doctrines - adopted unilaterally or agreed bilaterally or multilaterally with a view to codification in an international convention - would go a long way to devalue nuclear arms and send an important message to decision-makers of other countries that have not closed the nuclear-weapons option. Moreover, nofirst-use doctrines have an intriguing in-built disarmament logic: nobody would need them if nobody had them.

Genuine moves towards disarmament will be rooted in the premise that nuclear weapons are unnecessary and undesirable. Tightening of doctrines and international conventions to devalue the weapons must be accompanied by hardware reductions: the latter is necessary to ensure the credibility of the former. To the extent that it happens, the international context of national decision-making will change and become more benign for non-proliferation.

Specifically, how important is disarmament in order to align the three outliers with the non-proliferation regime? How important is it for nuclear rollback? And how important is it for non-proliferation outcomes in Iran and North Korea?

\section{Disarmament and the three-state problem}

India has not undertaken any Article VI obligation. The first part of Article VI - "cessation of the nuclear arms race at an early date" - is void of Indian 
commitments. It has not acceded to the CTBT; its support for an FMCT is an act of cynicism undertaken in the expectation that it will take a long time to bring negotiations to a conclusion, if it is possible at all; and since it is not formally recognised as an NWS, it is not a bona fide provider of security assurances to others. The second part of it - the commitment to disarm - is contradicted by Indian rearmament. Its declaratory policy is dual track: the pragmatic one which aligned it with the existing arms-control regime and positioned it for the nuclear cooperation agreement with the United States, and the normative long-term one charting a road to zero, revived by the American call for an NWFW. For the time being, these tracks co-exist, side-by-side (see Chapters 3 and 5).

In important respects, the impact of disarmament comes down to the timeline for US-Russian arms reductions versus the timeline for the establishment of an Indian minimum-deterrence force. Subsequent to the START I follow-on agreement, the next round of US-Russian negotiations is supposed to take a long time - a number of years. If it is successfully completed before the Indian deterrent is ready, and invitations for multilateral disarmament talks are issued, it is conceivable that the size of the Indian force will be affected. Then, the build-up might stop at a lower level than would otherwise have been the case. However, the basic assumption is that India is unlikely to be ready for cessation of its arms build-up and for nuclear disarmament talks until a minimum deterrent force - somehow defined - has been fully established. More and more, the impression is also that US-Russian negotiations will be very demanding and time-consuming.

A criteria-based approach to all three outliers, based on the commitments already undertaken by India plus signature or accession to the CTBT and limitations or a ban on fissile material production - the bar may be set higher or lower - may lead to de jure recognition of India as an NWS before the deterrent is complete (see Chapter 5). That would open up an opportunity for an extension of Indian security assurances to NWFZ and, in principle, for Indian participation in any multilateral arms-control and disarmament undertaking. Pakistan and Israel have a longer way to go in order to meet such criteria.

India wants to become a big power on the global scene, and its nuclearweapon programme has global ramifications. If it comes to multilateral talks, it wants to be in a position to take part. Pakistan's behaviour is inextricably linked to India's. Pakistani participation would be logical and desirable as well (see Chapter 10).

Israel's outlook is primarily regional. Its nuclear arsenal is part and parcel of the conflict formations of the Middle East. No NWS is so insulated against the effects of global disarmament as Israel, partly by its own policy of opacity and partly because it is shielded from external pressures by the Western powers (Cohen 2010). Generally, the more threatened an NWS feels, the more difficult it is to make it disarm; and the more intractable the conflict formations that gave rise to the nuclear weapons are, the harder it is to eliminate them. On both counts, Israel stands out as a formidable obstacle to the worldwide elimination of nuclear weapons. 
In no part of the world is the need for regional solutions stronger than in the Middle East. The name of the game is a nuclear-weapon-free zone (NWFZ) or a zone free of weapons of mass destruction (WMDFZ).

\section{Disarmament and nuclear rollback}

In Chapter 6, 27 cases of nuclear rollback - states that have "done something" in the direction of the weapons option and then abandoned it - were divided into three categories: rejectionist, hedging (active or passive) and practising restraint (stopping, but not rolling back). For the rejectionists, nuclear-weapon acquisition is a non-issue. For them, it would take revolutionary world-order changes and a radically enhanced role for nuclear weapons in international affairs to reconsider this stance. Australia, Canada, Germany, Italy, the Netherlands, Norway, Spain, Sweden and Switzerland are in this category. Being highly industrialised states, they have much of the knowledge and technical-industrial capacity to build nuclear weapons on short notice, but their non-nuclear status rests on a solid national political consensus. These states are therefore insensitive to questions of disarmament/rearmament, for they already decided to disconnect themselves from what the NWS are doing. Much the same goes for Romania and Serbia, which are technologically less advanced, and for the four states that possessed nuclear weapons but gave them up - Belarus, Kazakhstan, South Africa and Ukraine. However, some of them are politically less stable than the countries listed above.

Disarmament arguably begins to matter in relation to states that are passively hedging, such as Argentina and Brazil. Disarmament may confirm and reinforce their decisions to stay non-nuclear and broaden national support for that stance. No progress in disarmament affairs may work the other way around, reminding them of the utility that others continue to assign to nuclear weapons and strengthening factions that prefer a response in kind such as active hedging or, possibly, weapons acquisition.

South Korea and Taiwan are hybrids of active hedging and restraint. Their capability levels are higher today than at the time of rollback 20-30 years ago, but they have had to abstain from fuel-cycle facilities. In the past, both of them entertained the nuclear option for security reasons (Hersman and Peters 2006; Solingen 2007): developments in China and North Korea and concerns about Japan triggered material preparations for weapons on more than one occasion. Their security concerns have been offset by the US, which has kept them nonnuclear by extending security guarantees and providing weapons, and which continues to do so. In both countries, transitions from military to civilian rule, democratisation and growing sensitivity to international norms were helpful in rolling them back.

South Korea's and Taiwan's policies remain sensitive to changes in the regional security environment and in their ruling elites, but they are not directly affected by the disarmament policies of the leading nuclear powers. Major power disarmament is important only if it encourages North Korean reversal to 
non-nuclear status, Chinese moderation and Japanese restraint. The pertinent question is therefore whether the US and Russia can encourage the regional powers to go for arms control and disarmament by taking the lead and setting good examples.

To impress North Korea is a long shot. For the leaders in Pyongyang, nuclear weapons are the primary means of regime survival. The price for giving them up is not written in terms of global disarmament. China's nuclear posture depends on the overall size of US nuclear forces; the future of the US ballistic missile defence (BMD) programme; whatever conclusions it draws from the US global conventional strike programme; and its overall assessment of US policies for the long term. Will disarmament gain broad enough support in US political life to become a sustainable long-term ambition, or is it more likely to change from administration to administration? Will global disarmament become a dependable process, or is it more realistic to consider it a state of affairs where there is no certainty that one step will be followed by another in the same direction, and where new programmes - conventional and nuclear - can go forward in areas that have not been regulated? If at some stage it is seen to be the first, the impact will be significant. If the second is judged more likely, a rapidly growing China has the resources to take precautionary measures. Some significant probability - not necessarily a high one - may be enough to make it act defensively and keep the guard up.

Last but not least, there is some evidence to suggest that the single most important way to stem proliferation is to enhance the non-proliferation norm anchored in the NPT and in NWFZs (see Chapter 6). Disarmament is perhaps the most important way to secure the integrity of the NPT: it follows that much of what disarmament can do to sustain nuclear rollback goes via the nonproliferation norm upheld by the Treaty. In 1995, when the NPT was extended indefinitely, NWS leaders may have thought that proliferation could be managed without caring much about nuclear disarmament (see Chapter 4). This has changed: today, disarmament is widely seen as important for non-proliferation. ${ }^{4}$

\section{Does disarmament matter for North Korea and Iran?}

It is customary to assume that no such relationship exists. It simply does not speak to their vital concerns. Others take the view that, in the end, economic measures and security assurances will prove unsuccessful as long as the NWS demonstrate so strongly how important they consider nuclear weapons to be (Harrison 2006). It will not be possible to convince all others that what is good for the existing NWS does not serve the interests of anybody else.

A third view centres on the non-proliferation norm as an intermediate variable. By complying with the norm, states can build an image of being a nonthreatening member of the international community, and in that sense become a nation in good standing. By breaking the norm, proliferators risk being sanctioned against and turned into pariahs in international affairs. North Korea belongs to that category for many reasons other than its nuclear policies, but even so, the nature of its nuclear programme and its withdrawal from the NPT 
underscores it. North Korea says it aims at reconciliation and normalisation with the United States and other countries, and if a stronger non-proliferation norm evolves, reversal to non-nuclear status would be all the more important to make it happen. A strong non-proliferation norm therefore matters, and nuclear disarmament is crucial to achieve it.

The NPT has more members than any other multilateral arms control treaty, but this is not to say that it was the Treaty that shaped the non-nuclear policies of its prospective members. In many cases, it may have played little or no role in foreclosing the nuclear-weapon option. But once new members came on board, they have taken a distinct interest in other members' compliance with the Treaty. This is a bonus for the Treaty. Indeed, some states acceded to the NPT on the explicit condition that there would be no more than five NWS. However, a record number of members notwithstanding, the viability of the NPT and the strength of the nonproliferation norm have suffered from the NWS failure to honour their disarmament obligations. The end of the Cold War raised expectations that the numbers and roles of nuclear weapons would be radically reduced and limited, but while the arsenals were cut, the NWS did not abandon their long-term intention to retain nuclear weapons, and they widened the roles assigned to them. It was not until 2009, when the US revived the vision of an NWFW, US-Russian disarmament talks started again, and SC Resolution 1887 was adopted that trends began to turn for the benefit of the non-proliferation regime.

Iran is not North Korea. By early 2010 it remained a member of the NPT. In principle, it was on negotiating terms with the P5+1 to find a solution to the nuclear issue and associated economic, political and security problems, although the obstacles loomed high and new sanctions were underway. The government in Tehran was, moreover, hampered by internal conflicts. It was not alien to questions of global disarmament, but faced more urgent problems in relation to the Western powers and its immediate surroundings.

There was no prospect for US-Russian disarmament negotiations to have any direct impact on it. Even if, in principle, deep cuts and subsequent invitations for multilateral talks would have mattered, the timelines do not match. Deep cuts can hardly be achieved in time to affect the outcome of the Iranian nuclear problem. However, resolution of underlying political problems between the US and Russia, which is a prerequisite for progress in the nuclear negotiations, may also bring the parties closer together on matters pertaining to Iran. An indirect impact via the NPT could not be ruled out either, especially if Treaty implementation is seen to become more just and withdrawal becomes more difficult. Justice is a key word in Iranian politics and diplomacy.

\section{How does non-proliferation matter for disarmament?}

\section{Non-proliferation as a prerequisite for disarmament}

At the Reykjavik summit of 1986, it hardly occurred to Reagan and Gorbachev that nuclear disarmament was more than a two-state problem. The bipolarity of 
the Cold War was so dominant that if the superpowers leaped towards an NWFW, the other NWS were supposed to follow suit. As the bipolar world became history and the unipolar moment receded, no single state or dyad of states can trump the others. In the multi-centric world of this century, many states will weigh in on the politics of disarmament. The first thing to be said about the importance of non-proliferation for disarmament follows on that note: the more states that acquire nuclear weapons, the more complex and difficult the road to zero will be.

The four states that are not members of the NPT are all NWS, so another proliferator would come from the ranks of NPT members. A break-out would certainly be a set-back for nuclear disarmament: another NWS would have to be contained, deterred, isolated or accommodated into the international system; the importance of nuclear weapons in international affairs would be reconfirmed; and the risk of further proliferation might be significant.

Could it not be the other way around, a new NWS showing the dangers of nuclear proliferation, providing additional incentives for the large majority of states to get rid of all nuclear weapons? After all, it was in the aftermath of the Indian, Pakistani and North Korean tests, and of enhanced worries about nuclear terrorism after $9 / 11$, that the vision of an NWFW was revived. However, a more accurate reading of the factors that prompted the "four horsemen", President Obama and leaders of other countries to reach out for comprehensive nuclear disarmament starts by stressing the seriousness of where we are: if the trends are not turned now, it will be more difficult later.

That assessment is most probably correct. It is virtually inconceivable that a process of nuclear disarmament will prosper in a world where nuclear weapons are spreading. The existing nuclear powers are very unlikely to push for nuclear disarmament under those circumstances. Hence, a more robust, reliable and effective non-proliferation regime is indispensable for the cause of disarmament.

\section{Non-proliferation near zero: containing the break-out problem}

At very low levels, non-proliferation becomes of special importance in order to facilitate the final steps to zero. If each NWS is left, say, with some tens of weapons, the break-out risks could be too big for comfort. The retaliatory capabilities may be in doubt: some weapons may be destroyed in an enemy attack, others may be intercepted and yet others may not function as planned. As a result, bickering and nervousness over small numbers may increase the risk of surprise attack and inadvertent escalation when decision-makers begin to believe that war can no longer be avoided. Not only would the NWS be concerned about each other: they would also be concerned about possible newcomers - unless more effective non-proliferation barriers are developed.

Therefore, the closer disarmament comes to zero, the more important nonproliferation becomes. If there remains a significant risk of break-out from the ranks of NNWS, the NWS will hardly be willing to take the last steps to an NWFW. The nuclear powers are the ones to abandon their privileges and accept 
equal rules for all, so in contemplating the final qualitative jump from nuclear- to non-nuclear-weapon status, they will have to be convincingly assured against break-out. The distinction between civilian and military applications of nuclear energy inscribed in the NPT and the current safeguard agreements will certainly not be good enough.

A world immediately below zero may also be unstable. This is a world where a mobilisation base for rapid reintroduction of nuclear weapons is maintained. In such a world, the possibility of nuclear war might still be entertained. Many states may think that hedging is prudent, leading to hedging races to be able to turn capabilities faster and faster from virtual to real. Virtual arsenals also need arsenal keepers, and they are never neutral experts, but socio-economic actors with a vested interest in what they are doing. They would quite possibly push for stronger capabilities and even the reintroduction of weapons. In break-out scenarios, first-strike capabilities are more likely to emerge than in current nuclear constellations.

It follows that minimum deterrence levels in the low hundreds may have been chosen for good reason. They provide a greater degree of stability than arsenals in the low tens. In Chapter 10, it is therefore argued that it would be wise to stay at such levels until nuclear-weapons infrastructure and weapons-grade materials have been eliminated, and then go straight to a world below zero.

The path dependency of nuclear disarmament must always be kept in mind. It may be assumed that when disarmament approaches zero, the weapons have been devalued to such an extent that issues that appear important by today's standards have become of little significance. The concerns about nuclear stability may have changed or disappeared. Still, it may take only one state to rock the boat, so a robust non-proliferation regime would probably have to be in place. It is not possible to be definite about these issues, however heuristic assumptions about advanced stages of disarmament may be flawed, but they are important to stimulate the debate about the feasibility and desirability of an NWFW.

\section{Regional proliferation as a threat to global disarmament}

The consequences of break-outs are not uniform. They depend on who the proliferator is and on the circumstances in which it happens. A vulnerable regime fighting with its back against the wall, acquiring nuclear weapons in the belief that this would improve their chances of survival, does not necessarily trigger proliferation. North Korea did not, neither did South Africa. The hypothetical case of Myanmar may be similar. In Japan, some political factions stressed that in response to North Korea's acquisitions, the policies of extended deterrence and first-use would have to be maintained, and the question of Japanese nuclear weapons was brought into the public domain for discussion. Recently, however, the Hatoyama government has been working with the United States to reduce the role of nuclear weapons in the defence of Japan.

If Iran were to break out of the non-proliferation regime and establish itself as an NWS, the consequences would be more far-reaching. If it is bombed in 
preventive action, the consequences would be particularly detrimental. If it had not been going for nuclear weapons before being bombed, it would be most likely to do so afterwards. The experience from Iraq after the 1991 bombing of Osiraq - it was after the bombing that Saddam mobilised his resources behind a secret nuclear-weapons programme (see Chapter 4) - would repeat itself. The ominous comparison with North Korea would be confirmed and generalised: adversaries without nuclear arms risk being attacked; those who have them, do not.

The largest states are all NWS. In terms of size, the next in line are Japan, Brazil, Nigeria and other regional big powers followed by smaller states that are almost certain to be confined to regional politics. Further proliferation, if it happens, will therefore be embedded in regional-conflict formations. For some time, leading NWS have oriented their foreign policies and military preparations more and more towards regional affairs, their nuclear policies included. The introduction of more NWS would therefore interact with regional and global affairs in new and complex ways that defy prediction. In East Asia, the wars of the twentieth century still cast long shadows on international relations; the Taiwan problem has not been solved; and in the South China Sea there are many unresolved territorial issues. In the Middle East, the situation is as precarious as ever: this is the most volatile of all regions. The negative impact of further proliferation must therefore be seen through regional lenses.

\section{How to understand Iran: some theoretical reflections}

The break-out issue of immediate concern is that of Iran. If Iran weaponises its programme, more states will invest more in nuclear technologies, and ballisticmissile defence will get another boost, generating its own problems for nuclear disarmament. Then, regional-conflict dynamics in the Middle East would pose formidable obstacles in the way of nuclear disarmament. For good reason, the Iranian problem has come to drive a wide range of policies and debates about the non-proliferation regime.

In Chapter 6, two propositions of particular relevance for the Iranian problem were identified: playing the status gains of nuclear weapons down and/or playing status substitutes up; and paying special attention to oppositional nationalists combining fear and pride, security and status concerns. Chapter 7 takes a closer look at them.

Status ambitions are difficult to pin down because, for obvious reasons, governments are loath to talk about them. There is something illegitimate and even bizarre about seeking prestige through acquisition of the most destructive of weapons. For scarcity of empirical references to capture the importance of it, some theoretical reflections may be in order.

All NWS have justified their nuclear-weapon acquisitions in reference to national security. States need to deter potential attackers, and the gold standard of deterrence is nuclear weapons. What really made them acquire nuclear weapons is another matter. In France and India, status considerations were important, and such ambitions played a role in Britain, too. 
In Iran, national status considerations play out in ways that resemble France in the 1950s and 1960s. For France, the nuclear-weapon programme was instrumental in raising its international status and reviving an independent French foreign policy. For Iran, the nuclear programme is a status item that can be invoked to become recognised as an important power in the Middle East. Its influence in the region has increased after the invasions of Iraq and Afghanistan, but far from recognising it as a legitimate regional player, the United States and other countries are doing their best to contain it. ${ }^{5}$

To help explain how states handle their status concerns, the concept of "rank disequilibrium" is helpful. An actor high on some status dimensions and low on others is constantly reminded of it through the differential treatment it is exposed to: invited into the good company where its rank is high, and ignored where it does not matter (Galtung 1964). Rank disequilibrium is an untenable state to be in, calling for corrective action. Invariably, the answer is to try to raise one's rank on dimensions where it is low. The preferred solution is never to equilibrate by moving in the opposite direction, from high to low across the dimensions that matter. The tendency is always to maximise one's assets. High rank - being in the upper echelons of international hierarchies - is an important source of power.

One such top position is nuclear-weapon status. Karl Marx noted that the most effective power is the structural one that functions without being actively used. Military force is a case in point. It may translate into influence without being activated. States have a fine eye for who is more and who is less powerful and accommodate - consciously or not - to the strongest ones. By instilling respect and awe, military force can have an impact just by being there and being seen. Nuclear weapons are particularly effective in this respect, for not only do they represent the highest destructive potential known to humanity: possession of them is also limited to a few. Their status value is particularly precious as long as they are rare. No wonder that the five powers that first tested nuclear weapons - the five permanent members of the UN Security Council - tried to pull the ladder up behind themselves by urging everybody else to accede to the NPT as NNWS.

Of course, the possibility that the weapons may be used must always be there. If not, there would be nothing to fear and nothing to gain for the possessors. Nuclear weapons would cease to be a structural political asset. The impression that nuclear weapons may be used can, however, be maintained in a variety of ways short of war. The measures that have been taken throughout the nuclear age to stem the creeping norm of non-use amply illustrate this.

It is interesting to compare the status aspirations of India and Iran. For a long while, India was in a state of disequilibrium ranking high on many dimensions, but without enjoying nuclear-weapon status. It took steps to become a more generalised top dog in 1998, when it conducted a series of weapon tests, and took another step in that direction in 2008 when the US-India agreement confirmed its de facto possession of nuclear weapons and made it a bona fide partner in international nuclear commerce. Sooner or later, de jure recognition will follow. 
Iran is also in a state of disequilibrium. Compared with neighbouring Pakistan, it is in a domestic disequilibrium, a bit like India. Pakistan is poorer than Iran and a young and fragile state, while Iran is an old power with a glorious past. Yet Pakistan has nuclear weapons, an imbalance that Iran may remedy through its nuclear programme, be it a civilian prestige programme or, in the end, a military one. More important, however, is the international disequilibrium it is exposed to: it is a big country in the Middle East, representing a proud Persian civilisation and thinking at least as highly of itself as of its neighbours and opponents, but feels underestimated and humiliated, and for good reason. This situation cries out for correction (see Chapter 7). It may be overcome by giving Iran a regional role in the Middle East that comes closer to the role it feels entitled to. This is a delicate matter, however, for it takes nothing less than a new political equilibrium in the region at the cost of some Arab states. To avert the most imminent break-out threat must therefore be a shared responsibility, for a new equilibrium can only be worked out in cooperation between the P5+1 and regional states. If not, Iran may try to do what India did, only on a smaller scale tailored to its capabilities. If the first approach is blocked, it is more likely that the second will be tried.

India was an ardent supporter of nuclear disarmament for decades. In theory, disarmament - eliminating the very dimension on which it scored low - was a way to achieve rank equilibrium. It tested a nuclear device in 1974, but waited another 24 years before testing weapons. In the meantime, it argued for example for a nuclear-weapon convention with a timeline to zero. In this and other ways, the Indians exercised moral leadership, but the realism and sincerity of their disarmament efforts were open to doubt both in their own minds and in the eyes of others. In the mid-1990s, when the period of opportunity after the Cold War was closing, there could no longer be any illusion that this approach would succeed. Still, the diplomatic efforts were useful in building legitimacy for exercising the nuclear-weapon option. By 1998 India was, moreover, set on a path of solid economic growth, so it was in a better position to invest in the nuclear-weapon programme. The self-righteousness was there as well, meaning that it was determined to equilibrate upwards. Compensation in the form of a bonus in some other field for staying non-nuclear was out of the question. Such bonuses are the poor man's reward. Big India wanted to be recognised as an NWS.

In the case of Iran, the choice may still tip the other way. If Iran's status aspirations can be met and its security concerns alleviated, the incentives for going nuclear would be much reduced. Under such circumstances, peaceful uses of nuclear energy may be pursued to the satisfaction of all and under verification arrangements that may not have to go much beyond what is normal for a nonnuclear member of the NPT. Full transparency and growing confidence in a nonnuclear future are keys to it. If, on the other hand, the road to regional status is blocked, Iran may turn to nuclear weapons as a means of rank equilibration like India did. However, in two important respects there is no comparison between Iran and India: the body weight of Iran is far from that of India; and Iran would have to act in defiance of the NPT. India never joined the Treaty. 


\section{Shared responsibilities for disarmament and non-proliferation}

The NPT links disarmament (Article VI) and non-proliferation (Articles I and II), and gives all members an inalienable right to access nuclear energy (Article IV) in conformity with their non-proliferation undertakings (Articles I and II). These are shared responsibilities: Article VI says: "Each of the parties ... undertakes ..."; Article IV is "the inalienable right of all the Parties ..."; and nonproliferation - not to transfer (Article I) and not to receive (Article II) - is, similarly, a shared responsibility.

Scott Sagan has introduced a conceptual framework that addresses shared responsibilities for the management of nuclear break-out dangers; for developing a proliferation-resistant fuel-cycle regime; and for rethinking nuclear deterrence (Sagan 2009b). The novelty of his approach is the focus on what the NNWS can do to implement the Treaty, jointly with the NWS. What the Treaty actually says in this respect has been under-communicated, if not completely ignored, for the usual way of describing the grand bargain from the second half of the 1960s has been to emphasise what the two categories of states - nuclear and non-nuclear are obliged to do, each more or less on their own.

The following is a review of issues where NNWS can do more and better to meet their part of the Article VI commitment and the disarmament-nonproliferation bargain: fuel-cycle controls; transparency and safeguards improvements; reduced reliance on nuclear weapons for extended deterrence; anchoring non-nuclear-weapon commitments in domestic law; reserving the benefits of NPT membership; and clarifying the right to withdraw.

\section{Preventing the spread of fuel-cycle facilities}

The fuel-cycle issues are of immediate as well as long-term concern. Today, they are at the heart of the Iranian issue, and unless new arrangements to forego national fuel-cycle facilities are introduced, they will become a vexing problem as nuclear power spreads. At an advanced stage of nuclear disarmament, it is doubtful whether the NWS will proceed to an NWFW if other states have national fuel-cycle facilities that can produce weapon-grade materials on short notice (Perkovic and Acton 2008; Sagan 2009b). The NNWS should therefore see it as part of their disarmament obligations to promote multinational and/or international arrangements that draw a clearer distinction between civilian and military applications of nuclear energy. A variety of proposals have been made in this respect, first towards the end of the 1970s (SIPRI 1980) and in greater depth in this century (Yudin 2009). The development of such arrangements must be guided by the principle of equity (see Chapter 10).

\section{Transparency and safeguards improvements}

Transparency is needed in order to enhance predictability; predictability is essential for the development of mutual confidence; and mutual confidence is needed 
for arms control and disarmament. This is, in a nutshell, the philosophy behind military confidence-building measures, first introduced in the framework of the Conference on Security and Cooperation in Europe (CSCE) in the 1970s. Transparency is a fundamental condition for arms-control and disarmament agreements as well: what is not transparent cannot be verified, and without verification, arms-control and disarmament agreements are not relied upon. In view of the importance of nuclear weapons and the modest degrees of trust in inter-state affairs, transparency is particularly important in this field. Obviously, both nuclear and non-nuclear-weapon states have a responsibility to promote transparency on behalf of nuclear disarmament.

One such area of shared responsibility concerns improvement of the safeguards system of the non-proliferation regime - the non-nuclear states for accepting upgraded safeguards and the nuclear ones for accepting such safeguards on all of their civilian activities. ${ }^{6}$ The latter should be required under an FMCT: if verification is limited to reprocessing and enrichment facilities, it would introduce another distinction between the two categories of states - selective safeguarding of such plants in NWS and full-scope safeguards in NNWS. At the end of the disarmament road, the NWS would also become NNWS, so safeguards on all civilian activities can be seen as a step on the way to a world without nuclear arms. For the NNWS, acceptance of upgraded safeguards - the Additional Protocol and further improvements to come - is another way of enhancing the credibility of their non-nuclear status, adding to what an international fuel-cycle regime can do to facilitate disarmament.

In the beginning, acceptance of safeguards was not linked to implementation of other Treaty obligations. What was agreed when the NPT was negotiated was the need to reassure the parties that the non-proliferation obligations were kept. There was agreement, in principle, on the need for adequate safeguards. To be taken seriously, arms-control agreements must be verified, and the safeguards system that was adopted in the early 1970s was an advanced one for its time. However, what is considered adequate will obviously change as new technologies and new experiences are obtained: it began with full-scope safeguards (INFCIRC 153), continued with the model Additional Protocol (INFCIRC 540), and in due course further improvements will certainly be called for. However, while linkage arguments are not justified in the light of negotiating history, the linkage politics of a number of NNWS is a political fact that has to be attended to. They are holding back on their arms-control commitments as long as the implementation of rights and obligations under the NPT is deemed to be imbalanced. In the Middle East, many states are doing so as long as the Israeli arsenal is unrestrained.

\section{Cutting back on extended deterrence}

In Europe and East Asia, extended deterrence postures that are supposed to deter conventional as well chemical, biological and nuclear attack still exist. Since the end of the Cold War, NATO and Russian first-use doctrines have been out of 
touch with political realities, especially between the EU and Russia, which declared each other strategic partners many years ago. By January 2010, some 200 US nuclear weapons remained in Europe.

However, many NATO allies do not want nuclear weapons on their soil any longer, and the first-use doctrine is questioned both in Japan and Europe. The credibility of it was always in doubt. The French used to argue that only a national finger on the nuclear trigger would do (Ledwidge 1984). Henry Kissinger said much the same, criticising the Europeans for "asking us to multiply assurances that we cannot possibly mean" (Kissinger 1979). To pretend to be willing to defend Europe by inviting an act of mutual suicide was never credible. The best that could be said in support of it is that, since the doctrine has been consistently repeated over the years by all alliance partners, the adversaries may have assessed the likelihood of its implementation to be a figure above zero.

During the Cold War, the non-nuclear allies often worked with the US to reinforce extended deterrence postures based on first-use doctrines. Practitioners of threat-based policies fed on each other, cooperating to beef up threat perceptions and justify requests for more weapons. Referring to each other as "the Europeans" and "the Americans", they often monopolised the debates.

Such interactions have also been at work in US-Japan relations recently. The 2009 report of the US Congressional Commission on the Strategic Posture refers to private discussions with unnamed Japanese officials urging the US to maintain its nuclear presence in the Pacific, the nuclear-tipped Tomahawk cruise missile (TLAM/N) included. In a letter to Hillary Clinton, Foreign Minister Okada noted that neither the former government nor his own had expressed any views concerning weapon systems such as the TLAM/N or a robust nuclear earth penetrator. Instead, he reiterated his interest in discussing "suggestions that the role of nuclear weapons be restricted to deterrence of the use of nuclear weapons", i.e. transition to a no-first-use doctrine. ${ }^{7}$ In Europe, the issue is much the same. Neither NATO nor nuclear deterrence is at stake at this juncture, but the question is what the nuclear weapons should deter: any attack or nuclear attack only. NATO is conventionally superior - the US accounts for 45 per cent of world military expenditure and Russia for 3 per cent (SIPRI 2009) - so for NATO there is no military need to maintain the first-use option. There is no need to keep US nuclear weapons in Europe either. They serve no purpose, and if NATO functions democratically, they will soon be removed. If so, all the world's nuclear weapons will be back with their possessors.

By acting to remove all nuclear weapons from their soil and going for nofirst-use policies, states that remain under extended deterrence arrangements can help diminish the role of nuclear weapons in the nuclear planning of the US. Both in Europe and in East Asia, the governments of NNWS can now cooperate with the US government to move the nuclear postures in this direction, and some of them are actively doing so. In both regions, such cooperation is important to counteract and delegitimise whatever collusion goes on in secret, non-democratic channels between Cold War vintage believers in the importance of nuclear 
weapons. To prevent a fall-back to forward stationing, no nuclear weapons in the territories of others may be turned into a new, universal principle.

\section{Anchoring non-nuclear-weapon commitments in national law}

In 1971, the Japanese Diet endorsed three non-nuclear principles: not to possess, not to manufacture and not to introduce nuclear weapons into Japanese territory. It did so in the form of a resolution, not in the form of law. Nevertheless, the principles have been important in reassuring other countries, as well as the Japanese public, that Japan will stay non-nuclear.

In 1988, in a prelude to its accession to the Treaty of Tlatelolco and to the NPT, Brazil wrote a non-nuclear-weapon commitment into the constitution. ${ }^{8}$ This established a strong legal barrier against nuclear-weapon acquisition - the strongest possible in the legal system of any country. Other NNWS may consider doing the same - not non-proliferation stalwarts like Sweden and New Zealand, where it would be superfluous, and not countries like Egypt and Turkey, which would find it untimely under the current circumstances in the Middle East. However, countries that are less geared towards trading stronger non-proliferation commitments for something else - like Indonesia and South Africa - may consider some version of it. In the rollback terminology of Chapter 6 , it may be of interest first of all for countries in a state of passive hedging. This way, NNWS may facilitate disarmament by tying themselves more strongly to the non-proliferation pole.

Proposals for societal verification also have to be anchored in domestic law. ${ }^{9}$ In addition to transparency measures and inspections that are agreed in intergovernmental accords, this idea gives citizens the right and obligation to inform appropriate international authorities if they discover activities that are at odds with international commitments undertaken by their governments. It comes in two main modalities: citizens reporting or inspection by the people, and whistle blowing by those who have intimate knowledge of treaty violations, in particular scientists and technologists who are employed by the nuclear establishments. To work, those who sound the alarm must be assured that they can do so without being punished. The international agreements to be verified should therefore contain a clause requiring that the parties adopt national laws that guarantee the right and require the duty to inform.

In practice, the effectiveness of such legal assurances would be a matter of degree. Often, civil courage and civil disobedience would still be needed. However, the stronger the legal protection, the more legitimate the reporting and the more likely it is that it would make a difference. Societal verification has not been instituted so far, but is worth pursuing in pragmatic fashion as disarmament proceeds and national conditions become ripe for it. At low levels of arms, it may be much needed as a supplement to international means of verification.

The bottom line is that, in order to be broadly accepted, the NWS must be willing to disarm. If not - if societal verification were to be applied in a two-tier system based on the distinction between NWS and NNWS - it would further 
mark the imbalanced implementation of the NPT and therefore be rejected out of hand. One cannot have disarmament without verification and - equally obvious - one cannot have societal verification without disarmament.

\section{Reserving the benefits of NPT membership}

Article X provides a nearly unconditional legal option to withdraw. All that is required is three months' notification and an explanation of the reasons for withdrawal. There is no body with authority to pronounce on withdrawal decisions by member states, and there is nothing in the Treaty and its negotiating history to indicate that exercising the legal right to withdraw gives ground for sanctions or reprisals. When the NPT was negotiated, the typical case of withdrawal was seen to be a response by a Treaty member in good standing to a security threat coming from some other state.

From the beginning, it was also clear that a withdrawing state should not expect to enjoy the benefits of membership. Article IV reserves access to nuclear material, equipment and technology for NPT members - although for a long while, it was not practised with any systematicity, and in 2008 the NSG made an exemption for India. Withdrawal could also mean restrictions on the right to use or keep sensitive technologies that have been acquired under the Treaty regime. Numerous proposals have been made for what to do with such items. For instance, it has been emphasised that such items must be restricted to peaceful uses and remain under safeguards; that suppliers should have the right to request an immediate "return to sender"; and that there should be a provision for shutdown of relevant facilities to prevent their misuse. However, the problem with most of these proposals is how to enforce them.

Only states in good standing can withdraw in legal fashion. Withdrawal should not be an acceptable remedy for cheating. In accordance with international law, a withdrawing state remains responsible for violations committed while it was a party to the Treaty and continues to be subject to decisions made by the IAEA and the Security Council. To determine whether there has been any violations, immediate verification of the withdrawing party's compliance with the Treaty might be undertaken, mandated by the Security Council if necessary (Bunn and Rhinelander 2005; Perkovich et al. 2005; Harrison 2006). Also, it has been proposed that the Security Council should authorise an escalating series of measures against any country that refuses to abide by the rules, to be announced in advance in the form of a generic Security Council resolution in order to enhance their deterrent effect (Goldblat 2009).

The IAEA is entitled to apply sanctions in response to non-compliance with safeguards agreements. The measures that may be taken include suspension of assistance provided by the Agency or member states; return of materials and equipment that have been made available to the withdrawing state; and suspension of IAEA membership. This is less than biting, for assistance rendered by the Agency is modest and return of materials and equipment at the request of the Board of Governors depends on voluntary cooperation by the state being 
penalised, which is unlikely. Suspension of IAEA membership puts a pariah stamp on the state, which may hurt but, apart from the modest measures just mentioned, it is of no automatic material consequence.

In Resolution 1887, the Security Council "undertakes to address without delay any State's notice of withdrawal from the NPT". ${ }^{10}$ It is for the Security Council to decide whether there is a threat to international peace and security and, if so, what should be done to restore the peace. The Council may pass decisions on sanctions and mandate the use of force, but sanctions usually do not work as intended and use of force is even less likely to prove instrumental. Smart sanctions should not be dismissed, but they look nicer on paper than in practice, and experiences of military counter-proliferation actions have been discouraging (see Chapter 3). Diplomatic approaches therefore seem indispensable, and for that purpose bilateral talks and small-size negotiating frameworks are needed. Seven-power talks are conducted in the case of Iran and six-power talks in the case of North Korea, involving the P5 plus Germany and the big neighbouring states respectively. The role of the Council will usually be to back the negotiations and provide incentives to stay non-nuclear.

Many NNWS - members of the non-aligned movement (NAM) in particular - are generally opposed to referring withdrawal matters to the Security Council. One reason for this is their general objection to punitive measures. The role of the Security Council has often been to issue sanctions. Another reason is that the Security Council has become less and less representative of the international community of states, and the veto institute adds to its in-built bias in favour of the West and the veto powers.

\section{Clarifying the right to withdraw}

The withdrawal clause of Article $\mathrm{X}$ is logically linked to the disarmament obligation of Article VI. The closer one comes to zero, the stronger the connection. On the one hand, if the NWS irreversibly disarm with a view to freeing the world of nuclear arms, it will be easier for the NNWS to agree to restrict the withdrawal option. On the other hand, the NWS will find it easier to take the final steps towards zero if withdrawal becomes less likely. Other measures such as foregoing fuel-cycle facilities and instituting more effective safeguards may be more reassuring, but clarification of the right to withdraw from the NPT may also help.

The current situation is untenable. North Korea acceded to the NPT in 1985; entered a safeguards agreement with the IAEA in 1992; announced its intention to withdraw on 12 March 1993, but went back on that notice on 11 June, one day before it would have taken effect; and stated on 9 January 2003 that it would leave the Treaty the next day in reference to the 89 days' notice ten years earlier, which had merely been suspended (see Chapter 4). North Korea had violated its commitments, but the Security Council failed to act and the 2005 NPT Review Conference did not even record that one party had left the Treaty.

Amendment of Article X is not the issue. The NPT will not be amended unless or until it is implemented to the satisfaction of the great majority of its 
members. However, some of its provisions may be clarified. The options may be limited to (1) voluntarily giving up the right to withdraw, and (2) establishing better procedures for assessing the reasons for withdrawal and what can be done to alleviate them and maintain the integrity of the Treaty.

The first option has an interesting historical precedent. The Tlatelolco Treaty had strict requirements for entry into force, but gave the signatories the option to waive them, bringing the Treaty into force in gradual fashion. The NPT has a significant waiver potential too - i.e. for waiving the right to withdraw - first of all among those who followed the so-called Swedish example. In the 1960s, Sweden concluded that regardless of what the NWS were doing, it would not be in Sweden's interest to acquire nuclear weapons. The conclusion was virtually unconditional. The only reservation was in reference to possible long-term developments making "nuclear weapons standard equipment of ordinary states" (Prawitz 1995). States that have a strong commitment to the NPT and wish to exercise leadership in building a stronger regime might consider this possibility.

As for the second option, three months is too short a time to seriously address the questions raised by a notification to withdraw. The validity of the alleged reasons must be assessed; there may be a need for special inspections to determine whether the withdrawing party has been in compliance with its Treaty obligations prior to the notice to withdraw; and there should be time for measures to improve the security situation and maintain the integrity of the NPT. Over the years, the notification time has increased from three months in the NPT to 150 days in the CFE (1990) to six months in the CTBT (1996) to 12 months in the Treaty of Pelindaba (1996) and the Semipalatinsk Treaty (2006). However, even the simplest of amendments - changing the figure three to a higher figure seems out of the question for a long time to come. ${ }^{11}$

In view of the serious consequences that withdrawal might have for regional and international security, the statement of "the extraordinary events" that the withdrawing state "regards as having jeopardized its supreme interests" should be detailed and unambiguous. The Vienna Convention is helpful in determining what may reasonably be invoked. It says that changing circumstances cannot be used as a ground for withdrawal,

unless the existence of those circumstances constituted an essential basis of the consent of the parties to be bound by the treaty, and the effect of the change is radically to transform the extent of the obligations still to be performed under the treaty. ${ }^{12}$

By this criterion, the North Korean reference to US-South Korean military exercises, which had been conducted routinely for years, and to the IAEA request for special inspections, clearly did not constitute a bona fide reason for withdrawal. A list of criteria might be developed, explaining what the "extraordinary event, related to the subject matter of the Treaty", might be about. ${ }^{13}$

Much of this is controversial, with little chance of being agreed in the near future. The mainstream views of the non-aligned movement (NAM) differ from 
those of the Western states. NAM members stress that the right to withdraw is a sovereign right to be upheld. This does not mean that NAM states turn all proposals to improve the operationalisation of Article X down. For instance, there is a body of agreement among NPT members on the need for a consultation mechanism, in the Treaty framework, when faced with a notification to withdraw. ${ }^{14}$ However, agreement on more substantial measures to tighten the right of withdrawal will have to wait for better and balanced implementation of the NPT, of Article VI in particular. Having made a series of strong proposals in the immediate aftermath of the North Korean withdrawal, Western states seem to have realised this and are now going more carefully and realistically about the issue. 



\section{Part IV}

\section{Towards a nuclear-weapon- free world}





\section{Towards a nuclear-weapon-free world}

\section{Introduction}

In a speech in Prague on 5 April 2009, President Obama reconfirmed his intention to seek a nuclear-weapons-free world (NWFW): "today, I state clearly and with conviction America's commitment to seek the peace and security of a world without nuclear weapons" (Obama 2009b). In Cairo two months later, he defused the charge of double standards that has been levelled at the nuclear-weapons states (NWS) throughout the 40-year history of the Nuclear Non-Proliferation Treaty (NPT): "No nation should pick and choose which nation holds nuclear weapons. That's why I strongly reaffirmed America's commitment to seek a world in which no nations hold nuclear weapons" (Obama 2009a). By seizing the high ground he was set to win important debates. However, there are numerous obstacles in the way.

What might a NWFW look like? The term is used in a variety of ways, some of which appear more stable and satisfactory than others. Certain principles, prerequisites and transitional issues, as well as political order requirements, must be considered on the way to such a world. On the whole, growing international interdependence is helpful, but for nuclear disarmament to succeed, interdependence must be turned into cooperative security practices between the big powers, with a view to more effective collective security mechanisms.

\section{An NWFW: the rationale}

In their Wall Street Journal article of 4 January 2007, Shultz, Perry, Kissinger and Nunn emphasised the interrelationship between the vision of an NWFW and measures to that end: "without the bold vision, the actions will not be perceived as fair or urgent. Without the actions, the vision will not be perceived as realistic or possible."

To achieve a dynamic, interactive relationship between vision and measures, one has to be serious about both. To be serious about the vision means that a convincing rationale for a NWFW has to be spelt out; that the broadest possible agreement must be sought; and that the advantages of such a world should weigh in the assessment of specific steps to be taken. If not, the advantages and 
disadvantages of each single step will instead be weighed within the framework of the existing international system, with little or no regard for the gains that a NWFW offers, leaving the steps hostage to the obstacles that will surely be raised along the way. The "four horsemen" are therefore right in their emphasis on vision: if the vision is not persistently invoked in the discussions of how best to promote disarmament and non-proliferation, efforts in this direction may not lead very far. The dynamism will be missing.

One part of the rationale relates to the terrorist threat: terrorists seek nuclear weapons in order to use them. The weapons themselves may be in solid custody in nearly all NWS, but there is no guarantee that treacherous elements in a weak state like Pakistan would not be willing and able to leak a weapon or two to alQaeda or Lashkar-e-Tayyiba, the group behind the December 2008 commando raid in Mumbai. Access to significant amounts of HEU is a greater danger. ${ }^{2}$ If terrorists get their hands on fissile materials, the rest - building a first-generation uranium bomb - may be manageable. After the Cold War, a variety of measures have been instituted to reduce the amount of weapon-grade materials and secure what remains, but as more states pursue weapons programmes, new potential sources emerge. Sooner or later, catastrophic terrorism may therefore be a reality - unless weapons and fissile materials are eliminated and subject to stricter controls.

Another part of the rationale emanates from the state paradigm. In an increasingly multi-centric world with more NWS, nuclear weapons are likely to interact with inter-state conflicts in more regions and in new ways. New NWS do not have the benefit of warning, control and communications arrangements of the kind that were developed, step-by-step, during the Cold War, and the cold warriors are widely recognised to have benefited from good luck. Control mechanisms to prevent war by human error, accident or technical malfunction will, moreover, be more difficult to institute and practise in a multi-polar world than in the static, bi-polar configuration of the Cold War. The four horsemen summed it up this way:

the US will soon be compelled to enter a new nuclear era that will be more precarious, psychologically disorienting, and economically costly than Cold War deterrence.... Will new nuclear nations and the world be as fortunate in the next 50 years as we were during the Cold War?

There is a growing sentiment that nuclear weapons are too dangerous in an international system which is partly anarchic, partly chaotic.

A NWFW would also be safer for nuclear energy. This is not among the major factors in the case for such a world - the overriding objective is to prevent nuclear weapons from being used - but for proponents of nuclear power it is another attraction. Others emphasise that a NWFW would be far more sustainable as part of a double abolition: an end both to nuclear weapons and to nuclear energy. However, much like the compromise between the "no" to nuclear weapons and the "yes" to nuclear power built into the NPT, an NWFW would 
probably entail the same compromise. If and when a NWFW comes into being, the energy situation will certainly be a lot different from what it is today, but this is what full implementation of the Treaty implies.

Rationales that are phrased in international security and world-order terms will not be sufficient, however. In the words of Zia Mian, they may lead to agreement on abolition, "but it is just as likely, if not more likely, that these policy debates, all of which would be based on power, mistrust, threat, fear, and violence, could combine to derail the whole process" (Mian 2009). To avoid these pitfalls, the frame of discourse must be broadened to include normative, moral and legal considerations. In addition to their inherent merit, the normative arguments have the benefit of being universally relevant and applicable both to governments and to civil society. They widen an elitist process conducted in power and security terms to encompass popular movements as well. Normative arguments resonate across borders and "may contribute better to mobilize support for abolition, build confidence in good faith, inevitability, and irreversibility of the disarmament process and the global benefits that it would bring" (Mian 2009). Zia Mian wants them to be at the centre of the debate, not at the margins.

No yardstick can determine which line of argument is more important - a rationale based on security gains or one that sees nuclear weapons as a crime against humanity. The NWS would, for obvious reasons, concentrate on the security gains and reject the view that nuclear weapons are immoral and illegal. The custodians will not pass such sentences on themselves. Many NNWS argue both ways, as do popular campaigns to rid the world of nuclear arms. Without raising the legality or illegality of nuclear-weapon possession and use, NWS may also call for abolition out of ethical considerations as well as security gains. Reflecting on "what really happened at Reykjavik", Secretary Shultz came close to doing the same: "As I often said to the critics ... and proponents of status quo, 'What's so good about a world where you can be wiped out in thirty minutes?' I had never learned to love the bomb" (Shultz et al. 2008). The vision can best be promoted by both lines of argument.

\section{Doubts and pitfalls}

In the Final Declaration of the 2000 NPT Review Conference, adopted by consensus, the five NWS expressed their "unequivocal undertaking ... to accomplish the total elimination of their nuclear arsenals leading to nuclear disarmament, to which all States parties are committed under article VI" (United Nations 2000). In the years that followed, some NWS returned to guarded, conditional statements. ${ }^{3}$ Others simply fell silent. It was as if the NWS had come to regard Article VI of the NPT the way the parties have dealt with Article V on peaceful nuclear explosions: acting as if it does not exist. The four horsemen and the leaders of other countries who followed suit broke that silence. Barack Obama joined them. In commemorating Rajiv Gandhi's speech on nuclear disarmament before the UN General Assembly in 1988, Indian officials also reiterated the call for abolition (Sethi 2009), and the Security Council followed suit. 
Still, the call for a NWFW remains primarily a Western one. In other regions, nuclear- and non-nuclear-weapon states are waiting to see what comes of it. For a while, disarmament opponents have been on the defensive, but they may hit back with greater political clout both in the United States and elsewhere. The legacy of threat-based security policies remains a formidable obstacle in the way of a NWFW, and arms control and disarmament are still seen by many as part and parcel of an ongoing quest for unilateral advantage, not as a global common good. Sceptics noted, furthermore, that both the title and the measures advocated in the second WSJ article of 15 January 2008 by the same American horsemen seemed more modest than those of the first, ${ }^{4}$ and that SC Resolution 1887 of 24 September 2009 is mostly about non-proliferation. Will the grand disarmament ambition fizzle out? Will the domestic interests in nuclear weapons hit back and reaffirm the continued relevance of nuclear arms? Abolition has been proposed three times before - the Baruch plan in 1946, the McCloy-Zorin proposal of 1961 and the Reagan-Gorbachev attempt in 1986 - and they were all shortlived.

Yet others have more fundamental doubts about it all. They are concerned that the call is part of a double agenda, the real purpose of which is to sustain and enhance Western unilateral advantage. The synergies of disarmament and non-proliferation may stop smaller and weaker states from acquiring "the great equaliser" - nuclear weapons - thus minimising those states' ability to counter the vast US conventional superiority. So why should North Korea, Iran and other states at odds with the US willingly expose themselves to threats and humiliation? In a world without nuclear weapons, US forces may be even more superior than they are today; moreover, at low levels of offensive forces, an advanced ballistic-missile defence system may give the US a first-strike capability vis-àvis other NWS. Seen in one or more of these ways, nuclear disarmament is not a hallmark of progressive politics but a conservative goal: change in order to preserve the dominance of the United States and the West. ${ }^{5}$

Big powers have always gone for unilateral advantage. Recent history is rich on examples in this regard. The US withdrew from the ABM Treaty to be free to pursue ballistic-missile defence. Starting with Ronald Reagan's Strategic Defense Initiative (SDI), the US is unrivalled in this field. Outer space is a related arena where the US is the leading nation and so objects to arms control. The US will ratify the CTBT, critics surmise, when it can do without testing, while less-sophisticated NWS will be restrained by it. Having conducted 1,000 tests and having a sophisticated nuclear-stewardship programme, a CTBT could help maintain and even enhance its unilateral advantage in weapons design. Proponents of US ratification have actually argued that way. ${ }^{6}$ Non-proliferation of ballistic missiles is a high priority, especially because many Asian states pursue such weapons to counter the threat from US bases in their vicinity. Production of sophisticated aircraft, on the other hand, are beyond the capabilities of smaller and less-industrialised countries, so the advanced powers see no similar need for arms control in that sector. The US and Russia have aired the idea of making the INF Treaty global, which would eliminate the ballistic missiles of many Asian 
states while the two leading nuclear powers have a variety of other weapons that can be used over intermediate distances. To various degrees, the big powers have twisted the implementation of rights and obligations under the NPT so much in their own favour that by the time George W. Bush left, the Treaty may have been on the verge of crumbling. Ever since the first Gulf War of 1991, it has been argued that nuclear disarmament would make the US even more superior because nobody can match its conventional forces. Last but not least, the United States is about to reduce its reliance on nuclear weapons by preparing for some of their functions to be exercised with long-range high-precision conventional weapons that others do not have. This will make it more, not less, difficult for China, Russia and others to embark on disarmament (see Chapter 3).

In the NWS, there are various objections to the elimination of nuclear weapons. There is the view that nuclear weapons make major war very unlikely, if not impossible; that they provide unique and irreplaceable security benefits; that a world of zero would be highly unstable; and that approaching zero might spur proliferation by making it possible for very small arsenals to have large strategic implications not neutralised by the much bigger arsenals of the major NWS. Then there are the less legitimate, but still very real, unilateral advantages that nuclear weapons are seen to offer: they can be used to threaten and intimidate others, and they confer status on their possessors that is thought to be generally useful in the pursuit of national interests.

During the Cold War, deep-seated superpower concerns about upper edges turned into sterile obsessions with parity in order to block perceived attempts by the other side to gain unilateral advantages - so much so that parity became part of the problem, making agreements more difficult. Even then, however, there was one exception to the bickering for unilateral advantage: a string of arrangements were instituted to avoid war by human error, accident or technical malfunction. In the most fundamental of senses, this was a common interest because their own survival - and that of human civilisation - was at stake. Reagan and Gorbachev took it further, stating that a nuclear war cannot be won and must therefore never be fought.

In a multi-centric world, it is critically important to convince states - nuclear and non-nuclear - that disarmament will be pursued neither as a matter of unilateral advantage nor of national sacrifice, but as a common, public good. If the key players cannot be convinced that the initiative is no ploy for unilateral advantage, it will go nowhere. Also for this reason, the call for abolition must be phrased both in terms of international peace and security and in terms of moral leadership. Universal moral considerations - preventing mass slaughter; preserving human civilisation - must be turned into realpolitik. National interests will not be abandoned, but elimination must be seen as being in the best interest of states. All parties to the NPT are legally obliged to work for nuclear disarmament, but the NWS have a special responsibility.

Declaratory policies putting the rationale in universal terms while eschewing all talk about unilateral advantage are of the essence. Even more important, the military postures must be adapted to facilitate nuclear disarmament in the 
universal interest. In many cases, the crux of the matter will be to reduce the security concerns of states that currently rely on nuclear weapons by alleviating conflicts and adjusting conventional force constellations so that their nationalsecurity affairs can be managed without nuclear arms. This applies to states that are under the US nuclear umbrella; to states that are conventionally inferior in relation to neighbours that may use their military might for political gains; and to states that see nuclear weapons as insurance premiums of last resort.

To get going, US leadership is a must and Russian cooperation is vitally important. If Russia is not ready for major cuts, the disarmament ambition will not go far. Next in the line of importance is China, because of its geopolitical significance. Together, these are the states that most affect the security dynamics in regions of proliferation concern, i.e. in Northeast Asia, South Asia and the Middle East. As veto-wielding members of the UN Security Council, they also determine whether confidence will be built in the enforcement of disarmament commitments (Perkovich 2008). If they cannot stabilise their strategic relationships and put the nuclear order on the path of disarmament, the international non-proliferation regime will be on shaky ground. As for the other P5, the UK is positive to multilateral disarmament and sensitive to US priorities while France remains more of an independent actor and more strongly wedded to nuclear weapons (Tertrais 2009).

As the international distribution of power shifts towards the East and South, more attention must be paid to the priorities of the emerging powers. Not only do China and India care about their security, like all others: disarmament must also be compatible with their historical claims for greatness. If the process seems designed to contain and subdue their rise to prominence, they will not cooperate. While Western leverage is diminishing, the self-confidence and staying power of the emerging powers are growing (see Chapter 1). To get them on board, there has to be a significant element of equity in the disarmament strategy as well as in single steps, and the sooner they are drawn into strategic dialogues on how to proceed, the better. A strategy of co-option - starting with the US and US allies, continuing with NNWS that always made a case for abolition, and successively building pressure on the recalcitrant ones - would be to ask for trouble. ${ }^{7}$

Active involvement of NNWS is important as well. The goal is not just to disarm the armed but to create a world order free of nuclear weapons comprising all. In the NPT, disarmament is a shared responsibility for all members (see Chapter 9). NNWS always played an important role in keeping the big powers honest, and in reaching out for an NWFW, they will be much needed in that role.

\section{An NWFW: in what version?}

Words like "zero", "elimination" and "abolition" all have in common the idea of no nuclear weapons. However, "zero" can be conceived of in a variety of ways, and not everyone means the same when referring to it. It may be taken to mean no deployed weapons; no stockpiled weapons; no assembled weapons; no 
nuclear weapons in the hands of the military (but possibly under civilian governmental control as an insurance premium); or no national nuclear weapons (but possibly nuclear weapons controlled by an international body).

Beyond the various meanings of zero, the vision of an NWFW also comes in several other forms, one of which imagines a world where all ready-made weapons have been eliminated, but where many states maintain a mobilisation base for the rapid reintroduction of them. It might include fissile materials in stock, able nuclear-weapon engineers and manufacturing equipment on hand, and delivery vehicles ready for use. For the NWS, this would be a form of deep de-alerting, approaching the status of Japan today. The purpose of such a base is to deter others from breaking out of the agreement and to confront violators if deterrence breaks down.

Harald Muller argues convincingly that, as a fixed end state, virtual arsenals are a bad idea (Muller 2009). First, because they sustain the mentality that nuclear war is possible at any time. Many states may come to think that hedging is prudent, suspecting that others may be cheating, with the result of a hedging race: vertically towards capabilities that can be turned faster and faster from virtual to real; horizontally to involve more states. The trust on which abolition was achieved would then evaporate. Second, virtual arsenals need arsenalkeepers, and they are never disinterested experts, but socio-political actors legitimising their activities in terms of threats to be met and demanding more resources to counter them. In effect, the arsenal-keepers are likely to push for a hedging race, and would quite possibly prefer a return from virtual arsenals to real ones. Such an end state would therefore contain the seeds of its own destruction. Third, it is a particularly bad idea because in the break-out scenarios, firststrike capabilities are more likely to emerge than in current nuclear constellations.

It would therefore be better to go "below zero" to eliminate the fissile materials that have been dedicated to nuclear-explosive uses; to institute strict international control of all remaining materials; to dismantle the nuclear-weapons infrastructure; and to redirect the workforce to other sectors. Even more, nuclear materials that can be used to build weapons should be banned from civilian use as well. HEU is not the big issue here - there is little HEU left in the civilian sector and what remains is being phased out - but plutonium continues to pose a problem. Technical fixes may or may not solve it: if not, a compromise would have to be struck to accommodate the civilian industry. Dual-capable production facilities for civilian use would remain, possibly based on proliferation-resistant technologies and certainly subject to international control. This would be a more stable NWFW, building trust in a non-nuclear future. However, going below zero is a matter of more or less, so this image of a NWFW comes in several variations.

A third version relies on joint capabilities to intercept a nuclear attack before the weapons reach their targets - the idea that Reagan presented to Gorbachev in Reykjavik. Reagan offered to share his SDI technologies with the Soviet Union in order to erect a common shield against break-out attempts. An effective shield 
could be traded against milder restrictions on nuclear infrastructure and modified requirements of international control. However, 25 years and 150 billion dollars after the SDI was born, ballistic-missile defence remains an unproven technology with no certainty of success. Countermeasures seem to be simpler and cheaper. Furthermore, to convert the programme into a global asset to the benefit of all may not be possible, for it takes a much more cooperative world to overcome the formidable political problems involved. In Reykjavik, it was a matter of course for Reagan and Gorbachev that what they agreed to do would set the rules for all others. Their duopoly was tantamount to world order. In the multicentric world taking shape today, the technology would have to be shared by a consortium of big powers, not just two of them, making implementation much more complex. Still, in a world that has come close to elimination, missile defence is likely to be seen through other lenses. If the road to a NWFW results in, say, 100 or 200 weapons for each NWS, further steps will be considered in an environment much different from where the journey started. The pathdependence of the disarmament process must always be kept in mind, so the option should not be ruled out.

\section{The vision: a guide to action?}

A world that allows the disarmament process to proceed to the point where the end station is in sight defies description. Today, it would therefore be premature and presumptuous to select some version of the end state and discard others.

Nevertheless: for the reasons given above, a NWFW leaving a number of virtual arsenals intact seems unattractive. In classical nuclear terminology, this would be a world of many threshold states, and the risk is great that it would be unstable. A version that does away with fissile material stocks and dedicated nuclear infrastructure, with or without a shield against ballistic missiles and other means of delivery, appears preferable. However, removing the remnants of weapons programmes is a matter of degree - it can be more or less complete so such a version can take many different forms. If a global shield becomes part of the overall arrangement, the requirements of build down "below zero" might be less stringent.

With this caveat, can the vision be a guide to action?

\section{The principle of equity}

It is hard to imagine a NWFW with different ground rules for different categories of states. Some 40 years of discontent with the NPT's division of the world into nuclear- and non-nuclear-weapon states, and persistent complaints over the slow implementation of Article VI, which was supposed to end it, have led many NNWS to insist on equal rules for all. In general terms, Obama's Prague and Cairo speeches alluded to the same. New measures must therefore be equitable and capability differences reduced, more and more as the process unfolds. Different versions of the end state aside, the principle of equity will be important all 
throughout the disarmament process. If it is compromised by moves for unilateral advantage, the emerging powers of Asia, in particular, are unlikely to be cooperative.

The NPT was meant to be a regulatory mechanism for non-proliferation, disarmament and peaceful uses all the way to zero. The parties may wish to reinterpret some of its provisions, but they will probably see fit to keep it until it has been implemented, i.e. until all weapons have been eliminated. At that point, however, the equity that it prescribes stops. The NPT goes to zero, but says nothing about the precise meaning of zero. Therefore, a new convention outlining the ground rules of an NWFW has to be written before reaching that point. The NPT is, moreover, no more than a skeleton agreement, so new rules guiding the final approaches to an NWFW will be needed in any case. To be agreeable, those rules must be informed by the principle of equity and lead to a NWFW where the rules are the same for all.

\section{Elimination of fissile materials}

The importance of fissile material controls was universally recognised during the NPT negotiations in the 1960s, and became the central element of NPT safeguards in the early 1970s. The main hurdle on the way to a nuclear bomb is acquisition of weapons-grade materials. The first requirement in going "below zero" would therefore be to eliminate all stocks of fissile materials dedicated to military use.

Given the vast amounts of fissile materials that exist, more steps in this direction had better be taken right away. Uppermost on the international agenda is a Fissile Material Cut-Off Treaty (FMCT). Such a treaty should be conceived not only as an arms-control measure banning all activities at dedicated military production facilities - which would freeze the advantages of the big and advanced nuclear powers - but also as a measure limiting the size of existing stocks. The equity principle means that single steps should be designed to incrementally reduce the capability differences on the way to a NWFW setting the same rules for all.

The safeguards reassuring the international community that all military production facilities are effectively shut down would also have to be equitable. NNWS are unlikely to accept another differential deal such as safeguards limited to declared, dedicated facilities, which means selective safeguards for NWS and full-scope safeguards for all the others. In France, the UK and India, the civilian sectors are safeguarded - in the UK and France by EURATOM/IAEA and in India by the IAEA pursuant to the US-India agreement - but in the other NWS civilian activities are not fully covered. Under an FMCT, NWS may want to mothball their production facilities at first, leaving dismantlement for consideration later on.

So far, limitations and reductions of existing stocks has been a NNWS demand. The NWS have been more or less unwilling to include them in FMCT negotiations. For them, cut-off has primarily been a non-proliferation measure. 


\section{Towards a nuclear-weapon-free world}

However, if they were to subscribe to a NWFW below zero, that might change. Logically, both categories of states should then take an interest in the vertical as well as the horizontal dimension of the issue. This way, the vision could impact on the negotiability of an FMCT, illustrating what a dynamic interactive relationship between vision and measures might be about.

\section{Elimination of nuclear-weapon infrastructure}

In a world where virtual arsenals remain, nuclear infrastructure would be kept. Scenarios starting from this version of the end state tie in with a well-known argument of nuclear-weapon supporters: the more advanced the nuclear infrastructure, the further down one may go in operative nuclear weapon systems. The theoretical end point of that argument is zero operative weapons in return for a comprehensive capability to bring them swiftly back to operative status, maybe in a time span not much different from the time it takes to ready de-mated systems for use. From other versions, dismantlement of nuclear weapon infrastructure follows.

Of course, the nuclear-weapon infrastructure has many more components than fissile materials and their production facilities. Those components should be phased out as well. For instance, if it became known that a state was testing triggering mechanisms for nuclear devices, or was engaged in studies of weapons designs, the message would be unnerving. Under the NPT, such activities are already banned among the non-nuclear parties to the Treaty, for they constitute unambiguous signs of weapons intent. A NWFW allowing current NWS to stay engaged in weapon-oriented activities while prohibiting them for all others would be inequitable and therefore unacceptable.

However, knowing that the main bottleneck in weapons acquisition is access to fissile materials, elimination of other components might be a lower priority. For some of them, effective safeguards are, moreover, a bigger challenge than safeguarding nuclear materials. Today, non-nuclear components of nuclear weapons are beyond the reach of IAEA safeguards, and given the constraints on transparency in some NWS, more intrusive means must be pushed gradually as new opportunities emerge. Overambitious attempts may backlash and do more harm than good, especially in states in the East and South that go by the principles of state sovereignty and non-interference. For instance, universal acceptance of societal verification will be out of the question for some more time, even on the most optimistic of assumptions. For China, secrecy remains, moreover, a significant part of its nuclear posture.

\section{Proliferation resistance}

This leaves a big set of issues of how to make peaceful uses of nuclear energy more proliferation-resistant. Today, the promoters of proliferation resistance are mostly suppliers; with some important exceptions, the recipients tend to be naysayers. 
Progress has been hampered by the imbalanced implementation of the NPT. NNWS have put their feet down, objecting to any limitation of Article IV rights as well as stricter Article III safeguards as long as the NWS do not do more to meet their disarmament obligations. In this respect, declaratory policies conveying big power seriousness about a NWFW are helpful, although the great majority of NPT parties consider this to have been a legal obligation under the NPT all along, unequivocally confirmed by the 2000 NPT Review Conference. While welcoming recent statements in support of a NWFW, NNWS therefore hesitate to take anything for granted until the words are supported by facts.

Deep cuts and measures blocking qualitative developments of nuclear arsenals would create a benign context for radical approaches to proliferation resistance. In turn, enhanced proliferation resistance would make a NWFW more sustainable. In any scenario-writing tracing the implications of a NWFW back to the present, proliferation-resistant modes of nuclear energy appear desirable, regardless of which version one chooses. However, the main driver - the concerns about weapons proliferation in a world where nuclear power is proliferating - would seem stronger today and in the foreseeable future than in a NWFW. Today, the incentives to acquire nuclear capabilities and nuclear weapons are in some cases strong, while the mechanisms to enforce the non-nuclear commitments of the NPT and of NWFZ are generally recognised to be weak. In a NWFW, on the other hand, the further below zero one goes, the stronger the assurances against re-militarisation and the less concerns there are about the shape of the civilian sector. Therefore, when it comes to the proliferation resistance of peaceful uses, the vision is not a particularly powerful guide to action.

\section{Deep cuts}

If the US and Russia can agree on radical overall reductions of their nuclear forces, more is likely to follow. If not, the call for elimination may come to nought. A breakthrough presupposes resolution of at least some of the controversial political issues mentioned above, and of what to do about the tactical nuclear weapons. There is a strong case for including them, but Russia always dragged its feet when that question was raised. Other matters of contention are the US missile-defence programme and the emerging US conventional Prompt Global Strike capabilities. Russia would certainly like to bring both of them into the next round of negotiations.

A deep cut succeeding New Start (the START I follow-on agreement) and including all categories of nuclear weapons - tactical as well as strategic weapons, reserves as well as operative ones - would obviously be a major achievement. The build-down should be guided by the principles of transparency, implemented step-by-step; verification of agreed limitations on weapon holdings; and irreversibility to prevent weapons and materials that have been withdrawn from being redirected to operational status and military applications. It is conceivable that such an agreement would lead to multilateral talks involving all the P5 as well as other nuclear and non-nuclear weapon states. 
How deep do US and Russian cuts have to be to engage France, China and the UK in disarmament negotiations? The three used to say that the superpowers would have to come down to their level, i.e. to the low hundreds, although recently, the UK has shown flexibility in this respect. Maybe, the US and Russia need not come down to the same level as the smaller P5 powers before multilateral negotiations can begin. If they agree to cut their forces to three-digit figures while stating their readiness to go for common P5 ceilings at about the current level of the UK, France and China, this may suffice. With such an approach, reductions to 1,000 weapons may also be enough. But if they were to invite the others with proportional reductions in mind, so that the US and Russia would retain significantly larger arsenals than the others in the three-digit range, it might go nowhere. China used to say that it had the smallest arsenal of the P5. That may no longer be true - in terms of deployed warheads, the UK and France have been trimming their forces while China has gone up somewhat - but by 2009 they all had fewer than 200 operational weapons (SIPRI 2009).

In 2009, the US had 500 operational tactical weapons, 200 of them in Europe. On the basis of the number of available delivery platforms, it is estimated that Russia has approximately 2,000 weapons in this category (SIPRI 2009). Influenced by the bombing of Serbia in 1999, Russia upgraded the role of nuclear weapons in its military doctrine: if NATO could go to war against Serbia without any mandate from the UN Security Council, it might do it again closer to Russia's borders. Tactical nuclear weapons are deemed relevant in such contingencies. Presumably, tactical nuclear weapons also play a role in Russian considerations of how best to defend Siberia. However, inclusion of them would be an increasingly legitimate US demand, for the lower the level of strategic arms, the higher the stock of unregulated tactical weapons would loom. Agreed reductions of operationally deployed strategic weapons to the level of 1,000 or below while leaving 2,000 Russian sub-strategic weapons aside are virtually impossible to imagine. To prepare for their inclusion, Russia might do more of what the US has been doing, i.e. assigning long-range weapons to regional roles (see Chapter 3). Freedom to mix strategic and tactical weapons under common ceilings might also facilitate inclusion of them. However, the main approach to inclusion and reduction of them is alleviation of threat perceptions.

What about the reserves? The United States holds about 2,500 weapons in reserve for strategic and tactical use. ${ }^{8}$ The corresponding Russian figure is not known, but it may be higher. These reserves are much larger than those of the smaller P5. Not to leave the US and Russia with much larger break-out potentials than the others, all reserve warheads should therefore be included in the calculations at some stage, especially if there were to be few or no limits on the capabilities for delivery. In the US Congress, the bipartisan McGovern-Lungren resolution brings reserves into the deep-cut framework, proposing to limit US and Russian arsenals to no more than 1,000 weapons deployed and no more than 3,000 weapons in all, reserves included, and with a freedom to mix.

During the Cold War, arms-control limitations centred on delivery vehicles. SORT focused on operationally deployed strategic warheads, but the counting 
rules referred to delivery vehicles. ${ }^{9}$ Those rules became a matter of discussion when the US made plans for deployment of conventional warheads on some of its ballistic missiles. New START solved the problem by counting all warheads, conventional or nuclear, against the 1,550 limit: a conventional warhead can only be deployed at the expense of a nuclear one. But the US government was quick to underline that "New START protects the U.S. ability to develop and deploy a CPGS [Conventional Prompt Global Strike] capability. The Treaty in no way prohibits the United States from building and deploying conventionally armed ballistic missiles" (US Department of State 2010). Such systems may be physically separated from strategic nuclear weapons to facilitate verification. New methods to count nuclear weapons without revealing sensitive information may also help, and will be needed anyhow in order to take stock of tactical nuclear weapons and reserves. For tactical applications of nuclear weapons, a variety of dual-use vehicles may be used, and reserves may not be specifically assigned to particular delivery systems. Studies of how to do this are underway in many countries. ${ }^{10}$ However, CPGS leaves others with the intriguing problem of how to deter and defend against conventional strikes. Nuclear deterrence of pin-point conventional attacks where the objective is not to conquer another nation but to destroy specific objects may not be credible, and protective measures may be very costly or unfeasible. The Russians and the Chinese are concerned about it, and the concerns are by no means confined to them.

Reductions of total numbers, reserves included, mean that more weapons will be slated for dismantlement. In the US, 4,500 weapons are already waiting to be taken apart. ${ }^{11}$ In Russia the number is probably higher. ${ }^{12}$ The current pace of dismantlement is slow - approximately 350 warheads per year in the US. Therefore, stronger dismantlement capabilities, and codification of the principle of irreversibility, become all the more important in order to remove these weapons from hedging speculations and limit the mobilisation base for renewed arms build up. To build trust between the US and Russia; to convince others about the seriousness of the disarmament ambition; and to sustain the impression that there is no way back to arms racing, systematic application of the principles of transparency, verification and irreversibility - emphasised in the 13 steps for nuclear disarmament adopted by the 2000 NPT RevCon, but disregarded by the Bush administration and ignored by SORT - is of the essence.

\section{Missile defence}

The US cancelled the missile-defence plans for Poland and the Czech Republic, thereby facilitating the advent of New START. However, these plans were only a small part of the overall US ballistic-missile defence programme and, thus, only a small part of the problem.

For deep cuts to be agreed, some clarification and modification of the missiledefence programme will undoubtedly be needed. Russia cannot but be concerned about the viability of its nuclear deterrent if the programme continuous unrestrained in the face of far-reaching nuclear disarmament. Sooner or later, further 
cuts will not be possible if US defences that threaten to undermine the penetrability of diminishing Russian offensive forces are improving. In other words, if offensive systems are built down and defensive systems built up, there comes a point where the owner of the defensive systems might deny the other NWS a second-strike capability. What may be a problem for Russia in the future is already a problem for China: it develops its forces i.a. in response to emerging US missile-defence capabilities. The US BMD deployments in Alaska and California, allegedly to defend against North Korea, may be improved and expanded and directed against China as well.

Mutually assured destruction is far from being an ideal basis for international security. The risks of breakdown are too great. It is counterintuitive at that, because it says that we are best protected when we are naked. However, ballisticmissile defence makes an untenable situation even worse; for, by stimulating competitive acquisitions of offensive and defensive capabilities, it stands in the way of nuclear disarmament.

Ronald Reagan proposed a cooperative US-Soviet missile shield as a hedge in case somebody would try to break out of an NWFW. His idea was theoretically attractive, but in practice hard to implement. Like the Baruch-Lilienthal plans for global control of nuclear weapons after the Second World War, the technology developer could be left with an advantage. This was the way the Soviets saw it in 1946, and this was the way they looked at it in Reykjavik 40 years later.

In 1946 the Cold War was brewing; in 1986 it was dying. That year, the successful conclusion of the Stockholm conference on confidence and securitybuilding measures and the Reykjavik summit were the first signs of different times to come. Still, suspicions ran deep. What appeared practically impossible then may therefore tell little or nothing about the cooperative ventures that may be possible if and when the world approaches zero nuclear weapons. The trust that will still be missing during another round of deep US-Russian cuts, and the suspicions that would continue to burden disarmament negotiations well into the multilateral phase, may no longer be there - or be there, but in a much different way - when the goal is in sight.

Can a shield be developed as an option for an NWFW while nuclear disarmament is taking place? It is conceivable that research and development of defensive technologies could continue if deployment limitations are agreed upon. But would this be enough to reassure others? China and other states are not only concerned about the specific missile-defence applications of the US programme, but are also worried that someday there may be a technological breakthrough in another related area that leave them at a disadvantage. The trust-consuming effect of such an R\&D programme should therefore not be underestimated.

Scaling down missile defence is another way to reduce the overall concerns surrounding it. In the years ahead, the United States is likely to do so, as missile defence was always more of a Republican programme than a Democratic one. Additionally, there are strong financial pressures for cuts. Yet another option is a cooperative venture with Russia. For some time, Russia and the US have dis- 
cussed a cooperative shield against missiles from Iran and other countries in the Middle East. Such a joint venture could be seen as a pilot project illuminating technical problems and cooperative requirements that have to be solved and met on the way to a global shield. It may facilitate negotiations towards deep cuts, but would send a dubious signal not only to countries in the Middle East, but to China as well. Combined with the sword of overwhelming offensive weapons, it puts them on the spot. Richard Nixon phrased it simply and sharply when defending the ABM Treaty of 1972: if you have a shield, it is easier to use the sword. To enhance US-Russian security at the expense of the security of others is not in the spirit of global public good, and not the way to pursue the long-term ambition of a NWFW.

This builds up to an argument for deployment limitations on a slimmer US missile-defence programme. Deployment limitations mean reinstating the AntiBallistic Missile (ABM) Treaty or negotiating an updated version of it; a slimmer programme is the likely outcome of US politics anyhow. Whether the stability of a NWFW would best be enhanced by erecting a shield will be a matter for consideration in a world much different than ours now.

\section{Doctrines}

Article VI was always about hardware and software - both about the weapons and the roles assigned to them. For half a century, calls have been made to reduce the role of nuclear weapons in international affairs. Ever since the NPT was negotiated, assurances not to use or threaten to use nuclear weapons against non-nuclear parties have been sought. On and off, no-first-use doctrines have been advocated.

During the presidential campaign, Barack Obama promised to "work with Russia to take US and Russian ballistic missiles off hair-trigger alert". The US keeps roughly 1,000 nuclear warheads on alert atop ICBMs and SLBMs ready to be fired about 3-4 minutes and 12 minutes respectively after a presidential order has been issued. Russia retains approximately 1,200 warheads at top readiness, nearly all of them on ICBMs. British and French weapons might require days' notice to launch and Chinese, Indian and Pakistani weapons at least as long (Kristensen et al. 2009). De-alerting and de-mating are therefore primarily for the US and Russia to do. They are the ones lagging behind in this respect. However, neither New START nor the new US Nuclear Posture Review (NPR) introduce any change in existing alert postures.

The P5 have issued security assurances to the non-nuclear members of the NPT, summarised in Security Council Resolution 984 of 1995. Except for the Chinese assurances, they are all qualified in ways that limit their value. The NPT review conferences have therefore urged the NWS to be more forthcoming. This century, the opposite happened: national doctrines significantly widened the range of missions assigned to nuclear weapons (see Chapter 3), shedding doubt on the validity of the assurances contained in Resolution 984. Only China remained true to its original policy of no-first-use. In this respect, the Obama 
administration's NPR is a trend-breaker. Hereafter, the US will not use or threaten to use nuclear weapons against non-nuclear NPT members "in good standing" (see Chapter 3). It does not go as far as no-first-use (NFU), but promises to work in that direction.

NNWS are more vulnerable to use and threats of use than NWS. Where mutually assured destruction applies, resort to nuclear weapons is an ordained act of suicide while, in relation to NNWS, the aggressor may get away with it. Nonaligned states have therefore called for an international convention committing the NWS not to use or threaten to use nuclear weapons against NNWS parties to the NPT, no qualifications added. While the NPR may pave the way for a new SC resolution containing stronger security assurances than Resolution 984, it takes more to meet the non-aligned demand for an international convention (see Chapter 3).

NFU doctrines, limiting the role of nuclear weapons to that of deterring others from using theirs, would meet the same concerns and, in addition, reduce the role of nuclear weapons in inter-NWS affairs to the passive one of deterring others from using theirs. ${ }^{13}$ Unqualified undertakings never to be the first to use nuclear weapons have, moreover, an intriguing disarmament corollary: nobody would need them if nobody had them. In deep cuts and elimination scenarios, this proposition is therefore more relevant than extension of non-use assurances to NNWS, which are primarily a part of the non-proliferation bargain.

The Geneva Protocol of 1925 prohibited the use of chemical and biological weapons. These weapons were considered inhumane. Later, possession of them was outlawed as well: biological weapons by the BWC of 1972; chemical weapons by the CWC of 1992. The CWC set a timeline for destruction of the arsenals, and agreement was reached on a comprehensive verification system. In the 1990s, a verification protocol was negotiated for the BWC as well, but the Bush administration turned it down. Stressing that any use of nuclear weapons must be compatible with international humanitarian law, the ICJ Advisory Opinion of 1996 came close to a non-use position also for these weapons. The effects of nuclear arms are such that it is hard to imagine circumstances in which they could be used without colliding with humanitarian law. A reservation was made for situations where national survival is at stake (as in the case of Israel). The Court did not rule out the use of nuclear weapons in such circumstances.

A protocol banning the use of nuclear weapons, on the model of the Geneva Protocol, would convey the same message: the effects of nuclear weapons are such that no civilised state or sane leader should or would use them. An international legal instrument declaring their use to be a crime against humanity would send an even stronger message and be a better deterrent against use.

In effect, the Geneva Protocol was a no-first-use agreement. An agreement banning the use of nuclear weapons would similarly allow for nuclear retaliation; that is, it would be a no-first-use agreement. It may include provisions branding the use of nuclear weapons a crime against humanity. Alternatively, the Security Council could be invited to issue such a declaration.

Given its conventional preponderance, the US could more easily convert to no-first-use than could Russia. Nuclear weapons are critically important for Rus- 
sia's big power status, and to be confident that its enormous territory can be effectively defended without nuclear weapons, a combination of conventional force improvements and alleviation of threats will be needed. However, if the US seizes the initiative and progress is made in reassuring Russia to the point where it would be willing to generalise the bilateral Russia-China no-first-use commitment, the P5 would end up with such a doctrine, for it is hard to imagine that the UK and France would not follow the US lead, especially when reinforced by Russia. The US alliance commitments and nuclear umbrellas would have to be changed accordingly, reassuring its allies in other ways.

\section{Dealing with the break-out potentials}

Two disarmament scenarios - both of them outlined above - illustrate how differently the break-out concerns can be addressed. One says that the more advanced the nuclear infrastructure, the further down one may go. The logical end point being zero weapons in return for a capability to reintroduce them on short notice. The other says that such a world would be dangerously unstable because of its trust-consuming break-out potentials, and therefore recommends moving "below zero" to eliminate the mobilisation bases and the nuclear-weapon mentalities that they sustain. These very different worlds have very different implications for the structure of the disarmament processes to be pursued. The weight of the argument is in favour of a disarmament process that builds up to a world significantly below zero.

In both cases, the starting point is a world of limited confidence between the big powers, where fall-back positions will be maintained in case disarmament agreements break down or new demanding security challenges emerge. Foremost among those precautionary measures are weapons held in reserve; surplus stocks of weapon-grade materials; and a scientific-technical mobilisation base, including production facilities in a state of preparedness to be switched on again.

In one respect the end state is also the same: both scenarios lead to zero nuclear weapons. In both cases, the reserves must be eliminated along with the operational weapons, although the philosophy behind the hedging scenario means greater caution in doing away with the weapons than that leading below zero. More than others, hedging proponents read international affairs in terms of threats and conflicts, partly as a continuation of Cold War mentality and partly reinvigorated by $9 / 11$, so it takes more to convince them that the time is ripe for elimination. At best, hedging proponents may want to move more slowly and cautiously. In all other respects, the scenarios differ: the one wants to keep stocks of weapon materials, teams of nuclear engineers and scientists to uphold virtual arsenals, and the necessary physical infrastructure to start production anew; the other wants to close it all down, more or less, and to start doing it before all the weapons have been eliminated.

Two measures from the classical arms-control agenda aim to prevent renewed arms build up. In Article VI of the NPT, the phrase "cessation of the nuclear arms race at an early date" was always understood to refer to a CTBT and an 


\section{Towards a nuclear-weapon-free world}

FMCT, the former curbing qualitative improvements and the latter limiting quantitative expansion of the arsenals. The more universal these and other armscontrol measures become, and the more effectively they can be verified and enforced, the more difficult it will be to break out and return to arms racing.

The US and China have not ratified the CTBT while the other members of the P5 have done so. The US has conducted 1,000 tests and Russia 700; the others, far fewer. There is concern, moreover, that sooner or later, simulation techniques will allow the US to make new types of weapons without live testing. To stem these inequalities and avoid qualitative improvements in the face of a test ban, the P5 should be asked to join the CTBT and undertake not to develop and deploy qualitatively new types of weapons. This is also primarily up to the most advanced NWS, i.e. the US and Russia. China appears ready to ratify the CTBT, provided the US goes first.

Already at their first meeting in April 2009, presidents Obama and Medvedev called for an FMCT as well as further cuts of existing arsenals, but they did not address the question of what to do with existing stocks of fissile materials in the framework of an FMCT. The simplest would be to go for a ban on further production, leaving the stocks aside, but on the way to an NWFW, much if not all weapon-grade materials have to be eliminated, step-by-step, and a cut-off negotiation presents an opportunity to move in that direction. At least, implementation of the Trilateral Initiative (US, Russia and the IAEA) concerning permanent removal and verification of nuclear materials from the military stockpiles should be set in motion as a supplementary measure. Irreversibility is important at every stage of the process. Still, if and when it comes to multilateral negotiations, the participants would have very different fissile material stocks at hand. Those differences cannot be erased overnight, but reductions can be carried out in such a way that, gradually, the differences will be reduced. In the end, the same rules must also apply for all in this respect.

Like the other P5, China seems to have stopped production of fissile materials for weapons, but unlike the others it has made no statement or formal commitment in this respect. In view of the uncertainties surrounding missile defence and the future of US forces, it is not confident that it has enough fissile materials in stock. India and Pakistan, which are building up their forces, are far from being ready for a cut-off. Therefore, an FMCT does not seem to be near at hand.

A CTBT and an FMCT are also important because nuclear infrastructures would be shut down or dismantled, notably nuclear test sites and fissile material production facilities. There may be consequences for personnel as well. The treaties would signal that there will be less of a future for nuclear-weapon works, which may lead experts in other directions, unless they are absorbed by expanding stewardship programmes for the weapons that remain and for what may become virtual arsenals in the future. In the United States, where the stewardship programme has been a middle ground between weapon supporters and disarmers, the administration has increased the funding of it in order to build support for CTBT ratification. 


\section{From P2 to P5 and beyond}

\section{Categorising the nuclear powers}

Is it a matter of course that the transition from bilateral to multilateral negotiations would be, first, from the US and Russia to the P5 and then to all de facto NWS? Is this the logical way to group the nuclear powers?

Pan Zhenqiang suggests a different categorisation (Pan 2009). He puts them into three groups: (1) the US and Russia, the first among unequals; (2) the UK, France and India, which share one major motive for nuclear weapons: to be accepted by the international community as major powers; and (3) China, Pakistan and Israel, which acquired nuclear weapons in response to specific, serious threats - China from the US, Pakistan from India, and Israel from a hostile neighbourhood. For status and security reasons, respectively, groups (2) and (3) will find it hard to abandon their weapons.

China's nuclear weapons were not acquired to make up for conventional weakness. It declared a no-first-use policy from the beginning. Neither does it need nuclear weapons to bolster its international status. Surely, these weapons also have a status value for China, but its international leverage rests primarily on its size, economic performance and ability to concentrate and exercise political power. The status tag attached to its modest nuclear arsenal matters less and less. However, China is not ready to say what would be required of the US and Russia for it to join multilateral disarmament negotiations. The strategic relationship with the United States remains unsettled, and the ballistic-missile defence and conventional global-strike programmes complicate its calculations (see Chapter 3).

If the principle of enhanced security at lower levels of armaments is applied, it should be less difficult for China than for the UK and France to join the US and Russia in multilateral talks. This principle does not require parity: in the framework of large US cuts and limits on missile defence, it is easy to imagine a win-win situation. Parity may not be attained until all the weapons have been eliminated - and not necessarily then, either, depending on how the end state is defined - but the closer one comes to a NWFW, the more the configuration would resemble a relationship between equals. The UK and France may also find that there is more than one way in which their security can be enhanced, but for them a qualitative political asset would be lost: their big power status would probably disappear with their weapons. Increasingly, their status ambitions would have to be channelled through the EU. Russia would be left somewhere in-between the US/China and the UK/France, being bigger in terms of population and enormous in terms of territory, but modest in terms of economic strength. To cut the P5 short by taking China out would therefore seem artificial.

Neither would it make sense to embark on multilateral negotiations without the UK and France. What would be the rationale for leaving their forces out? Loss of status is a real concern for both of them, but it is not a legitimate concern in the view of others. Last not least, the P5 is a well-established concept. These 


\section{Towards a nuclear-weapon-free world}

are the five NWS recognised by the NPT and the five permanent members of the UN Security Council, which have a special responsibility for nuclear disarmament under Article VI of the NPT and for international peace and security under the UN Charter. All parties to the NPT have committed themselves to work for nuclear disarmament, but to hold the five and only de jure NWS accountable, in particular, is straightforward common sense.

\section{Involving the outliers}

Whether the multilateral phase should be limited to the P5 at first and widened to include the outliers thereafter, or include all NWS right away, is open to question.

The NPT defines a NWS as a state that had tested a nuclear explosive device before 1 January 1967. By that definition, the nuclear club became synonymous with the P5.

Another four states have acquired nuclear weapons since then. One of them, North Korea, may or may not be disarmed irrespective of what the other nuclear powers are willing to do about their arsenals. There remains the possibility that Pyongyang will trade its nuclear programme for economic assistance and normalisation with the US and others. In 1992 the two Korean states signed a "Joint Declaration on the Denuclearisation of the Korean Peninsula" which ruled out fuel-cycle facilities as well. In 2008, a denuclearisation agreement was reached in the framework of the six-power talks, although it did not explicitly provide for elimination of the weapons that have been produced. The Obama administration will probably be in a better position to deal with North Korea than the Bush administration, which was split on what do to.

The other three - India, Pakistan and Israel, sometimes referred to as "the outliers" - have come to stay. There is nothing to suggest that they will give up their nuclear weapons any sooner than any of the P5. From this point of view, it seems appropriate to include them from the beginning, together with the P5. For all we know, Israel's arsenal may be of a size not much different from those of the UK, France and China. India and Pakistan are at lower levels, but seem to be on their way to similar numbers of weapons. An agreement limiting the arsenals to the low hundreds would allow the South Asians to meet their minimum deterrence objectives, and by the time a multilateral negotiation gets started, they may be there. In principle, acceptance of such a deal should therefore be no problem for them. Including them and capping their arsenals is a necessary step on the way to an NWFW.

At the moment, accession to the CTBT is a problem for India and Pakistan. However, if the US and Russia continue to cut their arsenals and all P5 ratify the CTBT, they may no longer be in a position to resist, even if it would leave Pakistan, and maybe India too, without fusion weapons. ${ }^{14}$ A fissile material cut-off will hardly be agreeable until they have produced enough material to meet their minimum deterrence-force targets. They are unlikely to let an international agreement compromise that objective. 
Even if the United States and Russia undertake to burn plutonium in power reactors as fast as possible and dilute remaining HEU to reactor fuel, they are likely to have significantly bigger stocks than the others by the time a multilateral disarmament agreement comes up for negotiation. In a process perspective in the expectation that disarmament will continue and all nuclear weapons be eliminated - the differences may not matter much. The parties may accept them in anticipation of equal rules at the end of the process. In a static perspective, where the continuation is open to question and the parties may choose to stay where they are, different break-out potentials are likely to be more controversial.

The South Asians are less sensitive to the US missile-defence programme than China. India's security concerns relate to China and Pakistan; Pakistan's concerns relate to India; and none of them bother very much about a retaliatory capability towards the US. To the extent that India cooperates with the US on missile defence, it is actually a beneficiary of the programme. So is Israel.

\section{Israel}

Israel is a de facto NWS, but never acknowledged it, neither by confirmed testing nor by any public statement. ${ }^{15}$ Its declaratory policy - "never to be the first to introduce nuclear weapons in the Middle East" - is part of a general policy of opacity (Cohen 1999)

This policy has served Israel well. On the one hand, there is no formal basis on which to address its arsenal; on the other hand, everybody has to assume that the weapons exist, so the deterrent effect is there. The policy is therefore hard to change. It is all the harder because unless Israel goes public with its nuclear weapon possession, it cannot be drawn into multilateral disarmament talks, and as long as there is no regional peace arrangement in sight, Israel is not ready to participate in such talks. Israel argues that, first, regional affairs have to be normalised and a just and comprehensive peace established. Only then can a zone free of nuclear and other weapons of mass destruction be implemented, shoring up what has been achieved.

The rationale for Israeli nuclear weapons is distinctly regional. Elimination is therefore a regional issue more than a global one. This is another unique feature of Israel. South Asia comes closest, but India's foreign-policy reach goes beyond the subcontinent. India has global ambitions and no doubt considers it natural to take part in global, multilateral disarmament talks, time and circumstances permitting. Pakistan is a function of India in this respect and can hardly hold back if India enters the ring. Israel is therefore left to be treated separately, in the regional Middle Eastern context.

The name of that game is a zone free of weapons of mass destruction or, specifically, a nuclear-weapon-free zone. Security Council Resolution 687 - the ceasefire resolution for Iraq - explicitly linked the disarmament of Iraq to the establishment of such a zone. The proposal for a Middle Eastern zone was first made in 1974, and calls for the establishment of it have been made repeatedly over the years but often for purposes other than progress towards a zone. The 
disarmament of Iraq notwithstanding, no progress has been made in the implementation of it.

Therefore, two of the four outliers - Israel and North Korea - can best be addressed separately. For the other two - India and Pakistan - the ambition must be to draw them into global negotiations together with the P5. If a criteria-based approach is adopted in relation to the outliers, asking all three to abide by the commitments that India has undertaken and raising the bar for de jure recognition by demanding, say, accession to the CTBT and a moratorium on fissile material production, only India may be able to live up to these requirements. In that case, the table would be enlarged from five to six NWS.

NNWS should also be invited to the table, e.g. states with advanced civilian nuclear programmes, and with a view to regional representation. They can do much to facilitate disarmament by reassuring the NWS and each other that they would stay non-nuclear (see Chapter 9). Without stronger commitments in this respect - foregoing national fuel-cycle facilities; accepting improved safeguards - the NWS may not be willing to take the final steps to a NWFW.

\section{From the low hundreds to what?}

One or more NWS may find that they can go no further unless their security concerns have been much alleviated and the military and political role of nuclear weapons has been much diminished. Russia may be such a case. Others may be ready to push proposals pointing beyond the low hundreds: China to follow up on its no-first-use posture; India to push its long-standing proposal for a nuclearweapon convention; NNWS to press their case for a NWFW whether they are brought into the negotiations or not. Most importantly, the US may remain committed to the course initiated by President Obama. However, all of this is uncertain.

Ceilings in the low hundreds will presumably be drawn on the basis of some notion of minimum deterrence. In terms of hardware, minimum deterrence is a function of the vulnerability of the weapons, their ability to penetrate enemy defences, and the possibility that some of them will malfunction and fail to arrive on target for that reason. In terms of software, it is a function of the efficiency of the C3I system and the perceived political will to follow through on the deterrence doctrines. Today, the powers that subscribe to minimum deterrence keep close to 200 operative weapons. India and Pakistan may be going for forces in about the same range, and Israel may already be there.

It may be assumed that multilateral negotiations will be heading for ceilings in the lower end of this range, compatible with notions of minimum deterrence, but not allowing significant increases in any of the forces. Substantial additions would run against the declared aim of the exercise, which will be framed in disarmament terms. How could one go on from there? What approach would minimise the risks on the way to a NWFW and the advantages that it offers? The prize is high, but so may be the risks.

This is the point at which the continuation is hard to foresee, for the world will look much different. Indeed, it would be presumptuous to claim to know 
much about it. However, political-order issues aside, some force constellations are known to be more unstable and dangerous than others. A few parameters may therefore be laid down to steer the process away from the greatest risks in the final approach to the goal.

This pertains, in particular, to the worlds immediately above and immediately below zero. The dangers of a world immediately below - of virtual arsenals have been spelt out above (see pp. 200-202). Similar dangers would exist in a world immediately above. At the level of, say, 30 nuclear weapons, the retaliatory capabilities may be in doubt. Some weapons may be destroyed by an attacker, others may be intercepted, and yet others may not function as planned. As a result, first-strike propensities may be too great for comfort. It may lead to surprise attack, hitting an enemy when its guard is down, or to inadvertent escalation when decision-makers begin to think that war can no longer be avoided. However flexible the notion of minimum deterrence is, force levels in the low hundreds may have been chosen for good reason.

It may therefore be wise to skip those transitional phases immediately above and immediately below zero and go from the low hundreds directly to an NWFW significantly below zero. That can be done by eliminating weapon-grade materials, dismantling dedicated nuclear infrastructure and redirecting nuclear-weapon expertise before eliminating the remaining weapons. In other words, the stability of minimum-deterrence postures would be maintained until the stability of an NWFW has been ensured. Then, and only then, would it be time to move from the one state to the other.

\section{Disarmament: process or state of affairs?}

On the way to a NWFW, the differences between the NWS will diminish. Still, their capabilities will remain different in many respects, especially qualitative ones. The principle of equity should inform the process, but how agreeable is it and how will it be practised? Would China use the opportunity to go for equal status with the US and Russia in as many respects as possible and as soon as possible? Would India reach out for the same? Why should the US and Russia give up their nuclear superiority and accept equal status with the much smaller nuclear powers any sooner than is strictly speaking necessary? Would they ask for proportional reductions when they come to the multilateral table? Even if the US maintains its commitment to an NWFW, why should it yield to the others any more or any sooner than is strictly speaking necessary?

If the commitments to an NWFW are firm and the expectations that it will be achieved are strong, equal or unequal terms some steps earlier will not necessarily matter very much. The end result would be the same for everybody. In a process perspective, there would be more leeway in the negotiation of transitional steps than in a static perspective where each stage stands on its own and the future is open-ended. For instance, if a multilateral deal is struck in a static perspective - this far, but no promise of going further - the NWS are likely to be more sensitive to competitive edges and seek unilateral advantages. Then, the 
leading powers cannot be expected to generously relinquish their lead. More than in a process perspective pursued in the name of global public goods, the name of the game would be old-fashioned power politics.

A static perspective, seeing disarmament not as a process but as a state of affairs, presents a problem similar to a well-known question in integration theory (see Chapter 9). Integration is also seen variously as a process or a state of affairs. In the European Union, which has inspired integration theory more than any other empirical setting, there is the recurrent question of whether integration can stop and stay at some point without unravelling. Is there such a point of stability, or will stagnation be the beginning of reversal?

The same question is pertinent to the field of disarmament. If the US and Russia stay content after having reduced their forces to, say, 1,000 operative weapons all in all, losing sight of the objective of a NWFW, what will others do? Clearly, proliferation is more likely in a static context, where the NWS continue to demonstrate the significance that they attach to nuclear arms, than in a process perspective where proliferators would confront a big majority of states set on the course of continued disarmament. Stagnation may therefore lead to proliferation, which in turn may lead NWS to rearm.

Darwin Bond-Graham and Will Parish have raised a related question under the heading of "anti-nuclear nuclearism" (Bond-Graham and Parish 2009). They expect that the Obama administration will rely on overwhelming US power, nuclear weapons included, while making rhetorical and substantial commitments to disarmament, however vaguely defined. Anti-nuclear nuclearism thrives both in think tanks and weapons laboratories and is a tactical adaptation to the call for a NWFW. It means retention of slimmer arsenals, bringing disarmament to a halt at a level compatible with US national interest in continued military superiority. The President has declared higher aims for nuclear disarmament and so have many of his collaborators, but in the face of domestic and international opposition, he may have to strike a national compromise of this kind. However, a lower plateau does not mean a lower risk of proliferation. Like the disarmament agreements by the end of the Cold War, which were not followed by new agreements, but by revived national interests in nuclear arms instead, stagnation may be the beginning of reversal.

In SC Resolution 1887, the P5 declared themselves in favour of a world without nuclear weapons. Still, when it comes to specific measures, they tend to take one step at a time without making any further promises. Nevertheless, if President Obama and others manage to stay their course, promoting nuclear disarmament as a global common good, it may be possible to generate explicit commitments from one step to the next: from New START to a follow-on agreement on deep cuts to further steps setting the stage for multilateral negotiations; from an FMCT to further cuts in fissile material stocks; from the steps taken by the US NPR to limit the role of nuclear weapons to a new SC resolution to an international convention on unqualified non-use assurances to no-first-use doctrines; from procedural to material steps towards a NWFZ in the Middle East etc. - all the time invoking the advantages of a NWFW in support of the process. 
Endowed with big power and unwilling to tie their hands in the exercise of it, the same states have been against proposals for a convention on the elimination of nuclear weapons, with a timetable. To reduce the complexities of nuclear disarmament to a timeline is arguably reductionism beyond reason. However, at some stage of the process it will be necessary to supplement the NPT, which is but a skeleton agreement to zero, and to define what kind of NWFW to aim for. A convention defining the rules of the road towards nuclear-weapon freedom can also reduce the action space for spoilers and for unforeseen developments to take the process off-track. The lessons from the Oslo process on the Middle East and from negotiations with North Korea point in the same direction. If at all possible, a compressed, comprehensive approach to the final objective has distinct advantages.

Two arguments in support of the process perspective carry particular weight. First, 60 years of no use does not guarantee another 60 years without the use of nuclear arms. On the contrary: there is much to suggest that the risk of nuclearweapon use is greater than before. The premium on abolition has therefore grown. For many proponents of a NWFW, this is hard-nosed realism. The four US horsemen were always known to be realists, and so are many other statesmen that have joined them in the call for a NWFW. Second, the threat of mass destruction is morally unacceptable and should be made unambiguously illegal. Chemical and biological weapons are already outlawed on such grounds. Since the effects of nuclear weapons are stronger, more indiscriminate and longerlasting than those of any other weapon, there is all the more reason to ban them. From both angles, MAD is an appropriate acronym for continued reliance on nuclear deterrence.

\section{Political-order requirements}

The first stages of the disarmament process - US-Russian cuts leading to multilateral talks - do not presuppose any change of world order, but imply a distinct shift from antagonistic to cooperative behaviour. Subsequent stages require more of the same, gradually transforming the current security system based on nuclear deterrence into a system based on cooperation and mutual restraint. Arms control and disarmament can assume the role of catalyst and amplifier of such a change. It has had that role before: starting with the Stockholm agreement on confidence and security-building measures in 1986, it helped to move the world out of the Cold War (Muller 2008)

If disarmament is widely recognised as a high-priority global public good, it can become an important driver of systemic change. Confidence must be built, conflicts must be alleviated and solved, conventional force relationships must be adjusted and international politics better institutionalised as the process unfolds. There will always be many other drivers: economic interests may dovetail or collide; liberal internationalism confronts some of the norms that the UN Charter prescribed and that Asian states adhere to; unresolved border issues invoke national interests, etc. However, if there is broad agreement to make disarmament 
a global public good, disarmament can become one of the organising principles of international affairs, enhancing world security in many more respects than nuclear disarmament per se can offer.

The first test of disarmament as an organising principle was Obama's use of the re-set button, inviting Russia to follow-up on START I. For deeper cuts to be achieved, controversial military problems regarding tactical nuclear weapons, missile defence and new long-range conventional weapons must be solved. This in turn presupposes that contentious political questions like NATO's role and reach and other sensitive issues along Russia's southern borders and towards Iran are better managed to the satisfaction of all concerned.

When multilateral reductions to the low hundreds have been agreed, further steps will depend on fundamental world order changes, for it is from then on that the question of how to live without nuclear deterrence becomes pressing. A better system must be developed to substitute for it. Would all the NWS be ready to engage in that endeavour? Would the Middle East look peaceful enough for Israel to join in and disarm?

Contemplating what world-order changes may be needed to enhance international security and sustain disarmament, references have been made to the socalled "European concert" after the Napoleonic wars, when the European powers undertook to respect each other's vital interests and exercise restraint in a system characterised by balance of power. Henry Kissinger, an authority on concert diplomacy, describes it as a system where

the great powers work together to enforce international norms.... Common action grows out of shared convictions. Power emerges from a sense of community and is exercised by an allocation of responsibilities related to a country's resources. It is a kind of world order either without a dominating power or in which the potentially dominating power leads through selfrestraint.

Believing that the Obama administration favours some kind of concert diplomacy, he argues that American leadership will "result from the willingness to listen and to provide inspirational affirmations [of norms]" (Kissinger 2009).

A big power concert may be predicated on equilibrium between the participating states or it may be based on consensus. Generally, the former has been considered less demanding than the latter, although there are few examples of sustained operation of any version of power concerts. Today, however, when power is shifting so rapidly, a lasting equilibrium is dead on arrival. Better, then, to focus on norms - norms of mutual respect and self-restraint embedded in a growing body of international law, i.a. with a view to building a platform for effective enforcement action.

The NPT suffers very much from lack of well-functioning enforcement mechanisms. Not only is it difficult to forge consensus between the P5, but the Security Council is increasingly out of tune with the distribution of power in the international system. More and more, the legitimacy of its decisions is ques- 
tioned. Progress towards a NWFW requires cooperative security between the big powers with a view to more effective collective security mechanisms in the hands of a reformed world organisation.

Globalisation encourages development along these lines. Interdependence is growing by the day and necessitates broad-based international cooperation on regulatory measures. However, globalisation is far from portraying a golden age for international norms in general. Protectionism is back on stage, and liberal internationalism is pitted against state sovereignty, territorial integrity and nonintervention in internal affairs.

In East Asia, rapidly growing economic interdependence is a brake on conflict dynamics in the region. Use of force will come at tremendous cost to all involved. However, economic cooperation and security policies are conducted along different trajectories. Economic cooperation means interdependence, but it is pursued by sovereign states and does not translate into political integration (see Chapter 1).

Europe is different in this respect. Starting from the interdependence of the Coal and Steel Union, integration has been going on for more than 50 years. When the Cold War ended, the European Union and Russia named each other as strategic partners. Still, Russia and the European nuclear powers threaten to be the first to use nuclear weapons against each other. There is no reasonable connection between the political sphere and existing nuclear doctrines. Many elements of the nuclear postures have become anachronistic. In particular, extended deterrence in the form of forward basing of nuclear weapons and first-use doctrines are deemed increasingly dysfunctional both in Europe and in East Asia.

The EU is based on international rules, norms and standards, and is committed to follow up on them in its external affairs. The Europeans are strong and stable supporters of all ten of the requirements for a new non-proliferation and disarmament consensus outlined in Chapter 4, with some reservations made for France and to a smaller extent for the UK. The United States is less predictable in this respect because of the likely fluctuations of unilateralism. Where the US emphasises military strength and application of military means in international affairs, Europeans emphasise non-military solutions to problems out of conviction as well as necessity, having cut their military investments to the bone after the Cold War. As for relations with Russia, there are different cultures at work in Eastern Europe, Western Europe, the United States and in Russia itself (see Chapter 1), but there is more to suggest that Russia will be better integrated into European affairs than that it will be kept out.

The danger of nuclear-weapon-use may be highest in South Asia and the Middle East. These are volatile areas that call for combinations of regional measures and global initiatives. In the Middle East, the name of the game is a zone free of nuclear weapons or of chemical and biological weapons as well. These proposals are inextricably linked to the management of the conflict formations in the region. The 1995 review and extension conference adopted a resolution on the matter, but no progress has been made in implementing it. As long as the Israeli arsenal is untouched, Egypt and other Arab states are generally unwilling 


\section{Towards a nuclear-weapon-free world}

to undertake more arms-control obligations. Hence, Egypt has not acceded to the $\mathrm{CBC}$, the BWC, the CTBT, the Additional Protocol on safeguards and the Pelindaba Treaty on Africa as a nuclear-weapon-free zone. The emergence of the Iranian nuclear programme reinforces this attitude and inspires hedging.

Thinking beyond multilateral talks and nuclear arsenals in the low hundreds, the path-dependence of nuclear disarmament blurs the picture. That far ahead in political time, the nature of world politics defies prediction. However, much is known about force constellations that are threatening and non-threatening, dangerous and less dangerous, stable and unstable, so in such terms it is possible to formulate some guidelines for the final approaches to a NWFW. One such proposition has been forwarded here: since stability concerns and bickering over numbers are likely to become more of a problem at very low levels, and since virtual arsenals are likely to be unstable, it may be wise to stay at minimum deterrence levels until the nuclear-weapons infrastructure and weapons-grade materials have been eliminated, and then go straight to a world below zero.

For political leaders to act on complex realities, the realities have to be simplified. Heuristic assumptions to that effect may be flawed, but by making the move towards a NWFW more thinkable, realisation of it becomes more likely. 


\section{Notes}

\section{Power shifts and nuclear weapons}

1 The term "security dilemma" was coined by John H. Herz (1951) in Political Realism and Political Idealism. The British historian Herbert Butterfield (1951) described the same situation in History and Human Relations. He referred to it as the "absolute predicament and irreducible dilemma".

2 Department of Defense deployment numbers, 31 December 2007. Unofficial numbers are higher.

3 The FY 2009 budget, the last budget submitted by the Bush administration, was expected to result in defence outlays of $\$ 675$ billion, implying a real-terms increase in US military spending of 71 per cent during FYs 2000-2009. See SIPRI (2009).

4 Fareed Zakaria was the first to bring this to public attention. See Zakaria (2008a, b).

5 Chinese government statistics show that for every four students who left in the past decade, only one returned home. Recently, China has begun to exert a reverse pull, investing more in R\&D and playing on patriotism. See LaFraniere (2010).

6 A security community is a region where large-scale use of violence has not only become very unlikely, but has disappeared from the political agenda. Examples are the Nordic countries and the United States and Canada. Karl W. Deutsch et al. (1957) distinguished between amalgamated (e.g. USA) and pluralistic security communities (e.g. the Nordic countries; the United States and Canada). Raimo Vaÿrynen (2000) differentiates between interstate security communities where war between states is unlikely (e.g. Southeast Asia) and comprehensive security communities where both interstate conflicts and civil wars are deemed unthinkable (e.g. Western Europe).

7 India ranked 120 out of 178 economies according to the "World Trade Indicators 2008" report by the World Bank. See The Hindu Business Line (2008) and European Commission Directorate-General for Trade (2009).

8 The concept of "peaceful rise" was first introduced at the Boa'o Asia Forum in April 2004. See Bronson (2007).

9 This paragraph draws on Chapter 1 of Gill (2007).

10 Many scholars use Ray S. Cline's power equation in their measurements of comprehensive power. See Cline (1977).

11 "Asians welcomed the U.S. presence and role as their region's security and prosperity guarantor not because they loved America the most but because they feared America the least. Not any more" (Thakur 2007).

12 Russian officials usually refrain from commenting on the roles that nuclear weapons might have in Siberia. See SIPRI (2009). 


\section{The first nuclear era}

1 In addition, there were 98 tactical nuclear weapons in Cuba, which General Issa Pliyev, the Soviet commander in Cuba, had the authority to use. A total of 24 IRBM (intermediate-range ballistic missile) warheads of half-a-megaton yield, slated to be deployed on the IRBMs that never arrived, remained aboard the Alexandrovsk in the port of La Isabella and were not available to Pliyev.

2 The article applies to individuals and non-governmental units, as well as to governments, the latter being responsible for the behaviour of the former.

\section{Post-Cold War doctrines}

1 Existential deterrence is similar to the thesis of "fleet in being" which, in the words of Alfred Mahan, holds that "the presence of a strong force, even though inferior, near the scene of operations, will produce a momentous effect upon the enemy's action". The perceived existence of such a force would constrain and deter the enemy. Mahan rejected the thesis. See Westcott (1918).

2 The Soviet declaratory policy of no-first-use (NFU) had little credibility anyhow, as long as large numbers of tactical nuclear weapons were deployed along the dividing line in Europe. Oleg Grinevsky cites the former head of the Soviet General Staff Marshall Nikolay Ogarkov:

We are not about to wait when we are attacked. We ourselves will attack if we are forced to and when we find initial indications of a NATO nuclear assault.... We have the right to consider it as a response even without being under actual missile attack.

(Grinevsky 2004)

3 In Asia, nuclear weapons were withdrawn from Japan and South Korea. About 100 nuclear warheads for Tomahawk sea-launched cruise missiles were retained for deployment in case of emergency. In Europe, successive reductions brought the number of US nuclear weapons down to the low hundreds.

4

European allies should not keep asking us to multiply assurances that we cannot possibly mean, or that if we do mean, we should not want to execute because if we execute, we risk the destruction of civilisation. Our strategic dilemma isn't solved with reassurances.

(Kissinger 1980)

5 Had Saddam Hussein had nuclear weapons he might have used them as an act of last resort since the regime and his own life were at stake. Fortunately, the nuclear weapons programme had been found and destroyed by UNSCOM.

6 The background for these threats may also be understood in defensive terms. Iraq and Iran were viewed as revisionist states wanting to control much of the Middle East, with potentially severe effects on the flow of petroleum to the West. While it had been US policy to contain and deter these states, it seems that the original ambition of the Bush administration was to push all anti-status-quo states in the Middle East into obedience by regime change and use of military force if need be.

7 In his book, Feith does not identify the names of regimes to be targeted after 9/11 except Afghanistan, but when asked which of the regimes on Clark's list were included, he said "all of them". See Clark (2003), Feith (2008), Porter (2008).

8 More evidence is needed to establish whether there is a causal relationship here and not just a correlation due to other factors.

9 "Military-industrial" is shorthand for a complex with much wider ramifications, including R\&D establishments and vested political interests. 
10 The 2002 National Security Strategy was updated in 2006, building heavily on the 2002 version. See The National Security Strategy of the United States 2006.

11 President Nixon, when signing the ABM Treaty on 26 May 1972.

12 The authors of the UN Charter hardly saw it that way. In their view, the right to selfdefence did not include pre-emption. Today, however, most lawyers see pre-emptive action as being legal.

13 Linton Brooks says that there was no internal consideration of nuclear pre-emption, but that the administration failed to make this point explicit in its public pronouncements. See Brooks (2009).

14 The Clinton administration did that as well. The B-61-11 bunker-buster bomb was further developed without nuclear testing during the 1990s.

15 In the autumn of 2005, a Draft Doctrine for Joint Nuclear Operations had a special chapter on theatre nuclear operations - not in the previous version of 1995 - which extended the role of nuclear weapons from deterrence by retaliation to battlefield destruction of targets. It also lowered the bar for nuclear-weapon use by replacing "war" with "conflict", a change proposed by the Strategic Command. Clearly, the emphasis was moved from war between the major powers to regional contingencies, where the nuclear planners anticipated that nuclear weapons might be used in lessintense conflicts than previously envisioned. However, the text was never approved by the political authorities. For the text and editing comments, see www.nukestrat. com.

16 Donald Rumsfeld, in his foreword to the new NPR submitted to Congress on 8 January 2002.

17 On the contrary, the administration wanted to remove Clinton's signature from the Treaty, but did not find a way to do it.

18 The wording was slightly different from the statement at the first UN special session on disarmament in 1978:

The United States reaffirms that it will not use nuclear weapons against nonnuclear-weapon state-parties to the Treaty on the Non-Proliferation of Nuclear Weapons, except in the case of an invasion or any other attack on the United States, its territories, its armed forces or other troops, its allies, or on a state toward which it has a security commitment carried out, or sustained by such a non-nuclear-weapon state in association or alliance with a nuclear-weapon state.

19 NSC official Robert Bell. See Mendelsohn (1999).

20 To wait for its conventional forces to be strong enough to allow for no-first-use is no alternative: the US accounts for 45 per cent of world military expenditures, Russia for 3 per cent.

21 Oleg Grinevsky quotes the head of the Soviet General Staff Marshall Ogarkov:

We are not about to wait when we are attacked.... We ourselves will attack if we are forced to and when we find indications of a NATO nuclear assault.... We have the right to consider it a response even without being under actual missile attack.

(Grinevsky 2004)

22 The first official endorsement of this modification was in the 2001 NPR.

23 The war broke out at the end of 1999, after the new doctrine had been drafted, but it had been clear for some time that a second Chechnya war was imminent.

24 The bombing of Yugoslavia revived the worst instincts of the Cold War among Russian civil and military leaders, confirming assumptions of NATO hostility that only a few years before had been confined to extreme nationalists and communists. See Arbatov (2000).

25 Because of the Chinese factor, Russia's policy is to be "founded on nuclear weapons and presumes strategic cooperation with the West". See Ostankov (2005). Concerns 
about demography, the competition for resources and military imbalances are not expressed at the governmental level, however.

26 The new Military Doctrine was published on 5 February 2010. See Sokov (2010).

27 From 2009, the airborne component will be equipped with the ASMP-A cruise missile, deployed on Mirage 2003 NK3 and Rafael aircraft, stationed in France and carrier-based. The number of nuclear-capable land-based aircraft will be reduced from 60 to 40. See Defense et Securite national (2008). After the cut, the French stockpile would contain fewer than 300 weapons.

28 An English version of the speech is reproduced in Disarmament Diplomacy (2006), No. 82.

29 French Defence Minister Alliot-Marie, hearing on nuclear deterrence before the Foreign Affairs Commission on the Defence and Armed Forces, Ministry of Defence, 1 February 2006.

30 Speech by President Sarkozy on 21 March 2008. In an analysis of the speech, Bruno Tertrais emphasises that it was noteworthy in at least two respects: it signalled that continuity would prevail as far as nuclear-weapons policy is concerned, and it devoted an unusual amount of time to issues of disarmament. See Tertrais (2008).

31 Since Chinese nuclear assets are vulnerable, this policy may well be declaratory rather than based on credible options.

32 Fact sheet from the US Department of Defense, 9 April 2010. The Obama administration has requested \$239.9 million for prompt global-strike research and development across the military services in fiscal year 2011. Budget documents indicate that by the end of fiscal year 2015, \$2 billion may have been spent on the PGS programme.

\section{A global consensus on non-proliferation and disarmament}

1 Article X.2 says that 25 years after the entry into force of the NPT, a conference shall decide whether the Treaty "shall continue in force indefinitely, or shall be extended for an additional fixed period or periods".

2 Article V is about peaceful nuclear explosions (PNEs). PNEs have been found to be of little or no utility, so the article is commonly considered to be a "dead" one.

3 The Resolution asked all parties to the Treaty, and in particular the nuclear-weapon states, to "extend their cooperation and to exert their utmost efforts with a view to ensuring the early establishment by regional parties of a Middle East zone free of nuclear and all other weapons of mass destruction and their delivery systems" (Resolution on the Middle East (NPT/CONF.1995/32/RES/1) 1995).

4 The only reservation was in reference to possible long-term developments making nuclear weapons standard equipment of ordinary states. See Prawitz (1995).

5 In 2006, the author argued that to save the NPT, a high-level UN meeting should be called to confirm the validity of the three pillars on which it is based - nonproliferation, disarmament and peaceful uses - and to seek agreement on approaches to the implementation of Article VI. The reasoning, furthermore, was that the meeting might be convened in the autumn of 2009 - midway between the inauguration of a new US president and the 2010 review conference of the NPT - not in the belief that policies of exceptionalism, unilateralism and coalitions of the willing would suddenly be abandoned, but in the hope that they would soon be significantly modified in favour of multilaterally negotiated international agreements, of which the NPT occupies the centre-stage. See Lodgaard (2007).

6 The Council reaffirms

its firm commitment to the NPT and its conviction that the international nuclear non-proliferation regime should be maintained and strengthened to ensure its effective implementation [and recalls] in this regard the outcomes of past NPT Review Conferences, including the 1995 and 2000 final documents. 
In paragraph 6 it "Calls upon all States Parties to the NPT ... to set realistic and achievable goals in all the Treaty's three pillars: non-proliferation, the peaceful uses of nuclear energy, and disarmament".

7 Asked if he was worried that Obama's UNGA speech, calling for an NWFW, would apply to Israel, Netanyahu said:

It was utterly clear from the context of the speech that he was talking about North Korea and Iran.... I want to remind you that in my first meeting with President Obama in Washington I received from him, and I asked to receive from him, an itemised list of the strategic understandings that have existed for many years between Israel and the United States on this issue. It was not for naught that I requested, and it was not for naught that I received [that document].

(Quoted in Lake 2009; see also Cohen and Perkovich 2009)

8 Such as when military units begin to move in preparation of an attack. Terms like "about to attack" and "seeing the attack coming" leave much to interpretation, however. The downside of it is that pre-emption may trigger inadvertent escalation leading to war. For instance, during the Cold War, the offensive capabilities along the dividing line in Central Europe were commonly recognised to outweigh the defensive capabilities on the other side, so the temptation to pre-empt would have been strong had one or the other side begun to believe that an attack was coming. Pre-emption of terrorist attack is quite another matter: in this case, there may be no immediate warning signals, leading into an argument for preventive action against terrorists.

9 International law recognises a limited right of reprisal in addition to the right of selfdefence. It legitimises certain actions that would otherwise be unlawful, in response to an illegal act by or under the aegis of another state. Reprisals, too, are subject to the general requirements of necessity and proportionality. Non-coercive means should be considered before a reprisal is carried out. There is a substantial body of legal opinion holding that permissible reprisals are limited to measures other than armed force.

10 Osiraq was built to run on highly enriched uranium (HEU) and was a poor plutonium source. Had a natural uranium blanket been put around the core, some plutonium could have been produced, but without major reconstruction of the reactor it would not have been enough for weapon production. The HEU that had been stored at the reactor site was not hit by the bombs and stayed there until shortly before the 1991 war, when Saddam Hussein ordered it removed in a futile, last-minute effort to get a bomb. Had the Iraqis begun to adapt the reactor to make it a better source of plutonium, or removed the HEU it was designed to use, the alarm bell would have rung immediately, for the reactor complex was under IAEA safeguards. See Reiter (2006).

11 On the network of underground tunnels and protection of assets in hard rock, see Broad (2010).

12 By 6 October 2009, 129 states had signed an Additional Protocol.

13 The right to enrich is spelt out convincingly and in all necessary detail in Miller (2007b).

14 See Rauf (2007). In a much-noted article published in the autumn of 2003, Mohamed ElBaradei proposed a sequence of measures that formed a constructive agenda for further inquiry and action. The elements are: assurances of supply (of fuel) and access (to equipment and technology); a moratorium on new national fuel-cycle facilities; restricting enrichment and reprocessing operations to facilities under multinational control; investments in new proliferation-resistant nuclear energy systems; and multinational approaches to the management and disposal of spent fuel and radioactive waste (ElBaradei 2003). The High Level Panel on Threats, Challenges and Change of the United Nations (2004) supported many of these measures. So did UNGA/Kofi Annan's report, "In Larger Freedom" (2005).

15 Although the preamble pays particular attention to one specific measure: discontinua- 
tion of "all test explosions of nuclear weapons for all time". As noted below, the negotiating history sheds light on a number of other measures.

16 In 1965, a UNGA Resolution used the language "coupled with or followed by" to capture both positions.

17 This language is often used in NPT discussions, e.g. in the "Thirteen steps" of nuclear disarmament adopted by the 2000 Review Conference.

18 In case nuclear war nevertheless breaks out, NNWS want to be assured that they would not be targeted. Unqualified non-use assurances to non-nuclear parties to the NPT cover such contingencies, while no-first-use (NFU) doctrines do not. If somebody breaks the doctrine, the other NWS would be freed from their obligations. The prime objective, however, is to prevent a nuclear war from breaking out. Should it nevertheless occur, self-imposed restraints to spare NNWS of the horrors of nuclear warfare can realistically not be expected in any case, regardless of what kind of assurances that have been given in time of peace.

19 For a recent discussion of the pros and cons of NFU, see Sagan, Halperin, Tertrais and Subramaniam in Survival (2009).

20 In many ways, however, the policy of opacity is anachronistic and at odds with international liberal norms to which Israel generally adheres. See Cohen (2010).

21 A resolution of this kind has been proposed by Goldschmidt (2008). Paragraph 17 of S/Res/1887 notes ongoing discussions on how the NPT parties could collectively respond to notifications of withdrawal and affirms that a state remains responsible under international law for violations of the NPT committed prior to its withdrawal.

22 Paragraph 4 of S/Res/1887, which calls on all states to adhere to the NPT, adds "and pending their accession to the Treaty, to adhere to its terms".

23 Introduced by Representatives Lungren (Republican) and McGovern (Democrat) in March 2008.

24

Today, let me put forward four pillars that I believe are fundamental to the future that we want for our children: non-proliferation and disarmament; the promotion of peace and security; the preservation of our planet; and a global economy that advances opportunity for all people. First, we must stop the spread of nuclear weapons, and seek the goal of a world without them.

(President Obama addressing the UN General Assembly, 24 September 2009)

\section{The three-state problem}

1 In 1992, the two Korean states declared their intention to make the Korean peninsula an NWFZ: "Joint Declaration on the Denuclearisation of the Korean Peninsula", 20 January 1992, www.fas.org/news/dprk/1992/920219-D-4129.htm. In a joint statement from the six-party talks - North Korea, South Korea, China, Russia, Japan and the US - on 19 September 2005, the DPRK again "committed to abandoning all nuclear weapons and existing nuclear programs ..." (www.chinadaily.com.cn/english/ doc/2005-09/19/content_479150_2.htm). The statement reiterated that "the 1992 Joint Declaration of the $\bar{D}$ enuclearisation of the Korean Peninsula should be observed and implemented".

2 While the justifications have always been phrased in security terms, in some cases the main drivers have been different (see Chapter 6). On the UK and France, see Pélopidas (2010b). On India, see Perkovich (2001).

3 Among them Algeria, Argentina, Brazil, Japan, South Africa and South Korea.

4 Not only because the agreement contains such specifics, which is to state the obvious, but also for diplomatic and political reasons in order to facilitate ratification of it.

5 George Bush when signing the US-India Nuclear Cooperation Act, 18 December 2006 (www.acronym.org.uk/docs/0612/doc04.htm). 
6 New Framework for the US-India Defense Relationship, signed 28 June 2008 (http:// newdelhi.usembassy.gov/ipr062805.html).

7 Nicholas Burns at the Carnegie Endowment for International Peace, Washington DC, 5 April 2007 (www.state.gov/p/us/rm/2007/81207.htm). On the notion of "democratic bombs", see Perkovich (2006) and Hayes (2009).

8 In the ratification debate in the US Senate, Christopher Dodd (D-Conn.) said there were compelling geopolitical reasons to approve the bill, mentioning India's location near China, Afghanistan and Pakistan. Richard Lugar (R-Indiana) said the agreement was one of the most important strategic diplomatic initiatives undertaken in the last decade.

9 Because of the delay in India, adoption of the safeguards agreement with the IAEA had to wait until 1 August. The NSG gave its consent on 6 September, and the bill was introduced to Congress on 10 September. In order to conclude the deal before the Congressional recess, the Hyde Act of 2006 - which required that Congress be in 30 days of continuous session to consider the deal - had to be sidestepped. This was done: the House voted on 27 September, and the Senate on 1 October.

10 "Your voice was very effective, and I welcome it" - President Bush when signing the US-India nuclear cooperation act into law, 18 December 2006.

11 For an early discussion of the "as if" proposition, see Lodgaard (2004) and Lodgaard et al. (2005).

12 The Agreement was made on the basis of Section 123 in the US Atomic Energy Act, hence the references to "the 123 Agreement".

13 The paragraph commits the five NWS "not in any way to assist, encourage or induce" other states in the acquisition of nuclear weapons.

14 The US has claimed that all future breeders will be on the civilian side (Burns 2007).

15 The two US-built reactors at Tarapur, the two Canadian-built reactors in Rajastan and the two reactors being built by Russia at Kundankulam.

16

Given India's uranium ore crunch and the need to build up our minimum credible deterrent as fast as possible, it is to India's advantage to categorise as many power reactors as possible as civilian ones to be refuelled by imported uranium and conserve our native uranium fuel for weapon-grade plutonium production.

(K. Subramaniam in The Times of India, 12 December 2005)

Subramaniam is head of Prime Minister Singh's Global Strategic Development Task Force. After the Agreement was concluded, India made a deal with Russia to import 2,000 metric tons of uranium, and made an agreement with Kazakhstan that includes provisions for natural uranium deliveries to India.

17 George Perkovich says:

the deal's champions ... persuaded the president to issue internal guidelines to the negotiators that terms of the deal should not constrain India's strategic capabilities. Per implication, the negotiators could hardly require India to, say, limit its production of fissile materials or sign the CTBT.

(Perkovich 2010)

18 After the 1974 test, nuclear fuel to the power plant in Tarapur was withheld when a new nuclear non-proliferation act (NNPA) was passed by the US Congress.

19 A cut-off agreement, requiring that in the NWS safeguards would apply only to reprocessing and enrichment plants, would introduce another element of unequal treatment into the non-proliferation regime. On the one hand, there would be the NNWS, required to put all their activities under safeguards, and on the other, the NWS which should be trusted not to divert nuclear material from their unsafeguarded civilian reactors, fuel-fabrication plants, etc. To avoid yet another differential treatment in favour of the NWS, all civilian activities should also be placed under safeguards in these countries. See David Fischer (1994). 
20 Except for states with little or no nuclear activity where, in some cases, safeguards agreements remain to be concluded. The NPT mandates that safeguards agreements be concluded within 18 months of the Treaty's entry into force, so failure to do so is a violation of the Treaty. To date, however, this has not been a matter of much concern.

21 "By far the most forward looking foreign policy achievement of the current Administration", Senator Richard Lugar at the National Defense University, Washington, DC, 15 October 2008.

22 To the dismay of the Iranian government, in 2008 India launched an Israeli spy satellite, ostensibly to monitor Iranian nuclear facilities.

23 India has very friendly relations with Iran. It will continue to do so" (Defence Minister A.K. Anthony).

24 The "umbrella" agreement, adopted by consensus on 1 August 2008.

25 South Africa, Iraq, Nigeria, Morocco, Thailand, Chile, Ecuador, Ghana, Bolivia, the Philippines, Algeria, Ethiopia, Indonesia, Iran and Malaysia.

26 The Begin doctrine, named after Prime Minister Menachem Begin who authorised the attack on Osiraq.

27 Beyond the Additional Protocol, the "Commission of Eminent Persons", which was asked to reflect on the role of the IAEA up to 2020 and beyond, recommends that the IAEA's existing authorities be interpreted to give the Agency the responsibility to inspect for indicators of nuclear weaponisation activities. Reinforcing the Global Nuclear Order for Peace and Prosperity, Report prepared by an independent commission at the request of the Director General of the International Atomic Energy Agency, May 2008.

28 Commenting on the safeguards agreement with India, ElBaradei said that the Indiaspecific agreement could be used for the conclusion of other 66-type agreements as well, indicating that there might be a follow-up in other outlier states.

29 The International Commission on Nuclear Non-proliferation and Disarmament recommends that

Provided they [Israel, Pakistan and India] satisfy strong objective criteria demonstrating commitment to disarmament and non-proliferation, and sign up to specific future commitments in this respect, these states should have access to nuclear materials and technology for civilian purposes on the same basis as an NPT member.

(International Commission on Nuclear Non-Proliferation and Disarmament 2009,

\section{Rollback experiences}

1 The term "proliferation" was introduced by Albert Wohlstetter in 1961. For a discussion of the way it has been used and its in-built implications, see Pélopidas (2009, 2010c).

2 For a critical examination, see Sagan (2010).

3 In the first two decades of the nuclear age, no non-proliferation norm existed. No international legal instrument obliging the parties to stay non-nuclear had been established, and the safeguards that were introduced in the second decade (INFCIRC/66) had limited coverage. In this period, the P5 did not conduct their nuclear-weapons programmes under the guise of dual-use facilities. The existence of the programmes could not be hidden given the size of gaseous diffusion facilities. The dual-use option became attractive later on when there were more technologies and facilities to hide behind and when non-proliferation norms, obligations and safeguards had begun to take hold.

4 Today, all NNWS are members of the NPT, so proliferation means break-out of the 
regime and a certain likelihood of "publicity before consummation". India and Pakistan were the last ones not to violate any such commitment.

5 For a study of the US influence on the South Korean and Taiwanese cases, see Hersman and Peters (2006).

6 For fear of exposure, South Africa also refrained from using English-language experts. For a recent overview of the case, see du Preez and Maettig (2010). Waldo Stumpf, former Chief Executive Officer of the Nuclear Energy Corporation of South Africa, appointed by Frederik de Klerk to lead the dismantlement of the weapons programme, in a 1995 lecture entitled, "The Birth and Death of the South African Nuclear Weapons Programme", delivered in Castiglioncello in Italy.

7 See www.fas.org/nuke/guide/rsa/nuke/stumpf.htm. It was not until 24 March 1993 that President de Klerk publicly revealed to the Parliament and to the world that South Africa had built nuclear weapons. There remains about $500 \mathrm{~kg}$ of HEU in South Africa.

8 The three non-nuclear principles - not to possess, not to manufacture and not to introduce nuclear weapons into Japanese territory - were adopted by the Diet in 1971 in the form of a parliamentary resolution. It was never turned into law, but have been repeated by Japanese leaders ever since. Prime Minister Hatoyama did so in January 2010. See Kyodo News (2010).

9 Sudden departure from its non-nuclear policy is nevertheless deemed unlikely. See Hymans and Okagaki (2008) and Solingen (2010).

10 This unpredictability should not, however, be regarded as generating only worst-case outcomes. For a critique of this tendency, see Pélopidas (2010c).

11 This is not to say that it was the power play between the main antagonists of the Cold War that prevented proliferation, only that it is one of many factors accounting for it. See Muller and Schmidt (2010).

12 Henry Rowen coined this expression. See Wohlstetter et al. (1976).

13 Realism offers competing explanations that can a posteriori be compatible with many different outcomes. In epistemological terms, it suffers from under-determination: the rather vague notion of "security maximisation" tends to make it unfalsifiable. See Solingen (2007).

14 By using domestic perceptions of the international system and/or domestic incentives as intervening variables between distribution of power in the international system and foreign-policy decisions, neoclassical realism can explain more than classical realist and neo-realist approaches.

15 On the September 1979 double flash detected by a Vela satellite, interpreted by some as an Israeli or possibly a South African test, see Richelson (2006).

16 For an overview, see the slightly outdated but still relevant article by Goldblat (1997).

17 Comparing US allies in Europe, Asia, South East Asia and the Pacific with nonaligned countries in the same regions.

18 The Irish Resolution, adopted unanimously by the UN General Assembly on 17 August 1961, called on all states, the nuclear powers in particular, to conclude an international agreement to refrain from transfer and acquisition of nuclear weapons.

19 Relative, meaning as a share of the total number of states. In the $1960 \mathrm{~s}$, the number was fast increasing because of the decolonisation wave.

20 States without economic strength to start nuclear weapon activities not included. See Muller and Schmidt (2010).

21 In some cases, liberalisation is the consequence of democratisation, which may be the root cause of the non-proliferation effect otherwise assigned to openings towards the outside world.

22 "The features of the building, along with the connectivity of the site to adequate pumping capacity of cooling water, are similar to what may be found in connection with a reactor site" (IAEA 2008).

23 However, the stability of decision-points stopping just a little short of weaponisation 
is doubtful. A favoured way out is multinational or international solutions to the fuelcycle problems. These are complex propositions, however, and they have yet to be applied in any region of proliferation concern.

24 For a critique of the democratic peace theory as applied to South America, see Velazquez (2004).

25 This is close to being a truism, however.

\section{Challenge from within: the case of Iran}

1 The term "virtual arsenal" is a comprehensive one. It can be used in reference to many different sets of capabilities: reprocessing and enrichment plants, fissile materials on stock, nuclear-weapon design information, and triggering technologies - in short, different capability levels and different ways of producing nuclear explosives. Prohibited under the NPT are activities unambiguously related to nuclear-weapon production, such as weapon-design studies and development of implosion mechanisms.

2 Developed against the background of Iraq's nuclear weapon programme in the 1980s, which the IEA did not discover.

3 As required by Code 3.1 of the Subsidiary Arrangements General Part.

4

The Iranians made clear to IAEA inspectors that parts for centrifuges had been spread out in stockpiles and small factories around the country. They were insurance, it seemed, against losing the whole program at once. The message to the United States and Israel was clear: if you hit Natanz, we're ready to speed up elsewhere.

(Sanger 2009)

5 In June 2009, two proposals were up for consideration by the IAEA Board of Governors: a "Proposal for the Establishment of an IAEA Low Enriched Uranium Bank" and a "Russian Federation Initiative to Establish a Reserve of Low Enriched Uranium (LEU) for the Supply of LEU to the IAEA for its Member States".

6 It stopped short of offering Iran light-water reactors (LWR). While Article IV of the NPT commits supplier states to facilitate access to technology for NNWS parties, the Framework only promised "not to impede participation in open competitive tendering" (para. 19b). The United States was opposed to a European reactor offer.

7 "I have seen the Iranians ready to accept putting a cap on their enrichment [programme] in terms of tens of centrifuges, and then in terms of hundreds of centrifuges. But nobody even tried to engage them on these offers" (M. ElBaradei in an interview with Newsweek; see also Dickey 2009).

8 On 12 August 2009, 4,592 centrifuges were being fed with UF6 and an additional 3,716 centrifuges had been installed. See IAEA report by the Director General (2009).

9 For a comprehensive discussion of Iran's sovereign right in connection with this, see Miller (2007b).

10 For quotations of Iranian officials, see The Middle East Media Research Institute (4 June 2009).

11 Lessons based on 27 cases of rollback. See Muller and Schmidt (2010).

12 Iran "ignores parts of its security concerns ... for the sake of broader security goals for all countries ... despite the fact that threats to the national security of the Islamic republic all point to a security imbalance". Former Minister of Defence Ali Shamkani (2002), as quoted in Bar, S. (2009).

13 Takeyh argues that the main concern is to negate the American and Iraqi threats. The Israeli nuclear capability is a lesser worry. See Takeyh (2005).

14 For Chubin, the United States is a secondary factor and not the primary cause of the Iranian programme. See Chubin (2006).

15 Founded in 1985 by Iran, Pakistan and Turkey, the ECO is dedicated to development, trade and investment issues. The D8 consists of Bangladesh, Egypt, Indonesia, Iran, 
Malaysia, Nigeria, Pakistan and Turkey. The SCO consists of China, Russia and the Central Asian states except Turkmenistan. India, Iran, Mongolia and Pakistan are observers.

16 Iran has much in common with France in the 1950s and 1960s. While Hymans suggests that such leaders are rare, in Iran this is a common state of mind. See Hymans (2002).

17 Gone were references to sticks and carrots, "a policy suitable for a donkey but not for a proud nation" (Newsweek 2009). See Dickey (2009).

18 Crisis Group interview with Khalil Shirgholami, Centre for Euro-American Studies, Institute for Political and International Studies, Tehran, 25 February 2009, as quoted in International Crisis Group (2009).

19 The full text is available at www.mideastweb.org/iranian_letter_of_2003.htm (see MidEastWeb 2003). Whether it was a genuine offer, a means of alleviating a dire threat to Iranian security at that point in time, a matter of buying time for its nuclear programme, or a combination of these factors, remains unclear.

20 The most prominent of those who oppose nuclear weapons on an Islamic basis are Ayatollah Montazeri, Ayatollah Saanei, Ayatollah Ali Ayazi and Ayatollah Sistani (who has not made any statement on the matter, but is rumoured to support this stance). See Bar (2009).

21 The fatwa of September 2003 was instrumental in legitimising Iran's acceptance of the Additional Protocol a couple of months later.

22 For a reference to existing studies and an overall assessment of this issue, see Potter (2010).

23 An exception was made for North Korea. Shortly after North Korea's first nuclear test (October 2006), US and Korean representatives met in Berlin in January 2007: this was the beginning of the six-nation agreement later that year.

24 Obama sounded this threat on the campaign trail: "If we can prevent them from importing the gasoline that they need and the refined petroleum products, that starts changing their cost-benefit analysis." Here, as quoted in David Sanger (2009).

25 Iran declared the facility to the IAEA on 24 September 2009.

26 Code 3.1 of the Subsidiary Arrangement.

27 Shortly after the announcement of the facility, the IAEA was promised access to the site, starting 25 October 2009.

This is a contingency plant. It is one of the pre-emptive measures aimed at protecting our nuclear technology and human work force....This site ... was selected on purpose in a place that would be protected against aerial attack. That's why the site was chosen adjacent to a military site.

(Ali Akbar Salehi, head of the Atomic Energy Commission, as quoted in Associated Press 2009)

The site is located near a military compound of the Revolutionary Guard.

29 Statement by President Ahmadinejad, 29 November 2009. See e.g. Thomas Erdbrink, "Ahmadinejad vows dramatic expansion of Iran's nuclear program", Washington Post Foreign Service, 30 November 2009.

30 Turkey offered to serve as an alternative location for a fuel swap and Japan - which does not have the same troubled history with Iran as France and Russia do - offered to enrich the LEU.

31 While previous sanctions have been dysfunctional, measures to punish the Revolutionary Guards for their human-rights abuses and deprive them of incomes might be welcomed by many democratic activists. However, when levelled in the name of nonproliferation, the sympathisers would be fewer.

32 Co-chaired by US Deputy National Security Advisor Tom Danilon and Israeli National Security Advisor Uzi Arad.

33 They are described in Sanger (2009). 


\section{Notes}

34 It is not known who pulled the plug. The NIE also concluded, with a lower level of confidence, that the weapons-oriented activities have not been resumed.

35 Obama said "no system of government can or should be imposed upon one nation by any other"; the Helsinki Decalogue said "non-intervention in internal affairs". Obama spoke about democracy, religious freedom, human rights and the rights of women in particular; the Helsinki Decalogue said "Respect for human rights and fundamental freedoms, including the freedom of thought, conscience, religion or belief". In Europe, respect for other countries' systems of government was a confidence-building measure that facilitated agreement on human rights and political freedoms. In due course, however, the promotion of those rights and freedoms tend to translate into systemic change. This way, the Conference on Security and Cooperation in Europe (CSCE, later the Organisation for Security and Cooperation in Europe (OSCE)) became a precursor to regime-change in Eastern Europe in the wake of the Cold War.

\section{How to understand North Korea}

1 In 1993, North Korea referred to US military exercises, the IAEA demands for special inspections and the allegedly partisan basis of the Agency's demands that the DPRK comply with its safeguards obligations. In 2003, it said it withdrew because it was designated by the United States as part of the "Axis of Evil" and targeted by the US pre-emptive strike policy. See du Preez and Potter (2003).

2 This is the language of Article X of the NPT. Article X.1 says that notice of withdrawal shall be given to "all other Parties to the Treaty and to the United Nations Security Council". The 2005 NPT Review Conference failed even to note what North Korea had done.

3

In 2010, North Korea will try to improve relations with the United States, extend its olive branch to its rival South Korea, reach out to Japan by showing its willingness to resolve the issue of Japanese nationals who were abducted by North Korean agents in the 1980s, and also strengthen its ties with China and Russia.... The whole goal is to be recognized as a nuclear state.

(Zhang Liangui, a Chinese expert on North Korea at the Central Party School, in

Lee 2010)

4 At least in some phases and in the view of some Iranian leaders.

5 Sigal (2009a). Siegfried Hecker seems to agree: "We found that Pyongyang was willing to slow its drive for nuclear weapons only when it believed the fundamental relationship with the United States was improving, but not when the regime was threatened" Hecker (2010: 54).

6 In 1992, the two Korean states declared their intention to make the Korean peninsula a NWFZ. See "Joint Declaration on the Denuclearisation of the Korean Peninsula", 1992. In a joint statement from the Six-Party Talks - North Korea, South Korea, China, Russia, Japan and the United States - on 19 September 2005, the DPRK again "committed to abandoning all nuclear weapons and existing nuclear programs ..." (China Daily 2005). The statement reiterated that "the 1992 Joint Declaration of the Denuclearisation of the Korean Peninsula should be observed and implemented". The October 2007 Accord did not say that the weapons that North Korea has produced should be eliminated. The text is not explicit on this fundamentally important point. However, this is the US interpretation.

7 This was the agreement on disablement of the Yongbyon facilities. On 13 February 2007, the parties had reached agreement on "Initial Actions for the Implementation of the Joint Statement", in which North Korea undertook to close down and seal the facilities in Yongbyon and invite the IAEA back to monitor and verify these actions.

8 Juche is a national ideology of self-reliance. The regime justifies its dictatorship with arguments derived from concepts of collective consciousness and the superiority of 
the collective over the individual, appeals to nationalism and citations of "the Juche idea". The core concept of Juche is the ability to act independently without regard to outside interference. Originally described as a creative application of Marxism-Leninism in the national context, Juche is a malleable philosophy reinterpreted from time to time by the regime as its ideological needs change.

9 Cirus-line reactors are research reactors using natural uranium and heavy water. They are good plutonium sources. It was a Canadian reactor of this kind that produced plutonium for India's explosion in 1974, and Israel got the same type of reactor in the early 1960 s.

10 According to the CIA. Estimates vary from less than $2 \mathrm{~kg}$ to $10 \mathrm{~kg}$ (Hecker 2010: 46).

11 Also known as the Basic Agreement, signed on 31 December 1991.

12 According to Article III.4 of the NPT, negotiation of safeguards agreements shall commence within 180 days from the original entry into force of the Treaty, and the agreements shall enter into force not later than 18 months after the date of initiation of negotiations.

13 This was the first time the IAEA moved to exercise its right to conduct special inspections. The DPRK objected on the grounds that it was singled out. Had the Agency also asked for special inspections in other, less-sensitive settings than the North Korean one, the reaction may have been different. However, this was hardly the main reason for rejecting them. North Korea was not ready to make its nuclear programme fully transparent.

14 "The Six Parties agreed to take coordinated steps ... in a phased manner in line with the principle of 'commitment for commitment, action for action'”. See PIR Center (2005).

15 For plutonium production and weapons estimates, see Hecker (2010).

16 Only partially successful. The yield has been estimated as slightly below 1 kiloton. See Hecker (2010: 47).

17 In a rudimentary way, the terms of the Agreed Framework had been defined a year earlier. The United States indicated that it would support the introduction of lightwater reactors (LWR) in the DPRK, and Pyongyang suggested that it would invite the IAEA to implement safeguards to the Agency's satisfaction.

18 Rich countries in Europe, the Middle East and Asia had paid for the first Gulf War, and by 1994 there remained a willingness to cover the costs of collective actions under US leadership. Later, that willingness abated, as became obvious in connection with the occupation of Iraq in 2003.

19 Informal North Korean communication to the author.

20 North Korea finally agreed to accept KEDO's decisions regarding the selection of reactor model and the choice of prime contractor to carry out the project. KEDO selected the South Korean designed Ulchin 3-4 LWR as the reference model for the project and a South Korean firm to be the prime contractor. South Korea undertook to cover most of the costs, of the order of $\$ 3$ billion.

21 Uranium hexafluoride (UF6) to Libya. Evidence of nuclear cooperation with Myanmar is even weaker. See Borger (2009). The prime suspects for the UF6 in Libya are Pakistan and A.Q. Khan.

22 The term "disablement" was used in reference to an agreed list of 12 measures. In the view of Christopher Hill, the US negotiator, it meant that in the event North Korea wanted to restart its facilities in Yongbyon, it would take approximately a year to do so. See Hill (2007).

23 On 26 June 2008.

24 Condoleezza Rice at the Heritage Foundation, 18 June 2008.

25 It did not threaten to resume construction of the $50 \mathrm{MWe}$ and $200 \mathrm{MWe}$ gas graphite reactors. After the breakdown of the Agreed Framework, the North Koreans resumed construction of the $50 \mathrm{MWe}$ reactor, but the progress was slow. The damage to the $200 \mathrm{MWe}$ reactor was so great that they decided not to continue work on that reactor. See Albright (2007). 
During the period of the Initial Actions phase and the next phase ... economic, energy, and humanitarian assistance up to the equivalent of 1 million tons of heavy fuel oil (HFO), including the initial shipment equivalent to 50,000 tons of HFO, will be provided to the DPRK.

27 State Department spokesman P.J. Crowley, as quoted by Reuters.

28 According to Sigal and Wit (2009), at least seven times. For the Clinton administration's nuclear threat to North Korea, see Norris and Kristensen (2006).

29 "Barring a miraculous change in political culture and orientation in Washington and/ or in Pyongyang", Peter Hayes argues that the only solution is a regional system of nuclear non-proliferation to be developed by the local states, building on the Korean nuclear-weapon-free zone declaration of 1992 and consistent with the global non30 proliferation regime (Hayes 2007b).

How can you expect us to return to negotiations when it's clear your administration is paralysed by divisions between those who hate us and those who want to negotiate seriously? At the very time when we were engaged in such a long dialogue last year, your side was planning for sanctions.... We have concluded that your administration is dysfunctional.

(Harrison 2006)

\section{The relationship between disarmament and non-proliferation}

1 For a lucid analysis, see Miller (2007a).

2 Resolution on the Middle East. Conference of the States Parties to the Treaty on the Non-Proliferation of Nuclear Weapons, New York, 11 May 1995. NPT/ CONF.1995/32/RES/1.

3 Gill (2007), Sethi (2009). Chinese observers emphasise that the Soviet Union should never have let Estonia and the other Baltic states go. One domino can lead to the fall of others and end in dismemberment.

4 Like mainstream opinion in most Western countries, the op. ed. on nuclear disarmament by four French statesmen (Juppe, Norlain, Richard, Rocard) also sees it this way (www.regards-citoyens.com/article-pour-un-desarmement-nucleaire-mondialseule-reponse-a-la-proliferations-anarchique-par-41459606.html).

5 Of course there are many pertinent differences as well. De Gaulle felt that France had been sidelined. France also looked at the British Empire, which was considered to be stronger than the French, and saw it was declining. For France, it was therefore important not to be sliding on a downward slope. By comparison, Iran's influence in the Middle East has been growing in recent years. The challenge for Iran is that its influence is stiffly contested by the US, Arab states and others, which are building the broadest possible coalitions against it.

6 France, the UK and India have done so, but not the other NWS.

7 Letter of 24 December 2009 from Foreign Minister Okada to Secretary of State Clinton. Okada released the Japanese version of the letter at a press conference in Tokyo on 22 January 2010. See also his speech at the 174th Session of the Diet on 29 January 2010 (www.mofa.qo.jp/u news/2/20100129 201247.html).

8 Article 21 of the 1988 Brazilian Constitution states that "all nuclear activity within the national territory shall only be admitted for peaceful purposes and subject to approval by the National Congress". Brazil and Argentina ratified the Treaty of Tlatelolco in 1994 and joined the NPT in 1995 (Argentina) and 1998 (Brazil).

9 First proposed by Leo Szilard and further developed by Jo Rotblat and others. See Glaser et al. (2009).

10 Point 17 of Resolution 1887, adopted by the Summit Meeting of the Security Council on 24 September 2009, reads: 
[the Council] undertakes to address without delay any State's notice of withdrawal from the NPT, including the events described in the statement provided by the State pursuant to Article X of the Treaty, while noting ongoing discussions in the course of the NPT review on identifying modalities under which NPT States Parties could collectively respond to notification of withdrawal, and affirms that a State remains responsible under international law for violations of the NPT committed prior to its withdrawal.

11 It is conceivable that if an NPT Review Conference passes a decision by consensus, it may be easier to have it formally agreed later on through the Treaty amendment procedure, which requires the support of all NWS and all members of the IAEA Board of Governors.

12 The VCLT entered into force in 1980 and has no retroactive effect, but it is generally considered as a codification of existing customary international law. The United States and North Korea are not parties to the Convention.

13 NPT/conf.2005/pc.III/wp. 15, submitted by Germany on 29 April 2004.

14 Indonesian statement on Article X at the 2008 PrepCom, Geneva, 7 May 2008. A meeting of the parties could be modelled on the Open Skies Treaty, which rules that if a party to the Treaty announces its decision to withdraw, the depositaries are to "convene a conference of the States parties, no less than 30 days and no more than 60 days after they have received such notice".

\section{Towards a nuclear-weapon-free world}

1 See also the second and third Shultz et al. op. eds in the Wall Street Journal (15 January 2008 and 19 January 2010). A number of high-level statements have been made in support of this initiative, including the statement by German leaders (Bahr, Schmidt, Genscher, von Weizsäcker); the statement by British leaders (Rifkind, Hurd, Owen, Robertson); the statement by French leaders (Juppe, Norlain, Richard, Rocard); the statement by Norwegian leaders (Bondevik, Brundtland, Nordli, Stoltenberg, Willoch); the statement by Australian leaders (Fraser, Gration, Jones, Nossal, Sanderson); the statement by Polish leaders (Kwasniewski, Walesa, Mazowiecki); the statement by Italian leaders (D'Alema, Fini, La Malfa, Parisi); the statement by Dutch leaders (Lubbers, van der Stoel, Mierlo, Korthals Altes); the statement by Belgian leaders (Claes, Verhofstadt, Dehaene, Michel); the joint statement by Presidents Obama and Medvedev; and the joint statement by Carter, Gorbachev, Beckett, Rocard et al. (Global Zero). These and other statements by a great many leaders, individually and jointly, show that the interest in reviving the objective of a NWFW has also spread to the political mainstream in countries that had not been very vocal on this matter in the past.

Of the many academic contributions to the debate, this chapter draws, in particular, on Perkovich and Acton (2009). Perkovich and Acton's own contribution to that volume was first published as an Adelphi Paper in September 2008.

2 Plutonium - Pu-239 - contains small amounts of heavier, unstable isotopes and is, therefore, more difficult to work with. To set a plutonium explosion off, an implosion mechanism is needed. This is another technically demanding task.

3 In the run-up to the 2005 NPT Review Conference, US and French officials essentially disavowed the pledges made in 2000. See Johnson (2004).

4 At the conference commemorating Rajiv Gandhi's UN speech (9-10 June 2008), K. Subrahmanyam alluded to it. See also Walker (2009). A third article by the "four horsemen" in the Wall Street Journal of 19 January 2010 advocates increased support for the stewardship programme in order to maintain the safety, security and reliability of the nuclear arsenal. On 29 January, Vice President Biden announced that the administration's FY 2011 budget proposed an increase of $\$ 600$ million, and $\$ 5$ billion more for the next five years. See Biden (2010). 
5 In his essay "On Perpetual Peace", Immanuel Kant says that: "No state at war with another shall allow itself such acts of hostility as would make mutual trust impossible during a future peace." Kant warns that by following narrow prudential interests, leaders of victorious states undermine the possibility of constructing a durable peace, which is the ultimate aim of warfare. The same warning applies to arms control as a tool of unilateral advantage. During the US unipolar moment, the web of arms-control agreements broke up under the pressure of aggressive US unilateralism, and the most important remaining treaty - the NPT - was used to promote US non-proliferation interests while neglecting those parts that constrain US freedom of action. This was done at the expense of trust between nations, casting a shadow of suspicion into the future that jeopardises the prospects for arms control and disarmament. Heavy lifting is necessary to bring it on stream again. See Gregor (1996).

Under the CTBT, America would gain the security benefits of outlawing nuclear tests by others, while locking in a technological status quo that is highly favorable to us. We have conducted more than 1,000 nuclear tests - hundreds more than anyone else. We do not need more tests to protect our security. Would-be proliferators or modernisers, however, must test if they are to develop the kind of advanced, compact nuclear weapons that are the most threatening.

(US Secretary of State Madeleine Albright in the 1999 Senate ratification hearings of the CTBT; Albright 1999)

7 The case for such an approach has been made by Daalder and Lodal (2008).

8 By 30 September 2009, the figure was 2,613. See US Department of Defense (2010).

9 Weapons loaded on heavy bombers or stored in weapons storage areas at heavy bomber bases are counted as operational strategic weapons.

10 Work is being done by national laboratories in the United States, Russia, the United Kingdom and Norway. The United Kingdom and Norway are doing a joint project, the first of its kind between a nuclear- and a non-nuclear-weapon state. For the time being, societal verification is a non-starter. The proposition is very attractive, and by a Board of Governors' decision of 1992, the IAEA is already in a position to make use of information stemming from non-governmental sources. However, Russia and China are far from ready to institutionalise a verification system that recognises nongovernmental actors. As long as this is the case, it is better not to burden the process with ideas that are incompatible with their traditions and political systems.

11 As of 30 September 2009. See US Department of Defense (2010).

12 It is estimated that about 8,800 weapons are held in reserve or have been slated for dismantlement. See SIPRI (2009).

13 In case nuclear war nevertheless breaks out, the NNWS would like to be assured that they would not be targeted. Unqualified non-use assurances to non-nuclear parties to the NPT would cover such contingencies, while no-first-use (NFU) doctrines do not. If somebody breaks the doctrine, the other NWS would be freed from their obligations. However, the prime objective is to prevent a nuclear war from breaking out; and, should it nevertheless happen, self-imposed restraints to spare NNWS of the horrors of nuclear warfare can realistically not be expected in any case, regardless of what kind of assurances have been given in time of peace.

14 Two retired scientists, K. Santhanam and P.K. Iyengar, questioned the outcome of the tests, but were contradicted by A. Kakodkar, head of the Atomic Energy Commission, and R. Chidambaram, principal scientific advisor to the government, who said the tests had achieved the desired scientific objectives and would help India to build fission and fusion weapons from low yields up to $200 \mathrm{kt}$ (Deccan Herald 2009; Parthasarathi and Santhanam 2009).

15 In 2006, Israeli Prime Minister Olmert was guilty of a slip of the tongue: "Can you say that this [Iran] is the same level, when they are aspiring to have nuclear weapons, as France, America, Russia and Israel?" Interview with German television (December 2006). 


\section{References}

AFP (2009) "First Round of U.S.-Russia Arms Treaty Talks in May." Online, available at: www.google.com/hostednews/afp/article/ALeqM5jwFyeCTpI-1hOzY9RROFeYt Hfsqw (accessed 1 March 2010).

Albright, D. (2007) "Phased International Cooperation with North Korea's Civil Nuclear Programs”, Institute for Science and International Security (ISIS). Online, available at: http://isis-online.org/uploads/isis-reports/documents/CivilNuclearNK.pdf (accessed 1 March 2010).

Albright, M. (1999) “A Call for American Consensus", Time. Online, available at: www. time.com/time/magazine/article/0,9171,992615,00.html (accessed 1 March 2010).

Arbatov, A. (2000) "The Transformation of Russian Military Doctrine: Lessons Learned from Kosovo and Chechnya", The Marshall Center Papers, Garmisch-Partenkirchen, No. 2.

Arkin, W. (1996) "Calculated Ambiguity: Nuclear Weapons and the Gulf War", The Washington Quarterly, No. 4.

Associated Press (2009) "Iran: Nuclear Plant is Sited to Thwart Attack. Facility is Next to a Military Compound of the Elite Revolutionary Guard". Online, available at: www. msnbc.msn.com/id/33074159 (accessed 1 March 2010).

Baker, J. (1995) The Politics of Diplomacy, New York: Putnam.

Ball, D. (1993-1994) "Arms and Affluence: Military Acquisitions in the Asia-Pacific Region”, International Security, Vol. 18, No. 3.

Bar, S. (2009) "Iranian Nuclear Decision Making Under Ahmadinejad", paper submitted to the fourth Herzliya Conference, Tel Aviv. Online, available at: www.herzliyaconference.org/_Uploads/2814ShmuelBarIranianAhmadinejad.pdf (accessed 1 March 2009).

Barma, N., Ratner, E. and Weber, S. (2007) "A World Without the West”, The National Interest, The Nixon Center. Online, available at: www.carlisle.army.mil/ietcop/documents/TNI\%20-\%20A\%20World\%20Without\%20the\%20West\%20JUL\%2007.pdf (accessed 18 January 2010).

BBC News (2009) “Obama offers Iran 'new beginning'," Online, available at: http:// news.bbc.co.uk/2/hi/7954211.stm (accessed 1 March 2010).

Bedjaoui, M. (2009) "Address from Mohammed Bedjaoui, Former President of the International Court of Justice and Foreign Ministry of Algeria", at the Conference on Trident and International Law. Online, available at: www.acronym.org.uk/docs/0902/ bedjaoui.pdf (accessed 3 March 2010).

Berry, K., Lewis, P., Sokov, N. and Wilson, W. (2010) "Delegitimizing Nuclear Weapons", Monterey, California: Center for Nonproliferation Studies, the Monterey Institute of International Studies, forthcoming. 
Biden, J. (2010) “The President's Nuclear Vision”, The Wall Street Journal. Online, available at:: http://online.wsj.com/article/SB100014240527487048789045750313822 15508268.html (accessed 1 March 2010).

Blechman, Barry M. and Kaplan, Stephen S. (1978) Force without War. US Armed Forces as a Political Instrument, Washington, DC: the Brookings Institution.

Blix, H. (2004) Disarming Iraq: the Search for Weapons of Mass Destruction in Iraq, New York: Pantheon.

Bobo, L. (2009) "Medvedev and the New European Security Architecture", policy brief, Center for European Reform. Online, available at: www.cer.org.uk/pdf/pbrief medvedev_july09.pdf (accessed 3 March 2010).

Bond-Graham, D. and Parish, W. (2009) “Anti-Nuclear Nuclearism”, Foreign Policy in Focus. Online, available at: www.fpif.org/articles/anti-nuclear_nuclearism (accessed 1 March 2010).

Borger, J. (2009) "Burma Suspected of Forming Nuclear Link with North Korea", guardian.co.uk. Online, available at: www.guardian.co.uk/world/2009/jul/21/burma-northkorea-nuclear-clinton (accessed 1 March 2010).

Boutros-Ghali, B. (1999) Unvanquished: A U.S.-U.N. Saga, New York: Random House.

Bowen, W. (2006) "Libya and Nuclear Proliferation: Stepping Back from the Brink", Adelphi Paper, No. 380, Oxford University Press.

Bracken, P. (2000) Fire in the East: the Rise of Asian Military Power and the Second Nuclear Age, HarperPerennial.

Braut-Hegghammer, M. (2008) "Libya's Turnaround: Perspectives from Tripoli”, The Middle East Journal, Vol. 62, No. 1.

Bremmer, I. (2009) "Working Together, Brazil, Russia, China and India Increase Leverage." Online, available at: www.ihavenet.com/BRIC-Working-TogetherBrazil-Russia-China-India-Increase-Leverage-Ian-Bremmer.html (accessed 18 January 2010).

Brigagao, C. (2009) "Argentina and Brazil: a Regional Model of Confidence-Building Measures on Nuclear Non-Proliferation", paper for the Nobel Institute Conference on "The Spread of Nuclear Weapons: Past Experiences and Future Challenges", Oslo.

Broad, William J. (2010) "Iran Shielding its Nuclear Efforts in Maze of Tunnels", New York Times, 5 January.

Bronson, P. (2007) The Dragon Looks South: China and Southeast Asia in the New Century, Westport: Greenwood Publishing Group, Inc.

Brooks, L. (2009) "The Fragile Tradition of Nuclear Restraint", review of T.V. Paul's book The Tradition on Non-use of Nuclear Weapons. The Nonproliferation Review, Vol. 16, No. 3, pp. 521-525.

Bundy, M. (1969) “To Cap the Volcano", Foreign Affairs.

Bundy, M. (1988) Danger and Survival, New York: Vintage Books.

Bunn, G. and Rhinelander, J.B. (2005) "NPT Withdrawal: Time for the Security Council to Step In", Arms Control Today.

Bush, G.H.W. (1999) All the Best, George Bush: My Life in Letters and Other Writings, New York: Scribner.

Butterfield, H. (1951) History and Human Relations, New York: The Macmillan Co.

Carney, R. and Bitzinger, R.A. (2007) "From Hegemony to Loose Bipolarity: the Evolving Geopolitics of the US, EU, and China”, RSIS Commentary No. 5, S. Rajaratnam School of International Studies. Online. available at: www.rsis.edu.sg/publications/Perspective/RSIS0052007.pdf (accessed 18 January 2010).

Center for Nonproliferation Studies (1992) "Joint Declaration of South and North Korea 
on the Denuclearization of the Korean Peninsula." Online, available at: http://nti.org/e research/official_docs/inventory/pdfs/aptkoreanuc.pdf (accessed 1 March 2010).

Chase, M.S., Erickson, A. and Yeaw, C. (2009) "The Future of Chinese Deterrence Strategy", China Brief, The Jamestown Foundation, Vol. 9, No. 5.

China Daily (2005) "Full Text of 6-Party Talks Joint Statement." Online, available at: www.chinadaily.com.cn/english/doc/2005-09/19/content_479150_2.htm (accessed 1 March 2010).

Chirac, J. (2006) English version of President Chirac's speech in Disarmament Diplomacy (2006), No. 82.

Chubin, S. (2006) Iran's Nuclear Ambitions, Washington, DC: Carnegie Endowment for International Peace.

Cirincione, J., Wolfstahl, J. and Rajkumar, M. (2005) Deadly Arsenals, Washington, DC: Carnegie Endowment for International Peace.

Clark, W. (2003) Winning Modern Wars: Iraq, Terrorism, and the American Empire, New York: Public Affairs.

Clawson, P. and Eisenstadt, M. (2008) "The Last Resort: Consequences of Preventive Military Action Against Iran”, Agenda: Iran, The Washington Institute for Near East Policy.

Cline, R.S. (1977) World Power Assessment 1977: a Calculus of Strategic Drift, Boulder: Westview Press.

Cohen, A. (1998) Israel and the Bomb, New York: Columbia University Press, 1998.

Cohen, A. (2010) The Worst Kept Secret: Israel's Bargain with the Bomb, New York: Columbia University Press (forthcoming).

Cohen, A. and Perkovich, G. (2009) "The Obama-Netanyahu Meeting: Nuclear Issues", Carnegie Endowment for International Peace. Online, available at: www.carnegieendowment.org/publications/index.cfm?fa=view\&id=23124 (accessed 3 March 2010).

Cole, P. (1997) "Atomic Bombast: Nuclear Weapon Decision Making in Sweden 1945-72", The Washington Quarterly, Vol. 20, No. 2. Online, available at: http://pdfserve.informaworld.com/516885_731396941_918395380.pdf (accessed 3 March 2010).

Crowley, P.J. (2010) Briefing by Assistant Secretary of State for Public Affairs P.J. Crowley, Washington, DC, February 9. Online, available at: www.reuters.com/article/ id USTRE61707120100209

Daalder, I. and Lodal, J. (2008) "The Logic of Zero: Toward a World Without Nuclear Weapons", Foreign Affairs.

Deccan Herald (2009) "India Capable of Building Nuke Deterrence up to 200 Kilotons: Kakodkar", Mumbai, 24 September.

Defense et Securite national (2008) "Le livre blanc, Presidence de la Republique."

Deutsch, K.W. (1963) The Nerves of Government: Models of Political Communication and Control, New York: Free Press.

Dickey, C. (2009) "Mohamed ElBaradei: 'They are not fanatics'”, Newsweek. Online, available at: www.newsweek.com/id/199149 (accessed 1 March 2010).

Dobrynin, A. (1995) In Confidence: Moscow's Ambassador to Six Cold War Presidents, Seattle: University of Washington Press.

du Preez, J. and Maettig, T. (2010) "From Pariah to Nuclear Poster Boy: How Plausible is a Reversal?", in W.C. Potter (ed.) Forecasting Nuclear Proliferation: the Role of Theory, Palo Alto: Stanford University Press (forthcoming).

du Preez, J. and Potter, W. (2003) "North Korea's Withdrawal from the NPT: a Reality Check", James Martin Center for Nonproliferation Studies. Online, available at: http:// cns.miis.edu/stories/030409.htm (accessed 1 March 2010). 


\section{References}

Dunn, L. (2006) "Countering Proliferation: Insights From Past 'Wins, Losses, and Draws", The Nonproliferation Review, Vol. 13, No. 3. Online, available at: http://cns. miis.edu/npr/pdfs/133dunn.pdf (accessed 3 March 2010).

Dunn, Lewis A. (2007) Deterrence Today. Roles, Challenges and Responses, Paris: Ifri, Proliferation Papers.

Ehteshami, A. (2009) "Iranian Perspectives on the Global Elimination of Nuclear Weapons", North Korea and Iran, Washington, D.C.: The Stimson L. Center. Online, available at: www.stimson.org/nuke/pdf/NK_IRAN_FINAL.pdf (accessed 1 March 2010).

ElBaradei, Mohamed (2003) "Towards a Safer World”, The Economist, 16 October.

Ellsberg, D. (2009) "Roots of the Upcoming Nuclear Crisis", in D. Krieger (ed.) The Challenge of Abolishing Nuclear Weapons, New Brunswick and New Jersey: Transaction Publishers.

Encyclopedia of the Modern Middle East and North Africa (2004) "Osirak." Online, available at: www.answers.com/topic/osirak (accessed 3 March 2010).

Ericsson, S. (2001) "Economic and Technological Trends Affecting Nuclear Nonproliferation", The Nonproliferation Review, Vol. 8, No. 2. Online, available at: http://cns. miis.edu/npr/pdfs/82erick.pdf (accessed 1 March 2010).

European Commission Directorate-General for Trade (2009) "India (Bilateral relations)." Online, available at: http://ec.europa.eu/trade/creating-opportunities/bilateral-relations/ countries/india (accessed 18 January 2010).

Feith, D. (2008) War and Decision: Inside the Pentagon at the Dawn of the War on Terrorism, New York: HarperCollins Publishers.

Ferguson, C. and Potter, W.C. with A. Sands, L. Spector and F. Wehling (2005) The Four Faces of Nuclear Terrorism, New York: Routledge.

Fischer, D. (1994) "Some Aspects of a Cut-Off Convention", Halting the Production of Fissile Materials for Nuclear Weapons, Geneva: UNIDIR, Research Papers No. 31.

Fitchett, J. (1995) "Threat of Annihilation Deterred Iraq, They Say", New York Times.

Ford, C. (2007) "Debating Disarmament: Interpreting Article VI of the Treaty on the Non-Proliferation of Nuclear Weapons", The NonProliferation Review, Vol. 14, No. 3.

Galtung, Johan (1964) “A Structural Theory of Aggression”, Journal of Peace Research, Vol. 1, No. 2.

Gill, B. (2007) Rising Star, China's New Security Diplomacy, Washington, DC: Brookings Institution Press.

Glaser, A., von Hippel, F. and Mian, Z. (2009) The Global Fissile Material Report 2009: a Path to Nuclear Disarmament, Princeton: Princeton University Press and IPFM. Online, available at: www.fissilematerials.org.

Goldblat, J. (1997) "Nuclear-Weapon Free Zones: a History and Assessment", The Nonproliferation Review, Vol. 4, No. 3.

Goldblat, J. (2009) "Should the Right to Withdraw from the NPT be Withdrawn?", paper commissioned by the International Commission on Nuclear Non-proliferation and Disarmament.

Goldschmidt, P. (2008) "Strengthening the Non-Proliferation Regime", paper for the Seventh ROK-UN Joint Conference on Disarmament. Online, available at: www.carnegieendowment.org/files/goldschmidt_rok_20081124.pdf (accessed 3 March 2010).

Gorbachev, M. (1996) Memoirs, New York: Doubleday.

Graham Jr., T. (2007) "NPT: the Origin and Interpretation of Article VI", in M. May (ed.) P-5 Nuclear Doctrines and Article VI, Stanford University, CISAC Conference Report.

Gregor, M. (1996) "The Cambridge Edition of the Works of Immanuel Kant: Practical Philosophy”, Cambridge: Cambridge University Press. 
Grinevsky, O. (2004) The Turning Point: from Brezhnev to Gorbachev, Moscow: OlmaPress.

Haas, E.B. (1958) The Uniting of Europe, Stanford; Stanford University Press.

Halperin, M., Tertrais, B., Payne, K. and Subramaniam, K. (2009) Commentaries, "Forum: The Case for No First Use: An Exchange", Survival, Vol. 51, No. 5. Online, available at: http://iis-db.stanford.edu/pubs/22680/51-5_04_NFU_Forum_Proof.pdf (accessed 3 March 2010).

Hamilton, D. and Quinlan, J. (2010) The Transatlantic Economy 2010: Annual Survey of Jobs, Trade, and Investment Between the United States and Europe, Center for Transatlantic Relations: Johns Hopkins University.

Harrison, S. (2006) "North Korea: a Nuclear Threat", Newsweek International, 16 October.

Hayes, P. (2007a) "North Korea and the United States: What Deal?", openDemocracy. Online, available at: www.opendemocracy.net/globalization-institutions_government/ korea_us_4351.jsp (accessed 1 March 2010).

Hayes, P. (2007b) "North Korean Proliferation and the End of U.S. Nuclear Hegemony", in M.B. Mærli and S. Lodgaard (eds) Nuclear Proliferation and International Security, Abingdon and New York: Routledge.

Hayes, J. (2009) "Identity and Securitization in the Democratic Peace: The United States and the Divergence of Response to India and Iran's Nuclear Programs", International Studies Quarterly, No. 53.

Hecker, S. (2005) "Technical Summary of DPRK Nuclear Programme", at Carnegie Endowment for International Peace, Washington. Online, available at: www.nautilus. org/fora/security/0632Hayes.html (accessed 1 March 2010).

Hecker, S. (2010) "Lessons Learned from the North Korea Nuclear Crises", Daedalus. Online, available at: www.nautilus.org/fora/security/10006Hecker.pdf (accessed 1 March 2010).

Hersman, R. and Peters, R. (2006) "Nuclear U-Turns: Learning from South Korean and Taiwanese Rollback", The Nonproliferation Review, No. 3.

Herz, J.H. (1951) Political Realism and Political Idealism: a Study in Theories and Realities, Chicago: University of Chicago Press.

Hill, C. (2007) Press Conference at Japan National Press Club, Tokyo. Online, available at: http://merln.ndu.edu/archivepdf/northkorea/state/94608.pdf (accessed 1 March 2010).

The Hindu Business Line (2008) "High Tariff Barriers Make India's Business Environment 'Poor': Report.” Online, available at: www.thehindubusinessline.com/2008/07/12/ stories/2008071252241000.htm (accessed 18 January 2010).

Hymans, J. (2002) "Why Do States Acquire Nuclear Weapons? Comparing the Cases of India and France", in D.R. SarDesal and R. Thomas (eds) Nuclear India in the TwentyFirst Century, New York: Palgrave-Macmillan.

Hymans, J. (2006a) “Theories of Nuclear Proliferation: The State of the Field", The Nonproliferation Review, Vol. 13, No. 3.

Hymans, J. (2006b) The Psychology of Nuclear Proliferation: Identity, Emotions and Foreign Policy, New York: Cambridge University Press.

Hymans, J. (2010) "When Does a State Become a 'Nuclear Weapons State'? An Exercise in Measurement Validation", The Nonproliferation Review, Vol. 17, No. 1.

Hymans, J. and Okagaki, T. (2008) "Japan as a Non-Nuclear Weapon State: an Imposition or a Choice?", paper presented at the annual conference of the International Studies Association, San Francisco. 


\section{References}

IAEA (2005) Multinational Approaches to the Nuclear Fuel Cycle, Vienna.

IAEA (2008) Implementation of the NPT Safeguards Agreement in the Syrian Republic, GOV/2008/60, 19 November.

IAEA (2009) "Implementation of the NPT Safeguards Agreement and Relevant Provisions of Security Council Resolutions 1737 (2006), 1747 (2007), 1803 (2008), and 1835 (2008) in the Islamic Republic of Iran", report by the Director General. Online, available at: www.iaea.org/Publications/Documents/Board/2009/gov2009-55.pdf (accessed 1 March 2010).

IISS (2008) "Egypt: the Usual Suspect", Nuclear Programmes in the Middle East: In the shadow of Iran, London: The International Institute of Strategic Studies, chapter 1.

The Independent Commission on Disarmament and Security Issues (1982) Common Security: a Blueprint for Survival, New York: Simon and Schuster.

Information Office of the State Council of the People's Republic of China (2002) "China's National Defense in 2002." Online, available at: www.china.org. cn/e-white/20021209/index.htm (accessed 18 January 2010).

International Commission on Nuclear Non-Proliferation and Disarmament (2009) Eliminating Nuclear Threats, Canberra/Tokyo.

International Commission on Security and Disarmament Issues (ICDSI) (1982) Common Security, Report by the International Commission on Security and Disarmament Issues, under the chairmanship of Olof Palme, London: Pan Books.

International Court of Justice (CJ) (1996) "Legality of the Threat or Use of Nuclear Weapons", an Advisory Opinion delivered by the ICJ. Online, available at: www.fas. org/nuke/control/icj/text/9623.htm (accessed 3 March 2010).

International Crisis Group (2009) "U.S.-Iranian Engagement: the View from Tehran", Middle East Briefing No. 28, Tehran/Brussels. Online, available at: www.isn.ethz.ch/ isn/Digital-Library/Publications/Detail/?ots591=CAB359A3-9328-19CCA1D2-8023E646B22C\&lng=en\&id=101129 (accessed 1 March 2010).

Ivanov, S. (2006) "The Triad of National Values", Izvestiya.

Jiali, M. (2000) "Striving to Establish a Constructive Partnership Between China and India", China Report, Vol. 36, No. 3, pp. 375-381.

Jo, D.J. and Gartzke, E. (2007) "The Determinants of Nuclear Proliferation”, Journal of Conflict Resolution, Vol. 51, No. 1.

Johnson, R. (2004) "Is the NPT up to the Challenge of Proliferation?", Disarmament Forum, No. 4.

Jonter, T. (n.d.) "Why Sweden Did Not Build the Bomb, 1945-70", forthcoming.

Joshi, S. (2005) "China to Accept Arunachal Pradesh as Indian and India to Accept Aksai Chin as Chinese - a Secret Agreement in the Making", India Daily. Online, available at: www.indiadaily.com/editorial/4747.asp (accessed 18 January 2010).

Kajita, T. (2009) “U.S. Concerned By Japan's Changes in Foreign Policy”, The Japan Times. Online, available at: http://search.japantimes.co.jp/cgi-bin/nn20091028a5.html (accessed 18 January 2010).

Kang, D. (2007) China Rising: Peace, Power and Order in East Asia, New York: Columbia University Press.

Kaplan, F. (2004) "Ron and Mikhail's Excellent Adventure: How Reagan Won the Cold War." Online, available at: www.slate.com/id/2102081 (accessed 26 February 2010).

Kissinger, H. (1979) "Kissinger on NATO", Time, 17 September.

Kissinger, H. (1980) "The Future of NATO", in K. Myers (ed.) NATO: the Next Thirty Years, Boulder: Westview Press.

Kissinger, H. (2009) “Obama's Foreign Policy Challenge”, Washington Post. 
Kokubun, R., "East Asian Security and Japan-US-China Relations", a reference paper. Online, available at: http://brie.berkeley.edu/research/forum/Berkeley2R/kokubun.html (accessed 18 January 2010).

Krasner, S. (ed.) (1983) International Regimes, New York: Cornell University Press.

Kristensen, H.M. (2006) “Global Strike: a Chronology of the Pentagon's New Offensive Strike Plan", The Federation of American Scientists. Online, available at: www.fas.org/ ssp/docs/GlobalStrikeReport.pdf (accessed 18 January 2010).

Kristensen, H.M. (2007) “U.S. Strategic War Planning After 9/11", The Nonproliferation Review, No. 2.

Kristensen, Hans M., Norris, Robert S. and Oelrich, Ivan (2009) From Counterforce to Minimal Deterrence: A New Nuclear Policy on the Path Toward Eliminating Nuclear Weapons, Federation of American Scientists \& The Natural Resources Defense Council, Occasional Paper No.7, April.

Kyodo News (2010) "Japan to Stick to Non-Nuclear Principles: Hatoyama." Online, available at: www.japantoday.com/category/politics/view/japan-to-stick-to-non-nuclearweapons-principles-hatoyama (accessed 3 March 2010).

LaFraniere, S. (2010) "Fighting Trend, China is Luring Scientists Home", New York Times. Online, available at: www.nytimes.com/2010/01/07/world/asia/07scholar.html (accessed 18 January 2010).

Lake, E. (2009) “Obama Agrees to Keep Israel's Nukes Secret”, Washington Times. Online, available at: www.washingtontimes.com/news/2009/oct/02/president-obamahas-reaffirmed-a-4-decade-old-secr (accessed 3 March 2010).

Lavoy, P. (1993) "Nuclear Myths and the Causes of Nuclear Proliferation", Security Studies, Vol. 2, No. 3.

Lavoy, P. (2006) "Nuclear Proliferation Over the Next Decade: Causes, Warning Signs and Policy Responses", Nonproliferation Review, Vol. 13, No. 3. Online, available at: http://cns.miis.edu/npr/pdfs/133lavoy.pdf (accessed 1 March 2010).

Lavoy, P. and Walker, R. (2006) "Nuclear Weapons Proliferation: 2016", Conference report, The Center for Contemporary Conflict, U.S. Naval Postgraduate School. Online, available at: www.nps.edu/Academics/Centers/CCC/Conferences/recent/NuclearWeaponsProliferation2016Jul06_rpt.pdf (accessed 1 March 2010).

Ledwidge, B. (1984) De Gaulle et les Americains: Conversations avec Dulles, Eisenhower, Kennedy, Rusk, 1958-1964, Paris, Flammarion.

Lee, S. (2010) "North Korea Puts Out Policy Blueprint", TheNational. Online, available at: www.thenational.ae/apps/pbcs.dll/article?AID=/20100104/FOREIGN/701039888/ 1015/rss (accessed 1 March 2010).

Leverett, F. (2008) "Black is the New Green", The National Interest. Online, available at: www.newamerica.net/publications/articles/2008/black_new_green_6581 (accessed 18 January 2010).

Leverett, F. and Leverett, H. (2009) "When Will the Obama Administration Try Actually Engaging Iran?", The Race for Iran. Online, available at: www.raceforiran.com/ when-will-the-obama-administration-try-actually-engaging-iran (accessed 1 March 2010).

Levite, A. (2002-2003) "Never Say Never Again: Nuclear Reversal Revisited", International Security, Vol. 27, No. 3. Online, available at: http://iis-db.stanford.edu/ evnts/3863/LeviteAriel_2004-0513.pdf (accessed 1 March 2010).

Lodgaard, S. (2003) "Good News for Non-Proliferation? The Changing Relationship Between Russia, NATO and the NPT", Disarmament Diplomacy, No. 69.

Lodgaard, S. (2004) "Making the Non-Proliferation Regime Universal: Asking the 
Non-Parties to Behave 'As If’ They Were Members”, Working Paper No. 7, The International Commission on Weapons of Mass Destruction.

Lodgaard, S. (2007) "Regaining Common Ground", in M.B. Maerli and S. Lodgaard (eds) Nuclear Proliferation and International Security, Abingdon and New York: Routledge.

Lodgaard, S., Chari, P.R., Cheema, P.I. and Perkovich, G. (2005) "Making the NonProliferation Regime Universal", paper inspired by a roundtable discussion organised by the Norwegian Institute of International Affairs and the Islamabad Policy Research Institute, Islamabad, 11-12 March.

Mendelsohn, J. (1999) "The Rationale for No First Use", Arms Control Today.

Merchet, J.D. (2006) "Davantage de souplesse dans la dissuasion nucleaire", Liberation.

Mian, Z. (2009) "Beyond the Security Debate: the Moral and Legal Dimensions of Abolition", in G. Perkovich and J. Acton (eds) Abolishing Nuclear Weapons: a Debate, Carnegie Endowment for Peace. Online, available at: www.carnegieendowment.org/ files/Mian.pdf (accessed 10 February 2010).

MidEastWeb (2003) "Purported Iranian Letter of 2003 Proposing Cooperation with USA.” Online, available at: www.mideastweb.org/iranian_letter_of_2003.htm (accessed 1 March 2003).

Miller, S.E. (2007a) "Proliferation, Disarmament and the Future of the Non-Proliferation Treaty", in Morten Maerli and Sverre Lodgaard (eds) Nuclear Proliferation and International Security, Abingdon and New York: Routledge.

Miller, S.E. (2007b) "Proliferation Gamesmanship: Iran and the Politics of Nuclear Confrontation", Syracuse Law Review, Vol. 57, No. 3.

Ministry of Defence of the Russian Federation (2003) Immediate Tasks of Development of the Armed Forces of the Russian Federation. Online, available at: http://www.mil. $\mathrm{ru} /$ articles/article5005.shtml.

Mohan, R. (2007) "India's Nuclear Exceptionalism”, in M.B. Mærli and S. Lodgaard (eds) Nuclear Proliferation and International Security, Abingdon and New York: Routledge.

Mowatt-Larssen, R. (2010) “Al Qaeda Weapons of Mass Destruction Threat: Hype or Reality?", Belfer Center for Science and International Affairs. Online, available at: http://belfercenter.ksg.harvard.edu/publication/19852/al_qaeda_weapons_of_mass_ destruction_threat.html (accessed 3 March 2010).

Muller, H. (2007) "The Exceptional End to the Extraordinary Libyan Nuclear Quest", in M.B. Mærli and S. Lodgaard (eds) Nuclear Proliferation and International Security, Abingdon and New York: Routledge.

Muller, H. (2008) “The Future of Nuclear Weapons in an Interdependent World", The Washington Quarterly, Vol. 31, No. 2.

Muller, H. (2009) "The Importance of Framework Conditions", in G. Perkovich and J. Acton (eds) Abolishing Nuclear Weapons: a Debate, Carnegie Endowment for Peace. Online, available at: www.carnegieendowment.org/files/Muller.pdf (accessed 1 March 2010).

Muller, H. and Schmidt, A. (2010) "The Little Known Story of De-Proliferation: Why States Give Up Nuclear Weapon Activities", in W.C. Potter (ed.) Forecasting Nuclear Proliferation: the Role of Theory, Palo Alto: Stanford University Press (forthcoming).

Myrdal, A. (1977) The Game of Disarmament: How the United States and Russia Run the Arms Race, Manchester: Manchester University Press.

National Security Council (1950) "NSC 68: United States Objectives and Programs for National Security", a report to the President pursuant to the President's Directive of 31 
January 1950. Online, available at: http://ftp.fas.org/irp/offdocs/nsc-hst/nsc-68.htm (accessed 25 February 2010).

Nayan, R. (2006) Indo-US Nuclear Deal: The Bill and Apprehensions. IDSA Occasional Paper Series No. 1, Institute for Defence and Security Studies, New Delhi, November.

Newsweek (2009). "Mohamed ElBaradei: 'They Are Not Fanatics'." Online, available at: www.newsweek.com/2009/05/22mohamed-elbaradei-they-are-not-fanatics.html (last accessed: 25 June 2010).

Nicholas Burns, R. (2007) "Briefing on the Bilateral Agreement for Peaceful Nuclear Cooperation (123 Agreement)", US Department of State, 27 July. Online, available at: www.state.gov/p/us/rm/2007/89559.htm.

Nielsen, Jenny (2007) "Engaging India, Israel and Pakistan in Non-Proliferation", Disarmament Diplomacy, Autumn.

Niskanen, W. (1971) Bureaucracy and Representative Government, Chicago: AldineAtherton.

Norris, R. and Kristensen, H. (2006) "U.S. Nuclear Threats: Then and Now", Bulletin of the Atomic Scientists.

NPT/CONF.2000/PC.II/8

NPT/CONF2.2010/PCIII/WP.7, paragraphs 11 and 12.

Obama, B. (2007) Foreign Policy Speech at DePaul University, Chicago. Online, available at: www.cfr.org/publication/14946/candidates_on_us_policy_toward_russia.html (accessed 20 February 2010).

Obama, B. (2009a) "Remarks by the President to the United Nations General Assembly." Online, available at: www.whitehouse.gov/the_press_office/remarks-by-the-presidentto-the-united-nations-general-assembly (accessed 18 January 2010)

Obama, B. (2009b) Remarks by President Barack Obama (Czech Republic), The White House, Office of the Press Secretary. Online, available at: www.whitehouse.gov/the press_office/Remarks-By-President-Barack-Obama-In-Prague-As-Delivered (accessed 10 February 2010).

Obama, B. (2009c) Remarks by the President "On a New Beginning" (Egypt), The White House, Office of the Press Secretary. Online, available at: www.whitehouse.gov/the press_office/Remarks-by-the-President-at-Cairo-University-6-04-09 (accessed 10 February 2010).

Office of the Secretary of Defense (2007) "Military Power of the People's Republic of China 2007”, Annual Report to U.S. Congress.

Ostankov, V. (2005) "Geopolitical Problems and Possibility of Their Solution in a Context of a Security of Russia", Military Thought, No. 1, p. 7.

Pan, Z. (2009) “Abolishing Nuclear Weapons: Why Not Outlaw Them First?", in G. Perkovich and J. Acton (eds) Abolishing Nuclear Weapons: a Debate, Carnegie Endowment for Peace. Online, available at: www.carnegieendowment.org/files/Zhenqiang.pdf (accessed 1 March 2010).

Parthasarathi, A. and Santhanam, K. (2009) "Pokhran-II Thermo-Nuclear Test: A Failure", Mainstream, Vol. XLVII, 26 September. Online, available at: www.mainstreamweekly.net/article1669.html.

Paul, T.V. (2000) Power Versus Prudence: Why Nations Forgo Nuclear Weapons, Montreal: McGill-Queen's University Press.

Paul, T.V. (2009) The Tradition of Non-Use of Nuclear Weapons, Palo Alto: Stanford University Press.

Pélopidas, B. (2009) "Du fatalisme en matière de prolifération nucléaire: Retour sur une representation opiniâtre”, Swiss Political Science Review, No. 2. 
Pélopidas, Benoit (2010a) "La Couleur de cugne sud-africain: Le role des surprises dans l'histoire nucleaire et les effets d'une amnesie partiell", Annuaiere Francais des Relations Internationales, vol. XI.

Pélopidas, B. (2010b) The Seduction of the Impossible: a Study of renunciation of Nuclear Weapons, $\mathrm{PhD}$ dissertation, Science Po/University of Geneva.

Pélopidas, B. (2010c) "When Experts Back Policy Makers' Historical Memory and Biases: the Shared 'Nuclear Proliferation Paradigm' in the US Since the 1960s", paper presented at the 51st International Studies Association Conference, New Orleans.

Perkovich, G. (1999) India's Nuclear Bomb: the Impact on Global Proliferation, Berkeley: University of California Press.

Perkovich, G. (2006) "Democratic Bomb: Failed Strategy”, Policy Brief No. 49, Washington, DC: Carnegie Endowment for International Peace.

Perkovich, G. (2008) "Principles for Reforming the Nuclear Order", Proliferation Papers, IFRI Security Studies Center.

Perkovich, G. (2010) "Global Implications of the US-India Deal”, Daedalus.

Perkovich, G. and Acton, J.M. (2008) "Abolishing Nuclear Weapons", Adelphi Paper 396, London: the International Institute for Strategic Studies.

Perkovich, G. and Acton, J. (eds) (2009) Abolishing Nuclear Weapons: a Debate, Washington, DC: Carnegie Endowment for International Peace.

Perkovich, G., Mathews, J.T., Cirincione, J., Gottemoeller, R. and Wolfsthal, J.B. (2005) Universal Compliance: A Strategy for Nuclear Security, Washington, DC: Carnegie Endowment for International Peace.

Perry, W., Schlesinger, J., et al. (2009) “America's Strategic Posture: the Final Report of the Congressional Commission on the Strategic Posture of the United States", United States Institute for Peace, Washington, DC.

PIR Center (2005) "The Joint Statement of the Fourth Round of the Six-Party Talks." Online, available at: www.pircenter.org/data/resources/JointStat190905.pdf (accessed 1 March 2010).

Porter, G. (2008) "Pentagon Targeted Iran for Regime Change after 9/11.” Online, available at: www.antiwar.com/porter/?articleid=12795 (accessed 27 February 2010).

Potter, W.C. (2009) "Back to the Future: the Contemporary Relevance of the Nuclear Renunciation Decisions by Belarus, Kazakhstan, and Ukraine", paper for the Nobel Institute Conference on "The Spread of Nuclear Weapons: Past Experiences and Future Challenges", Oslo.

Potter, W. (2010) "The NPT and the Sources of Nuclear Restraint", Doedalus on The Global Nuclear Future Vol. 2, Vol. 139, No. 1.

Prawitz, J. (1995) "From Nuclear Option to Non-Nuclear Promotion: the Sweden Case", research report No. 20, The Swedish Institute of International Affairs. Online, available at: http://ui.se/admin/product_pdf/354Research\%20Report\%20No\%2020.pdf (accessed 1 March 2010).

Price, R. (2007) “Nuclear Weapons Don't Kill People, Rogues Do”, International Politics, Vol. 44, Nos 2-3.

Rauf, T. (2007) "International Export Controls and Multilateral Nuclear Arrangements", in M.B. Mærli and S. Lodgaard (eds) Nuclear Proliferation and International Security, Abingdon and New York: Routledge.

Reed, T. (2005) At the Abyss, New York: Ballantine Books.

Reiter, D. (2006) "Preventive Attacks Against Nuclear, Biological and Chemical Weapons Programs - the Track Record”, in W.W. Keller and G.R. Mitchell (eds) 
Hitting First: Preventive Force in U.S. Security Strategy, Pittsburg: University of Pittsburg Press.

"Report of the Commission to Assess the Ballistic Missile Threat to the United States", executive summary. Online, available at: www.fas.org/irp/threat/missile/rumsfeld/toc.htm and www.fas.org/irp/threat/missile/rumsfeld/execsum.htm (accessed 25 February 2010).

"Resolution on the Middle East", NPT/CONF.1995/32/RES.1, 11 May 1995.

Rhodes, R. (1986) The Making of the Atomic Bomb, New York: Simon and Schuster, Inc.

Rhodes, R. (2007) Arsenals of Folly: the Making of the Nuclear Arms Race, New York: Alfred A. Knopf.

Richelson, J. (2006) Spying on the Bomb: American Nuclear Intelligence from Nazi Germany to Iran and North Korea, New York: W.W. Norton.

Rublee, M. (2009) Nonproliferation Norms: Why States Choose Nuclear Restraint, Athens: Georgia Unicersity Press.

Rudolph, M. (2006) “Asia's New Strategic Triangle: US-China-India relations in eclectic perspective", paper presented at the annual conference of the American Political Science Association.

Rumsfeld, D. (2002) Foreword to the new Nuclear Posture Review, submitted to Congress on 8 January 2002. Online, available at: www.globalsecurity.org/wmd/library/ policy/dod/npr.htm (accessed 14 January 2010).

Sagan, S. (2009a) "The Case for No First Use", Survival, Vol. 51, No. 3. Online, available at: http://iis-db.stanford.edu/pubs/22534/51-3_12_Sagan_author_proof.pdf (accessed 3 March 2010).

Sagan, S.D. (2009b) "Shared responsibilities for nuclear disarmament”, Daedalus, Fall.

Sagan, S. (2010) "Nuclear Latency and Nuclear Proliferation", in William C. Potter and Gaukhar Mukhatzhanova (eds) Forecasting Proliferation in the 21st Century: The Role of Theory, Stanford: Stanford University Press.

Sanger, D. (2009) The Inheritance, New York: Harmony Books.

Sanger, David E. and Shanker, Thom (2010) "U.S. Faces Choice on New Weapons for Fast Strikes", New York Times, 22 April.

Savranskaya, S. and Blanton, T. (2005) "To the Geneva Summit Perestroika and the Transformation of U.S.-Soviet Relations", National Security Archive Electronic Briefing Book No. 172. Online, available at: www.gwu.edu/ nsarchiv/NSAEBB/ NSAEBB172/index.htm (accessed 26 February 2010).

Schell, J. (2007) The Seventh Decade: the New Shape of Nuclear Danger, New York: Henry Holt and Company, LLC.

Schoettle, E.C. (1979) Postures for Non-Proliferation: Arms Limitations and Security Policies to Minimize Nuclear Proliferation, London: Taylor and Francis.

Sethi, M. (ed.) (2009) Towards a Nuclear Weapons Free World, New Delhi: KW Publishers.

Sethi, M. (2010) "Building Credibility for a Nuclear Weapon Free World", New Delhi: Delhi Policy Group Paper for the International Commission on Nuclear NonProliferation and Disarmament.

Shamkani, A. (2002) Online, available at: www.netiran.com.

Shultz, G. (1993) Turmoil and Triumph: My Years as Secretary Of State, New York: Charles Scribner's Sons.

Shultz, G., Drell, S. and Goodby, D. (eds) (2008) Reykjavik Revisited: Steps Toward a World Free of Nuclear Weapons (Preliminary Report), Hoover Institution Press. Online, available at: www.hoover.org/publications/books/online/15766737.html (accessed 1 March 2010). 
Shultz, P., Perry. W.J., Kissinger, H.A. and Nunn, S. (2007) "A World Free of Nuclear Weapons”, Wall Street Journal, p. A15. Online, available at: www.fcnl.org/issues/item. php?item_id=2252\&issue_id=54 (accessed 20 February 2010).

Shultz, P., Perry. W.J., Kissinger, H.A. and Nunn, S. (2008) "Toward a Nuclear-Free World", Wall Street Journal. Online, available at: http://online.wsj.com/public/article print/SB120036422673589947.html (accessed 3 March 2010).

Shultz, P., Perry, W.J., Kissinger, H.A. and Nunn, S. (2010) "How to Protect our Nuclear Deterrent", Wall Street Journal.

Sigal, L. (2009a) "How to Bring North Korea Back to the NPT", paper for the Nobel Symposium 142 on Peace, Stability and the Nuclear Order, Drøbak.

Sigal, L. (2009b) "North Korea Policy on the Rocks: What Can Be Done to Restore Constructive Engagement?", Global Asia, Vol. 4, No. 2.

Sigal, L. and Wit, J. (2009) "North Korea's Perspectives on the Global Elimination of Nuclear Weapons", Washington, DC: The Henry L. Stimson Center. Online, available at: www.ssrc.org/workspace/images/crm/new_publication_3/\%7B0cedc1ce-2861de11-bd80-001cc477ec70\%7D.pdf (accessed 1 March 2010).

Singh, M. (2009) "Inaugural Address", in Manpreet Sethi (ed.) Towards a Nuclear Weapon Free World, New Delhi: KW Publishers Pvt Ltd, New Delhi, in association with Centre for Air Power Studies.

SIPRI (1980) SIPRI Yearbook 1980: World Armaments and Disarmament, London: Taylor and Francis Ltd.

SIPRI (2009 and 2010) SIPRI Yearbooks: Armaments, Disarmament and International Security, New York: Oxford University Press, Inc.

Sokov, N. (2007a) "The Origins of and the Prospects for Russian Nuclear Doctrine", The Nonproliferation Review, Vol. 14, No. 2, p. 212.

Sokov, N. (2007b) "Russian Academy of Military Sciences Debates Role of Nuclear Weapons in Conference on New Military Doctrine", WMD Insights. Online, available at: www.wmdinsights.com/113/113_R2_RussianAcademy.htm (accessed 14 January 2010).

Sokov, N. (2010) The New, 2010 Russian Military Doctrine: the Nuclear Angle, James Martin Center for Nonproliferation Studies.

Solingen, E. (2007) Nuclear Logics: Contrasting Paths in East Asia and the Middle East, Princeton: Princeton University Press.

Solingen, E. (2010) "The Perils of Prediction: Japan's Once and Future Nuclear Status", in W.C. Potter (ed.) Forecasting Nuclear Proliferation: the Role of Theory, Palo Alto: Stanford University Press (forthcoming).

Squassoni, S. (2006) “India's Nuclear Separation Plan: Issues and Views", Washington, DC: CRS Report to Congress.

Stockholm International Peace Research Institute (1980) Internationalization to Prevent the Spread of Nuclear Weapons, London: Taylor and Francis Ltd.

Subrahmanyam, K. (2009) "No First Use: an Indian View", Survival.

Takeyh, R. (2005) "Iran Builds the Bomb", Survival, Vol. 46, No. 4. Online, available at: www.cfr.org/content/publications/attachments/Takeyh_IranBomb.pdf (accessed 1 March 2010).

Tannenwald, N. (2007) The Nuclear Taboo: the United States and the Non-Use of Nuclear Weapons Since 1945, New York: Cambridge University Press.

Tellis, A. (2006) U.S.-India Civil Nuclear Cooperation and India's Nuclear Arsenal, Washington, DC: Carnegie Endowment for International Peace.

Tertrais, B. (2008) "France and Nuclear Disarmament: the Meaning of the Sarkozy Speech", Carnegie Endowment for International Peace. Online, available at: www. 
carnegieendowment.org/publications/index.cfm?fa=view\&id=20090 (accessed January 2010).

Tertrais, B. (2009) "French Prospectives on Nuclear Weapons and Nuclear Disarmament", in B. Blechman (ed.) Unblocking the Road to Zero: Perspectives of Advanced Nuclear Nations. France and the United Kingdom, Washington, DC: The Henry L. Stimson Center.

Thakur, R. (2007) “Asia's Strategic Triangle: China-India-Japan”, The Hindu. Online, available at: www.cigionline.org/article/2007/09/asia's-strategic-triangle-china-indiajapan (accessed 18 January 2010).

Time, in partnership with CNN (1985) "Who Has the Bomb?" Online, available at: www. time.com/time/magazine/article/0,9171,957761-7,00.html (accessed 20 February 2010).

TimesOnline (December 2006) "Olmert's Nuclear Slip-up Sparks Outrage in Israel." Online, available at: www.timesonline.co.uk/tol/news/world/middle_east/article752059. ece (accessed 1 March 2010).

United Nations (2000) "Final Document of the 2000 Review Conference of the Parties to the Treaty on the Non-Proliferation of Nuclear Weapons." Online, available at: www. un.org/disarmament/WMD/Nuclear/2000-NPT/pdf/FD-Part1and2.pdf (accessed 1 March 2010).

United Nations General Assembly (2005) "In Larger Freedom: Towards Development, Security and Human Rights For All", report of the Secretary General. Online, available at: www.un.org/largerfreedom/report-largerfreedom.pdf (accessed 3 March 2010).

United Nations General Assembly (2004) "A More Secure World: Our Shared Responsibility", the report of The High-Level Panel on Threats, Challenges, and Change of the United Nations. Online, available at: www.un.org/secureworld/report.pdf (accessed 3 March 2010).

US Department of Defense (2005) "The National Defense Strategy of the United States of America." Online, available at: www.defense.gov/news/Apr2005/d20050408strategy.pdf (accessed 18 January 2010).

US Department of Defense (2007) "Military Power of the People's Republic of China", Annual Report to Congress.

US Department of State (2010) Fact sheet, April 8. Online, available at: http:/www.gov/t/ $\mathrm{vci} / \mathrm{rls} / 139913 . \mathrm{htm}$.

Varnum, J. (2010) “Turkey in Transition: Towards or Away From Nuclear Weapons?" in W.C. Potter (ed.) Forecasting Nuclear Proliferation: the Role of Theory, Palo Alto: Stanford University Press (forthcoming).

Vaÿrynen, R. (2000) "Stable Peace Through Security Communities? Steps Towards Theory-Building", occasional paper \#18 from the Joan B. Kroc Institute for International Peace Studies. Online, available at: http://kroc.nd.edu/ocpapers/op_18_3.pdf (accessed 18 January 2010).

Velazquez, A.S. (2004) "Civil-Military Affairs and Security Institutions in the Southern Cone: the Sources of Argentine-Brazilian Nuclear Cooperation”, Latin American Politics and Society, Vol. 46, No. 4.

von Baeckmann, A., Dillon, G. and Perricos, G. (1995) "Nuclear Verification in South Africa", IAEA Bulletin, Vol. 37, No. 1.

Walker, W. (2009) "President-Elect Obama and Nuclear Disarmament", Proliferation Papers, IFRI Security Studies Center.

Wang, J. (2005) "China's Search for Stability with America”, Foreign Affairs. Online, available at: www.ucm.es/info/eid/pb/Wang05.pdf (accessed 18 January 2010). 
Westcott, A. (1918) Mahan on Naval Warfare: Selections from the Writings of Rear Admiral Alfred T. Mahan, Boston: Little, Brown, and Company.

White House (2002) The National Security Strategy of the United States of America. Online, available at: http://georgebush-whitehouse.archives.gov/nsc/nss/2002/ (accessed 4 February 2010).

White House (2004) President Bush's speech on non-proliferation issues, 11 February. Online, available at: www.nti.org/e_research/official.../whitehouse20040211_wmd.pdf. White House (2006) "The National Security Strategy of the United States of America." Online, available at: http://georgewbush-whitehouse.archives.gov/nsc/nss/2006 (accessed 3 March 2010).

White House (2009) Remarks by the President "On the Meeting of the P5+1 Regarding Iran." Online, available at: www.whitehouse.gov/the_press_office/Remarks-by-thePresident-on-the-meeting-of-the-P5-plus-1-regarding-Iran (accessed 1 March 2010).

Wit, J., Poneman, D. and Gallucci, R. (2004) Going Critical: the First North Korean Nuclear Crisis, Washington, DC: Brookings Institution Press.

Wohlstetter, A. (1961) "Nuclear Sharing: NATO and the N+1 Country", Foreign Affairs, No. 3.

Wohlstetter, A., Brown, T., Jones, G., McGarvey, D., Rowen, H., Taylor, V. and Wohlstetter, R. (1976) "Moving Toward Life in a Nuclear Armed Crowd?", report for the US Arms Control and Disarmament Agency (ACDA). Online, available at: www.npecweb.org/Frameset.asp?PageType=Single\&PDFFile=19751204-AW-EtAl-MovingTow ardsLifeNuclearArmedCrowd\&PDFFolder=Essays (accessed 1 March 2010).

Yan, X. (2006) "The Rise of China and its Power Status", Chinese Journal of International Politics, Vol. 1, Nos 5-33. Online, available at: www.irchina.org/en/pdf/yxt06. pdf (accessed 18 January 2010).

York, H. (1970) Race to Oblivion: a Participant's View of the Arms Race. Online, available at: www.learnworld.com/ZNW/LWText.York.Race.Access.html (accessed 20 February 2010).

Yudin, Y. (2009) Multilateralization of the Nuclear Fuel Cycle: Assessing the Existing Proposals, New York and Geneva: The United Nations Institute for Disarmament Research (UNIDIR).

Zakaria, F. (2008a) "The Future of American Power: How America Can Survive the Rise of the Rest", Foreign Affairs.

Zakaria, F. (2008b) The Post-American World, New York: W.W. Norton and Company.

Zakaria, F. (2009) "Boom Times Are Back, Outside the U.S." Online, available at: www. realclearmarkets.com/articles/2009/06/boom_times_are_back_outside_th.html (accessed 18 January 2010).

Zhao, X. (ed.) (2005) Coercive Deterrence Warfare: a Comprehensive Discussion of Missile Deterrence, Beijing: National Defense University Press. 


\section{Index}

$9 / 1150$

13 Steps $169,228 n 17$

"123 Agreement" see US-India Peaceful

Nuclear Cooperation Agreement

ABACC (Brazilian-Argentine Agency for Accounting and Control of Nuclear Materials) see Brazilian-Argentine Agency for Accounting and Control of Nuclear Materials

Abdul Qadeer Khan network 49, 123, 158, 161,165

ABM (Anti-Ballistic Missile) Treaty 51, 61, 62, 75, 78, 86, 209

Additional Protocol (INFCIRC 540) 80, 83, 100, 131, 134, 185

AEOI (Atomic Energy Organization of Iran) see Atomic Energy Organization of Iran

Africa 20; see also South Africa

African Nuclear-Weapon-Free Zone (ANWFZ) Treaty 63

Agreed Framework (1994), US-North Korea 157-8, 164-5

Agreement on Reconciliation, NonAggression, Exchanges and Cooperation (North and South Korea) 155

Ahmadinejad, Mahmoud 135, 141, 149

Al Kibar, Syria (2007) 81, 82, 126

al-Qaeda 139, 196

Albright, Madeleine 28, 238n6

Alfonsin, Raul 129

Anti-Ballistic Missile (ABM) Treaty see

ABM (Anti-Ballistic Missile) Treaty

anti-nuclear nuclearism 218

Arab-Israeli relationship 144

Arab states 107

Argentina 117, 128, 129

Argentina-Brazil Agency for Accounting and Control of Nuclear Materials

(ABACC) see Brazilian-Argentine

Agency for Accounting and Control of

Nuclear Materials (ABACC)

Arkin, William 56

arms racing 9, 24, 25, 49

arsenal-keepers 201

Article I 49, 99, 100, 101, 103, 184

Article II 184

Article III 205

Article III.2 84, 88, 99, 103

Article III.4 235n 12

Article IV 78, 84, 101, 184, 188, 205, $232 n 6$

Article V 78, 197, 226n2

Article VI 52, 78, 84, 85-6, 88, 99, 107, $111,112,113,121,138,142,168,169$, 174, 184, 189, 197, 202, 209, 211

Article X 89, 188, 189, 226n1, 234n2, $237 n 10,237 n 14$

"as if" formula 88-9, 98-108

ASEAN 20

ASEAN Regional Security Forum 25

ASEAN+1 (China) 20

ASEAN+3 (China, South Korea and Japan) 20

Asia 20, 21, 26-30, 73

asymmetric warfare capabilities 73

Atomic Energy Act (1946) 101, 229n12

Atomic Energy Organization of Iran (AEOI) 141

Australia 117, 118

"axis of evil" 47, 156, 234n 1

"B-teams" 45-6

Baker, James 56, 57

ballistic-missile defence (BMD) 198-9, 201-2, 207-9

ballistic-missile interceptors 73 
bargaining leverage: North Korea 156-7

Barma, N. 20

Baruch(-Lilienthal) Plan (1946) 1, 198, 208

Basic Agreement (1991) see Agreement on Reconciliation, Non-Aggression, Exchanges and Cooperation (North and South Korea)

Bedjaoui, Muhammed 85

Begin Doctrine 82, 126-7

Begin, Menachem 126

Belarus 119, 131

"below zero" 201, 202

Bhutto, Benazir 158

Bhutto, Zulfikar Ali 129

bin Laden, Osama 81

biological weapons 210

Biological Weapons Convention (BWC) 172, 210, 222

Biological Weapons Treaty see Biological Weapons Convention

Bitzinger, Richard 32

Blechman, Barry 57-8

Blix, Hans 124

Bond-Graham, Darwin 218

Bosworth, Stephen 163

Boutros-Ghali, B. 77

Bracken, Paul 73

Brazil 117, 128, 129, 187

Brazilian-Argentine Agency for Accounting and Control of Nuclear Materials (ABACC) 122, 155

break-outs 179-81, 211-12

breeder reactors 100

Bremmer, Ian 22

BRIC (Brazil, Russia, India and China) 22

Bundy, McGeorge 48, 53

"bunker busters" 61

Burns, Nicholas 98

Bush administration: and ABM Treaty 62; and communist regime 166; covert operations (Iran) 148; and EU 16; foreign policy 10, 11; Global Strike 12-13, 74; and India 105; preventive action 61 ; and regime change 12,79 ; and Russian borders 34; threats to Iran 57; threats to Iraq 57; and UNSC Resolution 98463

Bush, George H.W. 45, 56

BWC see Biological Weapons Convention

Canada 117, 118

Carney, Richard 32

Carter administration 62
Carter, Jimmy 46, 59, 156-7

Castro, Fidel 47

"ceasefire" Resolution 687 see Resolution 687

Central Europe 16

Central Intelligence Agency (CIA): "B-teams" review 45; covert operations 148

centrifuges: gas 136; Iran 136

CFE (Conventional Forces in Europe)

Treaty 16,190

Chechnya 34, 65

chemical weapons 210

Chemical Weapons Convention (CWC) see CWC (Chemical Weapons Convention)

China: arsenal 33, 69; asymmetric warfare capabilities 73 ; civil society management 23; contemporary 27-30; democratic practices 31 ; disarmament policies 38,69 ; economic growth 31 ; and EU 31-2; and globalisation 22-3; human rights 31 ; and India $32-3$; and Japan 23, 36; military budgets 24; modernisation of forces 73 ; and nationbuilding 24; nuclear deterrent policy 48-9; and nuclear disarmament 30; nuclear doctrines 69-70; nuclear forces 24-5, 37-8, 105; nuclear posture 27; nuclear profile 26; and NWFW 200, 213 ; rearmament 37 ; rejuvenation 26 , 27, 28; and Russia 34; secrecy 30, 204; security assurances 87; and USA 9-10, 15-16, 31-2; and US-India Agreement 106-7

Chirac, Jacques 67-8

CIA (Central Intelligence Agency) see Central Intelligence Agency

Cirus reactors 100,154

citizen reporting 187

civil society management 23

Clinton administration: and Agreed Framework (1994) 153, 157, 166; bunker-buster bomb $225 n 14$; and globalisation 14; "no options are ruled out" position 62-3; Nuclear Posture Review (NPR) 54, 71; threats to North Korea 57

Clinton, Hillary 147, 1186

Clinton, William J. 2, 59, 163

co-option strategy 200

Coal and Steel Union 24, 221

Cold War: arsenals 47-8; legacies 2, 44; nuclear deterrence $47-9$; politics of fear 
44-7; remnants 49-52; threat inflation 44-7

Collor de Mello, Fernando A. 129

Commission to Assess the Ballistic Missile Threat to the United States (Rumsfeld Commission) 47

Committee on the Present Danger (CPD) 146

common security $50-1$

Common System of Nuclear Materials Accountancy and Control (SCCC) 122 comprehensive power 29

Comprehensive Test-Ban Treaty (CTBT) see CTBT

concert diplomacy 220

Conference on Disarmament 3, 76, 103

Conference on Security and Cooperation in Europe (CSCE) 149, 185, 234n35

Conference on Security and Cooperation in the Middle East (CSCME) 149

confidence and security-building measures 208, 219

conflict management strategies: Iran 144-5; USA 143-4

control mechanisms 196

Conventional Forces in Europe (CFE) Treaty see CFE Treaty

Conventional Prompt Global Strike (CPGS) see CPGS

conventional weapons $74,225 n 14$

counter-proliferation 90-1

CPD (Committee on the Present Danger) see Committee on the Present Danger

CPGS (Conventional Prompt Global Strike) 14, 207

criteria-based approach 112-13

CSBM (Confidence and security-building measures) see Confidence and securitybuilding measures

CSCE (Conference on Security and Cooperation in Europe) see Conference on Security and Cooperation in Europe

CSCME (Conference on Security and Cooperation in the Middle East) see Conference on Security and Cooperation in the Middle East

CTBT (Comprehensive Test-Ban Treaty) $3,38,60,62,190,198,211-12$

Cuban missile crisis (1962) 46-7, 47-8, 55

"Cultural Revolution" 29

CWC (Chemical Weapons Convention) 210

D8 see Developing 8 de-alerting 201, 209

de Gaulle, Charles 120

de Klerk, F.W. 122, 129

Declaration on Security Cooperation 15

democratic practices: China 31

democratisation 131, 142

Deng Xiaoping 28

deterrence doctrines 48, 54-5, 67-8, 156

deterrence levels 180

Deutsch, Karl 77

Developing 8 (D8) 138, 232n15

diplomatic inducements 131

disarmament: as driver of systemic change 219-22; India 104; as process 170,

217-19; propositions 131-2; as state of affairs 217-19

Disarmament Diplomacy 96

disarmament impediments 71-5

disarmament-non-proliferation relationship: and NNWS 168; non-proliferation as prerequisite 178-9; non-proliferation near zero 179-80; and NPT review process 169; and NWS 169-70; regime management 172; regional proliferation 180-1; shared responsibilities 184-91; and state decision-making 173-8; timeline approach 171

discrete use of force $57-8$

dismantlement 72, 116, 117, 207

Dobrynin, Anatoly 51

domestic law: and non-nuclear-weapon commitments $187-8$

Draft Doctrine for Joint Nuclear Operations (2005) 225n15

E3/EU 135; see also European Union

East Asia: military budgets 24-5; and regionalisation $29-30$

East Asian financial crisis (1997) 29

Eastern Europe 16, 18

ECO (Economic Cooperation Organisation) see Economic

Cooperation Organisation

economic compensation 156-7

Economic Cooperation Organisation (ECO) 138, 232n15

economic inducements 131, 164-5

Egypt 119, 129, 221-2

Eighteen Nation Disarmament Committee (ENDC) 85

Eisenhower, Dwight D. 45, 47

El Shifa, Sudan (1998) 81

ElBaradei, Mohamed 146, 227n14, $230 n 28,232 n 7$ 
emerging powers 19-26, 200

ENDC (Eighteen Nation Disarmament

Committee) see Eighteen Nation

Disarmament Committee

energy market 23

energy prices $21-2$

enhanced radiation weapons 59

enrichment plants 84

equity: in disarmament strategy 200 , 202-3

ethical considerations 197

EU (European Union) see European Union

European Atomic Energy Community (Euratom) 100, 102, 103

"European concert" 220

European Union (EU): and China 31-2; and non-proliferation regime 18 ; and political integration 23-4; and Russia 34-5; as "second country" to USA 16; security cooperation 9; and USA 31-2 exceptionalism 11-12, 27, 60

excess fissile materials 44

"existential deterrence" 48, 53

export controls: India 103

extended deterrence 55, 185-7, 221; policies 39

Final Declaration of the 2000 NPT Review Conference 197

financial crisis (1997) 29

financial crisis (2008-9) 13, 14-15, 20, 21

Fire in the East: the Rise of Asian Military Power and the Second Nuclear Age 73 first Gulf War 137

first-use policy $54,55,56,185-6$

fissile material cut-off treaty (FMCT) see FMCT

Fitchett, Joseph 56

FMCT (fissile material cut-off treaty) 3 , $38,39,103,113,135,203-4,212$

force: discrete political use $57-8$; use of 17-18

Foster, John 45

"four horsemen" 179, 196, 197, 198, 219, 237n4; see also Kissinger, Henry; Nunn, Sam; Perry, William; Shultz, George

France: first-use doctrine 186; nuclear doctrines 18, 67-8, 69; nuclear weapons 53-4; and NWFW 200, 213; security assurances 87 ; status considerations 181,182

fuel bank 135

fuel-cycle facilities: multinational 101, 135; national 84, 136, 184
Fukuyama, Francis 26

full-scope safeguards 82, 101, 102, 106, 185,203

G8 Global Partnership 21

G20 21

G77 25

Gaddafi, Muammar al 122, 123, 125, 129

Gaither panel 45

Gandhi, Rajiv 1, 88, 197

gas centrifuges 136

GCC (Gulf Cooperation Council) 22, 138

Geneva Protocol 64, 210

Geneva summit (1985) 50

geopolitics 31-7

Georgia 34

Germany 18, 19, 117, 119

global consensus, new: balancing pillars of NPT 83-4, 111; implementing Article VI 84-6, 111; leadership 91-2, 111; negotiations $80-1,111$; nonproliferation and counter-proliferation 90-1, 111; preventive military action 81-2, 111; security assurances $87-8$; unit of account 79-80, 110; universality 88-9; verification 82-3, 111

global defence shield 208-9

global domestic product 14-15

Global Strike 12-13, 13-14, 60

globalisation 9, 13, 14, 19, 20, 24, 221

Goldman Sachs 22

Gorbachev, Mikhail 39, 50-2, 199

"Great Leap Forward" 29

Grinevsky, Oleg 224n2, 225n21

guidelines for nuclear transfers (NSG guidelines) see NSG guidelines

Gulf Cooperation Council (GCC) see GCC

Gulf War: (1990-1991) 56, 137, 235n18; (2003) 125

Hatoyama government 16, 39

heavy-water reactors (HWRs) see HWRs

Hecker, Siegfried 152, 161

hedging strategies 9-10, 116, 117, 120, 180, 201, 211

Hegel, Georg Wilhelm Friedrich 26

Helsinki Final Act 149

HEU (highly enriched uranium) 49, 196, 201

"high posture" hypothesis 123

highly enriched uranium (HEU) see HEU

Hiroshima bomb 49

Hitler, Adolf 43

Hoover plan 91 
Hu Jintao 36

human error, war by 199

human rights: China 31; Russia 34

Hussein, Saddam see Saddam Hussein

HWRs (heavy-water reactors) 100

Hyde Act 106

Hymans, Jacques 130

IAEA (International Atomic Energy Agency) see International Atomic Energy Agency

IAEO (Iranian Atomic Energy Organisation) see Iranian Atomic Energy Organisation

IBSA (the India, Brazil, South Africa Dialogue Forum) 20, 25

ICC (International Criminal Court) see International Criminal Court

ICJ (International Court of Justice) see International Court of Justice

ICJ Advisory Opinion (1996) 210

IMF (International Monetary Fund) see International Monetary Fund immigration limitations 15 import substitution 32

India: border conflict 32; and China 15-16, 32-3; and CTBT 214; deterrents 73; disarmament policies $38,70-1$, 214; exceptionalism 27; export controls 103; fragmentation risks 23 ; and geopolitics 32-3; and Japan 15-16; military budgets 24 ; and NAM 25; and nationalism 24; nuclear deterrent policy 49; nuclear diplomacy 88; and nuclear disarmament 30 ; nuclear doctrines $70-1$; nuclear forces 25 ; nuclear profile 26; nuclear testing see nuclear tests: India; nuclear weapon programme 38; and NWFW 200; and Pakistan 24; rearmament 37 ; restraint 116 ; separation plan 100-1; status aspirations 182, 183; status considerations 181; and USA 15-16, 33; US-India Peaceful Nuclear Cooperation Agreement 96, 97-108; see also "three state problem"

India-Pakistan relationship 33 individual mindsets 129

Indonesia $237 n 14$

INF Treaty 51, 55, 86, 198

Information Circulars (INFCIRC):

INFCIRC/66 79, 101, 111, 230n3;

INFCIRC 153 82-3, 100, 102, 166, 185; INFCIRC 540 83, 100, 131, 134, 185 integration theory 170,218

interdependence 221; without integration 23-4, 25

Intermediate-Range Nuclear Forces (INF) Treaty see INF Treaty

International Atomic Energy Agency

(IAEA): and India 97, 107; and intelligence information 83; and Iran 134-6; non-compliance reporting 90; and North Korea 151, 154, 155, 161, 166, 189; safeguards 101-2, 203, 204; sanctions 188-9; and South Africa 117; and Syria 126

International Court of Justice (ICJ) 85, 86, $169,174,210$

International Criminal Court (ICC) 11

international law: USA and 17-18

International Monetary Fund (IMF) 21

International Nuclear Fuel Cycle Evaluation 129

international system: power shifts 9, 20

internationalisation: of fuel-cycle facilities 135

Iran: Additional Protocol (INFCIRC 540)

134; Bracken on 73; break-out consequences 180-1, 181-4; and Bush administration 57; centrifuges 136; conflict management strategies 144-5; and India 105-6; multinational fuelcycle facilities $101,134-5$; negotiations (Geneva) 146-7; and Obama 80; oppositional nationalists 130; and Pakistan 139; and rollback 136-43; and Rumsfeld Commission 47; sanctions 146, 147; and USA 78, 139-40, 147-9; and US-India Agreement 107; verification 83; virtual arsenals 134-6; the West and Asia 22

Iran-Iraq war 137

Iranian Atomic Energy Organisation (IAEO) 141

Iranian Revolutionary Guard Corps (Pasdaran) see Pasdaran (Iranian Revolutionary Guard Corps)

Iraq: preventive action against 81 ; rollback 124-5; and Rumsfeld Commission 47; US deterrent threat 56-7; and US exceptionalism 12; verification 83

"Irish Resolution" 123-4

Israel: Al Kibar strike 81, 82, 126; "as if" formula 88-9, 114; disarmament policies 214; negotiations 111; nuclear weapons policy 215-16; and Obama 80; Osiraq strike 81-2; separation line 
Israel: Al Kibar strike continued

113-14; and Syria 81, 82, 126; and USA

144; and US-India Agreement 107

Israeli-Palestinian relations 144

Italy 119

Japan: and Australia 15; and China 23, 36; geopolitics 36-7; hedging strategies 117; and India 15-16, 108; and North Korea 180; and regionalisation 29-30; and Russia 35; and USA 15-16, 127

Japanese Diet 187

Jiang Zemin 28

Joint Declaration on the Denuclearisation of the Korean Peninsula (1992) 153, $155,156,162,164,214,228 n 1$

Joint Nuclear Control Commission 155

Juche ideology 154, 162

Kang, David 28

Kant, Immanuel $238 n 5$

Kaplan, Stephen 57-8

Kazakhstan 119, 131

KEDO (Korean Energy Development Organisation) 157

Kennedy, John F. 45

Khamenei, Ayatollah Ali 141

Khan, Abdul Qadeer see Abdul Qadeer Khan network

Khatami, Mohammad 141

Khomeini, Ayatollah 137, 140

Khrushchev, Nikita 47

Kim-Il-Sung 155, 157

Kim Jong-Il 163

Kim Kye-gwan 163

Kissinger, Henry 55, 195, 220

Korean Energy Development Organisation (KEDO) see KEDO

Korean War (1950-3) 45, 152

Kosovo 65

Kurile Islands 35

Kuznetsov, Vasily 47

Lashkar-e-Tayyiba 196

last step fallacy 43,48

Latin America 20

Lavoy, Peter 121

law, national: and non-nuclear-weapon commitments $187-8$

Lawrence Livermore National Laboratory 45

leaders: and national identity 122

leadership: and USA 28 legitimacy deficit 78

Leverett, Flynt 21-2

Levite, Ariel 115

liberal internationalism 21, 219-20, 221

liberalisation thesis 124,130

Libya 57, 122, 123, 125-6, 127, 129

light-water reactors (LWR) see LWR

London Club see NSG

low enriched uranium (LEU) 146, 147, $161,232 n 5,233 n 30$

Lugar, Richard 229n8, 230n21

LWR (light-water reactors) 154, 157, 158, 162,165

McCain, John 27

McCloy-Zorin proposal (1961) 1, 198

McGovern-Lungren resolution 206

McNamara, Robert 45

MAD (mutually assured destruction) 48, 54, 219

MAD policies 64

Madrid Conference 149

Manhattan Project 43

Mao Zedong 28

Marshall Plan 14

Marx, Karl 53, 137

MAUD report 43

Medvedev, Dmitry 39

Menem, Carlos Saul 129

Mian, Zia 197

Middle East Resolution 85, 92

military bases 16 ; foreign networks 13

military rule 141

military rulers 122,130

military superiority: USA $12-14$

minimum deterrence $216-17,222$

missile defence $12-13,60-1$

missile defence programme 205

missile-defence systems 73-4

missile technology 158

missile technology control regime

(MTCR) see MTCR

model agreement (INFCIRC 153) see

Information Circulars: INFCIRC 153

moral considerations 199

moratoria on nuclear-weapon tests 60,63 , 103-4

Moussavi, Mir Hossein 141

MTCR (missile technology control regime) 104

Muller, H. 123, 201

multinational facilities 101, 134-5

multinational fuel-cycle facilities 101 , $134-5$ 
mutually assured destruction (MAD) see MAD

Myanmar 127, 158, 165

Myrdal, Alva 86, 122

mythmaker approach 121-2, 129, 140-1

NAM (non-aligned movement) 25, 107, 190-1

Narayanan, Mayankote 112

Nasser, Gamal 129

nation-building 24

National Defense Strategy (2002) 12, 60, 61,81

National Defense Strategy (2005) 12, 60

National Defense Strategy (2006) 12, 61, 81

National Intelligence Estimate (NIE) 45, 141

national law: and non-nuclear-weapon commitments $187-8$

national missile defence systems 51, 61

nationalism 24, 129-30

NATO: first-use doctrine 185-6; and

Russia 65; as two-pillar structure 18; and Yugoslavia 34

naval nuclear weapons 58

negative security assurances $63,71,72,87$, 164

Nehru, Jawaharlal 27

neo-realists $119,121-2$

neoconservatives $11,60-1$

Netanyahu, Benjamin $227 n 7$

the Netherlands 119

neutron weapons 59

New START 74, 92, 205, 207, 209

NIE (National Intelligence Estimate) see National Intelligence Estimate

Nitze, Paul 45

Nixon administration 149

Nixon, Richard 12-13, 61, 148

no-first-use (NFU): China 38, 48, 69-70,

72,87 ; and disarmament 128 ; doctrines

57, 87-8, 186, 209-11; India 70, 72;

Japan 36; NPR (2001) 63-4; Russia 54,

64; US presidents 56

no-first-use doctrines 57, 87-8, 186, 209-11

non-aligned movement (NAM) see NAM non-interference 24

non-proliferation: and counter-proliferation

90-1; and disarmament, legal link 3;

golden age (early 1990s) 3; near zero

179-80; as prerequisite to disarmament $178-9$ non-proliferation norm 121, 123-4, 132,

$142,163,171$

non-state actors 91

non-use norm 58-60, 63

North Korea: arsenal 152, 165; Bracken on 73; current status 161-3; and denuclearisation 151-4; disarmament 214; foreign policy 160 ; and geopolitics 37; missile tests 78, 123; and NTP 88; nuclear history 154-5; nuclear programme 123; overt nuclearisation 155-61; rollback experiences 163-7; Rumsfeld Commission 47; sanctions 162; South Korea and 155; and US negotiations 80; US threats against 57; withdrawal from NPT 151, 189

Norway 119

NPR (Nuclear Posture Review) 54, 61, 62 , $63,64,71$

NPT (Nuclear Non-Proliferation Treaty): Article I 49, 99, 100, 101, 103, 184; Article II 184; Article III 205; Article III. 2 84, 88, 99, 103; Article III.4 235n12; Article IV 78, 84, 101, 184, 188, 205, 232n6; Article V 78, 197, 226n2; Article VI 52, 78, 84, 85-6, 88, $99,107,111,112,113,121,138,142$, 168, 169, 174, 184, 189, 197, 202, 209, 211; Article X 89, 188, 189, 226n1, $234 n 2,237 n 10,237 n 14$; basis of 54 ; and big powers 199; Bush administration 62; enforcement mechanisms 220-1; "good faith" provision 86; and international cooperation 10-11; and Iran 149-50; legitimacy deficit 78-9; nonproliferation 3; and North Korea 151, 189; and NWFW 203; obligation to disarm 2; post-Cold War 76; and realists 120-1; right to withdraw 189-90; shared responsibilities 184; testing criterion 133; UNSC Resolution (1887) 11

NPT membership: reserving benefits 188-9

NPT Review and Extension Conference (1995) 76-7, 86

NPT Review Conference (2000) 197

NPT Review Conference (2005) 18, 96

NPT Review Conference (2010) 11, 226n5

"NSC-68: United States Objectives and Programs for National Security" 45

NSG (Nuclear Suppliers Group) 84

NSG guidelines 96, 101, 102, 103, 106, $107,108,113$

nuclear deterrence 44, 47-9 
nuclear doctrines: British 18, 68-9;

Chinese 69-70; French 18, 67-8, 69, 186; Indian 70-1; Russian 64-7, 185-6; USA $61-4,72$

nuclear energy: peaceful uses 4 nuclear latency 115

nuclear mythmakers 121-2, 140-1

Nuclear Non-Proliferation Treaty (NPT) see NPT

Nuclear Posture Review (NPR) see NPR nuclear power 196-7

nuclear powers: categorisation 213-14

nuclear proliferation: as regional matter 169-70; responsibility for 168-70

Nuclear Suppliers Group (NSG) see NSG nuclear technology 158

nuclear terrorism 50

nuclear tests: India 38, 54, 73, 97, 98, 103-4, 116, 183; Israel 49, 120, 133, 212; North Korea 80, 95, 118, 123, 151 , 159, 160, 166; Russia 212; South Africa 49, 120, 231n 15 ; USA 212

nuclear threats: impact of 55-7

nuclear war-fighting 55

nuclear-weapon-free world (NWFW) see NWFW

nuclear-weapon-free zones (NWFZ) see NWFZ

nuclear weapon infrastructure: elimination 204

nuclear-weapon states (NWS) see NWS

nuclear weapons: functions 53-60

Nunn, Sam 195

NWFW (nuclear-weapon-free world): 2006 revival 1; break-out potentials 211-12; ceilings 216-17; disarmament process 217-19; doctrines 209-11; doubts 197-200; guide to action 202-5; Obama, Barack and 10; pitfalls 197-200; political-order requirements 219-22; principle of equity 202-3; rationale for 195-7; Reykjavik 50; Security Council resolution (2009) 92; versions 200-2

NWFZ (nuclear-weapon-free zones) 121, 132; Treaty of Pelindaba 190; Treaty of Tlatelolco 117, 122, 129, 187, 190

Obama administration 63, 64, 74, 111

Obama, Barack: and alliances 28; de-alerting weapons 209; defence budget 13; disarmament initiatives 55, 170; and image of US 14; and Iran 80, 139, 146, 147-8; and Israel 144; nuclear disarmament policy 18; and nuclear weapons use 13-14; and NWFW 1, 10, 92; and Russia 34; speech (Cairo, 2009) 149; speech (Prague, 2009) 195; and unilateralism 10

obligation: to disarm 2

Ogarkov, Nikolay $224 n 2$

oil exports 21-2

Okada, Katsuya 186

Okinawa 36

Open Skies Treaty $237 n 14$

openness 27, 121-2, 130, 141-2, 165

oppositional nationalists 130, 139

Osiraq, Iraq (1981) 81-2, 181

outliers 95, 214-15

P5 213-16

P5+1 80, 143, 146, 178

Pahlavi, Mohammad Reza Shah 137

Pakistan: "as if" formula 88, 89; and Bhutto 129; and CTBT 214; deterrents 73; disarmament policies 214; first-use policy 63; and India 24, 33; nuclear forces 25; restraint 116; and US-India Agreement 106

Palme Commission 50-1

Pan Zhenqiang 213

pariah states $121,159,165,177,189$

Parish, Will 218

Partial Test Ban Treaty 123

Pasdaran (Iranian Revolutionary Guard Corps) 140, 141

Paul, T.V. 59, 120

"peaceful rise" concept 28

peaceful uses 83-4, 204-5

Pelindaba, Treaty of 190

Perkovich, George 229n17

Perry, William 57, 195

PGS (Prompt Global Strike) 14, 74, 75, 205

playing for time $128,142-3,166$

politics of fear 44-7

power reactors 100

pre-emption strategy $61,68,81$

Presidential Initiatives (1991/1992) 55, 77

preventive action $11,12,60,61,68,81-2$, 111,126

Principles and Objectives for Nuclear Non-Proliferation and Disarmament (1995) 77, 85, 169

proliferation 115

proliferation resistance 204-5

Proliferation Security Initiative (PSI) 88, 97 
Prompt Global Strike (PGS) see PGS

protectionism 14, 27, 32, 221

prudential realism 120

PSI (Proliferation Security Initiative) see

Proliferation Security Initiative

Putin, Vladimir 35, 47

Qaddafi, Muammar al see Gaddafi, Muammar al

Qadeer Khan network see Abdul Qadeer Khan network

Rafsanjani, Ali Akbar Hashemi 141

rank disequilibrium 182-3

Reagan, Ronald 46, 50-2, 198, 199, 201, 208

Reagan-Gorbachev plan (1986) 1, 198

realism 119-21, 123

recognition: India 108-10

regime change $12,57,78,79-80,127$

regime management: and disarmament 172

regionalisation: East Asia 29-30

rejuvenation $26-7,28$

reprisal 81

research reactors 123

Resolution 687 (1991) 73, 124, 172, 215

Resolution 984 (1995) 209

Resolution 1172 (1998) 96

Resolution 1540 (2004) 91, 103

Resolution 1718 (2006) 160, 162

Resolution 1887 (2009) 11, 92, 96

review conferences see NPT Review

Conferences and NPT Review and

Extension Conferences

Reykjavik summit 50-2, 170, 178-9, 197, 201, 208

Rhodes, R. 45-6

Richardson, Bill 163

RNEP (robust nuclear earth penetration) warheads 61

rogue states 47,79

rollback: cases 117-19; concept 115-16; experiences and North Korea 163-7; and Iran 136-43; and Iraq 124-5; lessons learnt 127-32; Libya 125-6; quantitative analysis 123-4; Syria 126-7; theoretical approaches 119-23

Romania 119

Roosevelt, Franklin D. 43

Ross, Dennis 147

Rudolph, Matthew 33

Rumsfeld Commission 47

Rumsfeld, Donald 225n16

Russia: arsenal 35; and China 34, 66; civil society management 23 ; cooperation 200; deep cuts 205-6; disarmament 19, 39 ; and energy sector 23; and EU 16-17, 34-5; first-use doctrine 185-6; and geopolitics 33-6; and Iran 143-4; and Japan 35; Military Doctrine (2010) 66-7; National Security Concept 64; and nationalism 24; and nonproliferation 3; nuclear arsenal 64; nuclear doctrines 64-7; START II 86; and USA 10

SAARC (South Asia Association for Regional Cooperation) see South Asia Association for Regional Cooperation

SAC (Strategic Air Command) see Strategic Air Command

Saddam Hussein 2, 56, 57

safeguards 101-2, 184-5, 203; see also Additional Protocol (INFCIRC 540); full-scope safeguards

Sagan, Scott 184

sanctions 189; Iran 146, 147; North Korea 162

Sarkozy, Nicolas 18, 68

Sarney, Jose 129

Saudi Arabia 119

SCCC (Common System of Nuclear Materials Accountancy and Control) see Common System of Nuclear Materials Accountancy and Control

Schell, Jonathan 43

Schlesinger, James 57

Schmidt, A. 123

SCO (Shanghai Cooperation Organisation) 20-1, 34

SDI (US Strategic Defense Initiative) 51, 198, 201

"second country" problem 9, 15-17, 31

security communities 25

Security Council Resolution 154091

security dilemma 10

security sector: and interdependence 9

Semipalatinsk Treaty (2006) 190

separation line: Israel 113-14

separation plan: India 100-1

September 11, 2001 bombings 50

sequencing 38

Serbia 119

Seventh Decade: the New Shape of Nuclear Danger, The 43

Shanghai Cooperation Organisation (SCO) see $\mathrm{SCO}$

Shultz, George 1, 50, 52, 195, 197 
Siberia 35

Sigal, Leon 152

Sikkim 32

Singh, Manmohan 112

Sinkiang (Xingjiang) 31

six-party talks 153,162

societal verification $187-8,204,238 n 10$

Solingen, Etel 121, 124

SORT (Strategic Offensive Reductions

Treaty) see Strategic Offensive

Reductions Treaty

South Africa: December 1988 agreement 122; and normalisation 127; and NPT 3; nuclear tests $49,120,231 n 15$; rollback 117, 119

South Asia Association for Regional Cooperation (SAARC) 32

South Korea: capability level 129-30; hedging 117-18; and North Korea 155, 162 ; restraint 116

South-South political consultations 25

sovereign wealth funds (SWFs) see SWFs

Soviet Union: Cold War era 46-7; deterrence policies 54 ; security assurances 87; threat inflation 46-7; warheads $47-8$

Spain 119

Stalin, Joseph 46

START I 10, 86

START I follow-on agreement 207

START II 86

state sovereignty $9,21,23-4,221$

status ambitions $128,137-8,163,181-3$

Stockholm conference on confidence and security-building measures (CSBM) 208, 219

Strategic Air Command (SAC) 46

Strategic Arms Limitation Talks (SALT II) agreement 46

Strategic Arms Reduction Treaty (START I) 51,55

Strategic Defense Initiative (SDI) see SDI

Strategic Offensive Reductions Treaty (SORT) 55, 86, 206

structural impact: nuclear weapons 53-4

sub-strategic weapons 35-6, 62, 65-6, 206; see also tactical nuclear weapons

Subramaniam, K. 229n16

Sun Yat-sen 28

supply assurances $135-6$

Sweden 117, 119, 122, 190

Swedish example 78, 117, 190

SWFs (sovereign wealth funds) 22
Switzerland 119

Syria 126-7

Szilard, Leo 43

tactical nuclear weapons $54,55,60,64,77$, 155, 173, 205, 206-7; see also substrategic weapons

Taiwan: capability level 130; hedging 117-18; and Japan 36; restraint 116 technology denials 129

Teller, Edward 45

terrorism 2, 44, 49-50, 67, 71, 81, 196

Thatcher, Margaret 52

Thirteen Steps 169, 228n17; see also Article VI

Thorson, Inga 122

threat-based foreign policies 14,44 , 59-60, 71

threat inflation 44-7

"three state problem": approach to 95-7; "as if" formula 98-108; new global consensus 110-11; recognition 108-10; summary 111-14; US-India agreement 96, 97-8

Tibet 31,32

timeline approach: disarmament 171, 219

Tlatelolco Treaty 117, 122, 129, 187, 190

Tocqueville, Alexis de 165

Treaty of Pelindaba (Treaty on the African Nuclear Weapon-Free Zone) see Pelindaba, Treaty of

Treaty of Tlatelolco (Treaty for the Prohibition of Nuclear Weapons in Latin America and the Caribbean) see Tlatelolco Treaty

Treaty on the Non-Proliferation of Nuclear Weapons (NPT) see NPT (Nuclear NonProliferation Treaty)

Trilateral Initiative 212

Truman, Harry S. 45

UK (United Kingdom): nuclear arsenal 68; nuclear doctrines 18, 68-9; nuclear weapons 53; and NWFW 200, 213; security assurances 87 ; status considerations 181

Ukraine 34, 119, 131

UN Security Council (UNSC) Resolution $98462,63,71$

unilateral advantage 198, 199, 203, 238n5

unilateralism 10, 11-12, 17, 60, 82, 90, $221,238 n 5$

unipolar moment 11-12, 15, 238n5; United States 1-2 
United Nations Charter (1945) 21, 214 , 219

United Nations Monitoring, Verification and Inspection Commission (UNMOVIC) 83, 124, 125

United Nations Security Council 77, 200; "Irish Resolution" (1961) 123-4; Resolution 687 (1991) 73, 124, 172, 215; Resolution 984 (1995) 209; Resolution 1172 (1998) 96; Resolution 1540 (2004) 91, 103; Resolution 1718 (2006) 160, 162; Resolution 1887 (2009) 11, 92, 96

United Nations Security Council summit meeting (2009) 79, 92, 146, 236n10

United Nations Special Commission (UNSCOM) 73, 124

United States of America (USA) see USA universality $88-9$

UNMOVIC (United Nations Monitoring, Verification and Inspection

Commission) see United Nations

Monitoring, Verification and Inspection Commission

UNSCOM (United Nations Special Commission) see United Nations Special Commission

uranium programme: North Korea 161

US-India Business Council 98

US-India Peaceful Nuclear Cooperation Agreement 14, 96, 97-108

US-Japanese alliance 36, 37, 39, 127, 162, 186

US National Defense Strategy (2005) 12, 60

US National Security Strategy (2002) 12, $60,61,81$

US National Security Strategy (2006) 12, 61,81

US Nuclear Posture Review (2010) 82

US PGS capabilities 37-8

US-Soviet missile shield 208

US Strategic Defense Initiative (SDI) see SDI

USA (United States of America): ABM

Treaty 86; arsenal 206; and China 9-10, 15-16, 19, 27-8, 31-2; conflict management strategies 143-4; counterproliferation policy 90; and CTBT 198; deep cuts 205-9; deterrence policies 54; dominance of 1 ; economic strength
14-15; and EU 16, 31-2; and Europe 17-18; extended deterrence 55; and hegemony $9,60-1$; and international law 17-18; and Iran 139-40, 147-9; leadership 28, 91-2, 200; military superiority $12-14$; missile-defense systems 73-4; and non-proliferation policies 18; and North Korea 166-7; nuclear disarmament 9-10; nuclear doctrines 61-4, 72; nuclear threats 55-7; and nuclear weapons use 13-14; political power 14; rollback endeavours 132; and Russia 16-17, 63, 143; security assurances 87; threat-based foreign policies 14; threat inflation 44-6; unilateralism 10, 11-12, 17, 221, 238n5; unipolar moment 1-2, 11-12, 15, $238 n 5$; warheads $47-8$

Vajpayee, Atal Bihari 24

verification $82-3,125,134,185,187-8$, 207

Vienna Convention on the Law of Treaties 190

virtual arsenals 201, 202; restraining 133-6

Vorster, B.J. 129

war-fighting doctrines 55; and deterrence doctrines 48

"warning shots" 68

Warsaw Pact 34, 57, 60

whistle blowing 187

White Paper (2003): Russia 65

withdrawal right 188-91

World Bank 21

World Trade Organisation (WTO) 21, 142

World Without the West 19-26

WTO (World Trade Organisation) see World Trade Organisation

Xingjiang (Sinkiang) 31

Yeltsin, Boris 23

Yongbyon reactor 126, 152, 154, 159, 160, $234 n 7$

Yugoslavia 34

Zangger Committee 84

"zero" nuclear weapons: concept 200-1

Zheng He 26, 27 